\title{
What counts? : cognitive development and arithmetical performance: the role of child- and environment-related factors
}

Citation for published version (APA):

Martens, R. (2012). What counts? : cognitive development and arithmetical performance: the role of childand environment-related factors. [Doctoral Thesis, Maastricht University]. NeuroPsych Publishers. https://doi.org/10.26481/dis.20121018rm

Document status and date:

Published: 01/01/2012

DOI:

10.26481/dis.20121018rm

Document Version:

Publisher's PDF, also known as Version of record

Please check the document version of this publication:

- A submitted manuscript is the version of the article upon submission and before peer-review. There can be important differences between the submitted version and the official published version of record.

People interested in the research are advised to contact the author for the final version of the publication, or visit the DOI to the publisher's website.

- The final author version and the galley proof are versions of the publication after peer review.

- The final published version features the final layout of the paper including the volume, issue and page numbers.

Link to publication

\footnotetext{
General rights rights.

- You may freely distribute the URL identifying the publication in the public portal. please follow below link for the End User Agreement:

www.umlib.nl/taverne-license

Take down policy

If you believe that this document breaches copyright please contact us at:

repository@maastrichtuniversity.nl

providing details and we will investigate your claim.
}

Copyright and moral rights for the publications made accessible in the public portal are retained by the authors and/or other copyright owners and it is a condition of accessing publications that users recognise and abide by the legal requirements associated with these

- Users may download and print one copy of any publication from the public portal for the purpose of private study or research.

- You may not further distribute the material or use it for any profit-making activity or commercial gain

If the publication is distributed under the terms of Article 25fa of the Dutch Copyright Act, indicated by the "Taverne" license above, 


\section{WHAT COUNTS?}

Cognitive Development and Arithmetical

Performance: The Role of Child- and

Environment-Related Factors 


\section{COLOPHON}

ISBN

Print and production

Publisher

Illustrations
9789075579635

Wöhrmann Print Service

Neuropsych Publishers

(C) Mina Braun (www.minabraun.com)

(C) Rosa Martens, Maastricht 2012

All rights reserved. No part of this thesis may be reproduced, stored or transmitted in any way or by any means without prior permission of the author. 


\section{WHAT COUNTS? \\ Cognitive Development and Arithmetical Performance: The Role of Child- and Environment-Related Factors}

\section{PROEFSCHRIFT}

ter verkrijging van de graad van doctor aan de Universiteit Maastricht, op gezag van de Rector Magnificus, Prof. dr. L. L. G. Soete,

volgens het besluit van het College van Decanen,

in het openbaar te verdedigen

op donderdag 18 oktober om 14.00 uur

door

ROSA MARTENS

Geboren op 25 september 1983 te Nijmegen 


\section{PROMOTOR}

Prof. dr. J. Jolles (Vrije Universiteit Amsterdam)

\section{COPROMOTOR}

Dr. P. P. M. Hurks

\section{BEOORDELINGSCOMMISSIE}

Prof. Dr. P. E. H. M. Muris (voorzitter)

Prof. Dr. A. P. Aldenkamp

Prof. Dr. E. C. D. M. van Lieshout (Vrije Universiteit Amsterdam)

Dr. E. van Loosbroek

Prof. Dr. L. T. W. Verhoeven (Radboud Universiteit)

The research described in this thesis was conducted at the Department of Neuropsychology and Psychopharmacology, Maastricht University, The Netherlands. Funding for our research was provided by the Curious Minds program (www.talentenkracht.nl), which is supported by the Dutch Ministry of Education, Culture, and Science and the National Platform Science \& Technology.

Financial support for the publication of this thesis was kindly provided by Uitgeverij Schoolsupport (www.schoolsupport.nl). 


\section{Als ik wil, kan ik overal bij}

(Simone Schell - Marie Pouceline of de Nicht van de Generaal) 



\section{Contents}

Chapter $1 \quad$ Introduction 9

Chapter 2 Sex differences in arithmetical performance scores:

27

Central tendency and variability

Chapter 3 Impact of home learning environment, child's own initiative and cognition on young children's numeracy

Chapter $4 \quad$ Early cognitive characteristics of children aged 4-8 with persistent mathematical difficulties versus giftedness:

A longitudinal study

Chapter 5 Rey-Osterrieth Complex Figure performance in children aged 5-7: Development of organizational strategies and its relation to cognitive functioning.

Chapter 6 Training goal setting in children aged 4-6: Transfer effects through an age by training content interaction

Chapter $7 \quad$ Concluding remarks

Summary

Samenvatting

Curriculum Vitae

Publications

Dankwoord 



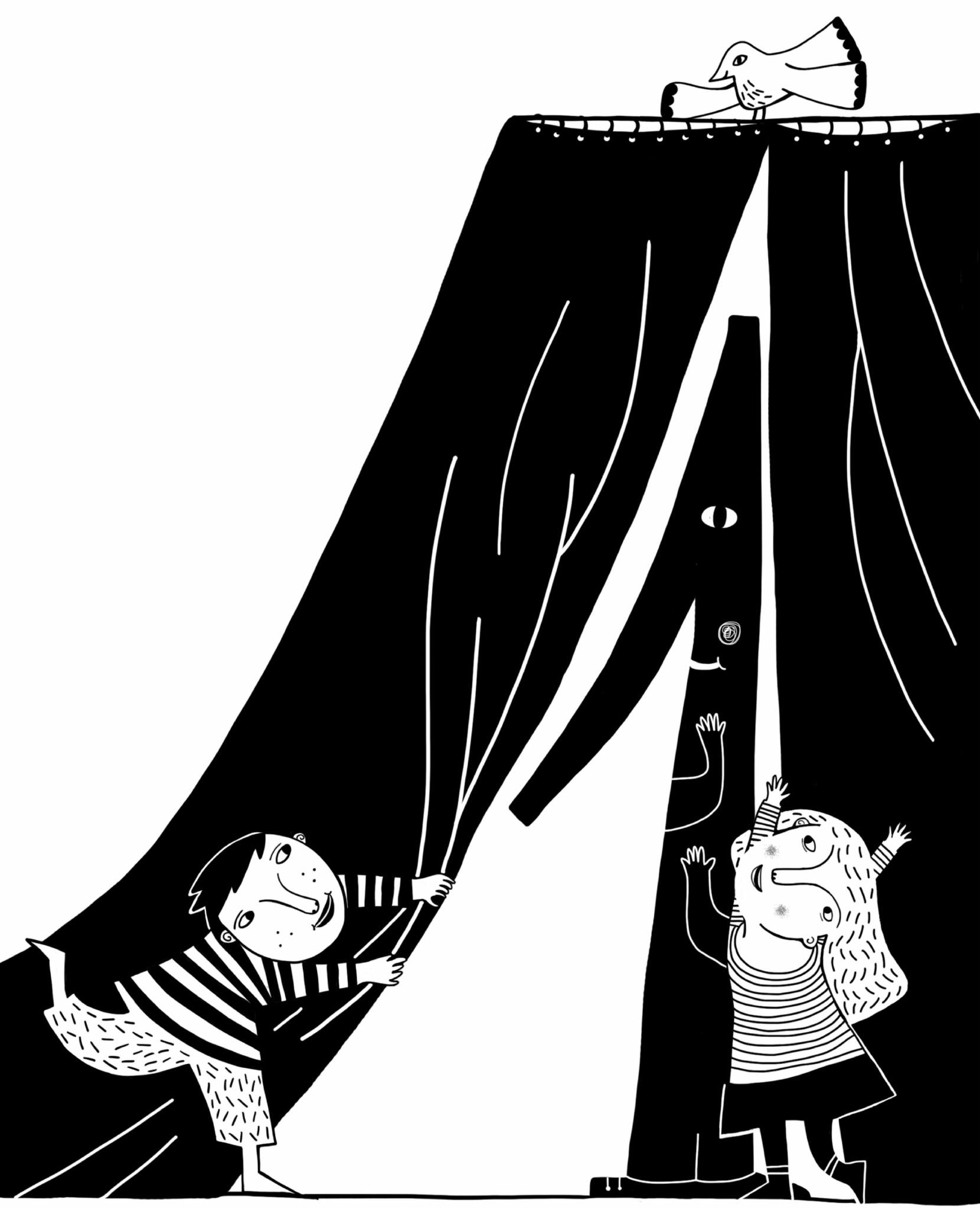





\section{Chapter 1}

Introduction 


\section{INTRODUCTION}

Research into mathematical development has received increased international attention in recent years in an effort to catch up to earlier strides made to support literacy development (National Mathematics Advisory Panel, 2008; National Research Council, 2009). According to the National Research Council (2009), almost all children possess the potential to learn mathematics. Unfortunately, many of these children do not reach their full potential in the course of their school career (National Mathematics Advisory Panel, 2008; National Research Council, 2009). This is alarming, since optimal mathematical development is essential for maintaining a technically educated workforce that is able to cope with international competition in the 21st century, thereby securing national economic well-being (National Mathematics Advisory Panel, 2008; National Research Council, 2009).

In the Netherlands, children's mathematical development in primary school has also become an important subject of concern and debate in recent years (Koninklijke Nederlandse Akademie van Wetenschappen [KNAW], 2009). One reason has been the Trends in International Mathematics and Science Study (TIMSS; Meelissen \& Drent, 2008; Mullis, Martin, \& Foy, 2008) that compared international performance of children in grade 4. TIMSS reported that mathematical test performance of Dutch 9- to 10-year-old children has steadily declined in comparison with other countries in the last decades. Although internationally Dutch students' performance in grade 4 is still in the top-ten of best achieving countries, researchers, politicians, and experts in education have expressed their concern about this downward trend. TIMSS (2007) has provided additional reasons for concern by reporting continued lower mathematical achievement of Dutch girls compared to boys in grade 4 as well as a low percentage of excellent students in the Netherlands compared to other countries such as Singapore ( $7 \%$ and $41 \%$ respectively). These findings have led to discussions in the media about the contents of teaching strategies used in Dutch primary schools, potential differences between boys and girls in optimal conditions needed for learning, and the reintroduction of single-sex schooling (e.g., NRC Handelsblad, 30-09-2008, 18-10-2008; Volkskrant, 29-09-2008, 24-03-2009, 0305-2010). 
Recently, the Dutch National Educational Council has acknowledged that the TIMSS-findings are cause for concern and has presented various recommendations to improve the Dutch educational system in a rapport, written on the authority of the Dutch Ministry of Education, Culture and Science (Onderwijsraad, 2011). These recommendations have included extra attention for mathematics in the primary school curriculum and more attention for differentiation in teaching activities to meet the individual needs of students. Other (international) reports and protocols have given similar recommendations and have underlined the importance of awareness of the role that inter-individual differences play in mathematical development. Mathematics education has to be attuned to the mathematical development and educational needs of the individual child (National Mathematics Advisory Panel, 2008; National Research Council, 2009; Van Groenestijn et al., 2011). The central question that follows from these recommendations is: How can individual (mathematical) abilities be stimulated, so that each child reaches his or her full potential?

Attention for the improvement of educational programs during the preschool period is of great importance (National Research Council, 2009; Onderwijsraad, 2010). The effect of an optimal development of mathematical abilities from an early age onward is long lasting and widespread. Not only does it affect children's scholastic career, it also has an important prolonged impact on daily functioning, career success, and prospects for future income (Butterworth, 2005; National Research Council, 2009; Rivera-Batiz, 1992). As Heckman and Masterov (2007, p. 447) state: "Skill begets skill; learning begets learning. Early disadvantage, if left untreated, leads to academic and social difficulties in later years. Advantages accumulate; so do disadvantages." Consequently, the most gain can be achieved through early interventions that are directed at stimulating mathematical development and preventing difficulties. However, thus far scientific research has focused only limitedly on inter-individual differences in mathematical abilities at preschool age and on possibilities to stimulate these abilities. In addition, these past studies have focused predominantly on mathematical development in primary school. The primary goals of the studies described in this thesis were twofold: firstly, identifying those environment- and childrelated factors that influence mathematical development at preschool and early primary school age. These factors may help to predict e.g., which children are at risk for mathematical difficulties and may benefit from early interventions. Secondly, we 


\section{CHAPTER 1}

aimed to explore the content and effectiveness of preschool interventions. One promising aspect of such interventions is the stimulation of underlying cognitive abilities through training at preschool age. A second aspect is the introduction of tailor-made mathematical education that takes individual differences between children into account. To design tailor-made education or cognitive training programs, an important step is to gather information about the effect of specific child- and environment-related factors on mathematical development, with particular attention for the preschool and early primary school period. This was a central focus of this thesis. Before providing a more detailed description of the objectives and outline of this thesis, the above-mentioned issues should be placed in a short theoretical context.

We approached our research aims from a developmental neuropsychological perspective, in line with an integrative vision on research that was introduced in the past decade (OECD, 2002, 2007; Jolles et al., 2005, 2006). This thesis aspired to approach research from a perspective that combined neuropsychology and education. Mathematical development was studied in light of this perspective, studying characteristics of the child and its environment in relation to the origin of interindividual differences (e.g., age, sex, cognitive functions, home learning environment). Consequently, conceptualizations of cognitive functions, such as working memory, were approached from a developmental neuropsychology perspective - in line with Lezak et al. (2004).

\section{BACKGROUND INFORMATION}

\section{ON DEFINITIONS OF MATHEMATICS, ARITHMETIC, AND NUMERACY}

Research into mathematical abilities is characterized by differences in use of terms and definitions. The terms numeracy, arithmetic and mathematics are used to define abilities that partly overlap. To provide more clarity on the use and meaning of these terms in this thesis, the terms numeracy, arithmetic and mathematics are defined and placed in the context of the studies discussed in the following chapters.

Mathematics as a term has been difficult to capture in one single clear definition in past research (Griffin, 2003). It comprises of a wide range of abilities that are related to learning both before and after the start of formal schooling and include e.g., counting, estimating, retrieval of arithmetical facts (also described as 12 
computational fluency), and solving mathematical word problems (Butterworth, 2005; Geary, 2006). According to the Organisation for Economic Co-operation and Development (OECD, 2007), mathematics can be divided into basic and advanced abilities. In line with this division, the studies described in this thesis explore both basic and more advanced aspects of mathematics in formal schooling - i.e., numeracy, computational fluency and mathematical problem solving. In this thesis computational fluency is considered as the ability to calculate simple sums on the basis of number fact knowledge (e.g., $2+3=$ ) ) and is also referred to as arithmetic. Computational fluency encompasses a time-restricted measurement of the following arithmetical abilities: addition, subtraction, multiplication, and division. According to Geary (1993, p. 347) "mastery of elementary arithmetic is achieved when all basic facts can be retrieved from long-term memory without error". The development of computational fluency forms the basis for learning more advanced mathematics, such as mathematical problem solving (e.g., Geary, 1996; Gersten et al., 2005). Mathematical problem solving refers to the ability to analyse and solve practical mathematical problems (e.g., Amy has 10 marbles and loses 4. How many marbles does she have left?). According to Geary (2000), the difficulty of such problems lies in the following requirements: children have to be able to identify the problem type (What do I have to do?) and translate and integrate the verbal representation of the problem into a mathematical representation.

Numeracy encompasses a variety of preparatory mathematical abilities, in which knowledge of different meanings and applications of numbers (i.e., Piagetian operations - for more information see Butterworth, 2005; Van de Rijt et al., 2003) as well as various counting skills are central. The development of these abilities begins long before the start of formal schooling (Van de Rijt et al., 2003; Van de Rijt \& Van Luit, 1999; Toll et al., 2010). There is no consensus on the exact definition of the term early numeracy and the factors that influence its development (Van de Rijt et al., 2003). When the term numeracy or numerical abilities is used in the present study, it refers to a broader range of early mathematical abilities measured at preschool and early primary school age (4 to 7 years of age). Numeracy forms the basis for mathematical abilities that are learned through formal schooling and its operationalization encompasses the following abilities: concepts of comparisons, classification, one-to-one correspondence, seriation, use of number words, structured 


\section{CHAPTER 1}

counting, resultative counting, and the application of general knowledge of numbers (for more information see Van de Rijt et al., 2003; Van de Rijt \& Van Luit, 1999).

On inter-individual differences and developmental pathways. Knowledge of developmental pathways to numerical and mathematical proficiency is considered important for the development and improvement of teaching materials and strategies. In addition to knowledge about general developmental trajectories of these skills, inter-individual differences in development need to be taken into account. Given that learning experiences differ and are specific to each individual child, curricula should strive for diversification to accommodate these inter-individual differences (OECD, 2007). This requires knowledge about the factors that predict which children will excel in mathematics and which children will struggle with it. Given the long-lasting impact of mathematical difficulties on children's scholastic careers, many studies have chosen to focus on this field of research. Yet, mathematics disorders are still not recognized or understood widely (Butterworth, 2005).

The development of mathematically gifted children has received far less attention. Yet, increasing knowledge in this research field is of equal importance, given the risk of gifted children becoming underachievers and developing e.g., fear of failure and negative attitudes towards school (McCoach \& Siegel, 2003; Reis \& McCoach, 2000). Central questions that research should pursue further, both in the field of mathematical giftedness and mathematical difficulties, concern the possibility of predicting individual mathematical development and the potential threats that can affect this development. What role do (early) cognitive abilities play as predictors of inter-individual differences? And how do inter-individual differences relate to other child- and environment-related factors?

\section{CHILD- AND ENVIRONMENT-RELATED FACTORS}

Past research has studied various child-related factors as potential predictors of interindividual variability in cognitive as well as mathematical performance. These childrelated factors include biological factors, such as sex and age, as well as psychological factors, such as cognitive abilities and initiative taking in learning. The influence of environment-related factors, more specifically the home learning environment, has also received attention in past research. These factors are discussed more extensively in the following paragraphs. 
Sex. One important child-related factor that has received much attention as a potential source of inter-individual differences in mathematical abilities is the child's sex. Sex differences have attracted much interest, given the continued underrepresentation of women in the field of mathematics, science, and engineering (Halpern, 2004; Halpern et al., 2007). The existence and strength of sex differences, however, remain subject of ongoing debate. Some researchers have reported the existence of sex differences, particularly in arithmetic test performance and strategy use (e.g., Geary et al., 2000; Lynn \& Irwing, 2008). For one, research has indicated that in first grade boys use retrieval as a primary strategy when solving basic arithmetic problems, while girls prefer to use manipulatives (i.e., count with fingers or counters; e.g., Carr \& Davis, 2001). Other studies have failed to find sex differences in arithmetical abilities (e.g., Imbo \& Vandierendonck, 2007; Lachance \& Mazzocco, 2006). One important question remains what causes these conflicting findings. A broader perspective on sex differences may realize new research insights, i.e., by studying sex differences in relation to factors such as age and level of mathematical abilities.

Child's own initiative in learning. Another potentially relevant factor for mathematical development is the child's own initiative in learning ( $\mathrm{Cl}$ ) - i.e., the initiation of learning-related activities by the child (e.g., asking to be read to, looking in books on his/her own initiative). Relatively little is known about the relation between $\mathrm{Cl}$ and mathematical abilities. Only a limited number of studies have described the importance of a child's curiosity, interest and motivation for the development of preschool mathematical abilities (e.g., Heckman, 2006; Schiefele, 1991; Trudewind, 2000; Leibham, Alexander, Johnson, Neitzel, \& Reis-Henri, 2005). A child's intrinsic motivation in early childhood plays an important role in explaining inter-individual differences in early numerical abilities as well as later levels of mathematics achievement (Gottfried et al., 2007). Further, both the number-related activities that a child initiates at home and joint parent-child activities influence numerical abilities in preschool (Blevins-Knabe \& Musun-Miller, 1996). Unfortunately, only a few studies have explored the interaction between $\mathrm{Cl}$ and the home learning environment. Research is needed to explore the extent to which these factors have a common or unique influence on mathematical development and how this influence is related to e.g., the cognitive abilities of the child. 


\section{CHAPTER 1}

Home learning environment. The term 'home learning environment' (HLE) refers to common activities or materials offered to a child at home to provide a stimulating learning environment (e.g., library visits, joint book reading, types of children's books at home). Although the role of the HLE in reading development has received far more attention, a few studies have shown that the HLE also plays an important role in mathematical development at preschool age (e.g., Melhuish, Phan, et al., 2008; LeFevre et al., 2010). The operationalization of the HLE differs from one study to the next. Some studies have only explored the influence of indirect HLE activities - e.g., exposure to books, library visits, playing games - that are suggested to stimulate both reading and mathematical development (Melhuish, Phan, et al., 2008; Melhuish, Sylva, et al., 2008). Others studies have also included activities that focus specifically on numerical abilities - e.g., learning to count or learning simple sums (LeFevre et al., 2010; LeFevre et al., 2009). Given the limited research in this area, many aspects of the relationship between HLE and numeracy have not been studied. In addition to unanswered questions about interactions between $\mathrm{HLE}$ and $\mathrm{Cl}$ in their influence on mathematical abilities, it remains unclear how different HLE activities impact on different aspects of mathematical development.

\section{COGNITIVE ABILITIES}

In this thesis, particular attention is given to cognitive abilities as child characteristics that potentially influence mathematical development. Past research has described the importance of cognitive abilities as predictors of inter-individual differences in mathematical development (e.g., Geary, 1996; Geary, 2011; Mazzocco \& Kover, 2007). Higher-order cognitive functions (also referred to as executive functions) have been the primary focus of past research, given their importance for daily functioning and scholastic achievement (Anderson et al., 2008). Although the definition and classification of higher-order cognitive functions remains a subject of debate, consensus has been reached on the vital role that these functions play as selfregulatory processes that guide purposeful, goal-directed behavior. In this context 'executive functioning' is often used as an overarching term that refers to a complex and inter-related collection of abilities that play an essential role in adaptive functioning (e.g., Anderson et al., 2008; Lezak et al., 2004). Thus far, no model of 
executive functioning has been universally accepted and only a few models have described the development of executive functions across a broad age range (Anderson et al., 2008; Best \& Miller, 2010).

In 2002, Anderson proposed an important, developmentally oriented framework of executive functioning. Although this conceptual framework has not been validated, recent publications have still referred to it because of the broad developmental context it provides for a range of executive functions (Anderson, 2002; Anderson et al., 2008; Best \& Miller, 2010). This model discerns four discrete domains of cognitive functioning that develop at different paces, yet operate in an integrative manner: attentional control, information processing, cognitive flexibility, and goal setting. According to Anderson's conceptual framework, as well as a developmental sequence proposed by Romine and Reynolds (2005), less complex higher-order cognitive functions develop before more complex functions. Functions within the domain of attentional control (i.e., inhibition) are among the first to reach full maturity. Conversely, more complex functions such as planning (i.e., goal setting domain) are characterized by a protracted development that continues (at least) into early adulthood.

The development of these diverse higher-order cognitive functions has been linked to the development of the prefrontal cortex, both in terms of maturation of frontal regions and connectivity to other brain regions (Anderson et al., 2008; Romine \& Reynolds, 2005; Tau \& Peterson, 2010). The sequence in which the cortex matures between early childhood and early adulthood corresponds with the maturation of lower- and higher-order cognitive functions. Brain areas associated with more basic functions, such as vision and motor functions, mature earlier than brain areas involved in higher-order cognitive functioning - i.e., the frontal lobes (Gogtay et al., 2004; Shaw et al., 2008; Tau \& Peterson, 2010). Given the late maturation of the most complex higher-order cognitive functions - i.e., in the goal setting domain: planning, strategic organization - the majority of past studies have chosen to focus on the development of less complex higher-order functions at preschool and early primary school age (i.e., 3-7 years), such as attention, working memory and inhibition. According to Isquith et al. (2005) this can be explained by the prominent notion among researchers that young children are incapable of more complex higher-order cognitive functioning, given the immaturity of less complex higher-order functions such as attention, 


\section{CHAPTER 1}

inhibition, self-monitoring, and cognitive flexibility at this age. However, the fact that more complex higher-order functions - i.e., planning, conceptual reasoning, fluency are only starting to develop at preschool age does not automatically imply that young children display no relevant development in these functions. According to Romine and Reynolds (2005), the greatest period of development of various higher-order cognitive functions - i.e., inhibition, verbal fluency, design fluency, planning - is actually between the ages of 5 to 8. And, as Anderson (2002) has described, even at 4 years of age children already display some complex higher-order cognitive functioning (i.e., planning and conceptual reasoning).

\section{INTERVENTIONS}

Insights into the relationship between child- and environment-related factors and inter-individual differences in mathematical abilities in preschool and early primary school may provide important leads for the design of more effective interventions, for instance for children at risk for mathematical difficulties. Interventions aimed at cognitive stimulation may alter brain functioning and development, thereby impacting on cognitive functioning as well as academic achievement (Hackman et al., 2010; Howard-Jones, 2010). According to the OECD (2007), it is likely that interventions can even impact on deficient neural circuitry underlying mathematical difficulties, given the plasticity of the neural circuitries involved in mathematics.

Higher-order cognitive functions are considered to be important candidates for interventions that impact on scholastic functioning, given their close relationship with academic achievement (e.g., Blair \& Razza, 2007; St Clair-Thompson \& Gathercole, 2006; Mazzocco \& Kover, 2008). Unfortunately, research into training programs that stimulate higher-order cognitive functions at preschool age has been limited. Past studies that focused on preschool interventions have aimed to stimulate inhibition and/or working memory in a classroom context (Diamond et al., 2007) or through a computerized training program, such as Cogmed or Memory Booster (St Clair-Thompson et al., 2010; Thorell et al., 2009). Although these studies have reported promising results for preschool interventions, it remains unclear whether more complex higher-order cognitive functions, such as conceptual reasoning and strategic organization, can be stimulated through training at preschool age. These functions in 
the goal setting domain (Anderson, 2002) form an interesting basis for early interventions, since self-regulated learning at preschool age (e.g., goal-directed behavior and organization) is related to mathematical development in primary school (DiPerna et al., 2007).

\section{OBJECTIVES OF THE THESIS}

Since past research has shown that preparatory mathematical abilities (i.e., numeracy) have a life-long impact, initiatives to optimize mathematical development as early as possible are vital. An essential step in fostering this development is the recognition of early inter-individual differences as significant predictors of this development. Interindividual differences stem from child-related as well as environment-related factors. This thesis aims to contribute insights into inter-individual differences in mathematical development by studying child-related factors and environment-related factors and their contribution to children's abilities. In particular, this thesis aims to provide new outlooks on the predictive value of various factors by (1) studying the influence of these factors at a younger age than previous research has done, and (2) exploring the combined influence of specific factors (e.g., the interaction between sex, age and arithmetical achievement level - see chapter 2).

\section{APPROACH}

Within the framework of the general objectives of the thesis, three studies were conducted: a cross-sectional study (see chapter 2), a longitudinal study (see chapters, 3,4 , and 5), and an intervention study (see chapter 6). Our cross-sectional study focused on children aged 6 to 15 . Our longitudinal study followed preschool children during a two-year-period. Children were tested three times: at the start of the study when they were in the first or second year of preschool (T0; i.e., age 4-6), approximately one year later ( $\mathrm{T} 1$; i.e., age $5-7)$, and approximately two years later (T2; i.e., age 6-8). Data collection for the cross-sectional and longitudinal studies included questionnaires filled out by parents as well as neuropsychological testing of the children, using an extensive test battery to measure (preparatory) mathematical and cognitive abilities. Our intervention study focused on preschool children (age 4-6). This 


\section{CHAPTER 1}

study encompassed a 6-week-intervention as well as neuropsychological pre- and post-testing. Together these three studies explored various child- and environmentrelated factors across different ages, thereby providing a broad context for research into inter-individual differences in mathematical abilities. Primary focus, however, was on the preschool period and the first years of primary school, given the potential relevance of findings at this age for early interventions to prevent or counter the development of scholastic adversities. Below an overview is provided with more detailed descriptions of the chapters that are included in this thesis in relation to these three studies.

\section{OUTLINE OF THE THESIS}

Chapter 2 focuses on one possible source of inter-individual differences in mathematical abilities: sex differences between the ages of 6 to 15 years in arithmetical performance. Inconsistent findings of previous studies have led to ongoing debate about the existence of these differences. Past research has differed greatly in age groups under study and has paid little attention to differences between arithmetical operations (i.e., addition, subtraction, multiplication, division). Further, nearly all studies have operationalized arithmetical performance as a group mean, even though cognitive research has shown that distribution curves (i.e., variability) differ for boys and girls (Halpern et al., 2007). The research described in this chapter explored the relative influence of the following factors: achievement level measure (i.e., central tendency versus performance variability), age of the child (6-15 years), and type of arithmetical operation under study (i.e., addition, subtraction, multiplication, division).

Chapter 3 deals with two other potential sources of inter-individual differences. The study that is described in this chapter explored the influence of the home learning environment (HLE) and child's own initiative in learning $(\mathrm{Cl})$ on the numerical abilities of 5- to 7-year-old children. Previous research that studied the influence of $\mathrm{HLE}$ and $\mathrm{Cl}$ on mathematical abilities in preschool and early primary school has been scare. In chapter 3 the influence of various HLE and $\mathrm{Cl}$ factors was studied in relation to the age and cognitive abilities of the child as well as the type of numerical ability under study (e.g., classification, seriation, counting). 
Chapter 4 describes a study that explored the stability of mathematical abilities between the ages of 4 to 8 years. The study focused on the predictive value of a broad range of cognitive abilities for inter-individual differences in the stability of mathematical abilities. Particular attention was given to differences between children with mathematical difficulties, typically achieving children and mathematically gifted children. Previous studies have reported on cognitive characteristics of children with mathematical difficulties at primary school age. Thus far, however, no study has explored differences in cognitive abilities at preschool age between children with mathematical difficulties, typically achieving children and mathematically gifted children.

Chapter 5 focuses on the use of organizational strategies by children aged 5 to 7 years. Surprisingly, knowledge on children's organizational strategy use before age 7 is limited, even though the ability to plan and organize facilitates learning and is of great importance for scholastic functioning. In our study the development of strategic functioning was assessed by recording the order in which 5- to 7-year olds copy the Figure of Rey. In addition, children's level of strategic functioning was studied in relation to their cognitive abilities. Our aim was to explore the development of organizational strategy use between preschool and early primary school, using two measures: RCF-OSS (Anderson et al., 2001) and Rey Initial Drawing Sequence (RIDS), a new measure that assesses initial drawing sequence.

Chapter 6 describes a study that explored the possibility of training strategic organization and conceptual reasoning in a sample of 4-to 6-year-old children during 6week-interventions. Training effectiveness was studied in relation to the age of the child. A number of studies have reported the possibility of training working memory at preschool age. Our study was the first to study the effectiveness of strategic organization and conceptual reasoning interventions at preschool age.

In Chapter 7, the findings described in the preceding chapters are discussed in light of a larger framework and related to the central goal of the thesis. Further, the findings are placed in a social context and implications for educational practice and future research are discussed. 


\section{REFERENCES}

Anderson, P. (2002). Assessment and development of executive function (EF) during childhood. Child Neuropsychology, 8(2), 71-82.

Anderson, P., Anderson, V., \& Garth, J. (2001). Assessment and development of organizational ability: The Rey Complex Figure Organizational Strategy Score (RCF-OSS). The Clinical Neuropsychologist, 15(1), 81-94.

Anderson, V., Jacobs, R., \& Anderson, P. J. (2008). Executive functions and the frontal lobes: A lifespan perspective. Philadelphia, PA US: Taylor \& Francis.

Best, J. R., \& Miller, P. H. (2010). A developmental perspective on executive function. Child Development, 81(6), 1641-1660.

Blair, C., \& Razza, R. P. (2007). Relating effortful control, executive function, and false belief understanding to emerging math and literacy ability in kindergarten. Child Development, 78(2), 647-663.

Blevins-Knabe, B., \& Musun-Miller, L. (1996). Number use at home by children and their parents and its relationship to early mathematical performance. Early Development \& Parenting, 5(1), 35-45.

Butterworth, B. (2005). Developmental dyscalculia. In J. D. Campbell (Ed.), Handbook of mathematical cognition (pp. 455-467). New York, NY US: Psychology Press.

Carr, M., \& Davis, H. (2001). Gender differences in arithmetic strategy use: A function of skill and preference. Contemporary Educational Psychology, 26(3), 330-347.

Christian, K., Morrison, F. J., \& Bryant, F. B. (1998). Predicting kindergarten academic skills: interactions among childcare, maternal education, and family literacy environments. Early Childhood Research Quarterly, 13(3), 501-521.

Diamond, A., Barnett, W. S., Thomas, J., \& Munro, S. (2007). Preschool program improves cognitive control. Science, 318(5855), 1387-1388.

DiPerna, J., Lei, P., \& Reid, E. E. (2007). Kindergarten predictors of mathematical growth in the primary grades: An investigation using the Early Childhood Longitudinal Study--Kindergarten cohort. Journal of Educational Psychology, 99(2), 369-379.

Geary, D. C. (1993). Mathematical disabilities: Cognitive, neuropsychological, and genetic components. Psychological Bulletin, 114(2), 345-362.

Geary, D. C. (1996). Children's mathematical development: Research and practical applications (2 ${ }^{\text {nd }}$ ed.). Washington, DC US: American Psychological Association.

Geary, D. C. (2000). From infancy to adulthood: The development of numerical abilities. European Child \& Adolescent Psychiatry, 9(Suppl 2), S11-S16. 
Geary, D. C. (2006). Development of Mathematical Understanding. In D. Kuhn, R. S. Siegler, W. Damon, R. M. Lerner (Eds.), Handbook of child psychology: Vol 2, Cognition, perception, and language (6th ed.) (pp. 777-810). Hoboken, NJ US: John Wiley \& Sons Inc.

Geary, D. C. (2011). Cognitive predictors of achievement growth in mathematics: A 5-year longitudinal study. Developmental Psychology, 47(6), 1539-1552.

Geary, D. C., Saults, S. J., Liu, F., \& Hoard, M. K. (2000). Sex differences in spatial cognition, computational fluency, and arithmetical reasoning. Journal of Experimental Child Psychology, 77(4), 337-353.

Gersten, R., Jordan, N. C., \& Flojo, J. R. (2005). Early Identification and Interventions for Students With Mathematics Difficulties. Journal Of Learning Disabilities, 38(4), 293-304.

Gogtay, N., Giedd, J. N., Lusk, L., Hayashi, K. M., Greenstein, D., Vaituzis, A. C., et al. (2004). Dynamic mapping of human cortical development during childhood through early childhood. Proceedings of the National Academy of the Sciences, 101, 8174-8179.

Gottfried, A., Marcoulides, G. A., Gottfried, A. W., Oliver, P. H., \& Guerin, D. (2007). Multivariate latent change modeling of developmental decline in academic intrinsic math motivation and achievement: Childhood through adolescence. International Journal of Behavioral Development, 31(4), 317-327

Griffin, S. (2003). Laying the foundation for computational fluency in early childhood. Teaching Children Mathematics, 9, 306-309.

Hackman, D. A., Farah, M. J., \& Meaney, M. J. (2010). Socioeconomic status and the brain: Mechanistic insights from human and animal research. Nature Reviews Neuroscience, 11(9), 651-659.

Halpern, D. F. (2004). A Cognitive-Process Taxonomy for Sex Differences in Cognitive Abilities. Current Directions In Psychological Science, 13(4), 135-139.

Halpern, D. F., Benbow, C. P., Geary, D. C., Gur, R. C., Hyde, J. S., \& Gernsbacher, M. A. (2007). The science of sex differences in science and mathematics. Psychological Science in the Public Interest, 8(1), 151.

Heckman, J. J. (2006). Skill Formation and the Economics of Investing in Disadvantaged Children. Science, 312(5782), 1900-1902.

Heckman, J. J., \& Masterov, D. V. (2007). The productivity argument for investing in young children. Review of Agricultural Economics, 29(3), 446-493.

Howard-Jones, P. (2010). Introducing neuroeducational research: Neuroscience, education, and the brain from contexts to practice. Abingdon: Routledge.

Imbo, I., \& Vandierendonck, A. (2007). The development of strategy use in elementary school children: working memory and individual differences. Journal of Experimental Child Psychology, 96(4), 284309. 


\section{CHAPTER 1}

Isquith, P. K., Crawford, J. S., Espy, K., \& Gioia, G. A. (2005). Assessment of executive function in preschoolaged children. Mental Retardation And Developmental Disabilities Research Reviews, 11(3), 209215.

Jolles, J., De Groot, R., Van Benthem, J., Dekkers, H., De Glopper, C., Uijlings, H., et al. (2005). Leer het brein kennen [Learning to know the brain]. The Hague: the Netherlands Organization for Scientific Research (NWO).

Jolles, J., De Groot, R., Van Benthem, J., Dekkers, H., De Glopper, C., Uijlings, H., et al. (2006). Brain lessons: $A$ contribution to the international debate on Brain, Learning \& Education. Maastricht: Neuropsych Publishers.

Koninklijke Nederlandse Akademie van Wetenschappen (2009). Rekenonderwijs op de basisschool: Analyse en sleutels tot verbetering [Mathematics education in primary school: Analysis and keys to improvement]. Amsterdam: KNAW.

Lachance, J. A., \& Mazzocco, M. M. (2006). A longitudinal analysis of sex differences in math and spatial skills in primary school age children. Learning and Individual Differences, 16, 195-216.

LeFevre, J., Polyzoi, E., Skwarchuk, S., Fast, L., \& Sowinski, C. (2010). Do home numeracy and literacy practices of Greek and Canadian parents predict the numeracy skills of kindergarten children?. International Journal of Early Years Education, 18(1), 55-70.

LeFevre, J., Skwarchuk, S., Smith-Chant, B. L., Fast, L., Kamawar, D., \& Bisanz, J. (2009). Home numeracy experiences and children's math performance in the early school years. Canadian Journal of Behavioural Science/Revue Canadienne Des Sciences Du Comportement, 41(2), 55-66.

Leibham, M. E., Alexander, J. M., Johnson, K. E., Neitzel, C. L., \& Reis-Henrie, F. P. (2005). Parenting behaviors associated with the maintenance of preschoolers' interests: A prospective longitudinal study. Journal of Applied Developmental Psychology, 26(4), 397-414.

Lezak, M. D., Howieson, D. B., Loring, D. W., Hannay, H., \& Fischer, J. S. (2004). Neuropsychological assessment (4th ed.). New York, NY US: Oxford University Press.

Lynn, R., \& Irwing, P. (2008). Sex differences in mental arithmetic, digit span, and g defined as working memory capacity. Intelligence, 36(3), 226-235.

Mazzocco, M. M., \& Kover, S. T. (2007). A Longitudinal Assessment of Executive Function Skills and their Association with Math Performance. Child Neuropsychology, 13(1), 18-45.

Meelissen, M. R., \& Drent, M. (2008). TIMSS-2007 Nederland: Trends in leerprestaties in exacte vakken in het basisonderwijs [TIMSS-2007 The Netherlands: Trends in learning performance in sciences in primary school]. Enschede: Twente University.

Melhuish, E. C., Phan, M. B., Sylva, K., Sammons, P., Siraj-Blatchford, I., \& Taggart, B. (2008). Effects of the home learning environment and preschool center experience upon literacy and numeracy development in early primary school. Journal of Social Issues, 64(1), 95-114. 
Melhuish, E. C., Sylva, K., Sammons, P., Siraj-Blatchford, I., Taggart, B., Phan, M. B., et al. (2008). Preschool influences on mathematics achievement. Science, 321(5893), 1161-1162.

McCoach, D., \& Siegle, D. (2003). Factors that differentiate underachieving gifted students from highachieving gifted students. Gifted Child Quarterly, 47(2), 144-154.

Mullis, I.V.S., Martin, M.O., \& Foy, P. (2008). TIMSS 2007 international mathematics report: Findings from IEA's Trends in International Mathematics and Science Study at the fourth and eighth grades. Chestnut Hill, MA: TIMSS \& PIRLS International Study Center, Boston College.

National Mathematics Advisory Panel (2008). Foundations for Success: The Final Report of the National Mathematics Advisory Panel. Washington, DC: U.S. Department of Education.

National Research Council (2009). Mathematics learning in early childhood: Paths towards excellence and equity. Committee on Early Childhood Mathematics, Christopher T. Cross, Taniesha A. Woods, and Heidi Schweingruber, Editors. Center for Education, Division of Behavioral and Social Sciences and Education. Washington, DC: The National Academies Press.

Onderwijsraad (2011). Een stevige basis voor iedere leerling [A solid basis for every student]. Den Haag: Onderwijsraad.

OECD (2002). Understanding the brain: Towards a new learning science. Paris: OECD Publishing.

OECD (2007). Understanding the Brain: The birth of a learning science. Paris: OECD Publishing.

Reis, S. M., \& McCoach, D. (2000). The underachievement of gifted students: What do we know and where do we go?. Gifted Child Quarterly, 44(3), 152-170.

Rivera-Batiz, F. L. (1992). Quantitative literacy and the likelihood of employment among young adults in the United States. The Journal of Human Resources, 27(2), 313-328.

Romine, C. B., \& Reynolds, C. R. (2005). A model of the development of frontal lobe functioning: Findings from a meta-analysis. Applied Neuropsychology, 12(4), 190-201.

Schiefele, U. (1991). Interest, learning, and motivation. Educational Psychologist, 26(3-4), 299-323.

Shaw, P., Kabani, N. J., Lerch, J. P., Eckstrand, K., Lenroot, R., Gogtay, N., et al. (2008). Neurodevelopmental trajectories of the human cerebral cortex. The Journal Of Neuroscience, 28(14), 3586-3594.

St Clair-Thompson, H. L., \& Gathercole, S. E. (2006). Executive functions and achievements in school: Shifting, updating, inhibition, and working memory. Quarterly Journal of Experimental Psychology, 59(4), 745-759.

Tau, G. Z., \& Peterson, B. S. (2010). Normal development of brain circuits. Neuropsychopharmacology, 35(1), 147-168.

Thorell, L. B., Lindqvist, S., Bergman Nutley, S., Bohlin, G., \& Klingberg, T. (2009). Training and transfer effects of executive functions in preschool children. Developmental Science, 12(1), 106-113.

Toll, S. M., Van der Ven, S. G., Kroesbergen, E. H., \& Van Luit, J. H. (2011). Executive functions as predictors of math learning disabilities. Journal of Learning Disabilities, 44(6), 521-532. 


\section{CHAPTER 1}

Trudewind, C. (2000). Curiosity and anxiety as motivational determinants of cognitive development. In J. Heckhausen (Ed.), Motivational psychology of human development: Developing motivation and motivating development (pp. 15-38). New York, NY US: Elsevier Science.

Van Groenestijn, (2011). Op weg naar gecijferdheid [The road to numeracy]. Utrecht: Hogeschool Utrecht.

Van de Rijt, B. M., Godfrey, R., Aubrey, C., Van Luit, J. H., Ghesquiere, P., Torbeyns, J. L., et al. (2003). The development of early numeracy in Europe. Journal of Early Childhood Research, 1, 155-180.

Van de Rijt, B. M., \& Van Luit, J. H. (1999). Milestones in the development of infant numeracy. Scandinavian Journal Of Psychology, 40(1), 65-71.

\section{DUTCH NEWSPAPER ARTICLES}

\section{NRC Handelsblad}

30-09-2008 Geef 'rekenzwakke' scholier de staartdeling terug [Give back the long division to the student with 'mathematical difficulties'].

18-10-2008

Ouderwets rekenen mag straks weer ['Old-fashioned' arithmetic methods will be allowed again].

\section{Volkskrant}

29-09-2008

Onderzoek rekenonderwijs op basisscholen [Investigation mathematics education at primary schools].

24-03-2009

Feit en fictie in de rekendiscussie [Fact and fiction in the mathematics discussion].

03-05-2010 De ideale jongen is een meisje [The ideal boy is a girl]. 


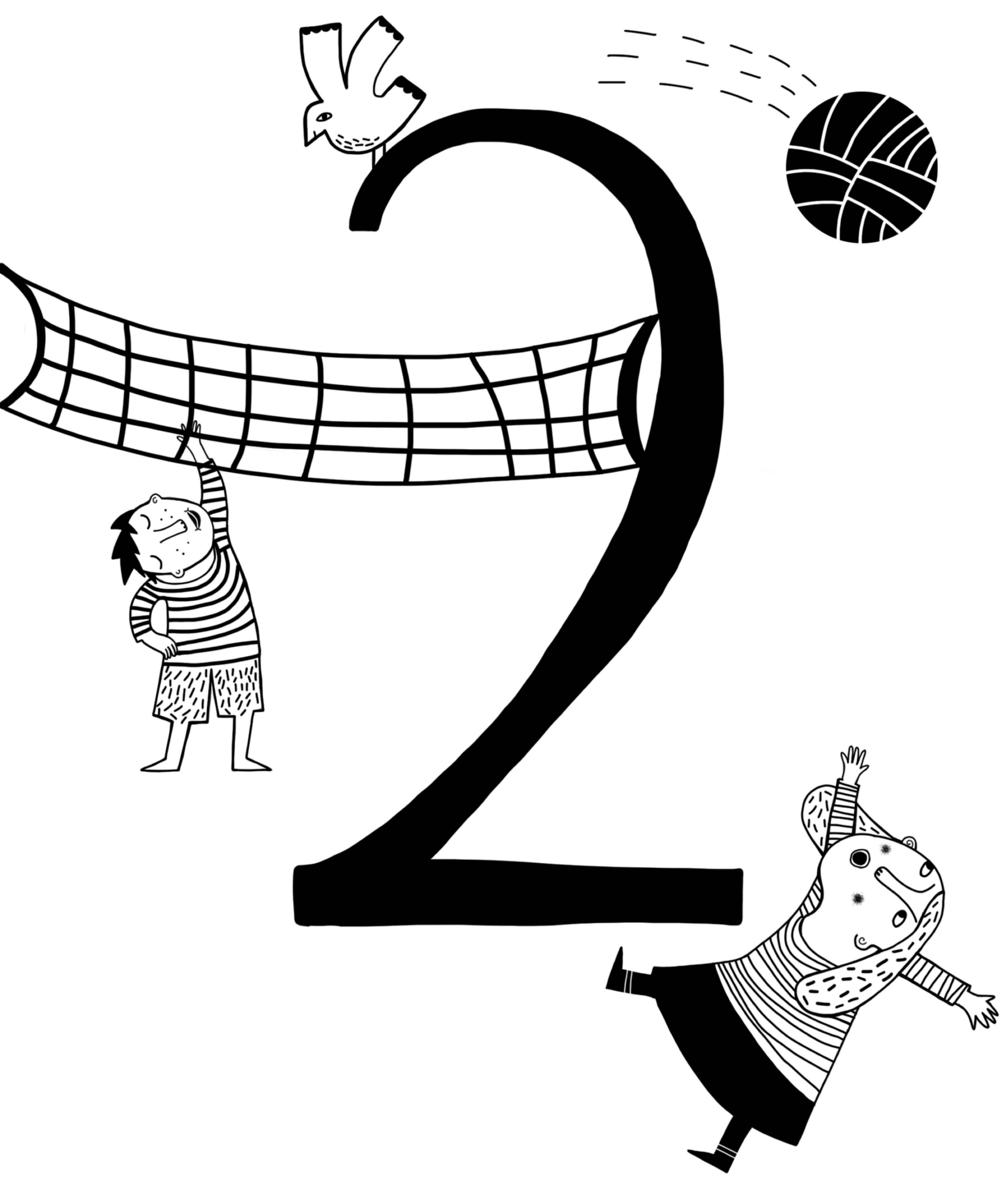





\section{Chapter 2}

\section{Sex differences in arithmetical performance scores: Central tendency and variability}

Martens, R., Hurks, P. P. M., Meijs, C., Wassenberg, R., \& Jolles, J. (2011). Sex differences in arithmetical performance scores: Central tendency and variability. Learning And Individual Differences, 21(5), 549-554. 


\section{ABSTRACT}

The present study aimed to analyze sex differences in arithmetical performance in a large-scale sample of 390 children (193 boys) frequenting grades 1-9. Past research in this field has focused primarily on average performance, implicitly assuming homogeneity of variance, for which support is scarce. This article examined sex differences in arithmetical operations (addition, subtraction, multiplication and division) in central tendency and variability. Central tendency analyses revealed a male advantage, predominantly in addition and subtraction, from grade 6 onward. Variability analyses showed that sex differences were largest among higher achievers and absent among lower achievers. Thus, central tendency and variability analyses provide complementary information on sex differences in arithmetical performance. In conclusion, sex differences in arithmetical performance exist, but depend on the studied arithmetical operation, age group and achievement level. The present study thereby offers new directions for future research by indicating the need for a broader perspective on sex differences. 


\section{INTRODUCTION}

In many industrialized countries in the world, women are increasingly dominating specific disciplines, such as law, medicine and psychology. In contrast, women continue to be underrepresented in mathematics, science, and engineering. Even in high school and college, this pattern of sex related interests is assumed to be present (Halpern, 2004; Halpern, Benbow, Geary, Gur, Hyde, \& Gernsbacher, 2007). Why are mathematics and science still dominated by males, while other disciplines have become progressively female-dominated? At the heart of this question lies the discussion if and how males and females differ innately in terms of, e.g., their mathematical skills. Studying sex differences across age may provide information about the robustness of such differences.

Questions about sex differences in the cognitive and scholastic abilities needed for success in mathematics have a long history in scientific psychology (Halpern et al., 2007). For instance, some researchers have studied sex differences in terms of arithmetical abilities (such as addition and multiplication). The levels of arithmetical abilities that children attain early in school seem to be predictive for more advanced mathematics later in life (e.g., Geary, Frensch, \& Wiley, 1993; Geary, 1994; Gersten, Jordan, \& Flojo, 2005). However, studies focusing on sex differences in arithmetic are limited and inconsistent in their outcome. Where some studies have failed to find sex differences in overall arithmetical abilities (e.g., Hyde, Fennema, \& Lamon, 1990; Imbo \& Vandierendonck, 2007; Lachance \& Mazzocco, 2006), others have reported sex differences in mean arithmetical test scores, primarily favoring males (e.g., Geary, Saults, Liu, \& Hoard, 2000; Lynn \& Irwing, 2008; Royer, Tronsky, Chan, Jackson, \& Marchant, 1999).

Most of these studies have focused primarily on male-female differences in average performance (i.e., central tendency) on arithmetic tests. This type of research implicitly assumes homogeneity of variance, even though support for the validity of that assumption is scarce. Studies reporting performance variability provide complementary information. Hedges and Nowell (1995) found, for instance, that in addition to (small) mean differences in e.g., mathematical and science abilities favoring older adolescent males, male performance was more variable than female performance, with variance ratios primarily between 5 and $28 \%$. Strand, Deary, and 
Smith (2006) found that male 11- and 12-year-olds dominated the top stanines of both quantitative and nonverbal reasoning tests. For instance, in the $9^{\text {th }}$ stanine (i.e., top $4 \%$ of all scores) of a quantitative reasoning test $60 \%$ was male. Thus, primarily at the top end of the distribution substantial sex differences in mathematical abilities are found (Hyde et al., 1990; Halpern et al., 2007). Unfortunately, these previous studies focused primarily on adolescents. To the best of our knowledge, only one study considered the variability of arithmetical scores in childhood. More specifically, Royer et al. (1999) reported on sex differences in the distribution of arithmetical abilities across grades, while focusing in particular on the high-end of the distribution. They found that in grades 5-8 the best achieving males were faster and more accurate than the best achieving females, while there was no clear difference between the best achieving males or females in grades 1-4 or the lowest achieving males or females in grades 1-4 and 5-8. These findings suggest that sex differences in arithmetical performance depend on both achievement level and age, making this method for studying sex differences very promising. However, although the mean scores for both males and females in the slow and fast groups were mentioned separately in this study, the level of significance and the effect sizes of the reported sex differences were not. This makes it difficult to assess how large the effects of these differences were. Also, Royer et al. (1999) only included a selection of arithmetical operations in their study (i.e., not including division). Given that previous studies have reported differential representations of arithmetical operations in the brain (e.g., Dehaene \& Cohen, 1995; Dehaene, Piazza, Pinel, \& Cohen, 2003), it may be that sex differences vary as a function of type of arithmetic operation (e.g., addition versus multiplication).

Hence, we aimed at increasing the knowledge on sex differences in arithmetical performance by reporting both significance levels and effect sizes and combining all factors discussed above: i.e., including all arithmetical operations separately (addition, subtraction, multiplication and division), an age range of 6-15 years, and multiple achievement level measures (central tendency and variability, with a particular interest in sex differences at the high end of the distribution). Apart from these factors, item difficulty (Bielinski \& Davison, 2001; Penner, 2003) and test format (i.e., multiple choice vs. open-ended; DeMars, 2000; Wester \& Henriksson, 2000) could also be considered as possible influences on the direction and magnitude of sex differences in mathematical abilities. To minimize the possible confounding influences 
of these factors in the present study, all participants completed the same timerestricted arithmetical abilities test (i.e., the Arithmetic Tempo Test; De Vos, 1992).

\section{METHOD}

\subsection{PROCEDURE AND PARTICIPANTS}

This study uses data of a large-scale, cross-sectional and longitudinal research program that focuses on mechanisms underlying cognitive development (e.g., Hurks et al., 2010; Wassenberg et al., 2008). In the present study, participants came from multiple schools for regular primary $\left(\mathrm{N}_{\text {schools }}=26\right)$ and secondary education (ranging from lower secondary professional education to pre-university education, $N_{\text {schools }}=5$ ) in the Netherlands. Participating schools were asked to distribute information packages among caregivers of all children in the first (i.e., 6-7 years), third, fifth, and sixth grades of primary school, and seventh, eight, and ninth grades of secondary school. Besides information about the purpose of the study, the information packages contained a stamped return envelope, an informed consent letter, and a questionnaire on characteristics of the child and his environment, which caregivers completed in if they agreed to participate. After consent was obtained, all children were screened on the bases of exclusion criteria (see Hurks et al., 2010; i.e., not being in the appropriate grade, not having the Dutch nationality, and current use of medication that could affect cognitive functioning. Developmental disorders, such as learning disorders, were not considered to be an exclusion criterion, thereby preventing the sample from being "overly normal". Instead, children were considered to develop at a normal pace when they attended a school for regular education and were in the appropriate grade for their age. After screening, only children meeting the predetermined requirements were approached for further testing.

In total, 390 children aged 6 to 15 (193 boys) participated in the present study. In Table 1, the descriptive statistics of all children are given per grade. All selected children completed a fixed-order neuropsychological test battery concentrating on various cognitive domains, such as arithmetical abilities, working memory and estimation. Four well-trained research assistants tested all children. Testing took place in stimulus-free rooms at the participating schools and took 


\section{CHAPTER 2}

approximately 90 minutes. The Ethics Committee of the Faculty of Psychology and Neuroscience of Maastricht University approved the research protocol.

\subsection{INSTRUMENTS}

\subsubsection{Arithmetical abilities}

The Arithmetic Tempo Test (ATT; De Vos, 1992) is a standardized paper-and-pencil test frequently used in Dutch and Flemish education to measure arithmetical abilities. Its psychometric value has been established using a sample of 10,059 children (Desoete, Stock, Schepens, Baeyens, \& Roeyers, 2009; Stock, Desoete, \& Roeyers, 2009). Four sets of 40 arithmetical problems were presented to the children, respectively containing addition (ATT 1,+), subtraction (ATT 2, -), multiplication (ATT 3, x), and division problems (ATT $4, \div$ ). Per set, the children have to solve as many problems as possible within one minute. All problems consisted of two-operand equations with an outcome smaller than 100 and both operands ranging between 0 and 90 . Test scores were calculated per set, i.e., the total amount of problems answered correctly minus the total amount of problems answered incorrectly. Additionally, an overall score (ATT Total) was calculated consisting of the sum of ATT 1-4.

\subsubsection{Verbal intelligence}

To have an estimate of verbal intelligence (VIQ), the WISC-R Vocabulary subtest (De Bruyn et al., 1986; Wechsler, 1974) was administered. Children were asked to give a definition of words (ranging from easy to difficult) as accurately as possible. Scaled scores ranged from 1 to $19(M=10, S D=3)$. Because the present study had already started when the WISC-III became available in the Netherlands, the WISC-R was used (Wassenberg et al., 2008). The reliability coefficient for the Vocabulary subtest in a Dutch population of children is .86-.88 (De Bruyn et al., 1986).

\subsection{STATISTICAL ANALYSES}

All analyses were performed using SPSS 16.0 for Macintosh OS X. Performance on all ATT outcome measures was equal among the four test administrators (F-values ranging from 0.08 to 1.65). For seven children the ATT data (or part of it) were missing or unreliable, due to refusal to cooperate (e.g., because of fatigue) and/or failure to 32 
execute a task according to instructions. Missing data were less than $5 \%$ of the total data; therefore, these were not replaced (Croy \& Novins, 2005). Unreliable data were excluded from later analyses. No extreme values (i.e., more than three times the interquartile distance $<25^{\text {th }}$ percentile or $>75^{\text {th }}$ percentile as defined by Huizingh, 2002) were found on the ATT outcome measures for any of the other children.

Two additional comments should be made. Firstly, in line with ATT guidelines (De Vos, 1992), all children in first grade only completed ATT 1 and 2. This was a deliberate choice, since multiplication (ATT 3) and division (ATT 4) are not yet taught at this age in the Dutch school system. As a consequence, scores of children from grade 1 could not be included in any of the Multivariate analyses containing ATT 3, ATT 4 or ATT Total scores (see below). Secondly, data on verbal intelligence were lacking for all children in grade 6. However, univariate analyses of variance (ANOVA) revealed no significant differences in VIQ scores between all other grades (see Table 1).

Using GLM Multivariate analyses, central tendencies measures of ATT 1-4 as well as ATT Total were analyzed as a function of grade and sex. Next, the participants were divided into two groups based on the grades they frequented: i.e., (a) grades 1, 3 and 5 vs. (b) grades 6 to 9. This division was made on the basis of the present study's results regarding the development of arithmetical abilities. This division was also in line with Royer et al. (1999) - see Introduction section. Analyses on central tendencies were repeated as a function of this division.

In addition to GLM analyses of central tendencies, performance variability (i.e., achievement level) was taken into account. For this purpose, per grade all participants were re-divided into three groups based on their performance (low, intermediate or high). Per ATT measure (ATT 1-4, ATT Total) the low, intermediate, and high performers were defined on the basis of percentile scores on the ATT, calculated separately for boys and girls. Per ATT measure, participants were placed in the low scoring group when scoring $<25^{\text {th }}$ percentile, in the intermediate scoring group when scoring between the $25^{\text {th }}$ and $75^{\text {th }}$ percentile, and in the high scoring group when scoring $>75^{\text {th }}$ percentile. Thereafter, differences in variability between boys and girls within the groups with low, intermediate and high scores were analyzed using separate univariate analyses of variance for each ATT measure. The sex by grade interactions were studied within the low, intermediate and high scoring groups in the same manner. Finally, the participants were divided into two grade groups as 


\section{CHAPTER 2}

mentioned above, i.e., grades 1-5 vs. grades 6-9. Separate univariate analyses for each ATT measure were performed per grade group to assess sex differences within groups with low, intermediate and high scores.

For all analyses, significance levels and effect sizes were reported and the alpha-value was set at .05. Effect sizes were calculated using the d statistic (Cohen, 1988; Halpern, 2000; Hyde \& Linn, 2006). In accordance with Hyde and Linn (2006), effect size values between 0 and 0.10 were considered trivial, values between 0.11 and 0.35 were considered small, values between 0.36 and 0.65 were considered medium, values between 0.66 and 1.00 were considered large, and values larger than 1.00 were considered very large. In case of significant differences in ATT performance for sex and/or grade, post-hoc Bonferroni comparisons were conducted.

\section{RESULTS}

\subsection{ARITHMETICAL ABILITIES, IN TERMS OF CENTRAL TENDENCY, ACROSS GRADES}

Figure 1 shows the mean ATT performance for addition (ATT 1), subtraction (ATT 2), multiplication (ATT 3), and division (ATT 4) across grades. GLM Multivariate analyses (without grade 1) including all outcome measures revealed a significant main effect for grade, Pillai's Trace: $F(20,1232)=13.01, p<.001$. The same holds true for GLM Multivariate analyses including only ATT 1 and 2 (i.e., with grade 1), Pillai's Trace: F (12, $742)=38.90, p<.001$. Results showed that, independent of type of operation tested, arithmetical performance improved significantly until grade 5, with each grade performing better on average than the previous one $(p<.001$ for comparisons of grades 1-5). Thereafter, a slight increase in performance could still be observed until grade 8 , however, this increase was less strong and less consistent (i.e., ATT 1: grade 6 vs. grade $7: p<.01$, grade 7 vs. grade $8: p<.05$, ATT 2: grade 7 vs. grade $8: p<.01$; ATT 3: grade 7 vs. grade 8: $p<.05$, ATT 4: grade 7 vs. grade 8: $p<.05$; ATT Total: grade 7 vs. grade $8: p<.01)$.

In addition, a significant differential effect was found for the type of arithmetical operation: addition > subtraction > multiplication > division (\# correct incorrect; for all univariate analyses: $p<$.001). This significant difference in development trajectories between the four arithmetical operations was confirmed by a GLM Repeated Measures analysis; Pillai's Trace: $F(15,942)=7.45, p<.001$. 34 


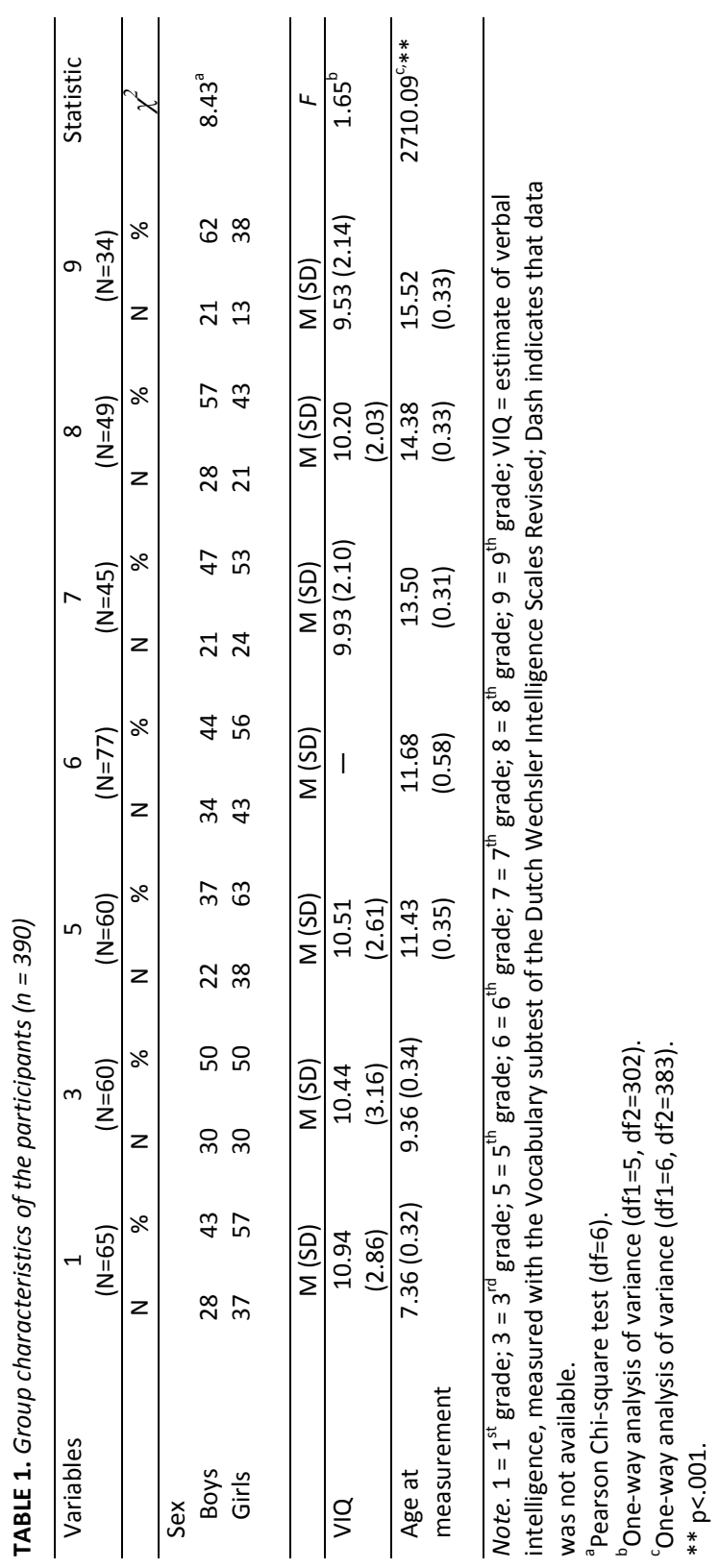




\section{CHAPTER 2}

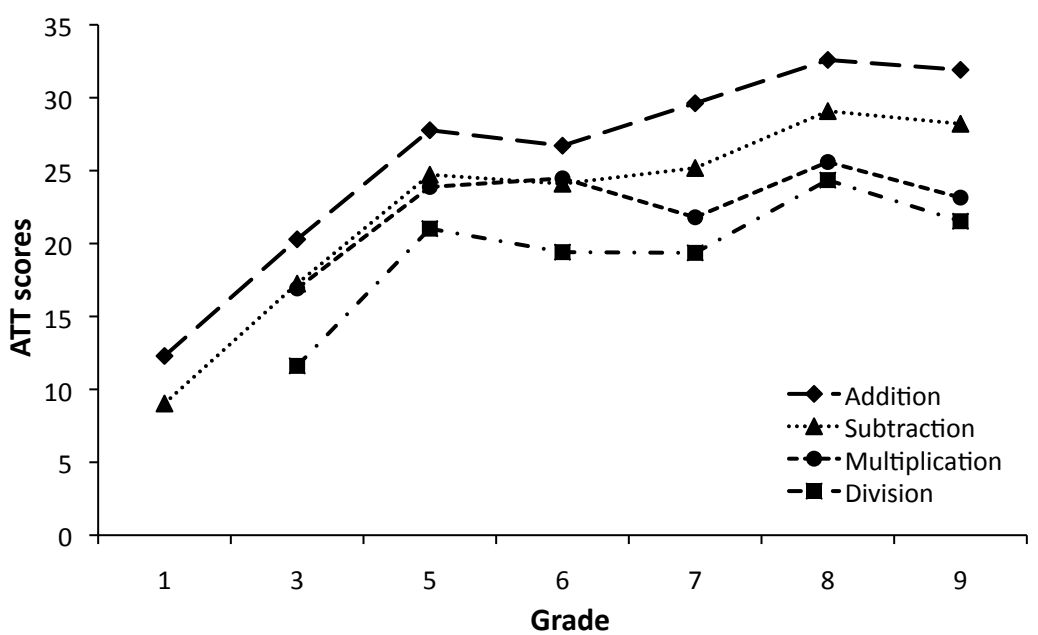

FIGURE 1. Arithmetical performance across grades shown per arithmetical operation

\subsection{SEX DIFFERENCES (AND SEX X AGE INTERACTIONS) IN ARITHMETICAL ABILITIES IN} TERMS OF CENTRAL TENDENCY

A GLM Multivariate analysis of all ATT performances indicated a trend towards a main effect of sex: i.e., boys tended to outperform girls in arithmetical performance independent of grade, $F(4,305)=2.48, p=.04$ (see Figure 2). Post-hoc Bonferroni comparisons revealed that this finding could primarily be explained by sex differences in ATT 1 (addition) and ATT 2 (subtraction) scores, resp. $F(1,308)=6.75, p=.01, d=$ 0.20 and $F(1,308)=7.95, p<.01, d=0.28$. The overall scores for ATT 1 were: $M_{\text {boys }}=$ $25.84(\mathrm{SD}=8.12)$ vs. $\mathrm{M}_{\text {girls }}=24.24(7.68)$, and for ATT 2: $M_{\text {boys }}=22.92(8.11)$ vs. $M_{\text {girls }}=$ 20.62 (8.06). Separate cross-sectional comparisons of ATT 1 and 2 for all grades (including grade 1), using GLM univariate analyses, revealed similar results.

The GLM Multivariate analysis also revealed a trend towards an interaction between grade and sex, Pillai's Trace: $F(20,1232)=1.53, p=.06$. Post-hoc Bonferroni comparisons showed that this trend was primarily caused by a grade $\mathrm{x}$ sex interaction for ATT 1 performance (i.e., a small male advantage was found only from grade 6 onward), Pillai's Trace: $F(5,308)=2.31, p=.04$. Two additional separate GLM Multivariate analyses of ATT performance for either grades 3-5 or grades 6-9, with sex as independent variable revealed similar results. In the analysis of grades 3-5 no 
significant sex differences were found, while the analysis of grades 6-9 indicated a trend towards a male advantage, Pillai's Trace: $F(4,196)=2.69, p=.03$. Post-hoc Bonferroni comparisons revealed that, in grades 6-9, sex differences were significant only for ATT 1 and 2; resp. $F(1,199)=7.95, p<.01, d=0.38$ and $F(1,199)=8.58, p<$ $.01, d=0.42$. A trend was found for ATT Total, $F(1,199)=5.77, p=.02, d=0.34$.

In sum, sex differences were found primarily in older children performing addition and to a lesser extent subtraction. In contrast, no effects of sex or grade $\mathrm{x}$ sex interactions were found on tasks measuring the ability to conduct multiplication and division.

\subsection{SEX DIFFERENCES IN LOW, INTERMEDIATE, AND HIGH ARITHMETICAL} PERFORMANCE: MEASURING VARIABILITY

In order to study sex differences in terms of the variability of ATT scores, the performance of low-, intermediate-, and high-scoring participants was analyzed independent of grade, using GLM Univariate analyses. Sex differences were found on all outcome measures within the high-scoring group, favoring boys (F-values varied between 16.44 and $37.36, \mathrm{p}$-values < .001, d-values ranged from 0.31 to 0.54 ; see Figure 3 for a reproduction of the pattern of sex differences on the ATT Total, which reflects the pattern seen on all ATT measures). For the intermediate-scoring group, some sex differences were also found, again favoring boys. However, these differences were only significant for ATT 1 and 2 scores (i.e., addition and subtraction), resp. F (1, $191)=17.69, p<.001, d=0.26$ and $F(1,190)=22.02, p<.001, d=0.33$ and ATT Total $(F(1,155)=7.60, p<.01, d=0.23$. For the low-scoring participants, no sex differences were found on any ATT measure.

To study grade $x$ sex interactions in this context, two groups were formed, i.e., children frequenting grades 1-5 vs. children frequenting grades 6-9. When studying performance in grades 1-5, no sex differences were found in the low-, intermediate-, or high-scoring groups. Conversely, when analyzing the performance in grades 6- 9, sex differences were found in the intermediate-, and high-scoring groups, again favoring boys. These results are similar to the results of the overall analyses of all grades: in the intermediate group significant differences were found for ATT 1 and 2 scores, resp. $F(1,106)=11.78, p=.001, d=0.63$ and $F(1,106)=12.57, p=.001, d=$ 


\section{CHAPTER 2}

0.65, as well as a trend for ATT Total, $F(1,102)=5.05, p=.03, d=0.43$. In the high performance group, the differences were significant for all ATT-measures (F-values varied between 16.44 and $24.30, \mathrm{p}$-values <.001, d-values ranged from 1.12 to 1.23 ).

In sum, taking variability scores into account, sex differences were primarily found in older, high- and to some extent intermediate-scoring children.

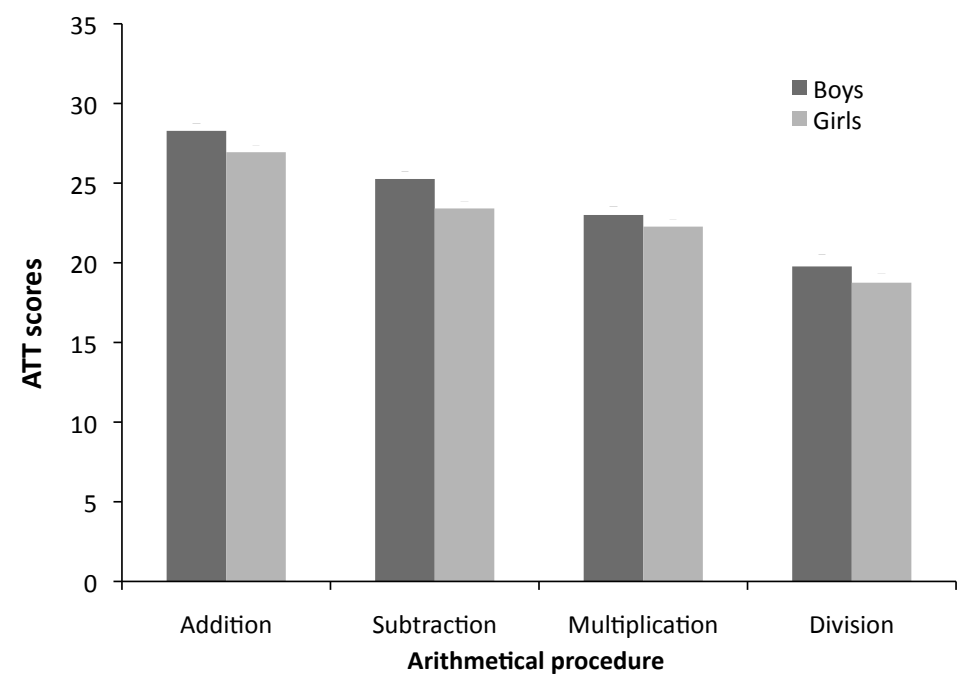

FIGURE 2. Sex differences in arithmetical performance (ATT scores) shown per arithmetical operation

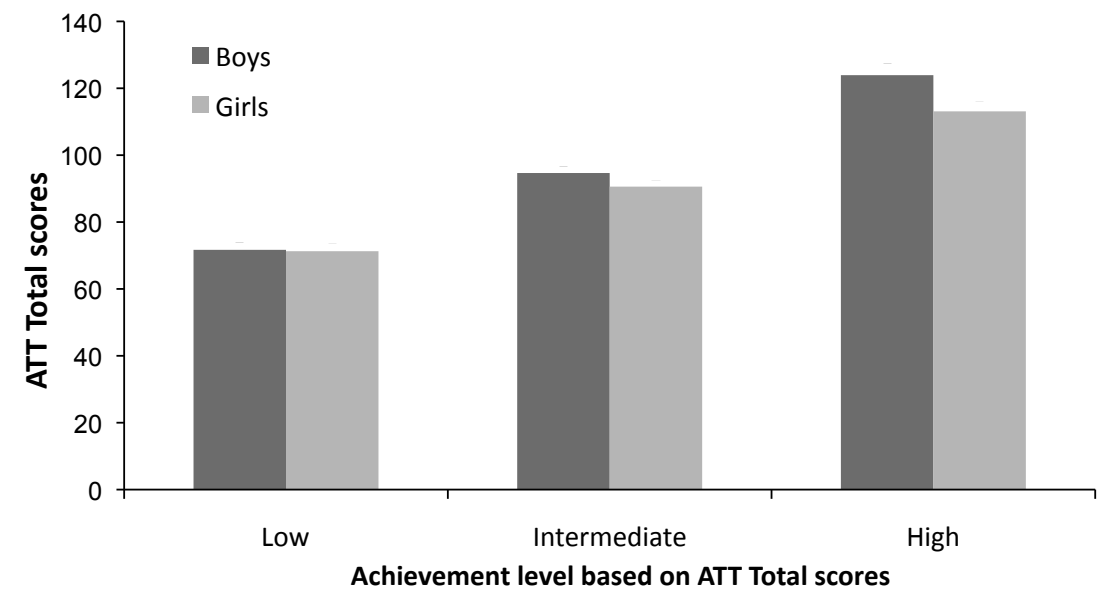

FIGURE 3. Sex differences in ATT Total scores shown per achievement level (low-intermediate-high) 


\section{DISCUSSION}

The influence of sex differences on arithmetical performance in children aged 6 to 15 years was studied in relation to arithmetical operation (i.e., addition, subtraction, multiplication and division), grade, and achievement level (i.e., central tendency and variability). With respect to the first factor, i.e., type of arithmetical operation, it should be noted that most studies reporting on sex differences in arithmetical performance do so on the basis of general achievement scores (e.g., Imbo \& Vandierendonck, 2007; Lynn \& Irwing, 2008; Rosselli, Ardila, Matute, \& Inozemtseva, 2009). Although the results of the limited number of studies into age-related sex differences in arithmetic were promising (i.e., Rosselli et al., 2009; Royer et al., 1999), these studies did not examine all four basic arithmetical operations separately. In the present study, the influence of sex differences on arithmetical abilities was examined more in detail by looking at sex differences per arithmetical operation (addition, subtraction, multiplication and division). On a behavioral level, children improved on all four arithmetical operations up to at least grade 8 (age 13-14 years), with the largest improvement up to grade 5 (age 10-11 years). More importantly, however, the results revealed significant differences in the development trajectories of the arithmetical operations (i.e., total number correct minus incorrect: addition > subtraction > multiplication > division). In line with this, previous studies have reported differential representations of arithmetical operations in the brain (e.g., Dehaene \& Cohen, 1995; Dehaene, et al., 2003) as well as differences in brain activation patterns when learning these operations (Ischebeck, et al., 2006). These studies support the necessity of analyses test performance separately per operation, when studying sex differences in arithmetical performance, as is done in the present study.

More importantly, the present study showed that there are sex differences in arithmetical performance, yet that these varied not only with the arithmetical operation being studied, but also with age and achievement level (i.e., variability vs. central tendency). More specifically, while using central tendency scores, sex differences (favoring boys) were found primarily in older children performing addition and to a lesser extent subtraction. In contrast, no effects of sex or grade $x$ sex interactions were found on tasks measuring the ability to conduct multiplication and division. The inclusion of variability scores, however, led to a subtler picture: sex 
differences (again favoring boys) were primarily found in older, high- and to some extent intermediate-scoring children. This emphasizes the relevance of simultaneously exploring the interaction between the type of operation, grade and achievement level to unravel the complex issue of sex differences.

These findings are in line with the only study that has previously included similar factors while relating sex differences to arithmetical abilities (i.e., Royer et al., 1999). However, the sample sizes in the study by Royer et al. were too small for statistical analyses; their results were based on observational comparisons of mean scores. Consequently, making inferences solely on the basis of Royer et al. (1999)'s results is difficult. The present study reported both the significance levels and the effect sizes of sex differences in arithmetical abilities per performance group, thereby providing more information about the extent of such differences. Our effect size calculations revealed that sex differences in terms of central tendency were small. In contrast, sex differences between high performers were accompanied by predominantly medium effect sizes for all grades and even very large effect sizes when only taking grades 6 to 9 into account. These findings further support the relevance of including variance scores when studying sex differences in children; i.e., small main effects can indeed conceal larger and more significant differences at the top end of the performance distribution.

The found results may well be explained theoretically in terms of interindividual differences in childhood use of fact retrieval versus other strategies (such as rehearsal) to solve arithmetical tasks. For one, addition and subtraction are learned first in primary school, while at least one year later formal schooling of multiplication and division starts. As a consequence, addition and subtraction may be better automatized in older children, causing fact retrieval to be used more frequently as a solution strategy. Conversely, if multiplication and division are learned later and are less automatized, even older children may prefer to use other solution strategies (i.e., overt strategies). Given the fact that in the present study sex differences were found primarily on addition and subtraction tasks, one might conclude that boys outperform girls in terms of more automatized fact retrieval, as was proposed by e.g., Royer et al. (1999). The time-restricted arithmetical abilities test that was used in the present study may have stimulated the use of fact retrieval more than a non-time-restricted test, since performance is based on a trade-off between speed and accuracy. 
Although the findings of the present study are interesting, there are also some limitations. Firstly, the present study only included one type of arithmetical abilities measure (i.e., an arithmetic tempo test) and a quantitative method for scoring. Using additional arithmetical tasks, such as arithmetical word problems and a complementary qualitative scoring method, such as a measure of strategy-use (as suggested by Carr, Jessup, \& Fuller, 1999), may provide an even more complete insight into sex differences in arithmetical performance. Secondly, although the present study's method for variability analyses is promising and may shed new light on sex differences in both arithmetical and other abilities, there is still no consensus on the correct manner of performance selection and which measures to use for this selection (i.e., reaction time or accuracy scores). Consequently, the method of analysis and type of measure used in the present study for dividing the participants into low, intermediate and high performers is different from the one used by for instance Royer et al. (1999). Finally, although our findings are consistent and promising, some prudence is in order due to the relatively low numbers of participants per group. Future research should expand this line of research using an even larger number of participants. This in turn may facilitate the application of more advanced statistical methods, such as multi-level analyses, with the additional benefit of ruling out possible effects of educational differences on our findings. Given the relatively small sample sizes per group, the influence of education-related factors could not be completely excluded. Further, it would be interesting to expand this line of research to older adolescents and adults, to explore if this leads to similar results or if sex differences in multiplication and division arise in older age groups.

\section{CONCLUSION}

The present study revealed differences in variance between boys and girls on arithmetical performance, with the most significant sex differences favoring high performing boys in grades 6 to 9. To the best of our knowledge, we are one of the first to study this combination of factors in a developmental context, thereby contributing significantly to the ongoing discussion of sex differences in terms of cognitive performance and educational achievement. 


\section{CHAPTER 2}

\section{REFERENCES}

Bielinski, J., \& Davison, M. L. (2001). A sex difference by item difficulty interaction in multiple-choice mathematics items administered to national probability samples. Journal of Educational Measurement, 38(1), 51-77.

Carr, M., Jessup, D. L., \& Fuller, D. (1999). Gender differences in first-grade mathematics strategy use: Parent and teacher contributions. Journal for Research in Mathematics Education, 30(1), 20-46.

Cohen, J. (1988). Statistical Power Analysis for the Behavioral Sciences (2nd ed.). Hillsdale, NJ Lawrence Erlbaum Associates.

Croy, C. D., \& Novins, D. K. (2005). Methods for addressing missing data in psychiatric and developmental research. Journal of the American Academy of Child and Adolescent Psychiatry, 44(12), 12301240.

De Bruyn, E. E. J., Van der Steene, G., Van Haasen, P. P., Coetsier, P., Pijl, Y. J., Spoelders-Claes, R., et al. (1986). Wechsler Intelligence Scale for Children-Revised (WISC-R). Lisse: Swets \& Zeitlinger.

DeMars, C. E. (2000). Test stakes and item format interactions. Applied Measurement in Education, 13(1), 55-77.

De Vos, T. (1992). Tempo Test Rekenen [Arithmetic Tempo Test]. Lisse: Swets \& Zeitlinger.

Dehaene, S., \& Cohen, L. (1995). Towards an anatomical and functional model of number processing. Mathematical Cognition, 1(1), 83-120.

Dehaene, S., Piazza, M., Pinel, P., \& Cohen, L. (2003). Three parietal circuits for number processing. Cognitive Neuropsychology, 20(3/4/5/6), 487-506.

Desoete, A., Stock, P., Schepens, A., Baeyens, D., \& Roeyers, H. (2009). Classification, seriation, and counting in grades 1, 2, and 3 as two-year longitudinal predictors for low achieving in numerical facility and arithmetical achievement? Journal of Psychoeducational Assessment, 27(3), 252-264.

Geary, D. C., Frensch, P. A., \& Wiley, J. G. (1993). Simple and complex mental subtraction: Strategy choice and speed-of-processing differences in younger and older adults. Psychology and Aging, 8(2), 242-256.

Geary, D.C. (1994). Children's mathematical development: Research and practical applications. Washington, DC: American Psychological Association.

Geary, D. C., Saults, S. J., Liu, F., \& Hoard, M. K. (2000). Sex differences in spatial cognition, computational fluency, and arithmetical reasoning. Journal of Experimental Child Psychology, 77(4), 337-353.

Gersten, R., Jordan, N. C., \& Flojo, J. R. (2005). Early identification and interventions for students with mathematics difficulties. Journal of Learning Disabilities, 38(4), 293-304.

Halpern, D. F. (2000). Sex differences in cognitive abilities (3rd ed.). Mahwah, NJ: Lawrence Erlbaum Associates. 
Halpern, D. F. (2004). A cognitive-process taxonomy for sex differences in cognitive abilities. Current Directions in Psychological Science, 13(4), 135-139.

Halpern, D. F., Benbow, C. P., Geary, D. C., Gur, R. C., Hyde, J. S., \& Gernsbacher, M. A. (2007). The science of sex differences in science and mathematics. Psychological Science in the Public Interest, 8(1), 151.

Hedges, L. V., \& Nowell, A. (1995). Sex differences in mental test scores, variability, and numbers of highscoring individuals. Science, 269(5220), 41-45.

Huizingh, E. (2002). Inleiding SPSS 11 voor Windows [Introduction to SPSS 11 for Windows]. Schoonhoven: Academic Service.

Hurks, P. P., Schrans, D., Meijs, C., Wassenberg, R., Feron, F. J., \& Jolles, J. (2010). Developmental Changes in Semantic Verbal Fluency: Analyses of Word Productivity as a Function of Time, Clustering, and Switching. Child Neuropsychology, iFirst, 1-22.

Hyde, J. S., Fennema, E., \& Lamon, S. J. (1990). Gender differences in mathematics performance: a metaanalysis. Psychological Bulletin, 107(2), 139-155.

Hyde, J. S., \& Linn, M. C. (2006). Diversity. Gender similarities in mathematics and science. Science, 314(5799), 599-600.

Imbo, I., \& Vandierendonck, A. (2007). The development of strategy use in elementary school children: working memory and individual differences. Journal of Experimental Child Psychology, 96(4), 284309.

Ischebeck, A., Zamarian, L., Siedentopf, C., Koppelstatter, F., Benke, T., Felber, S., et al. (2006). How specifically do we learn? Imaging the learning of multiplication and subtraction. Neuroimage, 30(4), 1365-1375.

Lachance, J. A., \& Mazzocco, M. M. (2006). A longitudinal analysis of sex differences in math and spatial skills in primary school age children. Learning and Individual Differences, 16, 195-216.

Lynn, R., \& Irwing, P. (2008). Sex differences in mental arithmetic, digit span, and g defined as working memory capacity. Intelligence, 36(3), 226-235.

Penner, A. M. (2003). International gender $x$ item difficulty interactions in mathematics and science achievement tests. Journal of Educational Psychology, 95(3), 650-655.

Rosselli, M., Ardila, A., Matute, E., \& Inozemtseva, O. (2009). Gender differences and cognitive correlates of mathematical skills in school-aged children. Child Neuropsychology, 15(3), 216-231.

Royer, J. M., Tronsky, L. N., Chan, Y., Jackson, S. J., \& Marchant, H., 3rd. (1999). Math-Fact Retrieval as the Cognitive Mechanism Underlying Gender Differences in Math Test Performance. Contemporary Educational Psychology, 24(3), 181-266.

Stock, P., Desoete, A., \& Roeyers, H. (2009). Predicting arithmetic abilities: the role of preparatory arithmetic markers and intelligence. Journal of Psychoeducational Assessment, 27(3), 237-351. 


\section{CHAPTER 2}

Strand, S., Deary, I. J., Smith, P. (2006). Sex differences in cognitive abilities test scores: A UK national picture. British Journal of Educational Psychology, 76, 463-480.

Wassenberg, R., Hurks, P. P., Hendriksen, J. G., Feron, F. J., Meijs, C. J., Vles, J. S., et al. (2008). Age-related improvement in complex language comprehension: results of a cross-sectional study with 361 children aged 5 to 15. Journal of Clinical and Experimental Neuropsychology, 30(4), 435-448.

Wechsler, D. (1974). Wechsler Intelligence Scale for Children-Revised. Manual. San Antonio, TX: The Psychological Corporation.

Wester, A., \& Henriksson, W. (2000). The interaction between item format and gender differences in mathematics performance based on TIMSS data. Studies in Educational Evaluation, 26, 79-90. 


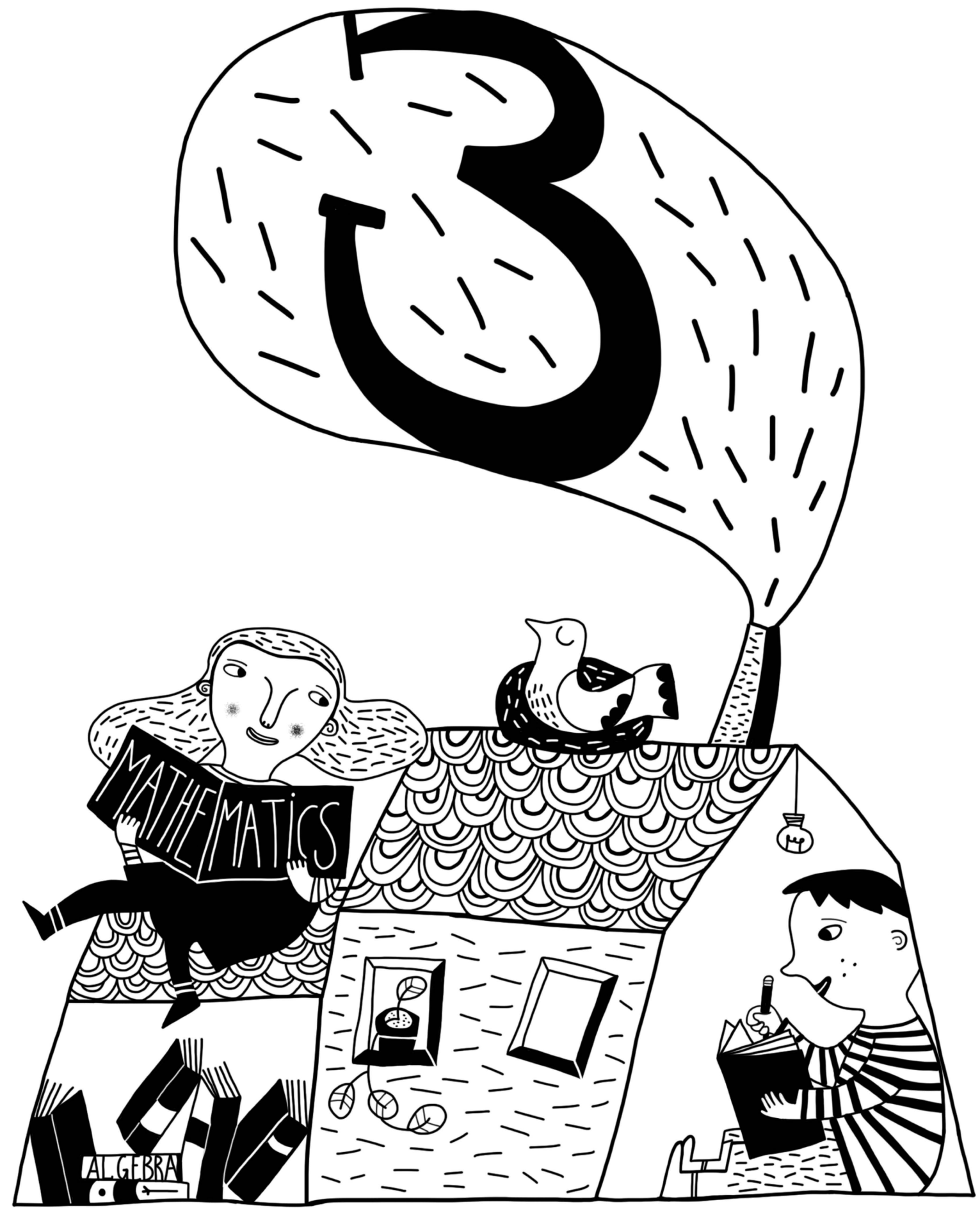





\section{Chapter 3}

Impact of home learning environment, child's own initiative and cognition on young children's numeracy

Martens, R., Hurks, P. M., \& Jolles, J. (2012). Impact of home learning environment, child's own initiative, and cognition on young children's numeracy. In preparation. 


\begin{abstract}
Numerical abilities at preschool and early primary school age are strongly associated with subsequent academic success. Limited research has focused on the influence of the home learning environment (HLE; e.g., reading to the child, initiating number and letter activities) on the development of these numerical abilities; particularly in relation to a child's own initiative in learning $(\mathrm{Cl}$; e.g., asking to be read to, looking in books). The present study explored the influence of both $\mathrm{HLE}$ and $\mathrm{Cl}$ on early numeracy in a sample of healthy children aged 5 to $7(n=211)$. In addition, the age and cognitive abilities of the child were taken into account. A factor analysis indicated that certain $\mathrm{HLE}$ and $\mathrm{Cl}$ factors were partly interrelated at preschool age, whereas other factors were unrelated. Therefore, the contribution of both $\mathrm{HLE}$ and $\mathrm{Cl}$ factors to numerical abilities in preschool and first grade was explored. Of the six factors that were found, only four (i.e., number and letter activities, reading books, looking in books, and educational television) were significantly related to numerical abilities. However, their influence was moderated by children's cognitive abilities (i.e., working memory, and phonological processing) and age (i.e., preschool or first grade) as well as the specific numerical abilities under study. Thus, a one-to-one correspondence between HLE and numeracy development cannot be inferred, child-related factors have to be taken into account as well. This has potential implications for the effectiveness of early interventions.
\end{abstract}




\section{INTRODUCTION}

Early numerical abilities are assumed to have an enduring impact on a child's future scholastic career. Preschool performance on numerical abilities tests is found to be predictive of mathematical abilities in third, fifth, and eighth grade and even in high school (Duncan et al., 2007; Stevenson \& Newman, 1986). Although this stability over time represents the typically found positive relationship between early and later knowledge (Bransford, Brown, \& Cocking, 1999), the stability of numerical abilities is unusually large (Siegler \& Ramahni, 2009). For one, Duncan et al. (2007) found that the predictive power of early numerical abilities at school-entry (i.e., age 4-6) for academic achievement in primary and secondary school (i.e., age 8, 10 and 13-14) was more than two times larger than the predictive power of e.g., early reading proficiency and attentional control. Furthermore, numerical abilities at preschool age are predictive of daily functioning, career success and prospects for future income (Butterworth, 2005; National Research Council, 2009; Rivera-Batiz, 1992). Although these findings stress the importance of early numeracy, many questions remain to be answered about the origin of inter-individual differences in numerical abilities. Therefore, the first aim of the present study was to explore the influence of different aspects of the home learning environment (HLE) on numerical abilities in a population of healthy children aged 5 to 7 years. The term 'home learning environment' is used to describe common activities or materials offered to a child at home to provide a stimulating learning environment (e.g., joint book reading - see paragraph 1.2). Past studies have focused principally on the relationship between home learning environment and literacy. Less research has been devoted to its effect on early numeracy (e.g., Anders et al., 2012; Christian, Morrison, \& Bryant, 1998; Melhuish, Phan, Sylva, Sammons, Siraj-Blatchford, \& Taggart, 2008). As a second aim, we studied the moderating influence of childrelated factors on the relationship between HLE and early numeracy. More specifically, we focused on the child's own initiative in learning, age, working memory and phonological processing abilities (see paragraph 1.3). In this context, the child's own initiative in learning ( $\mathrm{Cl}$ ) was defined as the initiation of learning-related activities by the child (e.g., looking in books on own initiative). 


\subsection{NUMERACY AS A CONCEPT}

As a first step in understanding the relationship between HLE and numeracy development, it is important to specify the types of numerical abilities under study. Numeracy is an overarching term that refers to preparatory mathematical abilities (e.g., basic number, counting and arithmetical skills; Geary, 2000; Toll, Van der Ven, Kroesbergen, Van Luit, 2010). For preschool-aged children, important abilities are: making comparisons, classification, one-to-one correspondence, seriation, the use of number words, structured and resultative counting and general understanding of numbers (for more detailed information see Aunio, Hautamäki, Heiskari, \& Van Luit, 2006; Ee, Wong, \& Aunio, 2006; Toll et al., 2010). Such early numerical abilities form the basis for more complex mathematical competencies (Ee et al., 2006; Geary, 2000). Given that some numerical abilities develop earlier than other abilities (Butterworth, 2005; Geary, 2000), the influence of HLE and $\mathrm{Cl}$ may vary among specific numerical abilities. For one, Jordan, Levine, and Huttenlocher (1994) and Starkey, Klein, and Wakeley (2004) have reported that the socio-economic background (as a proxy of HLE) of 3- to 5-year-old children has significant effects on task performance that includes verbally stated or written numerals. In contrast, for nonverbal numerical tasks (i.e., classification) no significant effects of socio-economic background were found. Unfortunately, most studies examining the effects of $\mathrm{HLE}$ and $\mathrm{Cl}$ have focused on early numerical abilities as a one-dimensional factor. The aim of the present study was to take a more multi-dimensional approach, by studying inter-individual differences in various early numerical abilities.

\subsection{HOME LEARNING ENVIRONMENT AS A CONCEPT}

As with numerical abilities, the concept "HLE" is characterized by a multitude of definitions and measurement approaches. Three approaches to the measurement and study of the HLE in relation to academic performance can be distinguished: i.e., (i) measures of socio-economic status (SES) that serve as a proxy for HLE (e.g., parental level of education or occupation); (ii) measures of indirect home learning opportunities, that focus on objects and materials located in the home (e.g., How many books are located in the home? Can the child watch educational television at home? What types of children's books are present in the home?); and (iii) measures of 
direct home learning opportunities, that focus on active parent-child interactions that are thought to stimulate learning (e.g., Are parents and children practicing letter writing together?; Iverson \& Walberg, 1982; Christian et al., 1998; Foy \& Mann, 2003; Melhuish, Sylva, Sammons, Siraj-Blatchford, Taggart, Phan, et al., 2008). The relative contribution of these separate HLE measures in explaining inter-individual variability has already been established for literacy development at preschool age (e.g., Bennett, Weigel, \& Martin, 2002; Christian et al., 1998; Melhuish, Phan, et al., 2008). The role of these HLE measures in explaining inter-individual differences in the development of numerical abilities in preschool and primary school has received far less attention, although researchers in the field of numeracy have made an effort to catch up.

In the majority of the (few) available studies, only indirect HLE activities (e.g., storybook reading, library visits and watching educational television) were included, which are likely to stimulate both numeracy and literacy in a general manner. The successful development of both numeracy and literacy is assumed to rely on fluency attainment (e.g., Howell \& Lorson-Howell, 1990; Johnson \& Layng, 1992) and may therefore be influenced in part by the same, indirect HLE activities. Melhuish, Phan, et al. (2008) and Melhuish, Sylva, et al. (2008) found a relationship between indirect HLE measures (i.e., an index of seven home activities including e.g., going to library and frequency of reading to the child) collected at 3 to 4 years of age and numerical achievement measured at 5 to 7 years of age and at 10 years of age. For one, Melhuish, Phan, et al. (2008) found that children who had a less stimulating HLE at age 3 were more likely to underachieve in numeracy at 5 to 7 years of age. Further, Christian et al. (1998) described that 4- and 5-year-old children who had spent less time in childcare centers displayed lower numerical performance if they had also been exposed less to indirect HLE activities (i.e., books in the home, daily reading, library visits) and if their mothers had a lower level of education.

In addition to indirect HLE activities, the present study aimed to include HLE activities that directly and specifically stimulate numerical skills. Engaging in this type of activities does not come as naturally to parents (or caregivers) as engaging in indirect HLE activities (Blevins-Knabe, 2008). For one, Anders et al. (2012) found that, although parents of 3- to 5-year-olds engage in literacy-related as well as numeracyrelated activities at home, literacy-related activities were more prevalent. Furthermore, both types of activities had a strong effect on early numeracy. 


\section{CHAPTER 3}

Advantages at age 3 of children with high-quality HLE remained constant at least until age 5. However, the effect of literacy-related activities was stronger than the effect of numeracy-related activities. According to Anders et al. (2012), this may be explained by the infrequency of numeracy-related activities at home or by the more general nature of literacy-related activities, since these partly overlap with indirect HLE activities - e.g., shared book reading, number of books in the home. LeFevre, Polyzoi, Skwarchuk, Fast, and Sowinski (2010) and LeFevre et al. (2009) found that direct HLE activities that focus specifically on numerical abilities (e.g., learning simple sums) as well as indirect HLE activities (e.g., playing games, book exposure) are uniquely related to numerical abilities in preschool, grade 1 and grade 2 . In sum, when studying the effect of HLE on numeracy, it is important to take both indirect and direct numeracyand literacy-related activities into account. The present study was particularly interested in differences between indirect and direct HLE activities.

\subsection{INTERACTIVE EFFECTS BETWEEN HLE AND CHILD-RELATED FACTORS}

Although research has established that both indirect and direct HLE activities play an important role in numerical development, many aspects of the relationship between HLE and numeracy are still open to investigation. For one, the differential effects of HLE activities on diverse numerical abilities have not been studied, which is unfortunate for reasons mentioned above. Further, only a limited number of studies have described the importance of $\mathrm{Cl}$ and its moderating influence on the relationship between HLE, cognitive development and learning (e.g., Heckman, 2006; Schiefele, 1991; Trudewind, 2000; Gottfried, Fleming, Gottfried, Oliver, 1998; Leibham, Alexander, Johnson, Neitzel, \& Reis-Henrie, 2005). As described earlier, we defined Cl as the initiation of learning-related activities by the child. Gottfried, Marcoulides, Gottfried, Oliver, \& Guerin (2007) have described that for 9- to 17-year-old children, academic intrinsic motivation in primary school - i.e., enjoyment of learning at school - plays an important role in explaining inter-individual differences in initial as well as later levels of mathematical achievement. Furthermore, as Scarborough, Dobrich, and Hager (1991) have stated, a child's own interest in book reading plays an even more important role in the development of reading abilities than joint book reading. BlevinsKnabe and Musun-Miller (1996) found that joint parent-child activities were also 
significantly related to numerical abilities in preschool and that the number-related activities that a child initiated had an equally significant influence. To the author's knowledge, such interactions between $\mathrm{HLE}$ and $\mathrm{Cl}$ have not been studied as a contributing factor to inter-individual differences in diverse numerical abilities at preschool age. Again, as stated above, almost all previous studies have investigated the influence of $\mathrm{HLE}$ and $\mathrm{Cl}$, using only an overall measure of numerical abilities.

In the present study the potential moderating effects of children's cognitive abilities (i.e., phonological processing and working memory) were also taken into account while studying the contribution of HLE and $\mathrm{Cl}$ to inter-individual differences in numerical abilities. Previous studies have described significant relationships (a) between HLE (e.g., shared reading interactions) and phonological processing abilities of preschool children (e.g., Burgess, 1997; Burgess, 2002), and (b) between phonological processing and working memory on the one hand and numerical abilities of preschool and primary school children on the other (e.g., Hecht, Torgesen, Wagner, \& Rashotte, 2001; Simmons, Singleton, \& Horne, 2008; Raghubar, Barnes, \& Hecht, 2010; Welsh, Nix, Blair, Bierman, \& Nelson, 2010). Results with respect to the relationship between phonological processing and numerical abilities are still inconclusive (e.g., Passolunghi, Mammarella, \& Altoè, 2008; Passolunghi, Vercelloni, \& Schadee, 2007). Based on this research, it may be hypothesized that children's working memory and possibly also phonological processing abilities form moderating factors in the relationship between $\mathrm{Cl}$ and HLE and the child's numerical skills. In addition, fluid intelligence was taken into account, given its importance for early numerical abilities (e.g., Blair \& Razza, 2007; Stock, Desoete, \& Roeyers, 2009). To the authors' knowledge, no study has investigated the relationship between these cognitive factors, $\mathrm{HLE}$ and $\mathrm{Cl}$, and numeracy.

Finally, in the present study, age (i.e., second year of preschool versus grade 1) was studied as a potential moderating factor. These two age groups mark a period of transition from informal to formal mathematical learning. According to BlevinsKnabe (2008) studying the role that the HLE plays during this transition is of great importance. Informal knowledge develops through indirect contact with numerical concepts in everyday life (e.g., counting objects during play), while formal knowledge builds on informal knowledge and develops through direct instruction at school. HLE and child-related factors may play a vital role in both informal and formal knowledge 


\section{CHAPTER 3}

acquisition and in the transition from informal to formal knowledge. Yet, the exact content of their role and potential differences in their influence on informal and formal mathematical knowledge are still open to investigation.

In sum, the present study aimed to unravel the complex relationship between HLE and child-related factors (i.e., $\mathrm{Cl}$, working memory, phonological processing and age) in determining inter-individual differences in early numerical abilities.

\section{METHOD}

\subsection{PROCEDURE AND PARTICIPANTS}

The Ethics Committee of the Faculty of Psychology of Maastricht University approved the research protocol. Data were derived from the first follow-up wave of a largescale, longitudinal study on cognitive development of school-aged children. In total, 243 preschool children (i.e., first and second year of preschool [K1 and K2]) participated at baseline measurement. Exclusion criteria were not speaking Dutch fluently, the use of medication (e.g., antihistamines) or the presence of neurological conditions (e.g., absence epilepsy) that could influence cognitive performance. All children attended schools for regular education and were in the appropriate grade for their age. Neurodevelopmental disorders (e.g., dyslexia, attention deficit hyperactivity disorder $[A D H D])$ were not considered to be an exclusion criterion, since these disorders are often not yet diagnosed at preschool age. All the parents (or caregivers) gave consent for their child to participate in this research project.

The first follow-up wave (T1) was conducted approximately one year after baseline measurement (TO). All the parents were contacted again to request participation of their child. Of the 217 parents who replied, 211 gave consent for their child's participation during T1. These parents were asked to complete a questionnaire to collect information about e.g., sociodemographic background, medical history, HLE, and $\mathrm{Cl}$. Since none of the children had to be excluded on the basis of the exclusion criteria between T0 and T1, all 211 children were approached for testing during T1. Testing consisted of a test battery measuring both numerical and cognitive abilities. In the present study, five subtests were included: i.e., Early Numeracy Test (ENT), Raven's Colored Progressive Matrices (Raven's CPM), Digit Span Forward and Backward, Spatial Memory, and Phonological Processing. In total, 85 children attending K2 (48 boys; $\mathrm{M}_{\text {age }}$ 52 
$=5.62, \mathrm{SD}=0.34)$ and 126 children attending grade $1\left(59\right.$ boys; $\left.\mathrm{M}_{\mathrm{age}}=6.59, \mathrm{SD}=0.39\right)$ participated in the present study.

\subsection{PARENT QUESTIONNAIRE}

Home Learning Environment (HLE). Based on previous research (e.g., LeFevre et al., 2009; Melhuish, Phan, et al., 2008; Stoep, 2008), a questionnaire was designed to measure common home activities that may provide a stimulating learning environment (HLE). More specifically, direct and indirect HLE activities were assessed. The questionnaire measured direct HLE activities by asking parents how many different exercises they engaged in with their child at home. To measure indirect HLE activities, five aspects were assessed: (1) how often the parent read to the child, (2) how often the child watched educational television programs at home, (3) how often the child played word games and board games at home, (4) how often the child visited the library and who accompanied the child to the library, and (5) how many different types of children's books were available at home.

Child's own initiative ( $\mathrm{Cl})$. The occurrence of learning activities initiated by the child $(\mathrm{Cl})$ was measured on the basis of 10 questions. Examples of these questions are: “Does your child ask to be read to? Does your child ask you to read text on packaging aloud? Does your child try to read numbers while playing? Does your child like to look in books or magazines?" Although a division of $\mathrm{Cl}$ and direct and indirect HLE into three separate factors was hypothesized on the basis of previous research, we found that the $\mathrm{Cl}$ and HLE measures were actually (partly) interwoven in six separate factors (for more details, see Results section 3.1). More information on the $\mathrm{Cl}$ and $\mathrm{HLE}$ measures and their factor loadings can be found in Table 1.

Level of maternal education. In the present study the level of maternal education was included as a family background factor (in line with Anders et al., 2012). On a commonly used Dutch educational rating scale, all mothers had to indicate the highest level of education attained, ranging from (1) primary school to (8) university degree (De Bie, 1987; Kalff et al., 2001). This system is similar to the International Standard Classification of Education (United Nations Educational Scientific and Cultural Organisation (UNESCO), 1997). 


\subsection{NUMERACY AND COGNITIVE MEASURES}

Early Numeracy Test (ENT; Van Luit, Van de Rijt, \& Pennings, 1994). This test consists of eight sections measuring different aspects of early numeracy: Comparison, Classification, One-to-one correspondence, Seriation, Use of number words, Structured counting, Resultative Counting, and General understanding of numbers. Each section consists of 5 items (40 items in total). The child receives 1 point per correct answer, with a maximum raw score of 5 per section and a maximum total raw score of 40 . The test has two parallel versions (Form A and B), of which Form B was administered in the present study (Cronbach's alpha $=.94)$. For more information about the ENT see e.g., Aunio et al. (2006) and Van de Rijt, Van Luit, \& Pennings (1999).

Raven's CPM (Raven, 1958). This measure of fluid intelligence consists of 36 items. The child is shown a pattern with a missing piece. From 6 possible pieces the child has to select the piece that completes the pattern. Items gradually increase in difficulty. One point is awarded per correct answer, with a maximum total raw score of 36 (Cronbach's alpha $=.90)$.

Digit Span Forward and Backward (Wechsler Intelligence Scales - Fourth Edition [WISC-IV]; Wechsler, 2003). These estimates of verbal working memory require children to repeat a sequence of digits (ranging from 0-9) in the same order as the experimenter (Digit Span Forward) or the reverse order (Digit Span Backward). Both subtests consist of 8 items composed of 2 trials of the same length, starting with 2 digits and increasing to 8 digits (Digit Span Forward) or 9 digits (Digit Span Backward). Item difficulty increases as trial length increases. The child receives 1 point per correct trial with a maximum raw score of 16 points per subtest. Administration is cut off if both trials of the same item are answered incorrectly. Internal consistency for the Digit Span Forward and Backward is good (Cronbach's alpha =.83 and Cronbach's alpha $=.80$, respectively).

Spatial Memory (Kaufman Assessment Battery for Children [K-ABC]; Kaufman, \& Kaufman, 1983). This measure assesses the child's ability to memorize the locations of pictures that are arranged randomly on a grid and to point to these locations on a similar, blank grid. The test consists of 21 items (Cronbach's alpha $=.82$; Kamphaus \& Reynolds, 1984). Item difficulty increases as the number of pictures on the grid 
increases. Per correct answer 1 point is awarded, with a maximum raw score of 21 points. Administration is cut off when the child answers a certain number of items incorrectly.

Phonological Processing (NEPSY; Korkman, Kirk, \& Kemp, 1998). This subtest assesses the child's phonemic awareness on the basis of two phonological processing tasks. In the first task, that includes 14 items, the child has to recognize a word on the basis of a word segment given by the experimenter and to point to one of three pictures that represent this word. During the second task, consisting of 22 items (Cronbach's alpha $=.91$ ), the child has to create a new word by omitting or replacing a syllable of phoneme in a word given by the experimenter. Administration is discontinued after 5 consecutive incorrect answers. Total raw score is between 0 and 36.

\subsection{STATISTICAL ANALYSES}

All analyses were performed using SPSS 16.0 for Macintosh OS X. Extreme values and missing data were checked first. No extreme values, i.e. values minimally three times the interquartile distance above the $75^{\text {th }}$ percentile or below the $25^{\text {th }}$ percentile as defined by Huizingh (2002), were found. The average percentage of missing values in the present study was 2.4\%; therefore replacement was not required (Croy \& Novins, 2005). Yet, missing values were replaced by the mean in all regression analyses in order to prevent distortion of the results due to exclusion of a relatively large number of participants with a minimal percentage of missing data. Further statistical analyses consisted of a factor analysis, correlation analyses and regression analyses. These analyses are described in more detail in the Results section. For all analyses significance levels were reported and the alpha-value was set at .05.

\section{RESULTS}

\subsection{ANALYSIS OF HLE AND CI FACTORS}

To investigate which of the $20 \mathrm{HLE}$ and $\mathrm{Cl}$ variables group together, a principal component analysis with oblique rotation was performed. Six factors were extracted:

(1) Number and letter activities, (2) Reading books, (3) Joint parent-child leisure 


\section{CHAPTER 3}

activities, (4) Library visits, (5) Looking in books, and (6) Educational television. Table 1 shows the variables that loaded on each factor. Together the factors accounted for $61 \%$ of the variability. Cronbach's alpha for the summed measures of the factors was acceptable, ranging between .44 for Reading books and .64 for Number and letter activities.

\subsection{CORRELATIONS BETWEEN HLE, Cl, AND COGNITIVE ABILITIES AS A FUNCTION OF GRADE}

Correlation analyses of all $\mathrm{HLE} / \mathrm{Cl}$ factors and cognitive measures (as well as sex and level of maternal education) were performed separately for $\mathrm{K} 2$ and grade 1 . As Tables 2 and 3 reveal, the correlations between $\mathrm{HLE}, \mathrm{Cl}$, and cognitive abilities differed as a function of grade. For example, although the cognitive measures generally correlated significantly in both grades, the interrelations between cognitive measures were more prominent for children enrolled in grade 1 - i.e., 7 significant correlations ranging between .23 and .38 for children enrolled in $\mathrm{K} 2$ versus 10 significant correlations ranging between .21 and .50 for children enrolled in grade 1 . In addition, $\mathrm{HLE} / \mathrm{Cl}$ factors were more frequently related to cognitive measures for children enrolled in grade 1 - i.e., 1 significant correlation of .27 for K2 versus 5 significant correlations ranging between -.26 and .20 for grade 1 . These findings supported our initial hypothesis concerning the moderating effect of age (as reflected by grade), while studying the influence of $\mathrm{HLE}, \mathrm{Cl}$ and cognitive abilities on numerical performance.

\subsection{INTERACTIVE EFFECTS OF HLE, CI, COGNITIVE ABILITIES AND AGE ON NUMERICAL} ABILITIES

Stepwise regression analyses were conducted separately for children enrolled in K2 and grade 1 , since different relationships were expected for both age groups between children's numerical abilities as outcome measures and the predictors (i.e., all HLE/Cl factors, Raven CPM, Digit Span Forward, Digit Span Backward, Spatial Memory, Phonological Processing). These analyses were performed to assess direct relationships between these predictors and children's numerical abilities as well as indirect relationships between the $\mathrm{HLE} / \mathrm{Cl}$ factors and numerical performance through interactions with children's cognitive abilities. Variables were entered into the 56 
regression analyses in four blocks. The first block consisted of the control variables (i.e., maternal level of education, sex). In the second block, the cognitive measures were entered. In the third block, the six $\mathrm{HLE} / \mathrm{Cl}$ factors were entered. As a fourth block, all interactions between the $\mathrm{HLE} / \mathrm{Cl}$ factors and the cognitive measures were entered. These regression analyses were performed separately for all eight ENT section scores and the ENT Total score as dependent measures. After the initial regression analyses per ENT measure, further regression analyses were conducted by replicating the previous analyses and only entering the significant variables per ENT measure (in line with Field, 2005). This process was repeated until only significant variables were left. The results of these final regression analyses are shown in Table 4.

TABLE 1. Factor analyses of home learning environment and child's own initiative

\begin{tabular}{|c|c|c|c|c|c|}
\hline \multicolumn{2}{|c|}{ Description } & $\begin{array}{l}\text { Factor } \\
\text { loading }\end{array}$ & M & SD & Mdn \\
\hline \multicolumn{6}{|c|}{ 1. Number and letter activities } \\
\hline$\bullet$ & Reading letters during play ${ }^{a}$ & .67 & 1.48 & 0.70 & 2 \\
\hline • & Reading numbers during play ${ }^{a}$ & .76 & 1.73 & 0.49 & 2 \\
\hline & Naming letters during play ${ }^{a}$ & .78 & 1.40 & 0.62 & 1 \\
\hline & Naming numbers during play ${ }^{a}$ & .72 & 1.59 & 0.56 & 2 \\
\hline & Writing letters on drawings ${ }^{a}$ & .62 & 1.53 & 0.64 & 2 \\
\hline & Writing numbers on drawings ${ }^{a}$ & .67 & 1.14 & 0.75 & 1 \\
\hline & Asking parent to read packaging ${ }^{a}$ & .55 & 1.52 & 0.62 & 2 \\
\hline • & Exercises done at home ${ }^{f}$ & .51 & 6.13 & 3.23 & 7 \\
\hline \multicolumn{6}{|c|}{ 2. Reading books } \\
\hline • & Asking to read a favorite book ${ }^{a}$ & .78 & 1.50 & 0.64 & 2 \\
\hline & Asking to be read to ${ }^{a}$ & .77 & 1.62 & 0.54 & 2 \\
\hline & Being read to ${ }^{a}$ & .76 & 1.70 & 0.51 & 2 \\
\hline • & Types of books in the home ${ }^{\mathrm{g}}$ & .44 & 5.10 & 1.91 & 5 \\
\hline \multicolumn{6}{|c|}{ 3. Joint parent-child leisure activities } \\
\hline$\bullet$ & Playing word games ${ }^{a}$ & .71 & 0.98 & 0.70 & 1 \\
\hline & Playing board games ${ }^{a}$ & .69 & 1.04 & 0.65 & 1 \\
\hline - & Library visits (yes/no) $^{\text {b }}$ & .66 & 0.80 & 0.40 & 1 \\
\hline \multicolumn{6}{|c|}{ 4. Library visits } \\
\hline$\bullet$ & Frequency of library visits ${ }^{c}$ & .79 & 1.54 & 1.11 & 2 \\
\hline • & Who accompanies the library visits ${ }^{d}$ & .73 & 0.66 & 0.83 & 0 \\
\hline \multicolumn{6}{|c|}{ 5. Looking in books } \\
\hline$\bullet$ & Likes looking in books ${ }^{\mathrm{e}}$ & .82 & 1.72 & 0.46 & 2 \\
\hline - & Looks in books on own initiative ${ }^{a}$ & .77 & 1.62 & 0.55 & 2 \\
\hline \multicolumn{2}{|c|}{ 6. Educational television ${ }^{a}$} & .71 & 1.19 & 0.72 & 1 \\
\hline
\end{tabular}

Note ${ }^{a}$ Coded as followed: 1 = never/almost never, $2=$ sometimes, $3=$ often/very often. ${ }^{b}$ Coded as followed: $1=$ yes, $2=$ no. ${ }^{\mathrm{C}}$ Coded as followed: 1 = less than once a month, $2=1-2$ times per month, $3=$ every week, $4=$ several times per week. ${ }^{\mathrm{d}}$ Coded as followed: 1 = parents, $2=$ school. $^{\mathrm{e}} 1=$ no, $2=$ sometimes, $3=$ a lot. ${ }^{f}$ Composite score of 10 possible exercises (e.g., practicing names of letters, writing letters, reading numbers; range: $0-10) .{ }^{\mathrm{g}}$ Composite score of 8 possible categories (e.g., picture books, early reader books, comic books, informative books; range: 0-8). 


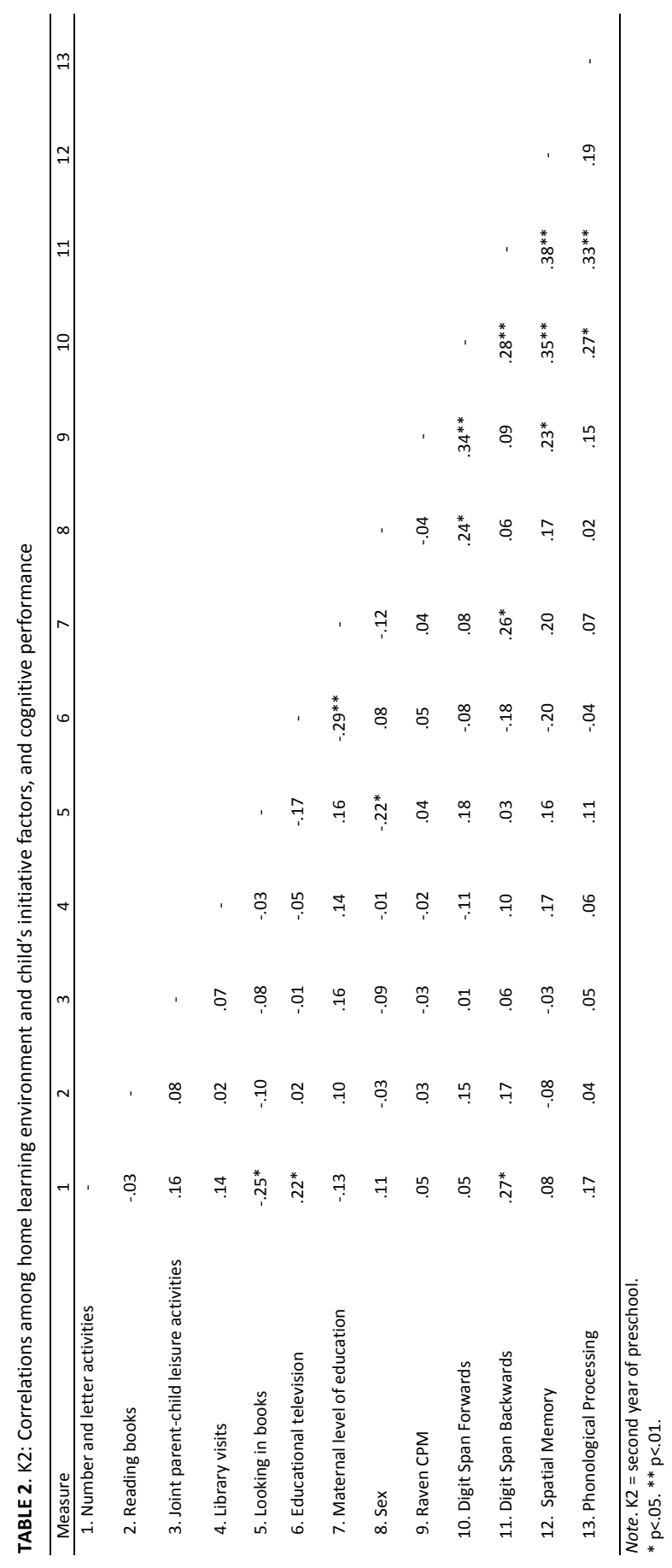


INFLUENCE OF HLE, CI AND COGNITION ON NUMERACY

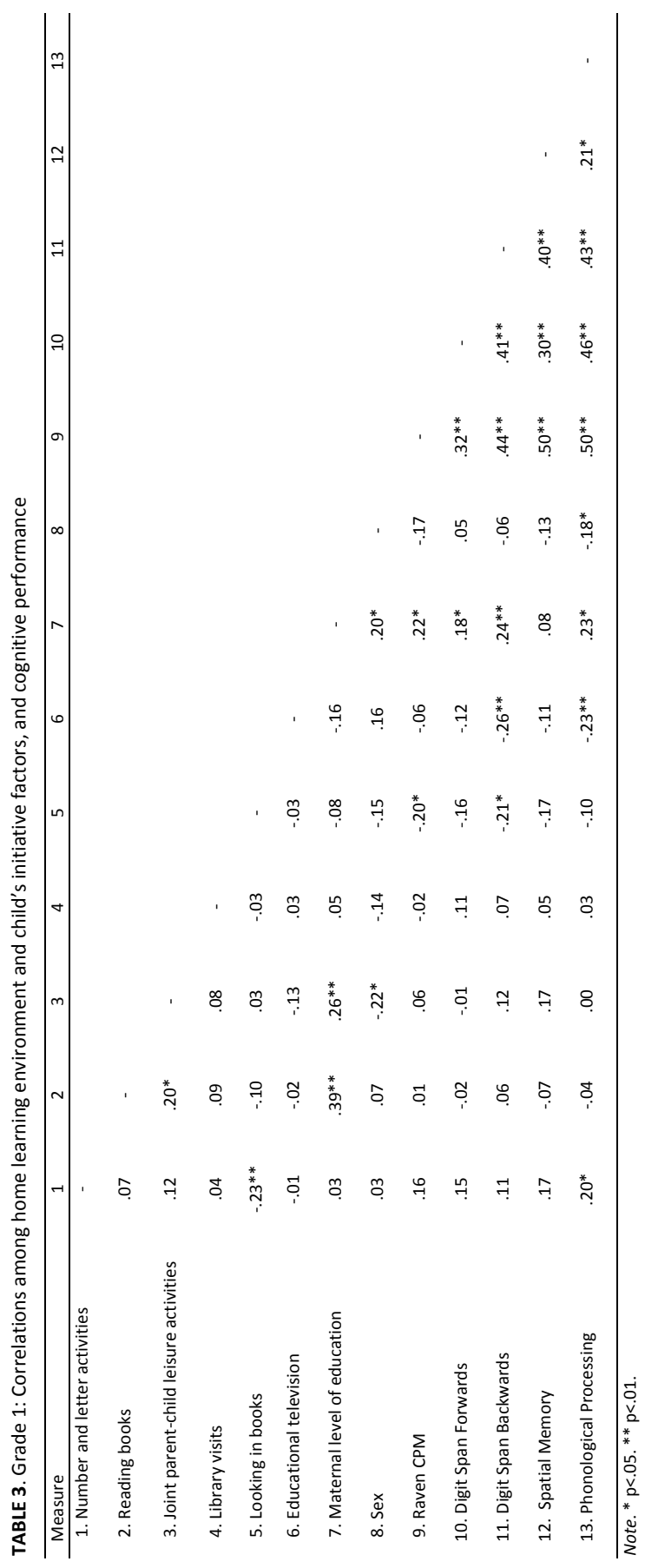




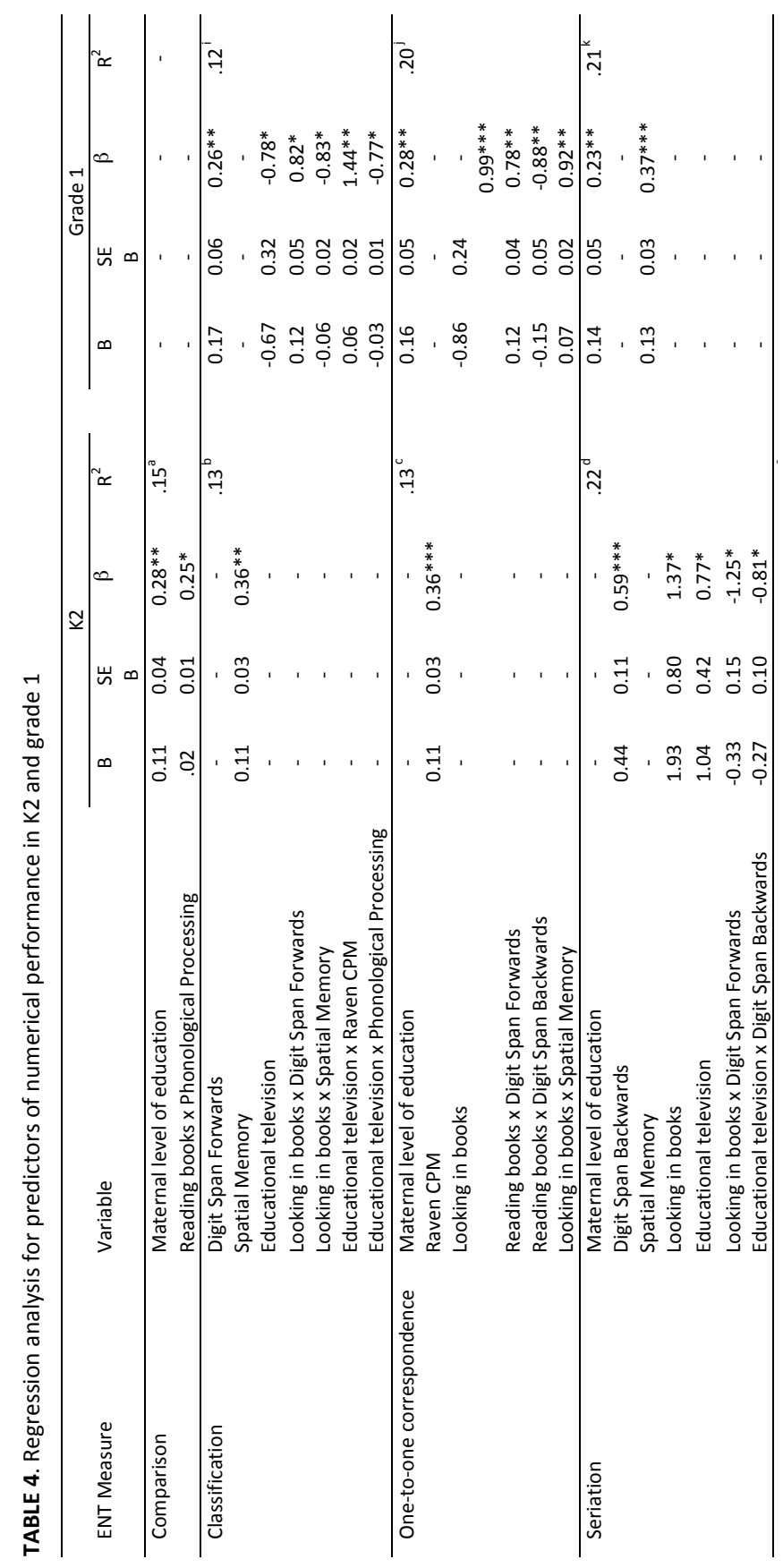




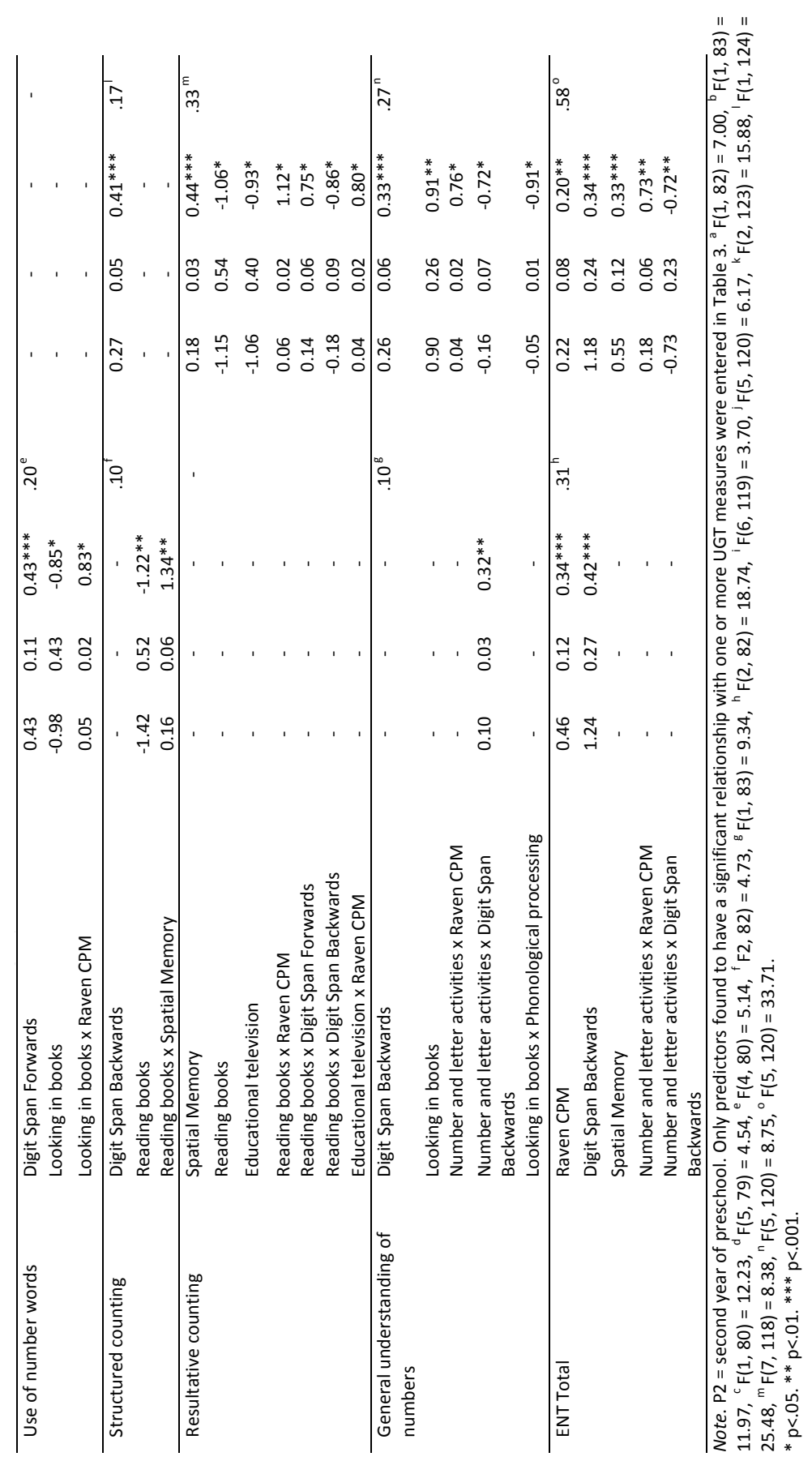


A general pattern became visible in the findings. Firstly, for both $\mathrm{K} 2$ and grade 1 , the predictors that were significantly related to the ENT Total score differed greatly from the predictors that were related to performance on the eight ENT sections. Secondly, only specific HLE/Cl factors, i.e., Number and letter activities, Reading books, Looking in books, and Educational television, were significant predictors of numerical abilities, either individually and/or in interaction with cognitive measures. For instance, the interaction between the HLE factor 'Number and letter activities' and the cognitive measures Raven CPM and Digit Span Backward predicted numerical performance (i.e., ENT Total). Thirdly, for certain ENT measures (i.e., Comparison in K2 and One-to-one correspondence and Seriation in grade 1), the level of maternal education was found to be a significant predictor of numerical abilities.

Although there were similarities across K2 and grade 1, the significant relationships between predictors and numerical abilities differed greatly between $\mathrm{K} 2$ and grade 1 and across ENT measures. Firstly, fewer significant relationships between predictors and numerical abilities were found in $\mathrm{K} 2$ compared to grade 1 - i.e., across all ENT measures 17 significant relationships were found in K2 compared to 31 significant relationships in grade 1 . This difference in the number of significant relationships was most prominent in the interactions between $\mathrm{HLE} / \mathrm{Cl}$ factors and cognitive measures (i.e., 6 significant relationships in $\mathrm{K} 2$ compared to 16 significant relationships in grade 1). Secondly, the pattern of the significant relationships between predictors and ENT measures also differed between grades. For instance, although Raven CPM and Digit Span Backward performance was related to performance on the ENT Total performance in $\mathrm{K} 2$ as well grade 1, ENT Total performance was only related to interactions between these cognitive measures (i.e., primarily related to working memory) and the $\mathrm{HLE} / \mathrm{Cl}$ factor 'Number and letter activities' in grade 1.

\section{DISCUSSION}

The present study investigated the relative contributions of the HLE and child-related factors (i.e., $\mathrm{Cl}$ and cognitive abilities [working memory and phonological processing]) in explaining inter-individual differences in early numerical abilities. As the results revealed, the relationship between $\mathrm{HLE}, \mathrm{Cl}$ and numerical development is complex. 
The significance of the relationship depends on: (1) the HLE and $\mathrm{Cl}$ activities that are studied (i.e., their individual or joint contributions), (2) the unique numerical abilities under study, (3) specific or general cognitive abilities (i.e., working memory, phonological abilities, and fluid intelligence), and (4) the age group that is studied (i.e., second year of preschool [K2] or grade 1). These results will be discussed in more detail next.

\subsection{HLE AND CI IN RELATION TO NUMERICAL ABILITIES}

First, as our factor analysis revealed, specific aspects of $\mathrm{HLE}$ and $\mathrm{Cl}$ were at least partly interrelated (i.e., in the factors 'number and letter activities' and 'reading books'), whereas other $\mathrm{HLE} / \mathrm{Cl}$ aspects were unrelated - i.e., the $\mathrm{Cl}$ aspects 'looking in books' and HLE activities 'joint parent-child leisure activities', 'library visits', and 'educational television'. It is not surprising that in part HLE and $\mathrm{Cl}$ were found to load onto the same factors, given the importance of parent-child interactions in the development of a child's interests. As described by Leibham et al. (2005), a child's interest in objects and activities is based on the child's own experiences as well as the obtained support from his or her environment. This support can be offered either on the initiative of the parents or the child.

Next, only four of the six $\mathrm{HLE} / \mathrm{Cl}$ factors were significantly related to early numerical abilities - i.e., number and letter activities, reading books, looking in books, and educational television. According to Blevins-Knabe (2008) and Ginsburg, Cannon, Eisenband, \& Pappas (2006), these specific activities provide contexts in which counting occurs - e.g., during book reading, games, and in educational television programs. Since counting is one of the most prevalent mathematical activities during the preschool years and plays an essential role in mathematical development (BlevinsKnabe, 2008), it is not surprising that counting-related activities were most strongly related to children's numerical abilities in the present study.

4.2 THE MODERATING INFLUENCE OF COGNITIVE ABILITIES, AGE, AND SPECIFIC NUMERICAL ABILITY

The influence of specific $\mathrm{HLE} / \mathrm{Cl}$ factors on numerical abilities was often moderated by specific cognitive abilities (i.e., fluid intelligence, working memory, and phonological 
processing). For example, for children enrolled in grade 1, their performance in terms of one-to-one correspondence was related to the $\mathrm{Cl}$ factor 'looking in books' as well as to the interaction between 'looking in books' and e.g., working memory performance. These findings provide further support for the importance of these specific cognitive abilities for scholastic success. Our findings are in line with previous studies that have described the significance of these cognitive precursors at preschool age (e.g., Kroesbergen, Van Luit, Van Lieshout, Van Loosbroek, Van de Rijt, 2009; Raghubar et al., 2010) and primary school age (e.g., Passolunghi et al., 2007; Passolunghi et al., 2008; Van der Sluis, De Jong, \& Van der Leij, 2007). The importance of children's phonological processing abilities for numerical development remains subject of some debate. In line with e.g., Simmons et al. (2008), our findings suggest that phonological processing is indeed related to numerical abilities, whereas other studies have found no relationship (e.g., Passolunghi et al., 2007; Passolunghi et al., 2008). However, most of the studies did not include $\mathrm{HLE}$ and $\mathrm{Cl}$ factors and their interactions with cognition, whereas our study has indicated that the relation between phonological processing and numerical abilities is moderated by interactions with $\mathrm{HLE}$ and $\mathrm{Cl}$. These results support the hypothesis that it is relevant to include both environment- and childrelated factors while studying early numerical abilities.

As our results further suggest, whether $\mathrm{HLE}, \mathrm{Cl}$, and cognitive abilities predict early numerical abilities also depends on the aspects of numerical abilities that are studied and this relation varies as a function of age. Although significant relationships were found between $\mathrm{HLE} / \mathrm{Cl}$ activities and all aspects of numerical abilities, the pattern of these relationships differed greatly between children in $\mathrm{K} 2$ and grade 1 . For instance, for children in $\mathrm{K} 2, \mathrm{HLE} / \mathrm{Cl}$ activities were related to five aspects of numeracy (and not the general measure) - i.e., comparison, seriation, use of number words, structured counting, and general understanding of numbers. For children enrolled in grade $1, \mathrm{HLE} / \mathrm{Cl}$ activities were related to the general measure as well as four aspects of numeracy (i.e., classification, one-to-one correspondence, resultative counting, and general understanding of numbers). Also, the number of relationships between $\mathrm{HLE} / \mathrm{Cl}$ factors and numerical abilities was higher in grade 1 than in $\mathrm{K} 2$. This may indicate that the effects of parental stimulation and children's curiosity and eagerness to learn on children's numerical abilities may actually become stronger as children move from informal numerical knowledge (i.e., preschool) to formal numerical acquisition (i.e., 64 
grade 1). As Ginsberg, Klein, and Starkey (1998) have described, the transition from informal to formal numerical knowledge acquisition is facilitated by a solid base of informal knowledge. Children who enter preschool with higher numerical performance - i.e., have acquired more informal numerical knowledge at home - maintain their advantage over children with lower performance at least until grade 2 . In fact, the advantage actually increases over time (Aunola, Leskinen, Lerkkanen, \& Nurmi, 2004). Thus, our findings may point to a cumulative effect in which the influence of $\mathrm{HLE} / \mathrm{Cl}$ factors on (formal) numerical abilities in grade 1 builds on (informal) numerical abilities acquired during preschool.

\subsection{IMPLICATIONS AND FUTURE RESEARCH}

Together our findings seem to indicate that early numerical development is influenced by complex age-dependent contributions of environment-related as well as childrelated factors and that the influence of these contributions differs per numerical ability. These findings are consistent with Parker, Greer, and Zuckerman (1988)'s notion that both successful and at-risk development rely on the interplay between various factors, including the home environment, parent-child interactions and the child's characteristics. Consequently, children are not just shaped by their environment, they also shape it by the manner in which they approach their surroundings. Yet, how $\mathrm{HLE}, \mathrm{Cl}$ and cognitive abilities interact with numerical development remains to be investigated in more detail. As our results showed, there is no simple one-to-one correspondence between $\mathrm{HLE}, \mathrm{Cl}$, and cognitive abilities and numerical performance. Our findings of positive relationships between specific cognitive and numerical abilities were constant. Yet, relationships between HLE and $\mathrm{Cl}$ - individually or in interaction with children's cognitive abilities - and numerical performance were far more varied, reflecting both positive and negative effects. Such varied relationships cannot be not easily explained. Additional research is needed to study and explain these complex interactions between $\mathrm{HLE}, \mathrm{Cl}$ and cognition and their influence on numeracy. For one, in the present study, questions about HLE and $\mathrm{Cl}$ were asked in a fairly general manner - e.g., we enquired after the frequency, but not the manner in which parents read to their child. A more detailed questionnaire might have provided more specific information to clarify or explain the present study's findings. 
Further research is also required to address other questions that follow from the present study. For one, the present study's findings provide leads for future research in term of early interventions that stimulate numerical development by promoting parent-child (or teacher-child) numeracy stimulating activities or as well as stimulating the child's eagerness and own initiative in engaging in these activities. As Heckman (2006) stresses, the earlier an intervention is implemented, the higher the benefits in terms of direct gains in cognitive and non-cognitive skills (e.g., IQ and motivation respectively) as well as long term gains. Our study seems to indicate that early interventions may become even more efficient when they are tailor-made, for instance by focusing on the effects of interventions on specific instead of general numerical abilities and by taking specific age-related contributions of both environment- and child-related factors into account - in terms of initiative taking as well as cognitive abilities. A study by Martens, Hurks, Schrans, and Jolles (2012), provides a preliminary indication for such age-related intervention effects in relation to aspects of executive functioning. 


\section{REFERENCES}

Anders, Y., Rossbach, H., Weinert, S., Ebert, S., Kuger, S., Lehrl, S., \& von Maurice, J. (2012). Home and preschool learning environments and their relations to the development of early numeracy skills. Early Childhood Research Quarterly, 27(2), 231-244.

Aunio, P., Hautamäki, J., Heiskari, P., \& Van Luit, J. H. (2006). The Early Numeracy Test in Finnish: Children's norms. Scandinavian Journal of Psychology, 47(5), 369-378.

Aunola, K., Leskinen, E., Lerkkanen, M., \& Nurmi, J. (2004). Developmental Dynamics of Math Performance From Preschool to Grade 2. Journal of Educational Psychology, 96(4), 699-713.

Bennett, K. K., Weigel, D. J., \& Martin, S. S. (2002). Children's acquisition of early literacy skills: Examining family contributions. Early Childhood Research Quarterly, 17(3), 295-317.

Blair, C., \& Razza, R. (2007). Relating effortful control, executive function, and false belief understanding to emerging math and literacy ability in kindergarten. Child Development, 78(2), 647-663.

Blevins-Knabe, B. (2008). Fostering early numeracy at home. Encyclopedia of Language and Literacy Development (pp. 1-8). London, ON: Canadian Language and Literacy Research Network. Retrieved February 17, 2011 from http://www.literacyencyclopedia.ca/pdfs/topic.php? topld $=245$

Blevins-Knabe, B., \& Musun-Miller, L. (1996). Number use at home by children and their parents and its relationship to early mathematical performance. Early Development \& Parenting, 5(1), 35-45.

Bransford, J. D., Brown, A. L., \& Cocking, R. R. (Eds.). (1999). How people learn: Brain, mind, experience, and school. Washington, DC: National Academy Press.

Burgess, S. (1997). The role of shared reading in the development of phonological awareness: A longitudinal study of middle to upper class children. Early Child Development and Care, 127-128, 191-199.

Burgess, S. R. (2002). The influence of speech perception, oral language ability, the home literacy environment, and pre-reading knowledge on the growth of phonological sensitivity: A one-year longitudinal investigation. Reading and Writing, 15(7-8), 709-737.

Butterworth, B. (2005). The development of arithmetical abilities. Journal of Child Psychology and Psychiatry, 46(1), 3-18.

Christian, K., Morrison, F. J., \& Bryant, F. B. (1998). Predicting kindergarten academic skills: interactions among child care, maternal education, and family literacy environments. Early Childhood Research Quarterly, 13(3), 501-521.

Croy, C. D., \& Novins, D. K. (2005). Methods for addressing missing data in psychiatric and developmental research. Journal of the American Academy of Child and Adolescent Psychiatry, 44(12), 12301240. 


\section{CHAPTER 3}

De Bie, S. E. (1987). Standaardvragen 1987: Voorstellen voor uniformering van vraagstellingen naar de achtergrondkenmerken en interviews [Standard questions 1987: Proposal for the uniformization of questions regarding background variables and interviews] (2nd ed.). Leiden, The Netherlands: Leiden University Press.

Duncan, G. J., Dowsett, C. J., Claessens, A., Magnuson, K., Huston, A. C., Klebanov, P., et al. (2007). School readiness and later achievement. Developmental Psychology, 43(6), 1428-1446.

Ee, J., Wong, K., \& Aunio, P. (2006). Numeracy of Young Children in Singapore, Beijing \& Helsinki. Early Childhood Education Journal, 33(5), 325-332.

Field, A. (2005). Discovering statistics using SPSS (2nd ed.). Thousand Oaks, CA US: Sage Publications, Inc.

Foy, J. G., \& Mann, V. (2003). Home literacy environment and phonological awareness in preschool children: Differential effects for rhyme and phoneme awareness. Applied Psycholinguistics, 24(1), 59-88.

Geary, D. C. (2000). From infancy to adulthood: The development of numerical abilities. European Child \& Adolescent Psychiatry, 9(Suppl 2), S11-S16.

Ginsburg, H. P., Cannon, J., Eisenband, J., \& Pappas, S. (2006). Mathematical Thinking and Learning. In K. McCartney, D. Phillips (Eds.), Blackwell handbook of early childhood development (pp. 208-229). Malden: Blackwell Publishing.

Ginsburg, H. P., Klein, A., \& Starkey, P. (1998). The Development of Children's Mathematical Thinking: Connecting Research with Practice. In W. Damon, I. E. Sigel, K. Renninger (Eds.), Handbook of child psychology: Vol 4. Child psychology in practice (5th ed., pp. 401-476). Hoboken, NJ US: John Wiley \& Sons Inc.

Gottfried, A., Fleming, J. S., \& Gottfried, A. W. (1998). Role of cognitively stimulating home environment in children's academic intrinsic motivation: A longitudinal study. Child Development, 69(5), 14481460.

Gottfried, A., Marcoulides, G. A., Gottfried, A. W., Oliver, P. H., \& Guerin, D. (2007). Multivariate latent change modeling of developmental decline in academic intrinsic math motivation and achievement: Childhood through adolescence. International Journal of Behavioral Development, 31(4), 317-327.

Hecht, S. A., Torgesen, J. K., Wagner, R. K., \& Rashotte, C. A. (2001). The relations between phonological processing abilities and emerging individual differences in mathematical computational skills: A longitudinal study from second to fifth grades. Journal of Experimental Child Psychology, 79(2), 192-227.

Heckman, J. J. (2006). Skill Formation and the Economics of Investing in Disadvantaged Children. Science, 312(5782), 1900-1902.

Howell, K. W., \& Lorson-Howell, K. A. (1990). What's the hurry? Fluency in the classroom. Teaching Exceptional Children, 22(3), 20-23. 
Huizingh, E. (2002). Inleiding SPSS 11 voor Windows [Introduction to SPSS 11 for Windows]. Schoonhoven: Academic Service.

Iverson, B. K., \& Walberg, H. J. (1982). Home environment and school learning: A quantitative synthesis. Journal of Experimental Education, 50(3), 144-151.

Johnson, K. R., \& Layng, T. (1992). Breaking the structuralist barrier: Literacy and numeracy with fluency. American Psychologist, 47(11), 1475-1490.

Jordan, N. C., Levine, S., \& Huttenlocher, J. (1994). Development of calculation abilities in middle- and lowincome children after formal instruction in school. Journal of Applied Developmental Psychology, 15(2), 223-240.

Kalff, A. C., Kroes, M. M., Vles, J. H., Bosma, H. H., Feron, F. M., Hendriksen, J. M., et al. (2001). Factors affecting the relation between parental education as well as occupation and problem behaviour in Dutch 5- to 6-year-old children. Social Psychiatry and Psychiatric Epidemiology, 36(7), 324-331.

Kamphaus, R. W., \& Reynolds, C. R. (1984). Development and structure of the Kaufman Assessment Battery for Children (K-ABC). Journal of Special Education, 18, 213-228.

Kaufman, A. S., \& Kaufman, N. L. (1983). Kaufman Assessment Battery for Children. Circle Pines, MN: American Guidance Services.

Korkman, M., Kirk, U., \& Kemp, S. (1998). NEPSY: A developmental neuropsychological assessment-manual. San Antonio, Texas: Psychological Corporation.

Kroesbergen, E. H., Van Luit, J. H., Van Lieshout, E. M., Van Loosbroek, E. E., \& Van de Rijt, B. M. (2009). Individual differences in early numeracy: The role of executive functions and subitizing. Journal of Psychoeducational Assessment, 27(3), 226-236.

LeFevre, J., Polyzoi, E., Skwarchuk, S., Fast, L., \& Sowinski, C. (2010). Do home numeracy and literacy practices of Greek and Canadian parents predict the numeracy skills of kindergarten children?. International Journal of Early Years Education, 18(1), 55-70.

LeFevre, J., Skwarchuk, S., Smith-Chant, B. L., Fast, L., Kamawar, D., \& Bisanz, J. (2009). Home numeracy experiences and children's math performance in the early school years. Canadian Journal of Behavioural Science/Revue Canadienne Des Sciences Du Comportement, 41(2), 55-66.

Leibham, M. E., Alexander, J. M., Johnson, K. E., Neitzel, C. L., \& Reis-Henrie, F. P. (2005). Parenting behaviors associated with the maintenance of preschoolers' interests: A prospective longitudinal study. Journal of Applied Developmental Psychology, 26(4), 397-414.

Martens, R., Hurks, P. P., Schrans, D., \& Jolles, J. (2012). Training goal setting in children aged 4-6: Transfer effects through an age by training content interaction. Unpublished manuscript.

Melhuish, E. C., Phan, M. B., Sylva, K., Sammons, P., Siraj-Blatchford, I., \& Taggart, B. (2008). Effects of the home learning environment and preschool center experience upon literacy and numeracy development in early primary school. Journal of Social Issues, 64(1), 95-114. 


\section{CHAPTER 3}

Melhuish, E. C., Sylva, K., Sammons, P., Siraj-Blatchford, I., Taggart, B., Phan, M. B., et al. (2008). Preschool influences on mathematics achievement. Science, 321(5893), 1161-1162.

National Research Council (2009). Mathematics learning in early childhood: Paths towards excellence and equity. Committee on Early Childhood Mathematics, Christopher T. Cross, Taniesha A. Woods, and Heidi Schweingruber, Editors. Center for Education, Division of Behavioral and Social Sciences and Education. Washington, DC: The National Academies Press.

Parker, S., Greer, S., Zuckerman, B. (1988). Double jeopardy: the impact of poverty on early child development. Pediatric Clinics of North America, 35(6), 1227-1240.

Passolunghi, M., Mammarella, I. C., \& Altoè, G. (2008). Cognitive abilities as precursors of the early acquisition of mathematical skills during first through second grades. Developmental Neuropsychology, 33(3), 229-250.

Passolunghi, M., Vercelloni, B., \& Schadee, H. (2007). The precursors of mathematics learning: Working memory, phonological ability and numerical competence. Cognitive Development, 22(2), 165-184.

Raghubar, K. P., Barnes, M. A., \& Hecht, S. A. (2010). Working memory and mathematics: A review of developmental, individual difference, and cognitive approaches. Learning and Individual Differences, 20(2), 110-122.

Raven, J. C. (1958). Guide to using the Coloured Progressive Matrices. Oxford England: H. K. Lewis \& Co.

Rivera-Batiz, F. L. (1992). Quantitative literacy and the likelihood of employment among young adults in the United States. The Journal of Human Resources, 27(2), 313-328.

Scarborough, H. S., Dobrich, W., \& Hager, M. (1991). Preschool literacy experience and later reading achievement. Journal of Learning Disabilities, 24(8), 508-511.

Schiefele, U. (1991). Interest, learning, and motivation. Educational Psychologist, 26(3-4), 299-323.

Simmons, F., Singleton, C., \& Horne, J. (2008). Brief report--Phonological awareness and visual-spatial sketchpad functioning predict early arithmetic attainment: Evidence from a longitudinal study. European Journal of Cognitive Psychology, 20(4), 711-722.

Starkey, P., Klein, A., \& Wakeley, A. (2004). Enhancing young children's mathematical knowledge through a pre-kindergarten mathematics intervention. Early Childhood Research Quarterly, 19(1), 99-120.

Stevenson, H. W., \& Newman, R. S. (1986). Long-term prediction of achievement and attitudes

in mathematics and reading. Child Development, 57, 646-659.

Siegler, R. S., \& Ramani, G. B. (2009). Playing linear number board games - but not circular ones - improves low-income preschoolers' numerical understanding. Journal of Educational Psychology, 101 (3), 545-560.

Stock, P., Desoete, A., \& Roeyers, H. (2009). Predicting arithmetic abilities: The role of preparatory arithmetic markers and intelligence. Journal Of Psychoeducational Assessment, 27(3), 237-251.

Stoep, J. M. (2008). Opportunities for early literacy development: Evidence from home and school support. Unpublished doctoral dissertation, Radboud University, Nijmegen, The Netherlands. 
Toll, S. M., Van der Ven, S. G., Kroesbergen, E. H., \& Van Luit, J. H. (2011). Executive functions as predictors of math learning disabilities. Journal of Learning Disabilities, 44(6), 521-532.

Trudewind, C. (2000). Curiosity and anxiety as motivational determinants of cognitive development. In J. Heckhausen (Ed.), Motivational psychology of human development: Developing motivation and motivating development (pp. 15-38). New York, NY US: Elsevier Science.

United Nations Educational Scientific and Cultural Organisation (UNESCO) (1997). International standard classification of education (ISCED). Paris: UNESCO.

Van de Rijt, B. M., Van Luit, J.H., \& Pennings, A. H. (1999). The construction of the Utrecht Early Mathematical Competence Scales. Educational and Psychological Measurement, 59(2), 289-309.

Van der Sluis, S., de Jong, P. F., \& van der Leij, A. (2007). Executive functioning in children, and its relations with reasoning, reading, and arithmetic. Intelligence, 35(5), 427-449.

Van Luit, J. H., Van de Rijt, B. M. \& Pennings, A. H. (1994). Utrechtse getalbegrip toets [The Utrecht Numeracy Test]. Doetinchem: Graviant.

Wechsler, D. (2003). WISC-IV: Technical and interpretive manual. San Antonio, TX: The Psychological Corporation.

Welsh, J. A., Nix, R. L., Blair, C., Bierman, K. L., \& Nelson, K. E. (2010). The development of cognitive skills and gains in academic school readiness for children from low-income families. Journal of Educational Psychology, 102(1), 43-53. 



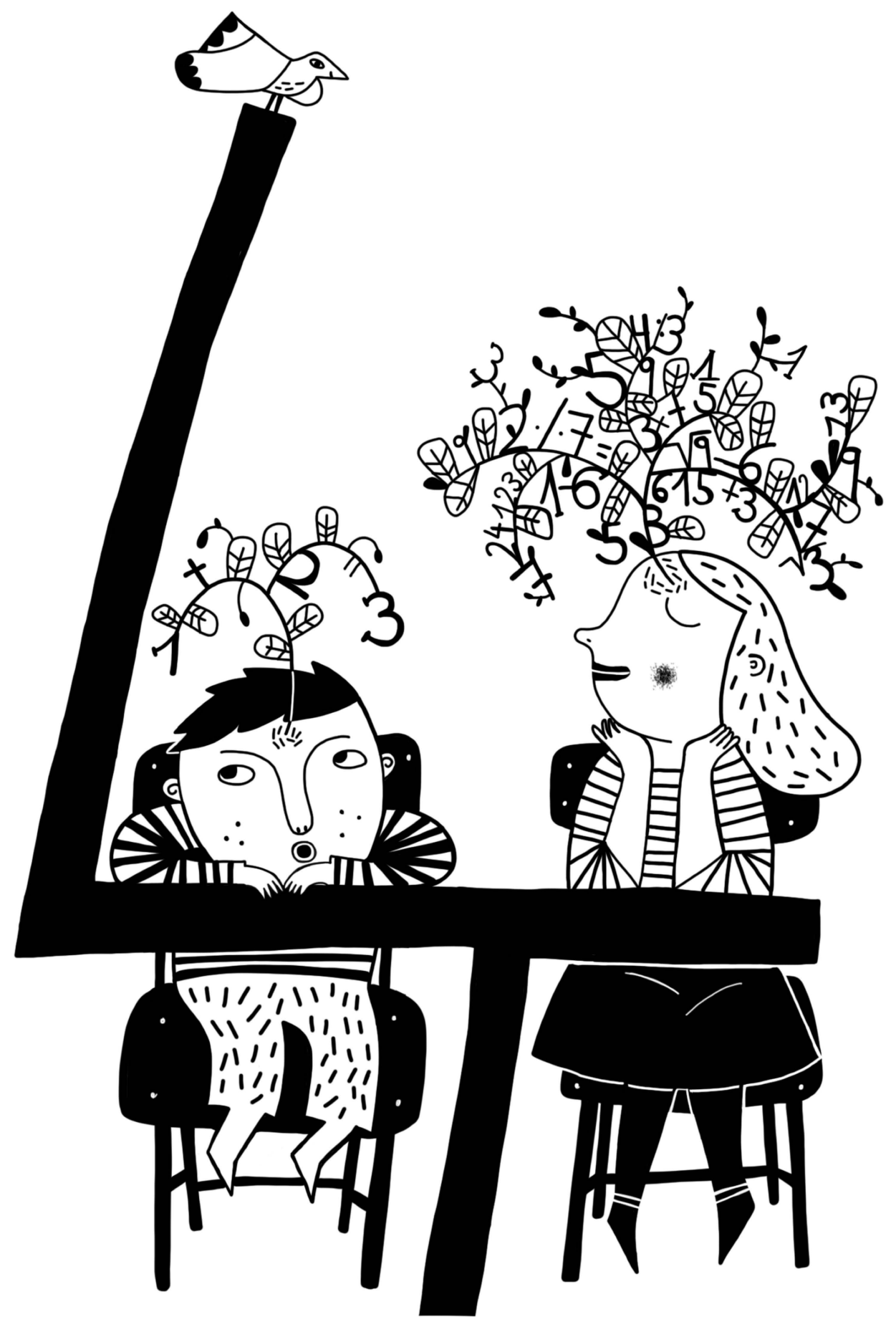





\section{Chapter 4}

\section{Early cognitive characteristics of children aged 4-8 with persistent mathematical difficulties versus giftedness: A longitudinal study}

Martens, R., Hurks, P. M., Keulers, E. H. \& Jolles, J. (2012). Early cognitive characteristics of children aged 4-8 with persistent mathematical difficulties versus giftedness: A longitudinal study. In preparation. 


\section{ABSTRACT}

The research discussed in this chapter focused on two key research aims and can therefore best be viewed as two separate, partly overlapping studies that were based on the same longitudinal sample of 162 children aged 4 to 8 . For reasons of clarity, these studies are discussed separately throughout Chapter 4. Our first research aim was to evaluate stability of mathematical performance from preschool to early primary school age. Particular attention was given to transience and persistence of mathematical difficulties (MD) and mathematical giftedness (MG). Persistent MD was defined as low mathematical performance $\left(\leq 25^{\text {th }}\right.$ percentile) in preschool as well as early primary school. Persistent MG was characterized by constant high mathematical performance ( $\geq 75^{\text {th }}$ percentile). Our second research aim was to distinguish those preschool cognitive characteristics that differentiate children with persistent MD, persistent MG and typical mathematical achievement (TA). With respect to the first aim, our results indicated that mathematical performance was moderately stable between preschool and grade 1 and 2 and that MG was more stable than MD. Only 43$53 \%$ of the children with low preschool performance showed persistent MD. Of the children with high preschool performance, 61-68\% showed persistent MG. These findings suggest that mathematical performance is still quite variable at this age, making it an interesting period for (cognitive) interventions. With respect to our second aim, differences in preschool working memory, short-term memory, visualspatial reasoning and design fluency were found between children with MD, TA, and MG (irrespective of transience or persistence of performance). Children with transient and persistent MD predominantly had the lowest mean scores, while children with transient and persistent MG in general had the highest mean scores. These findings underline the potential importance of preschool cognitive characteristics for the development of MD and MG. Together these findings may have implications for the implementation of early prevention and interventions in an educational context. 


\section{INTRODUCTION}

An individual's level of mathematical abilities can have a profound effect on daily living, academic performances and future career opportunities (Rivera-Batiz, 1992; Statistics Canada and Organization for Economic Cooperation and Development [OECD], 2005). Yet, almost 60 percent of North American adults have mathematical skills below the level that is considered necessary for coping with professional demands and everyday life in the $21^{\text {st }}$ century (Statistics Canada and OECD, 2005). Furthermore, the estimated prevalence of mathematical difficulties (i.e., scoring $\leq 25^{\text {th }}$ percentile on math tests) at school age roughly varies between 4 and $7 \%$ (Andersson, 2010; Fuchs et al., 2005; Geary, 2011b; Mazzocco, 2007). Though research into mathematical development of school-aged children has begun to accumulate, many questions remain unanswered. For one, more studies need to focus on the characteristics of early mathematical difficulties, given potential implications for early identification and intervention (e.g., Vukovic \& Siegel, 2010). Research into (deviant) mathematical development in preschool and primary school should be a major priority for researchers and practitioners. In the present, longitudinal study, we explored the mathematical and cognitive characteristics of 4- to 8-year-old children with mathematical difficulties (MD), typical mathematical achievement (TA), and mathematical giftedness (MG). Particular attention was given to persistence and transience of MD and MG between preschool and early primary school age. In the next paragraphs, past research that underlies our research questions will be discussed. Firstly, previous studies exploring stability of mathematical performance in preschool or primary school will be discussed (paragraph 1.1). These studies have focused on children with MD. Secondly, an overview is given of previous studies into cognitive characteristics of MD and MG in primary school (paragraph 1.2). These overviews of past studies demonstrate the need for further research into stability of MD and MG between preschool and early primary school as well as preschool cognitive characteristics of MD and MG. The rationale for the present study is discussed in paragraph 1.3. 


\subsection{STABILITY OF MATHEMATICAL PERFORMANCE BETWEEN PRESCHOOL AND EARLY PRIMARY SCHOOL}

According to Geary (2004), stability of low performance across successive academic years is an important feature of MD. Not all children that display low performance at one point in time are children with MD. Vukovic (2006) revealed that of all children that were identified as having MD in first grade, $61 \%$ still fulfilled the criteria for MD in grade 4. MD was defined as mathematical performance below the $25^{\text {th }}$ percentile. Additionally, Chong and Siegel (2008) have described that the gap in performance between children with MD and TA is persistent between grades 2 and 5. Children with severe MD (i.e., $<11^{\text {th }}$ percentile) as well as children with mild MD (i.e., $11^{\text {th }}$ to $25^{\text {th }}$ percentile) started out with lower mathematical performance in grade 2 than children with TA, but showed similar growth rates between grade 2 and 5 . These findings applied only to computational fluency performance - i.e., the fluency with which addition, subtraction, and multiplication facts were retrieved from memory. In terms of procedural deficits, children with MD managed to catch up with their typically achieving peers. Together these findings suggest that MD are quite stable across primary school years, irrespective of severity of MD, and that the presence of MD at early primary school age is highly predictive of mathematical abilities throughout primary school. What about the predictive value of MD at preschool age? Past research has described the general predictive power of mathematical abilities at preschool age for later mathematical development in primary and secondary school (Duncan et al., 2007; Siegler \& Ramani, 2009). We aimed to explore whether MD and MG are equally stable between preschool and the first years of primary school.

Stability of mathematical abilities (i.e., MD, MG, and TA) between preschool and primary school has been studied very limitedly and the primary focus has been on MD. According to Chong and Siegel (2008), differences in fact fluency performance between children with MD and TA remain stable between grade 2 and 5, while children with MD catch op in terms of procedural skills. Aunola et al. (2004) have reported that children's level of mathematical performance is highly stable between preschool and grade 2. In fact, the authors have described that differences between children with high and low performance levels actually increase over time. Children who entered preschool with higher levels of mathematical performance displayed 
faster growth of mathematical abilities than those who entered preschool with lower levels of mathematical performance. However, the findings of Aunola et al. (2004) cannot be linked directly to research into MD, since high and low performance were not put on par with definitions of MD and MG. In another study that focused on mathematical development of young children with MD, Morgan et al. (2009) showed that preschool children with persistent MD (in this case performance $<11^{\text {th }}$ percentile in both fall and spring of preschool) had the worst prognosis in terms of growth rates of mathematical performance across grades 1, 3 and 5. Children with transient MD (i.e., only performance $<11^{\text {th }}$ percentile in fall or spring of preschool) had the secondlowest growth rates; they also displayed slower growth than children with TA. These findings underline the predictive value of $M D$ at preschool age for mathematical learning in primary school, irrespective of persistence or transience of MD in preschool.

Research into the stability of MG between preschool and primary school age is absent. Yet, according to Hodge and Kemp (2006), an accurate recognition of children's performance level and potential is essential for the generation of appropriate expectations and learning experiences by teachers. This applies as much to gifted children as to children with difficulties, since giftedness also requires e.g., specific educational provision and support (Hodge \& Kemp, 2006; Reis \& McCoach, 2000). In addition, Hodge and Kemp (2006) have shown that teachers find it more difficult to recognize giftedness in mathematics than in reading at preschool and early primary school age. Consequently, more research into the stability of MG at this age is needed.

In sum, the question remains how stable MD and MG are between preschool and early primary school. Past research suggests that MD are rather persistent throughout preschool and primary school (Aunola et al., 2004; Morgan et al., 2009; Vukovic, 2006), although Chong and Siegel (2008) have found that it depends on the type of mathematical ability under study. Thus far the influence of type of mathematical ability has been scarcely studied. In addition, to the authors' knowledge, no studies have explored stability of MG. The present study aimed to complement the few studies that have investigated transience and stability of MD between preschool and early primary school age and broaden the outlook on stability of mathematical abilities by studying both children with MD and MG. 


\subsection{PRESCHOOL COGNITIVE CHARACTERISTICS OF MD AND MG}

In addition to stability of mathematical performance, the present study focused on preschool cognitive characteristics of children with MD, TA and MG. Much remains to be investigated about cognitive predictors of MD at primary school age (Geary, 2011b) and even more research is required into cognitive characteristics of MG (Swanson, 2006). Previous studies that explored differences between children with MD and TA have described a number of cognitive predictors of MD at primary school age - i.e., working memory (e.g., Chong \& Siegel, 2008; Geary, Hoard, Nugent, \& Bailey, 2012; Passolunghi \& Cornoldi, 2008; Passolunghi \& Siegel, 2004; Swanson, Jerman, \& Zheng, 2008; Toll, Van der Ven, Kroesbergen, \& Van Luit, 2011), verbal and visual-spatial short-term memory (Geary et al., 2012), processing speed (Geary et al., 2012), and attention (Geary et al., 2012; McLean \& Hitch, 1999). Although studied limitedly, cognitive predictors of $M G$ at primary school age have also been reported - i.e., working memory, verbal short-term memory, and naming speed (Swanson, 2006).

An important unanswered question remains what cognitive abilities characterize children with MD and MG at preschool age. The importance of this research question has been underlined by past research into the general relationship between mathematical and cognitive abilities at this age. Research exploring this general relationship has reported the importance of a number of cognitive predictors at preschool and (early) primary school age. Various studies have described the contribution of working memory (e.g., Andersson, 2008; Bull et al., 2008; Geary, 2011a; Swanson \& Kim, 2007; Passolunghi et al., 2007), verbal short-term memory (e.g., Bull et al., 2008; Berg, 2008; Rasmussen \& Bisanz, 2005; Swanson \& Kim, 2007), visual-spatial short-term memory (e.g., Bull et al., 2008; Geary, 2011a; Swanson et al., 2008), processing or naming speed (Berg, 2008; Geary, 2011a; Swanson \& Kim, 2007), attention (Aunola et al., 2004; Duncan et al., 2007), and verbal fluency (Rosselli et al., 2009). This last cognitive predictor has not been studied in relation to MD, but previous studies have reported abnormalities in verbal en design fluency performance of children with reading disorders (e.g., Brosnan, Demetre, Hamill, Robson, Shepherd, \& Cody, 2002; Reiter, Tucha, \& Lange, 2005).

In addition, limited attention has been given to longitudinal research into the relationship between cognitive abilities and stability of mathematical performance. 
The few studies that have taken stability into account, focused on primary school children with MD. For one, Vukovic and Siegel (2010) investigated cognitive characteristics of transient and persistent MD (i.e., MD-t and MD-p) between grades 1 and 4. The authors found that, in addition to phonological processing in grades 1 to 4 , working memory in grades 1 and 4 and processing speed in grades 3 and 4 could distinguish children with MD-p from children with MD-t and TA. Short-term memory and visual-spatial abilities could not discern between MD and TA. Geary, Hamson, and Hoard (2000) also found that children with MD-p in grades 1 and 2 showed working memory deficits in comparison with TA children. Conversely, children with MD-t (i.e., primarily low performance in grade 1 and average performance in grade 2) did not differ significantly from TA children. Although these two studies have provided interesting findings, they have only compared children with transient and persistent MD to typical achievement, which encompassed both average and above average performance. Yet, as Swanson (2006) has shown, children with MG differ significantly from children with TA in terms of cognitive characteristics. It would therefore be interesting to discern children with MG from children with TA, instead of treating these children as a single group - particularly since the inclusion of MG children in a TA group can cause misrepresentation of actual differences between MD and TA children.

In sum, cognitive abilities that characterize MD and MG at preschool age have not been explored in past research. Based on research at primary school age, however, a number of cognitive abilities - e.g., working memory, verbal and visual-spatial shortterm memory, processing speed, and verbal fluency - could be considered as potential predictors of MD and MG at preschool age (e.g., Bull et al., 2008; Geary et al., 2012; Swanson, 2006). The present study aimed to provide new insights through a longitudinal investigation of the contribution of preschool cognitive abilities to mathematical performance between 4 to 8 years of age. More specifically, we intended to distinguish those preschool cognitive characteristics that differentiate between MD, TA, and MG. On the basis of findings described in past research, the presented study aimed to explore these cognitive characteristics by assessing differences across a broad range of abilities - i.e., working memory, short-term memory, visual-spatial reasoning, processing speed, attention, and verbal and design fluency. 


\section{CHAPTER 4}

\subsection{RATIONALE OF THE PRESENT STUDY}

The cognitive characteristics of children with MD-p and MD-t have only been studied at primary school age. No studies have explored these cognitive characteristics at preschool age. In addition, no studied have explored transience and persistence of MG between preschool and primary school age and its relation to cognitive characteristics. The present longitudinal study aimed to widen the scope by integrating the extremes of mathematical performance - MD and MG - in one study. Firstly, by exploring stability of mathematical performance in a sample of 162 children aged 4 to 8 years, with particular interest in persistence and transience of MD as well as MG. Secondly, by mapping differences between children with transient and persistent MD and MG across a broad range of preschool cognitive abilities. Thereby, to the authors' knowledge, our study was the first to investigate the relationship between preschool cognitive abilities and stability of mathematical performance between preschool and primary school age for both children with MD and MG.

\section{METHOD}

\subsection{PROCEDURE AND PARTICIPANTS}

Children enrolled in the preschool program of 24 Dutch schools were invited to participate in a large-scale, longitudinal study on developmental trajectories of cognition and academic performance. All caregivers were asked to give written consent for their child's participation. Those caregivers who agreed to participate completed a questionnaire to collect information about the development and medical history of the child and the level of maternal education (LME), ranging from primary school (1) to university degree (8) (De Bie, 1987; Kalff et al., 2001). After consent was obtained, all children were screened on the bases of exclusion criteria: not speaking Dutch fluently, the use of medication (i.e., antihistamines) and the presence of neurological conditions (i.e., absence epilepsy). Developmental disorders (i.e., attention deficit hyperactivity disorder, pervasive developmental disorder, dyslexia) were not considered to be an exclusion criterion, since we wanted the sample to be representative of children frequenting regular schools in the Netherlands. Accordingly, all children were considered to be developing at a regular pace when they attended a 
school for regular education and were in the appropriate grade for their age. After initial screening, further testing consisted of a test battery measuring both mathematical and cognitive abilities. Well-trained research assistants tested all children. Testing took place in a stimulus-free room at the participating schools and took approximately 90 minutes. All tests were administered in the same order for each child and a break was introduced halfway if needed. Two years later (i.e., at T2), the procedure discussed above was repeated, if parental consent was obtained for the participating children. The Ethics Committee of the Faculty of Psychology of Maastricht University approved the research protocol. In total, 228 children (113 boys; mean age $=5.15, \mathrm{SD}=0.60)$ participated at preschool age (T0) and 183 children at the two-year follow-up (T2; 99 boys; mean age $=7.40, \mathrm{SD}=0.61$ ). After excluding children who repeated or skipped a grade in preschool or primary school $(n=21)$, the final longitudinal sample consisted of 162 children ( 89 boys; mean age $=7.40, \mathrm{SD}=0.63$ ).

\subsection{INSTRUMENTS}

\subsubsection{Measures of mathematical and reading abilities}

To measure children's mathematical abilities, the present study used the Early Numeracy Test, the Arithmetic Tempo Test and the Arithmetic subtest of the WISC-III ${ }^{\mathrm{NL}}$ (Kort et al., 2005). To measure children's reading abilities, the present study used the Klepel reading test (Van den Bos, Lutje Spelberg, Scheepstra, \& De Vries, 1994).

Early Numeracy Test (ENT; Van de Rijt, Van Luit \& Pennings, 1994). This test, administered during the first measurement, consists of 8 sections measuring different aspects of numeracy in preschool and grade 1: Comparison, Classification, One-to-one correspondence, Seriation, Use of number words, Structured counting, Resultative counting, and General understanding of numbers. Each section consists of 5 items (40 items in total). The child receives 1 point per correct answer, with a maximum total raw score of 40 . This total raw score was used as a measure of early numeracy. The ENT has two parallel versions (Form $A$ and $B$ ), of which Form $A$ was administered in the present study. The ENT is a moderately to highly reliable measure of early numeracy with good construct validity (Aunio, Hautamaki, Heiskari, \& Van Luit, 2006; Torbeyns, Van den Noortgate, Ghesquière, Verschaffel, Van de Rijt, \& Van Luit; Van de Rijt, Van Luit, \& Pennings, 1999). 
The Arithmetic Tempo Test was selected as a measure of computational fluency (ATT, De Vos, 1992). This standardized paper-and-pencil test has frequently been used in Dutch and Flemish education to measure mathematical abilities (Desoete, Stock, Schepens, Baeyens, \& Roeyers, 2009; Stock, Desoete, \& Roeyers, 2009). In the present study part of the ATT was presented to the children, consisting of two sets of 40 mathematical problems, respectively containing addition and subtraction problems. Per set, the child has to solve as many problems as possible within one minute. All problems consist of two-operand equations with an outcome smaller than 100 and both operands ranging between 0 and 90 . The total score was based on addition as well as subtraction performance, i.e., composed of the total amount of problems answered correctly minus the total amount of problems answered incorrectly.

The Arithmetic subtest of the WISC-III ${ }^{\mathrm{NL}}$ was selected as a measure of mathematical problem solving (Wechsler Intelligence Scales - Third Edition ${ }^{\mathrm{NL}}$ [WISC$\mathrm{III}^{\mathrm{NL}}$ ]; Kort et al., 2005). The child is given 26 mathematical word problems of increasing difficulty that are read out loud to the child - of which the first four are accompanied by pictures and the final eight are accompanied by cards on which the child can read the problem. The child is awarded 1 or 2 points per item, dependent on item difficulty and solution speed, with a maximum raw score of 34 points. Administration is cut of after 3 consecutive incorrect answers.

Klepel reading test (Van den Bos et al., 1994). This measure of nonword decoding requires the child to read as many words as possible from a list of nonwords. With each item the complexity of the words increases. The child receives one point for each word that is read correctly in one minute. The total raw score consisted of the number of words read correctly in one minute minus the number of words read incorrectly.

\subsubsection{Estimate of intelligence}

Estimated IQ was calculated in accordance with Sattler (1992) on the basis of two WISC-III ${ }^{\mathrm{NL}}$ subtests: Vocabulary and Block Design (Wechsler Intelligence Scales Third Edition $^{\mathrm{NL}}$ [WISC-III ${ }^{\mathrm{NL}}$; Kort et al., 2005). This estimate of intelligence has good psychometric properties (mean reliability $=.91$, mean validity $=.86$; Sattler, 1992 ) and is a sufficient estimate of intelligence for research purposes (Donders, 1997). 


\subsubsection{Cognitive measures}

Verbal Fluency (NEPSY; Korkman et al., 1998). This semantic category verbal fluency test is a measure of automatic and controlled processing and retrieval from semantic memory (Hurks et al., 2011; Korkman et al., 1998). In this test the child is instructed to name as many different animals as possible in 60 seconds. Main outcome variable was the total number of correct responses.

Design Fluency (NEPSY; Korkman et al., 1998). This non-verbal paper-andpencil test provides information on cognitive flexibility and the ability to employ strategies for producing non-verbal designs (Lezak, 2004). It consists of two trials in which sheets of paper are presented that depict 70 squares, each containing five dots. These dots are arranged in either (1) a structured array or (2) a random array. The child has to generate as many different designs as possible within 1 minute by connecting two or more dots using straight lines. The total raw score consisted of the number of unique, correct drawings summed across the two trials, with a maximum score of 70 .

Visual Attention (NEPSY; Korkman et al., 1998). This measure of focused and divided visual attention consists of two trials in which the child has to search and cross out drawings on a sheet of paper as fast as possible. If the child is still searching after 180 seconds, administration is cut off. In the present study only the second, more challenging trial was administered: searching for two specific types of faces amidst distracting faces. The total raw score consisted of the number of correctly identified items minus the number of incorrect items, with a maximum score of 20.

Digit Span Forward and Backward (Wechsler Intelligence Scales - Fourth Edition [WISC-IV]; Wechsler, 2004). These measures are respectively included as estimates of numerical short-term memory and working memory (Bull et al., 2008). The child is required to repeat a sequence of digits (ranging from 0-9) in the same order as the experimenter (Digit Span Forward) or the reverse order (Digit Span Backward). Both subtests consist of 8 items composed of 2 trials of the same length, starting with 2 digits and increasing to 8 digits (Digit Span Forward) or 9 digits (Digit Span Backward). Item difficulty increases as trial length increases. The child receives 1 point per correct trial with a maximum raw score of 16 points per subtest. Administration is cut off if both trials within one item are answered incorrectly. 


\section{CHAPTER 4}

Block Counting (Kaufman Assessment Battery for Children [K-ABC]; Kaufman \& Kaufman, 1983). This measure provides information on visual-spatial reasoning and consists of two-dimensional drawings of three-dimensional stacks of blocks. The child must determine the number of blocks in each pile, meanwhile taking into account that some blocks cannot be seen. Items increase in difficulty and the child is awarded 1 or 2 points per item dependent on item difficulty. The maximum raw score is 44 . Administration is cut of after 4 consecutive incorrect answers.

Coding (Wechsler Intelligence Scales - Fourth Edition [WISC-IV]; Wechsler, 2004). This measure of processing speed requires the child to copy symbols that are paired with five basic geometric shapes. The shapes are presented in a random order on a sheet of paper and the child has to draw the symbols in the corresponding shapes as fast as possible. The child has 2 minutes to complete the test and is awarded a maximum of 59 points for completing all the symbols correctly as well as a timedependent bonus if all symbols are completed in less than 2 minutes (i.e., an extra 1-6 points).

Verbal Learning (Brand \& Jolles, 1985; Van der Elst, Van Boxtel, Van Breukelen, \& Jolles, 2005). This measure was included as a second non-numerical estimate of short-term memory. One trial of the Verbal Learning test was administered. Fifteen words are read aloud to the child. These words are common, acquired early (i.e., words acquired before age four) and refer to concrete objects such as spoon and drum. The child has to remember and verbally recall as many words as possible, irrespective of the order in which the words were presented. The child receives one point per word that is remembered correctly (maximum raw score: 15 points).

\subsection{STATISTICAL ANALYSES}

All analyses were performed using SPSS 16.0 for Macintosh OS X. Extreme values and missing data were checked for. No extreme values were found - i.e., values minimally three times the interquartile distance above the $75^{\text {th }}$ percentile or below the $25^{\text {th }}$ percentile as defined by Huizingh (2002). The missing data were less than $5 \%$ of the total data and were therefore not replaced (Croy \& Novins, 2005). 
Stability of mathematical achievement was determined in two steps. As a first step, children's level of achievement (i.e., low, average, or high) was determined at two points in time (i.e., T0 and T2). Categorizations of level of achievement were performed separately for children who were in the first and second year of preschool at T0, to prevent misclassification on the basis of age effects. Children's performance on the ENT, ATT, and Arithmetic test was categorized as low (i.e., $\leq 25^{\text {th }}$ percentile), average (i.e., $26^{\text {th }}-74^{\text {th }}$ percentile), or high achievement (i.e., $\geq 75^{\text {th }}$ percentile). The low-end cutoff criterion was in line with frequently used guidelines for MD classification (e.g., Passolunghi \& Siegel, 2004; Swanson, Jerman, \& Zheng, 2008; Vukovic \& Siegel, 2010). Since no such classification criterion exists for MG, the criterion for high-end cutoff within the normal curve was chosen as a balanced opposite of the criterion for low-end cutoff.

As a second step, we determined stability of two types of mathematical abilities: computational fluency and mathematical problem solving. As Chong and Siegel (2008) have described, stability of MD can differ as a function of the mathematical ability under study. In line with Chong and Siegel (2008) and Vukovic (2006), the present study chose a simple view of mathematics that reflected lower order as well as higher order abilities (i.e., respectively referred to as Computational Fluency and Mathematical Problem Solving). To determine stability of computational fluency performance, ENT performance at TO was compared to performance on the ATT at T2 (i.e., referred to as Computational Fluency). This is partly in line with Geary et al. (2000) and Vukuvic (2010). On the basis of these comparisons five groups emerged: (1) children with persistent mathematical difficulties (MD-p; i.e., stabile low performance), (2) children with transient mathematical difficulties (MD-t; i.e., low performance at T0 and average performance at T2 or the reverse), (3) children with typical achievement (TA; i.e., stabile average performance), (4) children with transient mathematical giftedness (MG-t; i.e., high performance at T0 and average performance at $\mathrm{T} 2$ or the reverse), and (5) children with persistent mathematical giftedness (MG-p; i.e., stabile high performance).

The same procedure was followed to determine stability of mathematical problem solving performance. ENT performance at TO was compared to WISC-III ${ }^{\mathrm{NL}}$ Arithmetic test performance at T2 (i.e., Mathematical Problem Solving), resulting in five groups, in line with Computational Fluency. Children with extreme performance 
variability (i.e., low performance at T0 and high performance at T2 or the reverse) were excluded from Computational Fluency $(n=10)$ and Mathematical Problem Solving ( $n=18)$ comparisons. Tables 1 and 2 respectively show the descriptive statistics of the five Computational Fluency and Mathematical Problem Solving groups. Group differences in age, estimated IQ, sex, maternal level of education, boy:girl ratio, Klepel reading test performance, and ENT, ATT, and Arithmetic test performance were explored (see Tables 1 and 2).

TABLE 1. Demographics of the Computational Fluency groups $(n=152)$

\begin{tabular}{|c|c|c|c|c|c|c|}
\hline \multirow[t]{2}{*}{ Variables } & $\begin{array}{c}\text { MD } \\
(N=16)\end{array}$ & $\begin{array}{c}\mathrm{LV} \\
(\mathrm{N}=45)\end{array}$ & $\begin{array}{c}\text { TA } \\
(\mathrm{N}=30)\end{array}$ & $\begin{array}{c}\mathrm{HV} \\
(\mathrm{N}=36)\end{array}$ & $\begin{array}{c}M G \\
(N=25)\end{array}$ & \multirow[t]{2}{*}{$\begin{array}{c}\text { Statistic } \\
F / \chi^{2}\end{array}$} \\
\hline & $\mathrm{M}(\mathrm{SD})$ & $\mathrm{M}(\mathrm{SD})$ & $\mathrm{M}(\mathrm{SD})$ & $\mathrm{M}(\mathrm{SD})$ & $\mathrm{M}(\mathrm{SD})$ & \\
\hline $\begin{array}{l}\text { Age at } \\
\text { measurement }\end{array}$ & $7.26(0.64)$ & $7.41(0.65)$ & $7.39(0.65)$ & $7.49(0.56)$ & $7.38(0.66)$ & $0.36^{\mathrm{a}}$ \\
\hline Estimated IQ & $98.67(15.73)$ & $98.02(15.31)$ & $\begin{array}{l}103.90 \\
(12.90)\end{array}$ & $\begin{array}{l}103.25 \\
(13.18)\end{array}$ & $\begin{array}{l}107.56 \\
(10.45)\end{array}$ & $2.43^{b}$ \\
\hline LME & $5.44(1.75)$ & $4.89(1.71)$ & $4.70(1.44)$ & $5.06(1.57)$ & $5.76(1.48)$ & $34.00^{c}$ \\
\hline ENT & $14.38(5.10)$ & $19.09(7.03)$ & $22.27(6.33)$ & $25.67(6.64)$ & $28.76(6.31)$ & $17.25^{* * a}$ \\
\hline ATT & $12.63(6.30)$ & $18.49(8.96)$ & $21.67(8.29)$ & $26.44(8.91)$ & $29.48(10.03)$ & $13.21^{* * a}$ \\
\hline Arithmetic test & $12.56(2.58)$ & $12.29(2.68)$ & $13.00(3.06)$ & $13.94(2.52)$ & $14.92(3.16)$ & $4.41^{* a}$ \\
\hline Klepel reading & $13.56(9.77)$ & $16.02(10.27)$ & $18.43(8.50)$ & 22.11 (9.19) & $23.36(11.84)$ & $4.29^{* b}$ \\
\hline & $\%$ & $\%$ & $\mathrm{~N}$ & $\mathrm{~N}$ & $\%$ & \\
\hline Sex & & & & & & \\
\hline Boys & 50.0 & 51.1 & 53.3 & 55.6 & 68.0 & $2.18^{d}$ \\
\hline Girls & 50.0 & 48.9 & 46.7 & 44.4 & 32.0 & \\
\hline
\end{tabular}

Note. $\mathrm{MD}=$ mathematical difficulties, $\mathrm{LV}=$ variable low performance, $\mathrm{TA}=$ typical achievement, $\mathrm{HV}=\mathrm{variable}$ high performance, $M G$ = mathematical giftedness. $L M E$ = maternal level of education ranging from primary school (1) to university degree (8). Estimated IQ = an estimate of intelligence based on Block Pattern and Vocabulary subtests of the Dutch Wechsler Intelligence Scales III (Wechsler, 1991). ENT (Van de Rijt et al., 1994) = a measure of different aspects of numeracy. ATT (De Vos, 1992) = a measure of computational fluency. Arithmetic test = a measure of mathematical problem solving; subtest of the Dutch Wechsler Intelligence Scales III (Wechsler, 1991). Klepel reading test (Van den Bos et al., 1994) $=$ a measure of reading ability.

${ }^{a}$ One-way analysis of variance ( $\left.\mathrm{df} 1=4, \mathrm{df} 2=147\right)$.

${ }^{b}$ One-way analysis of variance $(\mathrm{df} 1=4, \mathrm{df} 2=146)$.

${ }^{c}$ Pearson Chi-square test ( $\left.\mathrm{df}=24\right)$.

${ }^{d}$ Pearson Chi-square test $(\mathrm{df}=4)$.

$* p<.01$.

$* * \mathrm{p}<.001$

Next, the relationship between cognitive and mathematical performance was studied by performing GLM Multivariate analyses with group as independent variable and cognitive tests performance as dependent variables (i.e., Verbal Fluency, Design Fluency, Digit Span Forward, Digit Span Backward, Visual Attention, Coding, Block Counting, Verbal Learning). Estimated IQ was inserted as a covariate in all analyses, 86 
since an analysis of variance revealed that the Mathematical Problem Solving groups differed significantly in mean estimated IQ $(F(4,138)=7.04 ; p<.001)$. In the Computational Fluency groups a notable, corresponding trend could be observed ( $F(4$, $146)=2.43 ; p=.051)$. Further, Geary (2011b) and Taub, Keith, Floyd, and McGrew (2008) state that intelligence is an important contributing factor to MD. According to Geary (2011b), however, it does not seem to be the primary factor. Many children have MD for reasons unrelated to their intelligence. We were interested in those cognitive factors that predict MD beyond general intelligence.

TABLE 2. Demographics of the Mathematical Problem Solving groups ( $n=144)$

\begin{tabular}{|c|c|c|c|c|c|c|c|c|c|c|c|}
\hline \multirow[t]{2}{*}{ Variables } & \multicolumn{2}{|c|}{$\begin{array}{c}M D \\
(N=19)\end{array}$} & \multicolumn{2}{|c|}{$\begin{array}{c}\text { LV } \\
(N=50)\end{array}$} & \multicolumn{2}{|c|}{$\begin{array}{c}\text { TA } \\
(N=21)\end{array}$} & \multicolumn{2}{|c|}{$\begin{array}{c}\mathrm{HV} \\
(\mathrm{N}=31)\end{array}$} & \multicolumn{2}{|c|}{$\begin{array}{c}M G \\
(N=23)\end{array}$} & \multirow[t]{2}{*}{$\begin{array}{c}\text { Statistic } \\
F / \chi^{2}\end{array}$} \\
\hline & \multicolumn{2}{|c|}{$\mathrm{M}(\mathrm{SD})$} & \multicolumn{2}{|c|}{$M(S D)$} & \multicolumn{2}{|c|}{$M(S D)$} & \multicolumn{2}{|c|}{$\mathrm{M}(\mathrm{SD})$} & \multicolumn{2}{|c|}{$\mathrm{M}(\mathrm{SD})$} & \\
\hline $\begin{array}{l}\text { Age at } \\
\text { measurement }\end{array}$ & \multicolumn{2}{|c|}{$7.51(0.68)$} & \multicolumn{2}{|c|}{$7.27(0.66)$} & \multicolumn{2}{|c|}{$7.64(0.49)$} & \multicolumn{2}{|c|}{$7.52(0.54)$} & \multicolumn{2}{|c|}{$7.36(0.64)$} & $1.76^{\mathrm{a}}$ \\
\hline Estimated IQ & \multicolumn{2}{|c|}{$94.56(16.68)$} & \multicolumn{2}{|c|}{$97.10(14.58)$} & \multicolumn{2}{|c|}{$\begin{array}{l}105.48 \\
(12.32)\end{array}$} & \multicolumn{2}{|c|}{$105.65(9.46)$} & \multicolumn{2}{|c|}{$\begin{array}{l}111.35 \\
(11.69)\end{array}$} & $7.04^{* * b}$ \\
\hline LME & \multicolumn{2}{|c|}{$5.16(1.74)$} & \multicolumn{2}{|c|}{$4.72(1.70)$} & \multicolumn{2}{|c|}{$5.00(1.58)$} & \multicolumn{2}{|c|}{$5.42(1.36)$} & \multicolumn{2}{|c|}{$5.61(1.59)$} & $30.11^{c}$ \\
\hline ENT & \multicolumn{2}{|c|}{$16.63(5.70)$} & \multicolumn{2}{|c|}{$18.16(6.66)$} & \multicolumn{2}{|c|}{$25.19(4.59)$} & \multicolumn{2}{|c|}{$25.61(7.00)$} & \multicolumn{2}{|c|}{$29.04(6.44)$} & $18.94^{* * a}$ \\
\hline ATT & \multicolumn{2}{|c|}{$21.11(10.38)$} & \multicolumn{2}{|c|}{17.50 (9.08) } & \multicolumn{2}{|c|}{26.10 (8.99) } & \multicolumn{2}{|c|}{$26.26(8.83)$} & \multicolumn{2}{|c|}{$27.39(11.05)$} & $7.00^{* * a}$ \\
\hline Arithmetic test & 11.2 & (1.72) & & $(2.60)$ & 14.3 & $(1.07)$ & $15 . C$ & (1.67) & 16. & $(2.80)$ & $28.34^{* * a}$ \\
\hline Klepel & 16.1 & (9.63) & 15. & $(8.66)$ & 22.8 & 12.35) & 21.4 & (9.06) & 22.0 & 11.48) & $3.65^{* b}$ \\
\hline & $\mathrm{N}$ & $\%$ & $\mathrm{~N}$ & $\%$ & $\mathrm{~N}$ & $\%$ & $\mathrm{~N}$ & $\%$ & $\mathrm{~N}$ & $\%$ & \\
\hline Sex & & & & & & & & & & & \\
\hline Boys & 9 & 47.4 & 28 & 56.0 & 9 & 42.9 & 16 & 51.6 & 17 & 73.9 & $5.18^{d}$ \\
\hline Girls & 10 & 52.6 & 22 & 44.0 & 12 & 57.1 & 15 & 48.4 & 6 & 26.1 & \\
\hline
\end{tabular}

Note. $\mathrm{MD}=$ mathematical difficulties, $\mathrm{LV}=$ variable low performance, $\mathrm{TA}=$ typical achievement, $\mathrm{HV}=$ variable high performance, $M G$ = mathematical giftedness. $L M E$ = maternal level of education ranging from primary school (1) to university degree (8). Estimated $\mathrm{IQ}=$ an estimate of intelligence based on Block Pattern and Vocabulary subtests of the Dutch Wechsler Intelligence Scales III (Wechsler, 1991). ENT (Van de Rijt et al., 1994) = a measure of different aspects of numeracy. ATT (De Vos, 1992) = a measure of computational fluency. Arithmetic test = a measure of mathematical problem solving; subtest of the Dutch Wechsler Intelligence Scales III (Wechsler, 1991). Klepel reading test (Van den Bos et al., 1994) = a measure of reading ability.

${ }^{a}$ One-way analysis of variance ( $\left.d f 1=4, d f 2=139\right)$.

${ }^{b}$ One-way analysis of variance $(\mathrm{df} 1=4, \mathrm{df} 2=138)$.

${ }^{c}$ Pearson Chi-square test $(\mathrm{df}=24)$.

${ }^{d}$ Pearson Chi-square test $(\mathrm{df}=4)$.

$* \mathrm{p}<.01$.

** $p<.001$. 


\section{CHAPTER 4}

Further, although significant group differences were found in mean Klepel reading test scores (see Tables 1 and 2), this variable was not inserted as a covariate, given the partial overlap between intelligence and reading performance. For all analyses significance levels and effect sizes were reported. The alpha-value was set at .05. Effect sizes were calculated using the d statistic (Cohen, 1988; Halpern, 2000; Hyde \& Linn, 2006). In accordance with Hyde and Linn (2006), effect size values between 0 and 0.10 were considered trivial, values between 0.11 and 0.35 were considered small, values between 0.36 and 0.65 were considered medium, values between 0.66 and 1.00 were considered large, and values larger than 1.00 were considered very large.

\section{RESULTS}

\subsection{DEMOGRAPHICS FOR MD-P, MD-T, TA, MG-T, AND MG-P}

Table 1 represents demographic information of the five groups (i.e., MD-p, MD-t, TA, MG-t, and MG-p) formed on the basis of Computational Fluency performance. Table 2 shows demographic information of the five groups that were based on Mathematical Problem Solving performance. Analyses of variance revealed significant group differences in terms of mathematical performance on all measures - see Tables 1 and 2. As expected, children in the MD-p group in general had the lowest mean mathematical test scores, while children in the MG-p group had the highest mean scores. Furthermore, it was notable that children with MD-t performed lower on all mathematical abilities tests than children in the TA group. Conversely, children in the MG-t group had higher mean mathematical test scores than children in the TA group.

Further, as is shown in Tables 1 and 2, no significant differences were found between MD-p, MD-t, TA, MG-t, and MG-p groups in terms of age, boy:girl ratio, or level of maternal education. However, a notably high percentage of boys was found in the MG groups - see Tables 1 and 2. In terms of estimated IQ, no significant differences were found between the Computational Fluency groups, although differences approached significance (see paragraph 3.3). As Table 2 shows, significant differences in estimated IQ were found for the Mathematical Problem Solving groups. The MD-p and MD-t groups had the lowest mean estimated IQ scores, the TA and MG-t had comparable intermediate scores, and MG-p group had the highest mean score. 


\subsection{STABILITY OF MATHEMATICAL ACHIEVEMENT BETWEEN PRESCHOOL AND EARLY PRIMARY SCHOOL}

Comparison of the Computational Fluency and Mathematical Problem Solving groups revealed that, although the correlation was high $(r=.81, p<.001)$, the groups did not overlap completely. This finding supports the present study's decision to compare ENT performance at preschool age to both ATT and Arithmetic test performance at primary school age (i.e., Computational Fluency and Mathematical Problem Solving).

Overall stability was found to be moderate, independent of the mathematical ability under study. In total, $47 \%$ of the Computational Fluency classifications at T2 were in line with level of achievement at T0 (i.e., MD-p, TA, and MG-p), in comparison with $44 \%$ of the Mathematical Problem Solving classifications. In line with overall stability, stability of MD was found to be moderate. For Computational Fluency, $43 \%$ of the children classified as low achiever (or MD) at TO (i.e., $\leq 25^{\text {th }}$ percentile of the population) were also classified as such at T2 (i.e., MD-p). Similarly, for Mathematical Problem Solving, 53\% of the children with MD (low achievers) at T0 was also classified as low achieving at T2 (i.e., MD-p).

MG was found to be more stable than MD over time - both in terms of Computational Fluency and Mathematical Problem Solving - although still quite variable. For Computational Fluency, 61\% of the children classified as high achiever (MG) at TO (i.e., $\geq 75^{\text {th }}$ percentile of the population) were also classified as such at T2 (i.e., MG-p). Correspondingly, for Mathematical Problem Solving group, 68\% of the children with MG (high achievers) at T0 also showed high achievement at T2 (i.e., MGp).

\subsection{COGNITIVE ABILITIES IN RELATION TO COMPUTATIONAL FLUENCY}

In terms of Computational Fluency, significant overall group differences were found for the following tests: Digit Span Backward $(F(4,144)=2.66, p<.05, d=0.07)$, Block Counting $(F(4,144)=2.73, p<.05, d=0.07)$, and Verbal Learning $(F(4,144)=2.80, p<$ $.05, d=0.08$ ). For all other tests (i.e., Verbal Fluency, Design Fluency, Visual Attention, Digit Span Forward and Coding), no significant overall differences were found between the five groups, although trends were observed for Verbal Fluency $(F(4,144)=2.36, p$ 
$=.057, \mathrm{~d}=0.06)$ and Design Fluency $(\mathrm{F}(4,144)=2.27, \mathrm{p}=.065, \mathrm{~d}=0.06)$ performance. Figures 1 to 5 respectively show the mean performance per group for the Design Fluency, Digit Span Forward, Digit Span Backward, Block Counting, and Verbal Learning tests. A general pattern could be observed: an increase in mean cognitive test scores as a function of mathematical abilities (in line with the mean estimated IQ scores). In general MD groups had the lowest mean scores and MG groups had the highest mean scores. One notable exception was the relatively low Block Counting score for the TA group in comparison with the other groups.

\subsection{COGNITIVE ABILITIES IN RELATION TO MATHEMATICAL PROBLEM SOLVING}

Significant overall group differences were found in terms of Mathematical Problem Solving on the following tests: Design Fluency $(F(4,136)=2.46, p<.05, d=0.07)$, Digit Span Forward $(F(4,136)=3.38, p<.05, d=0.09)$, Digit Span Backward $(F(4,136)=$ 2.47, $p<.05, d=0.07)$, Block Counting $(F(4,136)=3.29, p<.05, d=0.09)$, and Verbal Learning $(F(4,136)=2.45, p=.05, d=0.07)$. For all other tests (i.e., Verbal Fluency, Visual Attention, and Coding), no significant overall group differences were found. Mean group performance for the Design Fluency, Digit Span Forward, Digit Span Backward, Block Counting, and Verbal Learning tests is shown in Figures 1 to 5 respectively. In line with the Computational Fluency groups, an increase in mean test scores, as a function of mathematical abilities, was visible for the Mathematical Problem Solving groups - i.e., low mean scores for MD groups and high mean scores for MG groups. Again with the exception of the Block Counting task, where no such performance pattern could be observed. 


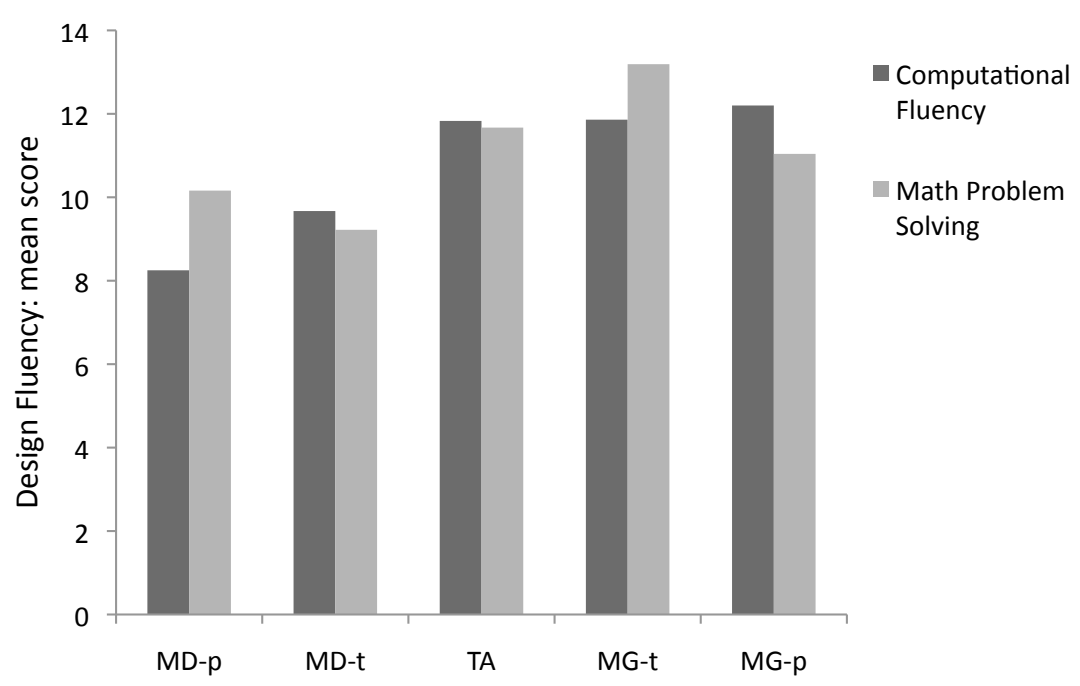

FIGURE 1. Design Fluency performance of children with MD-p, MD-t, TA, MG-t, and MG-p

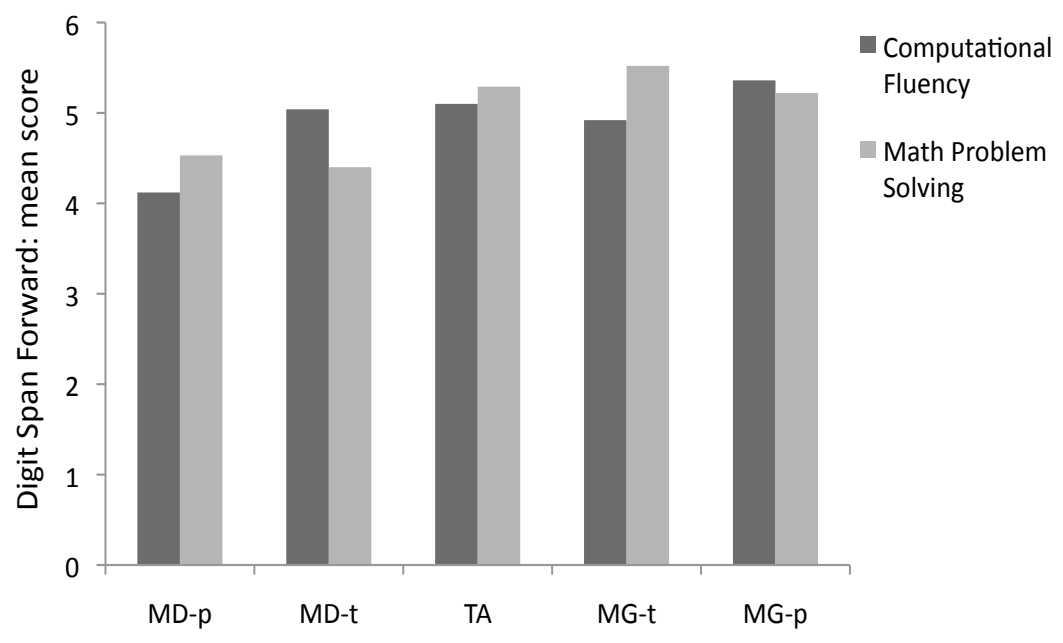

FIGURE 2. Digit Span Forward performance of children with MD-p, MD-t, TA, MG-t, and MG-p 


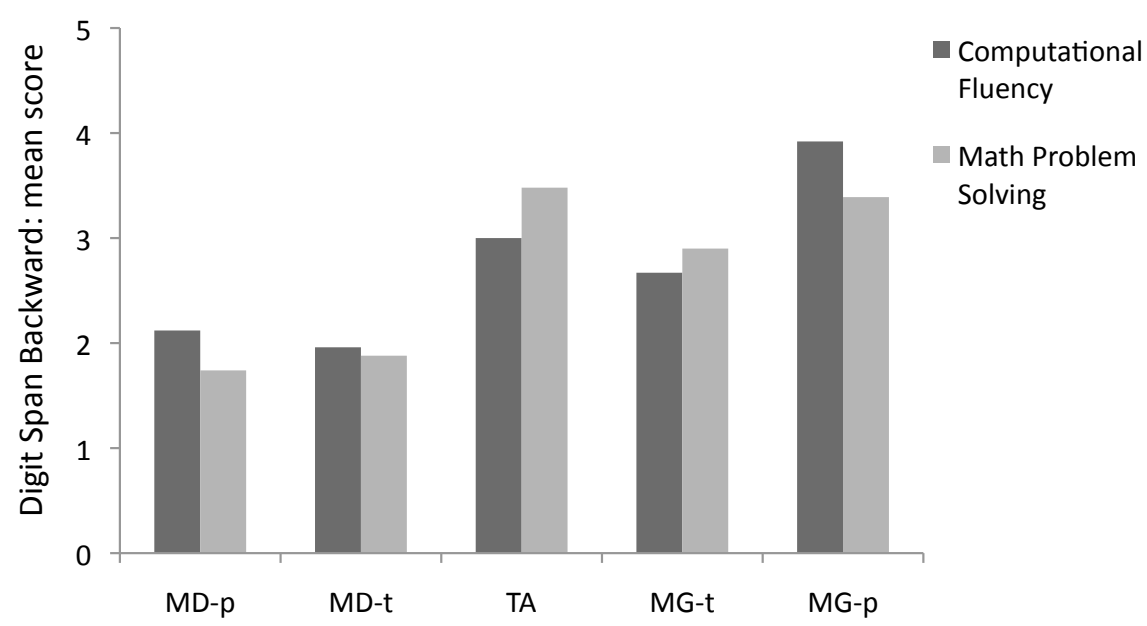

FIGURE 3. Digit Span Backward performance of children with MD-p, MD-t, TA, MG-t, and MG-p

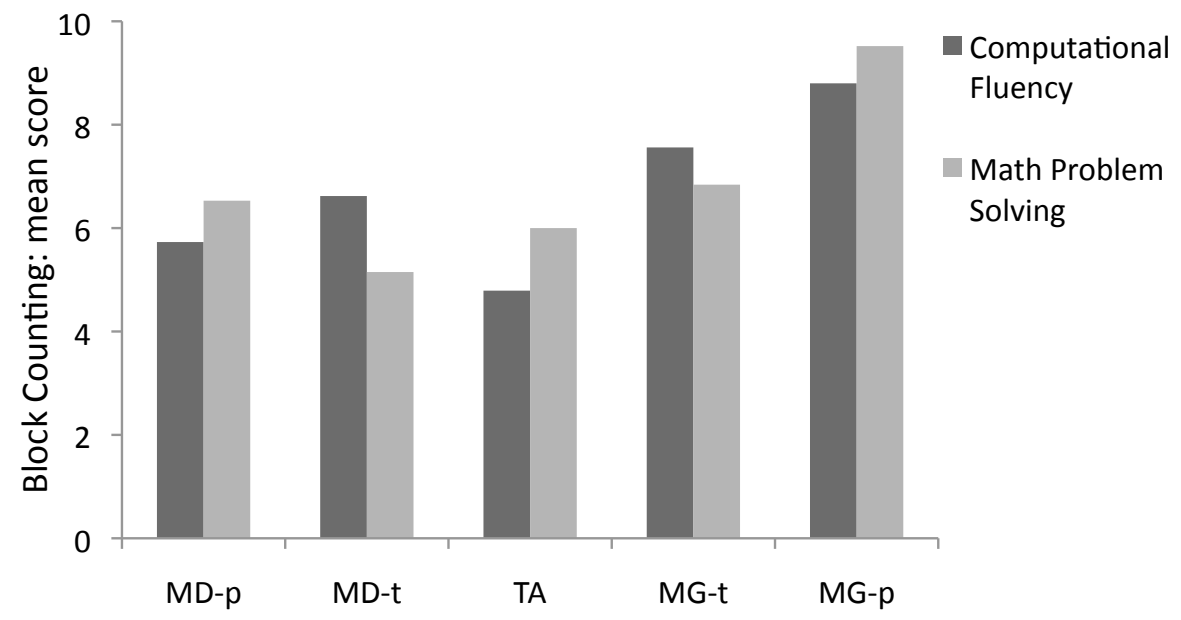

FIGURE 4. Block Counting performance of children with MD-p, MD-t, TA, MG-t, and MG-p 


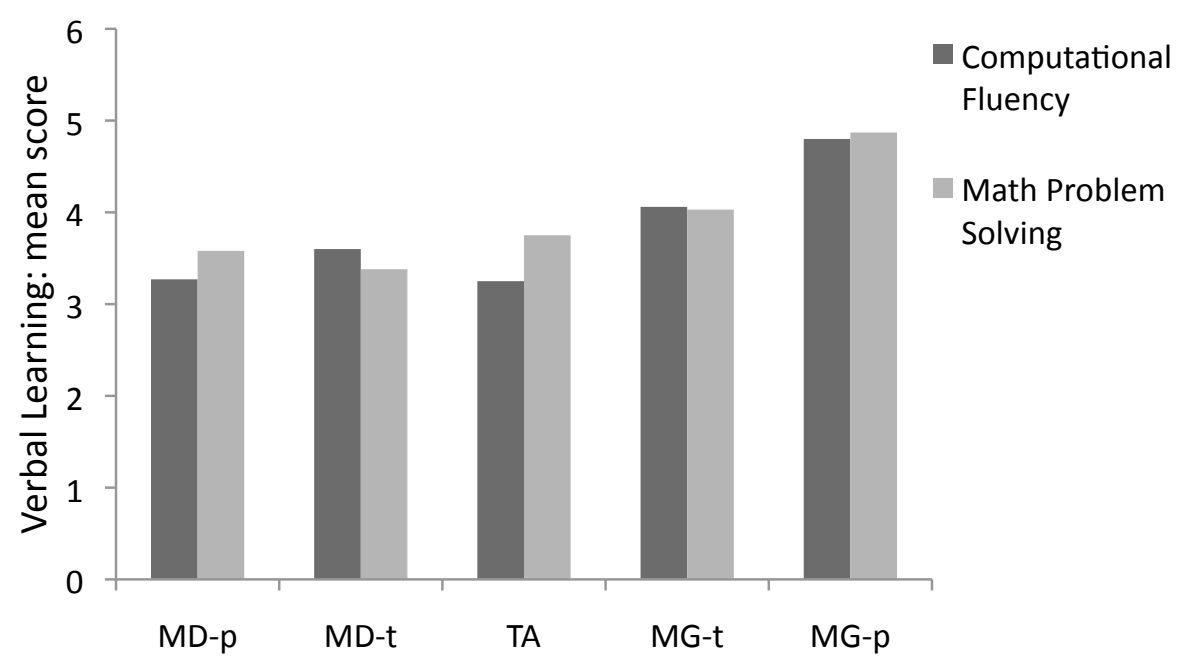

FIGURE 5. Verbal Learning performance of children with MD-p, MD-t, TA, MG-t, and MG-p

\section{DISCUSSION}

As a first focus, the present study investigated stability of mathematical performance in a longitudinal sample of 162 children aged 4 to 8 years. In particular, we were interested in studying the transience and persistence of MD and MG between preschool and early primary school. On the basis of level and stability of performance, children were classified as: MD-p, MD-t, TA, MG-t, and MG-p. Classifications were performed separately for computational fluency and mathematical problem solving at primary school age in relation to preschool numeracy, to discern stability of lower and higher order mathematical abilities (i.e., in line with Vukovic, 2006). A second, important focus was the exploration of preschool cognitive characteristics of children with transient and persistent MD and MG. Although a few studies have reported on stability of MD and cognitive abilities at primary school age (i.e., Geary et al., 2000; Vukovic, 2010), no studies have explored preschool cognitive characteristics in relation to stability of MD and MG between preschool and early primary school. 


\subsection{STABILITY OF MATHEMATICAL PERFORMANCE BETWEEN PRESCHOOL AND EARLY PRIMARY SCHOOL}

As our results showed, 'mathematical ability' is not a highly stable construct for children aged 4 to 8 . Of the children who were classified as low performing (i.e., $\leq 25^{\text {th }}$ percentile) in preschool, only 43 to $53 \%$ also showed low achievement in primary school (i.e., MD-p; percentages reflect computational fluency and mathematical problem solving respectively). Of the children classified as high achievers in preschool, 61 to $68 \%$ was categorized as high performing in primary school (MG-p). In terms of stability of mathematical performance, these findings indicate that mathematical performance is somewhat more variable between preschool and the first two years of primary school than between grades 1 to 4 of primary school (at least with respect to MD). MD are quite stable throughout most of primary school (Chong \& Siegel, 2008; Vukovic, 2006). As Vukovic (2006) showed, a majority of children (i.e., 61\%) with low achievement in grade 1 is still a low achiever in grade 4 . This discrepancy in stability of MD across grades may be linked to the decreasing influence of the home learning environment as children grow older. Melhuish et al. (2008) found that, at 5 years of age, the learning opportunities provided at home differentiated children with MD and MG from typically achieving children. By age 7, however, the home learning environment could only differentiate children with MD. The influence of the home learning environment is suggested to decrease relative to the influence of schooling after the start of formal schooling in grade 1 (Melhuish et al., 2008).

The present study is the first to report on stability of MG between preschool and early primary school age. As our findings showed, MG is characterized by higher stability than MD. Around one third of children with MG at preschool age displayed transient abilities (MG-t) between preschool and early primary school. Our findings also indicate that MG is not an invariable factor, which is underlined by research into underachievement of gifted children and adolescents (e.g., McCoach \& Siegle, 2003; Reis \& McCoach, 2000). Hereby our findings showed that children who are regarded as gifted at preschool age should not be perceived as a uniform group. Differences in performance stability between preschool and early primary school may provide an interesting starting point for the early identification of gifted children at risk for underachievement. 


\subsection{COGNITIVE CHARACTERISTICS OF MD AND MG}

The present study revealed significant differences in cognitive performance between children with MD, TA, and MG that parallel the found mathematical performance differences. Mathematical performance in preschool and early primary school was linearly related to MD or MG status, in line with Vukovic (2006) and Morgan et al. (2009). Children with MD-p and MD-t where characterized by the lowest mathematical scores, while children with MG-p and MG-t had the highest scores. Our results revealed a similar pattern for preschool cognitive performance: on the whole, children with MD predominantly had the lowest mean cognitive scores, while children with MG in general had the highest mean cognitive scores. Significant differences in working memory, non-numerical short-term memory (as reflected by Verbal Learning performance), and visual-spatial reasoning were found between the Computational Fluency groups as well as the Mathematical Problem Solving groups. In addition, significant differences were found in numerical short-term memory (as reflected by Digit Span Forward performance) and design fluency between the Mathematical Problem Solving groups. These findings seem to indicate that differences between children with MD, TA, and MG are predicted by specific cognitive abilities instead of children's general level of cognitive functioning. Preschool performance on design fluency, working memory, visual-spatial reasoning and short-term memory tasks potentially reflects early cognitive characteristics that discern young children with MD and MG from typically achieving children. Visual-spatial reasoning performance forms an exception in terms of differentiation of MD, as can be observed in Figure 4. Test performance of children with MG does stand out in terms of the highest scores. The question remains if the cognitive advantage of these children is permanent or if the abilities of MG children at this age are only characteristics of faster development.

The present study was one of the few studies that explored differences in cognitive abilities at preschool age and the first one to take stability of mathematical abilities between preschool and primary school into account for children with MD, TA and MG. Hereby, our study was the first to show that working memory, short-term memory, and visual-spatial reasoning form important cognitive characteristics of MD and MG at preschool age - both in terms of computational fluency and mathematical 


\section{CHAPTER 4}

problem solving abilities. In addition, the present study's findings indicate that design fluency abilities play a role, although more so for mathematical problem solving performance. Together these findings seem to indicate that design fluency is a more specific predictor of higher order mathematical development, while the other cognitive predictors contribute both to lower order and higher order mathematical development (respectively computational fluency and mathematical problem solving). Our findings of the importance of these cognitive predictors are in line with studies focusing on the general relationship between arithmetic and cognition at primary school age as well as studies exploring this relationship in children with MD and to a lesser extent MG. These studies have consistently reported working memory as an important predictor of mathematical development in preschool and/or primary school (e.g., Bull et al., 2008; Geary et al., 2000; Hoard et al., 2008; Passolunghi et al., 2007; Swanson et al., 2008). The present studies' findings of relationships between mathematical stability and visual-spatial abilities as well as short-term memory were also reported by several of these studies (e.g., Bull et al., 2008; Hoard et al., 2008; Swanson \& Kim, 2007). Given that our study was the first to focus on preschool characteristics of $M D$ and $M G$, the contribution of these cognitive abilities to differences between children with MD, TA, and MG at preschool age remains to be investigated further. For one, more research is needed into the differential cognitive predictors of lower and higher order mathematical development, both in preschool and primary school. In addition, the present study was not able to discern the cognitive characteristics of children with transient and persistent MD or MG sufficiently. It remains to be investigated further whether specific cognitive abilities of children with transient MD and MG more closely resemble the abilities of children with persistent MD and MG or the abilities of typically achieving children. Findings by Morgan et al (2009) have indicated that mathematical development of children with transient MD falls between that of children with persistent MD and typical achievers. Their cognitive development may follow the same path. On the other hand, Geary et al. (2000) have found that children with transient MD do not differ from typically achieving children in terms of cognitive abilities in grade 1 and 2 . 


\subsection{EVALUATION OF PRESENT FINDINGS IN LIGHT OF PAST STUDIES AND FUTURE RESEARCH}

The present study was the first to explore the relationship between preschool cognition and stability of mathematical performance between preschool and early primary school, with attention for children with MD as well as MG. Differences between the reported findings of the present study and past research may be explained by a number of factors. Firstly, previous studies have generally focusing on children with MD and have included children with MG as typically achieving. However, cognitive performance of children with MG can differ significantly from children with TA (Swanson, 2006). As a result, findings of differences in cognitive abilities between children with MD and TA may have been enlarged in past studies. Secondly, past research differs in terms of the age of the selected samples. Thus far, stability of mathematical performance was only studied in relation to cognitive performance in primary school. Thirdly, differences in findings may also be attributed to differences in the definition and measurement of the cognitive and mathematical abilities under study. Past research that is described in this article is e.g., characterized by differences in cut-off criteria for MD and measurement instruments for mathematical as well as cognitive performance.

Future research may provide important information on the predictive value of preschool cognition and stability of mathematical abilities between preschool and primary school for the course of MD as well as MG in the later years of primary school and potentially even secondary school. In addition, it may strengthen the findings of the present study. For one, it may shed light on the ecological validity of the present study's findings: although many studies have chosen a similar approach to assessment of mathematical abilities as the present study, the question remains whether the findings of the present study actually reflect children's classroom performance in terms of e.g., motivation and grades. According to Reis and McCoach (2000), actual functioning at school is not reflected by achievement on standardized tests. Thus, an important research question remains if and in how far our findings can be generalized to educational practice. In a future study, we intend to shed light on this issue by including children's grades as well as teacher evaluations. Secondly, it would be interesting to take factors such as motivation or initiative-taking in learning into 


\section{CHAPTER 4}

account to create an even broader outlook beyond cognitive predictors of mathematical abilities. For one, Martens, Hurks and Jolles (2012) have described that the child's own initiative in learning and the home learning environment play an important role in learning aspects of numeracy.

Another point of attention is the present study's sample size. Although the size of the sample is in line with studies by Geary et al. (2000) and Vukovic (2006), a larger sample size would have strengthened the reliability of our findings. The sample size may also have contributed to the relatively low effect sizes reported in our study, given the number of groups and cognitive abilities included in our analyses. Correction for IQ in the analyses has also contributed to lower effect sizes. A larger sample would also have created possibilities for a more detailed study of the sample, e.g., in terms of sex differences. For one, an observation of the present study's sample has revealed a notably high percentage of boys in the group of MG children, which could be an interesting starting point for further research.

\subsection{RELEVANCE IN AN EDUCATIONAL CONTEXT}

Despite these remaining questions and unresolved issues and the need for follow-up research, our study was the first to relate preschool cognition to mathematical performance stability between preschool and primary school. The present study's findings provide an interesting starting point for preschool interventions that e.g., could prevent the development of persistent MD. Although the findings show that a substantial percentage of children varies in the stability of their mathematical performance between preschool and early primary school, there is also an important group of children that already display stable MD at this early age. According to Morgan, Farkas, \& Wu (2009), children with persistent MD at preschool age have the lowest growth rates in mathematical performance in grades 1 to 5 . Thus, stability of $M D$ at an early age poses a serious risk for permanent MD. Further, our findings have shown that, irrespective of transience or persistence of MD or MG between preschool and primary school, preschool cognitive characteristics can discern children with MD and MG from typically achieving children. These findings e.g., underline the importance of early interventions for children with MD. In particular, since Chong and Siegel (2008) have shown that the foundation for MD is laid before grade 2 and that, 
without intervention, MD continue to exist throughout primary school. Interventions may focus directly on the mathematical abilities of children with MD (e.g., Aunio et al., 2005; Starkey et al., 2004), but can also target underlying cognitive weaknesses. Hereby interventions can tackle general risk factors for learning difficulties instead of focusing on specific mathematical abilities. For one, past research has shown that preschool intervention can be effective in training working memory (Thorell, Lindqvist, Bergman Nutley, Bohlin, \& Klingberg, 2009), thereby also improving mental arithmetic performance indirectly (St Clair-Thompson, Stevens, Hunt \& Bolder, 2010).

In sum, the present study's findings indicate that preschool cognitive abilities can provide an interesting source of information with respect to the level of mathematical performance at preschool and early primary school age. As our findings showed, mathematical abilities are still very variable at this age. Furthermore, children with MD, TA, and MG differed significantly in terms of their numerical and mathematical abilities as well as their cognitive abilities - i.e., design fluency, working memory, short-term memory and visual-spatial reasoning. These findings, in particular the preschool cognitive characteristics of $M D$ and $M G$, provide a potential starting point for interventions aimed at e.g., preventing stagnation in learning by tackling underlying cognitive risk factors. 


\section{REFERENCES}

Andersson, U. (2008). Working memory as a predictor of written arithmetical skills in children: The importance of central executive functions. British Journal of Educational Psychology, 78(2), 181203.

Aunio, P., Hautamäki, J., Heiskari, P., \& Van Luit, J. H. (2006). The Early Numeracy Test in Finnish: Children's norms. Scandinavian Journal of Psychology, 47(5), 369-378.

Aunola, K., Leskinen, E., Lerkkanen, M., \& Nurmi, J. (2004). Developmental Dynamics of Math Performance From Preschool to Grade 2. Journal of Educational Psychology, 96(4), 699-713.

Berg, D. H. (2008). Working memory and arithmetic calculation in children: The contributory roles of processing speed, short-term memory, and reading. Journal of Experimental Child Psychology, 99(4), 288-308.

Brand, N., \& Jolles, J. (1985). Learning and retrieval rate of words presented auditorily and visually. Journal of General Psychology, 112(2), 201-210.

Brosnan, M., Demetre, J., Hamill, S., Robson, K., Shepherd, H., \& Cody, G. (2002). Executive functioning adults and children with developmental dyslexia. Neuropsychologia, 40(12), 2144-2155.

Bull, R., Espy, K., \& Wiebe, S. A. (2008). Short-term memory, working memory, and executive functioning in preschoolers: Longitudinal predictors of mathematical achievement at age 7 years. Developmental Neuropsychology, 33(3), 205-228.

Chong, S., \& Siegel, L. S. (2008). Stability of computational deficits in math learning disability from second through fifth grades. Developmental Neuropsychology, 33(3), 300-317.

Cohen, J. (1988). Statistical Power Analysis for the Behavioral Sciences (2nd ed.). Hillsdale, NJ Lawrence Erlbaum Associates.

Croy, C. D., \& Novins, D. K. (2005). Methods for addressing missing data in psychiatric and developmental research. Journal of the American Academy of Child and Adolescent Psychiatry, 44(12), 1230 1240.

De Bie, S. E. (1987). Standaardvragen 1987: Voorstellen voor uniformering van vraagstellingen naar de achtergrondkenmerken en interviews [Standard questions 1987: Proposal for the uniformization of questions regarding background variables and interviews] (2nd ed.). Leiden, The Netherlands: Leiden University Press.

Desoete, A., Stock, P., Schepens, A., Baeyens, D., \& Roeyers, H. (2009). Classification, seriation, and counting in grades 1, 2, and 3 as two-year longitudinal predictors for low achieving in numerical facility and arithmetical achievement?. Journal of Psychoeducational Assessment, 27(3), 252-264.

De Vos, T. (1992). Tempo Test Rekenen [Arithmetic Tempo Test]. Lisse: Swets \& Zeitlinger.

Donders, J. (1997). A short form of the WISC--III for clinical use. Psychological Assessment, 9(1), 15-20. 
Duncan, G. J., Dowsett, C. J., Claessens, A., Magnuson, K., Huston, A. C., Klebanov, P., et al. (2007). School readiness and later achievement. Developmental Psychology, 43(6), 1428-1446.

Fuchs, L. S., Compton, D. L., Fuchs, D., Paulsen, K., Bryant, J. D., \& Hamlett, C. L. (2005). The Prevention, Identification, and Cognitive Determinants of Math Difficulty. Journal Of Educational Psychology, 97(3), 493-513.

Geary, D. C. (2004). Mathematics and Learning Disabilities. Journal of Learning Disabilities, 37(1), 4-15.

Geary, D. C. (2011a). Cognitive predictors of achievement growth in mathematics: A 5-year longitudinal study. Developmental Psychology, 47(6), 1539-1552.

Geary, D. C. (2011b). Consequences, characteristics, and causes of mathematical learning disabilities and persistent low achievement in mathematics. Journal of Developmental And Behavioral Pediatrics, 32(3), 250-263.

Geary, D. C., Hamson, C. O., \& Hoard, M. K. (2000). Numerical and arithmetical cognition: A longitudinal study of process and concept deficits in children with learning disability. Journal of Experimental Child Psychology, 77(3), 236-263.

Geary, D. C., Hoard, M. K., \& Hamson, C. O. (1999). Numerical and arithmetical cognition: Patterns of functions and deficits in children at risk for a mathematical disability. Journal of Experimental Child Psychology, 74(3), 213-239.

Geary, D. C., Hoard, M. K., Nugent, L., \& Bailey, D. H. (2012). Mathematical cognition deficits in children with learning disabilities and persistent low achievement: A five-year prospective study. Journal of Educational Psychology, 104(1), 206-223.

Halpern, D. F. (2000). Sex differences in cognitive abilities (3rd ed.). Mahwah, NJ: Lawrence Erlbaum Associates.

Hoard, M. K., Geary, D. C., Byrd-Craven, J., \& Nugent, L. (2008). Mathematical cognition in intellectually precocious first graders. Developmental Neuropsychology, 33(3), 251-276.

Hodge, K. A., \& Kemp, C. R. (2006). Recognition of Giftedness in the Early Years of School: Perspectives of Teachers, Parents, and Children. Journal for the Education of the Gifted, 30(2), 164-204.

Huizingh, E. (2002). Inleiding SPSS 11 voor Windows [Introduction to SPSS 11 for Windows]. Schoonhoven: Academic Service.

Hurks, P. M., Schrans, D. D., Meijs, C. C., Wassenberg, R. R., Feron, F. M., \& Jolles, J. J. (2010). Developmental changes in semantic verbal fluency: Analyses of word productivity as a function of time, clustering, and switching. Child Neuropsychology, 16(4), 366-387.

Hyde, J. S., \& Linn, M. C. (2006). Diversity. Gender similarities in mathematics and science. Science, 314(5799), 599-600.

Kalff, A. C., Kroes, M. M., Vles, J. H., Bosma, H. H., Feron, F. M., Hendriksen, J. M., et al. (2001). Factors affecting the relation between parental education as well as occupation and problem behaviour in Dutch 5- to 6-year-old children. Social Psychiatry and Psychiatric Epidemiology, 36(7), 324-331. 


\section{CHAPTER 4}

Kaufman, A. S., Lichtenberger, E. O., Fletcher-Janzen, E., \& Kaufman, N. L. (2005). Essentials of KABC-II assessment. Hoboken, New Jersey: John Wiley \& Sons.

Korkman, M., Kirk, U., \& Kemp, S. (1998). NEPSY: A developmental neuropsychological assessment-manual. San Antonio, Texas: Psychological Corporation.

Kort, W., Schittekatte, M., Dekker, P. H., Verhaeghe, P., Compaan, E. L., Bosmans, M., et al. (2005). WISC-IIINL. Handleiding en verantwoording. Nederlandse bewerking [WISC-III-NL: Manual and account. Dutch adaptation]. London: Harcourt Test Publishers.

Lezak, M. D., Howieson, D. B., Loring, D. W., Hannay, H., \& Fischer, J. S. (2004). Neuropsychological assessment (4th ed.). New York, NY US: Oxford University Press.

Martens, R., Hurks, P. M., \& Jolles, J. (2012). Impact of home learning environment, child's own initiative, and cognition on young children's numeracy. Unpublished manuscript.

Mazzocco, M. M. (2007). Defining and differentiating mathematical learning disabilities and difficulties. In D. B. Berch \& M. M. Mazzocco (Eds.), Why is math so hard for some children? The nature and origins of mathematical learning difficulties and disabilities (pp. 29-47). Baltimore: Brookes.

McCoach, D., \& Siegle, D. (2003). Factors that differentiate underachieving gifted students from highachieving gifted students. Gifted Child Quarterly, 47(2), 144-154.

McLean, J. F., \& Hitch, G. J. (1999). Working memory impairments in children with specific arithmetic learning difficulties. Journal of Experimental Child Psychology, 74(3), 240-260.

Morgan, P. L., Farkas, G., \& Wu, Q. (2009). Five-year growth trajectories of kindergarten children with learning difficulities in mathematics. Journal of Learning Disabilities, 42(4), 306-321.

Passolunghi, M., \& Cornoldi, C. (2008). Working memory failures in children with arithmetical difficulties. Child Neuropsychology, 14(5), 387-400.

Passolunghi, M., \& Siegel, L. S. (2004). Working memory and access to numerical information in children with disability in mathematics. Journal of Experimental Child Psychology, 88(4), 348-367.

Passolunghi, M., Vercelloni, B., \& Schadee, H. (2007). The precursors of mathematics learning: Working memory, phonological ability and numerical competence. Cognitive Development, 22(2), 165-184.

Rasmussen, C., \& Bisanz, J. (2005). Representation and working memory in early arithmetic. Journal of Experimental Child Psychology, 91(2), 137-157.

Reis, S. M., \& McCoach, D. (2000). The underachievement of gifted students: What do we know and where do we go?. Gifted Child Quarterly, 44(3), 152-170.

Reiter, A., Tucha, O., \& Lange, K. W. (2005). Executive Functions in Children with Dyslexia. Dyslexia: An International Journal of Research and Practice, 11(2), 116-131.

Rivera-Batiz, F. L. (1992). Quantitative literacy and the likelihood of employment among young adults in the United States. The Journal of Human Resources, 27(2), 313-328.

Rosselli, M., Ardila, A., Matute, E., \& Inozemtseva, O. (2009). Gender differences and cognitive correlates of mathematical skills in school-aged children. Child Neuropsychology, 15(3), 216-231. 
Sattler, J. M. (1992). Assessment of children: WISC-III and WPPSI-R supplement. San Diego, CA England: Jerome M. Sattler.

Siegler, R. S., \& Ramani, G. B. (2009). Playing linear number board games - but not circular ones - improves low-income preschoolers' numerical understanding. Journal of Educational Psychology, 101 (3), 545-560.

Starkey, P., Klein, A., \& Wakeley, A. (2004). Enhancing young children's mathematical knowledge through a pre-kindergarten mathematics intervention. Early Childhood Research Quarterly, 19(1), 99-120.

Statistics Canada and Organization for Economic Cooperation and Development. (2005). Learning a living: First results of the adult literacy and life skills survey. Ottawa and Paris: Author.

St Clair-Thompson, H. L., Stevens, R., Hunt, A., \& Bolder, E. (2010). Improving children's working memory and classroom performance. Educational Psychology, 30(2), 203-219.

Stock, P., Desoete, A., \& Roeyers, H. (2009). Predicting arithmetic abilities: The role of preparatory arithmetic markers and intelligence. Journal of Psychoeducational Assessment, 27(3), 237-251.

Swanson, H. (2006). Cognitive processes that underlie mathematical precociousness in young children. Journal of Experimental Child Psychology, 93(3), 239-264.

Swanson, H., Jerman, O., \& Zheng, X. (2008). Growth in working memory and mathematical problem solving in children at risk and not at risk for serious math difficulties. Journal of Educational Psychology, 100(2), 343-379.

Swanson, L., \& Kim, K. (2007). Working memory, short-term memory, and naming speed as predictors of children's mathematical performance. Intelligence, 35(2), 151-168.

Taub, G. E., Keith, T. Z., Floyd, R. G., \& Mcgrew, K. S. (2008). Effects of general and broad cognitive abilities on mathematics achievement. School Psychology Quarterly, 23(2), 187-198.

Thorell, L. B., Lindqvist, S., Bergman Nutley, S., Bohlin, G., \& Klingberg, T. (2009). Training and transfer effects of executive functions in preschool children. Developmental Science, 12(1), 106-113.

Toll, S. M., Van der Ven, S. G., Kroesbergen, E. H., \& Van Luit, J. H. (2011). Executive functions as predictors of math learning disabilities. Journal of Learning Disabilities, 44(6), 521-532.

Torbeyns, J., van den Noortgate, W., Ghesquière, P., Verschaffel, L., van de Rijt, B. M., \& van Luit, J. H. (2002). Development of early numeracy in 5- to 7-year-old children: A comparison between Flanders and The Netherlands. Educational Research and Evaluation, 8(3), 249-275.

Van den Bos, K. P., Lutje Spelberg, H. C., Scheepstra, A. J., \& de Vries, J. R. (1994). De Klepel, vorm A en B: een test voor de leesvaardigheid van pseudowoorden [The Klepel, form A and B: A test for the reading skills of pseudowords]. Lisse: Swets \& Zeitlinger.

Van de Rijt, B. M., Van Luit, J.H., \& Pennings, A. H. (1999). The construction of the Utrecht Early Mathematical Competence Scales. Educational and Psychological Measurement, 59(2), 289-309.

Van der Elst, W., Van Boxtel, M. J., Van Breukelen, G. P., \& Jolles, J. (2005). Rey's verbal learning test: Normative data for 1855 healthy participants aged 24-81 years and the influence of age, sex, 


\section{CHAPTER 4}

education, and mode of presentation. Journal of the International Neuropsychological Society, 11(3), 290-302.

Van Luit, J. H., Van de Rijt, B. M. \& Pennings, A. H. (1994). Utrechtse getalbegrip toets [The Utrecht Numeracy Test]. Doetinchem: Graviant.

Vukovic, R.K. (2006). The development of numeracy: A longitudinal study of children from first to fourth grade. Unpublished doctoral dissertation, University of British Columbia, Canada.

Vukovic, R. K., \& Siegel, L. S. (2010). Academic and cognitive characteristics of persistent mathematics difficulty from first through fourth grade. Learning Disabilities Research \& Practice, 25(1), 25 38.

Wechsler, D. (2003). WISC-IV: Technical and interpretive manual. San Antonio, TX: The Psychological Corporation. 


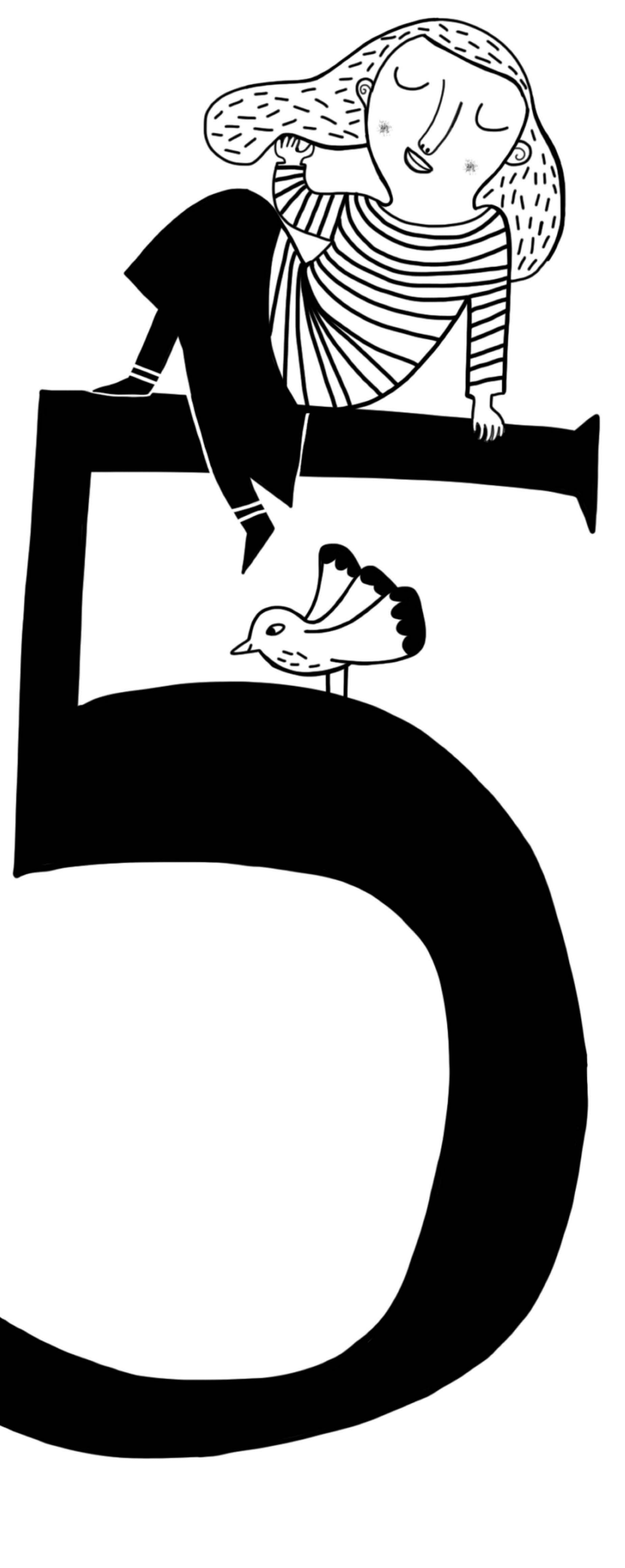





\section{Chapter 5}

\section{Rey-Osterrieth Complex Figure performance in children aged 5-7: Development of organizational strategies and its relation to cognitive functioning}

Martens, R., Hurks, P. M., \& Jolles, J. (2012). Rey-Osterrieth Complex Figure performance in children aged 5-7: Development of organizational strategies and its relation to cognitive functioning. Submitted. 


\section{ABSTRACT}

Although the Rey-Osterrieth Complex Figure (ROCF) is an established and well-studied instrument for research and diagnostics, its potential value for the assessment of young children's organizational strategy use has received limited attention. The aim of the present study was to investigate the validity of two measures of ROCF organizational strategy use in a sample of 217 healthy 5- to 7-year-old children (109 boys) - i.e., RCF-OSS (Anderson et al., 2001) and Rey Initial Drawing Sequence (RIDS), a newly developed measure. Firstly, our findings indicated that children's organizational approach undergoes a significant developmental change between the age of 5 to 7 years, with the largest performance improvement occurring between the ages of 5.5 and 6.5 years. A comparable pattern was found for RCF-OSS and RIDS: while younger children were inclined to use a more local approach to copying the ROCF, older children adopted a more advanced, global approach. Secondly, ROCF organizational strategy use was found to correlate significantly with various aspects of cognitive functioning at this age. Organizational strategy use, as measured by RCF-OSS, correlated with numeracy, fluency, visual attention, visual-motor integration, spatial memory, working memory, processing speed, and spatial reasoning. The organizational strategies measure RIDS only correlated with numeracy. Together these findings suggest that RCF-OSS and RIDS reflect different organizational processes and can therefore be used as complementary measures of organizational strategy use. To the best of our knowledge our study is one of the first to shed light on the important changes that take place in children's organizational strategies between 5 to 7 years of age. 


\section{INTRODUCTION}

The ability to organize information in a meaningful manner facilitates learning and is thereby an important determinant of academic performance (e.g., Cornford, 2002; Garner, 2009, Pintrich \& De Groot, 1990; Weinstein \& Mayer, 1986). Organizational strategies require transformation of information into a different form and the establishment of relationships between parts or elements. In classroom situations, organizational strategies may lead to a deeper understanding of teaching material (Cornford, 2002). Consequently, assessment of organizational strategies may be useful for the identification of children with or at risk for learning difficulties and for designing interventions for this risk group (e.g., organizational scaffolding of information; Frisk, Jakobson, Knight, Robertson, 2005). A well-known test that enables the assessment of organizational strategies, at least in adults, is the Rey-Osterrieth Complex Figure (ROCF; Anderson, Anderson, \& Garth, 2001; Lezak, Howieson, Loring, Hannay, \& Fischer, 2004; McConley et al., 2008; Mitrushina, Boone, \& D’Elia, 1999; Rey, 1941; Osterrieth, 1944). It requires participants to copy (and later reproduce from memory) a complex geometrical figure as accurately as possible. This complex figure consists of a large rectangle with vertical and horizontal centerlines, two diagonals, internal sections, and external attachments (see Figure 1). Surprisingly, explorations of the potential use of the ROCF in pediatric and developmental neuropsychological research have only started in recent years (e.g., Anderson et al., 2001; Nakano et al., 2006). Given this limited attention, especially for young children's ROCF performance, the present study aimed to map the organizational strategy use of 5- to 7-year-olds when copying the ROCF.

\subsection{QUANTITATIVE AND QUALITATIVE ASSESSMENT OF ROCF PERFORMANCE}

The most commonly used quantitative scoring method was devised by Rey (1941) and standardized by Osterrieth (1944). This method distinguishes eighteen unique ROCF elements and rates them on the basis of accuracy and placement. It is used as a global indicator of cognitive performance in the context of research into normal development and aging (Akshoomoff \& Stiles, 1995; Lezak et al., 2004). Unfortunately, this scoring method does not enable users to disentangle the diverse cognitive processes underlying ROCF task performance, such as organizing complex visual information, 


\section{CHAPTER 5}

maintaining attention, and responding to visual feedback (Anderson et al., 2001; Lezak et al., 2004). Qualitative descriptions based on adult studies suggest that it should be possible to make finer process analyses in terms of applied organizational strategies, that are suitable for use in clinical case formulation as well as research (Kaplan, 1988 cited in Mitrushina et al., 1999, p. 163). For instance, frontal lobe patients have been found to modify elements into more familiar items (e.g., replacing a circle with three dots by a smiley) and to repeat elements that are already present, as a consequence of disorganized strategy use or an inefficient self-control mechanism (Messerli et al., 1979 cited in Lezak et al., 2004, p. 547; Osterrieth, 1944). Therefore, researchers have introduced alternative, more qualitative scoring methods to quantify strategy use while copying the ROCF (as discussed in paragraph 1.2 of this introduction). Unfortunately, the psychometric properties of these alternative scoring methods are still scarcely studied, especially in pediatric populations.

\subsection{ASSESSMENT OF ROCF PERFORMANCE IN PEDIATRIC POPULATIONS: EXISTING} METHODS

Over the past decades, four qualitative scoring methods have been developed or adapted for children - i.e., the Developmental Scoring System (DSS; Bernstein \& Waber, 1996); the Boston Qualitative Scoring System (BQSS; Stern et al., 1994), the Rey Complex Figure Organizational Strategy Score (RCF-OSS; Anderson et al., 2001), and the Savage-Deckersbach organizational scoring system (Deckersbach et al., 2000; Savage, Baer, Keuthen, Brown, Rauch, \& Jenike, 1999; Smith \& Zahka, 2006). These alternative scoring methods are based on the hypothesis that perceptual organization is reflected by the order in which a participant copies the elements of the figure (Anderson et al., 2001). The four methods primarily assess the degree of fragmentation and/or aspects of drawing order of lines and elements. The RCF-OSS (Anderson et al., 2001) is the only method that was specifically designed to study the developmental level of children in terms of organizational strategy use. According to Anderson et al. (2001), the RCF-OSS allows for variability in development and is better equipped to assess young children's strategies than the DSS, BQSS and SavageDeckersbach organizational scoring system. The RCF-OSS assesses the sequence in which elements are drawn and rates children's organizational strategies according to 
seven categories or levels. In RCF-OSS assessment, the base rectangle and the horizontal and vertical midlines are considered to be significant elements, since they play a vital role in the organization of the other elements (Anderson et al., 2001). According to Anderson et al. (2001), the RCF-OSS correlated moderately with traditional measures of executive functioning at ages 7 to 13 (i.e., $r=.12$ to .35). No other study has published on the psychometric properties of the RCF-OSS (Davies, Field, Andersen, \& Pestell, 2011).

\subsection{RATIONALE FOR A NEW SCORING SYSTEM}

To this day there is no consensus on the best scoring method to judge ROCF performance in pediatric populations (e.g., Troyer \& Wishart, 1997; Davies, Field, \& Andersen, 2011). All methods have limitations, such as insufficient normative data or inadequate research with respect to psychometric properties. Most importantly, no method has quantified how children start to copy the ROCF (e.g., which lines do these children copy first and more concretely: what are the first 11 lines they draw?). This is unfortunate, since drawing sequence and particularly the first steps a child takes in copying the ROCF may provide valuable information about children's perception of the figure as well as their organizational strategy use. The RCF-OSS incorporates some information on initial drawing order in their classification of organizational strategy use, but merely as part of the overall scoring system. Only at the highest organizational level (excellent organization), the RCF-OSS criteria state that the rectangle has to be drawn first. At 7 years of age, this level of organization is not reached yet (Anderson et al., 2001). Lower organizational levels do not discern the initial steps in copying the ROCF. Hereby, the RCF-OSS cannot provide information about the initial drawing sequence used by younger children. Therefore, the present study introduced a new method based on the actual initial drawing order (i.e., how many of the first 11 lines that are drawn are part of the large rectangle or contour of the ROCF?). This method is assumed to provide an addition to the assessment of children's organizational approach and will be compared to organization as measured by the RCF-OSS. More information about our new scoring method Rey Initial Drawing Sequence (RIDS) can be found in the Method-section. 


\section{CHAPTER 5}

In sum, the present study aimed to explore the validity of two methods for organizational strategy use of children aged 5 to 7: the RCF-OSS and the RIDS, a new method. Validity was assessed on the basis of developmental profiles (paragraph 1.4) and correlations with measures of cognitive functioning (paragraph 1.5).

\subsection{MEASUREMENT OF ROCF PERFORMANCE AT PRESCHOOL AGE}

Although the ROCF is described as an appropriate test for the measurement of developmental trends in children aged 6 years or older (Akshoomoff \& Stiles, 1995), most studies on ROCF performance have only included healthy children aged 7 years or older. This is unfortunate, since recent research has indicated that cognitive functions underlying ROCF task performance (including executive functions) are already developing early in life - i.e., at preschool age (e.g., Anderson et al., 2008; Diamond Barnett, Thomas, \& Munro, 2007; Romine \& Reynolds, 2005). In addition, several studies that have described the development of drawing abilities of children have reported large differences in graphic copying strategies of 4- and 5-year-old children compared to 6-year-old children. Where 4- and 5-year-olds adopted a more local approach to copying figures (i.e., focusing on elements of the drawing), 6-yearolds were already capable of planning the construction of their drawing on a more global level (Minary \& Vinter, 1996; Vinter, 1994; Vinter \& Marot, 2007; Vinter, Picard, \& Fernandes, 2008). Copied drawings included composite figures with varying orientations and/or groupings - e.g., rectangles grouped in an increasing or decreasing sequence of lengths and presented upright or upside down. Since these studies seem to indicate that major changes take place in young children's graphic copying strategies, the present study aimed to zoom in on ROCF copying performance of 5- to 7-year-olds. More specifically, by focusing on 5- to 7-year-old children, we intended to compare organizational approaches in the second year of preschool (i.e., before the start of formal schooling) and grade 1 (i.e., formal schooling). Only performance on the ROCF Copy-condition was explored in this study, given that we were primarily interested in how children copy complex information (and not so much how they recall this information). Moreover, previous studies have shown that the strategic approach that is applied when copying the ROCF is predictive of later recall-performance (Anderson et al., 2001; Lezak, 2004). 
In sum, it was hypothesized that an age effect would be found in terms of organizational strategy use. Preschoolers were expected to copy the ROCF at a more local level than children in grade 1.

\subsection{ROCF PERFORMANCE IN RELATION TO COGNITIVE ABILITIES}

The present study intended to explore the relationship between organizational performance on the ROCF - as measured by RCF-OSS and our new method RIDS - and performance on tests measuring cognitive - executive and non-executive - abilities (i.e., visual attention, processing speed, design fluency, working memory, spatial memory, visual-motor integration, spatial reasoning, arithmetical abilities). To the authors' knowledge, no studies have addressed the relationship between organizational strategies and cognitive performance in normally developing children aged 5 to 7. A few studies have reported relationships between various executive functions and aspects of ROCF performance of children and adults with neuropsychological disorders (Ogino et al., 2009; Somerville, Tremont, \& Stern, 2000; Watanabe et al., 2005; Weber, Riccio, \& Cohen, 2012). For instance, Ogino et al. (2009) and Watanabe et al. (2005) reported positive correlations between ROCF performance (as measured by the BQSS) and executive functioning, in particular planning and organization, in school-aged children with neurological disorders (i.e., 5-15 yrs). The question remains how organizational strategy use of ROCF copying performance is related to different aspects of cognitive functioning (including executive functioning) in healthy children aged 5 to 7 . More specifically, we aimed to study how children's organizational approach, as measured by RCF-OSS and RIDS, correlates with other measures of executive and non-executive functioning (in line with Anderson et al., 2001).

\section{METHOD}

\subsection{PROCEDURE AND PARTICIPANTS}

The present study's data was derived from a large-scale study into "normal" cognitive development. The ROCF was administered in the springtime to 217 children (109 boys; mean age $=6.23, S D=0.62$ ), enrolled in the second year of preschool and grade 1 or 2 


\section{CHAPTER 5}

of primary school. Of these children, 184 were right-handed, 32 were left-handed, and 1 was ambidextrous. Additional testing consisted of a test battery measuring both numerical and cognitive abilities - see paragraph 2.2.2 of the Instruments-section for further details. Testing took place individually in a stimulus-free room at the participating schools. Exclusion criteria were not speaking Dutch fluently, the use of medication (e.g., antihistamines) and the presence of neurological conditions (e.g., absence epilepsy) that could influence cognitive performance. Developmental disorders (e.g., dyslexia, attention deficit hyperactivity disorder) were not considered to be an exclusion criterion, since we aimed to study a sample that was representative of children in average Dutch classrooms. Accordingly, children were considered to be developing at a normal pace when they attended a school for regular education and were in the appropriate grade for their age. The Ethics Committee of the Faculty of Psychology of Maastricht University approved the research protocol. Demographic information is presented in Table 1.

TABLE 1. Group characteristics of the participants ( $n=217)$

\begin{tabular}{|c|c|c|c|c|c|c|c|c|c|c|c|}
\hline \multirow[t]{2}{*}{ Variables } & \multicolumn{2}{|c|}{$\begin{array}{l}5.0-5.5 \\
(\mathrm{~N}=35)\end{array}$} & \multicolumn{2}{|c|}{$\begin{array}{l}5.5 .-6.0 \\
(\mathrm{~N}=45)\end{array}$} & \multicolumn{2}{|c|}{$\begin{array}{l}6.0-6.5 \\
(\mathrm{~N}=56)\end{array}$} & \multicolumn{2}{|c|}{$\begin{array}{l}6.5-7.0 \\
(\mathrm{~N}=53)\end{array}$} & \multicolumn{2}{|c|}{$\begin{array}{l}7.0-7.5 \\
(\mathrm{~N}=28)\end{array}$} & Statistic \\
\hline & \multicolumn{2}{|c|}{$\mathrm{M}(\mathrm{SD})$} & \multicolumn{2}{|c|}{$M(S D)$} & \multicolumn{2}{|c|}{$M(S D)$} & \multicolumn{2}{|c|}{ M (SD) } & \multicolumn{2}{|c|}{$\mathrm{M}(\mathrm{SD})$} & $F$ \\
\hline $\begin{array}{l}\text { Age at } \\
\text { measurement }\end{array}$ & \multicolumn{2}{|c|}{$5.33(0.02)$} & \multicolumn{2}{|c|}{$5.73(0.02)$} & \multicolumn{2}{|c|}{$6.27(0.02)$} & \multicolumn{2}{|c|}{$6.73(0.02)$} & \multicolumn{2}{|c|}{$7.17(0.03)$} & $\underset{* * a}{1075.74}$ \\
\hline \multirow[t]{2}{*}{ Raven's CPM } & \multicolumn{2}{|c|}{$3.34(0.87)$} & \multicolumn{2}{|c|}{$3.31(0.93)$} & \multicolumn{2}{|c|}{$3.45(0.85)$} & \multicolumn{2}{|c|}{$3.34(0.94)$} & \multicolumn{2}{|c|}{$3.70(0.54)$} & $1.10^{b}$ \\
\hline & $\mathrm{N}$ & $\%$ & $\mathrm{~N}$ & $\%$ & $\mathrm{~N}$ & $\%$ & $\mathrm{~N}$ & $\%$ & $\mathrm{~N}$ & $\%$ & $x^{2}$ \\
\hline \multicolumn{12}{|l|}{ Sex } \\
\hline Boys & 21 & 60 & 25 & 55.6 & 23 & 41.1 & 25 & 47.2 & 15 & 53.6 & $4.05^{c}$ \\
\hline Girls & 14 & 40 & 20 & 44.4 & 33 & 58.9 & 28 & 52.8 & 13 & 46.4 & \\
\hline \multicolumn{12}{|l|}{ Handedness } \\
\hline Right & 28 & 80 & 37 & 82.2 & 53 & 94.6 & 42 & 79.2 & 24 & 85.7 & $8.96^{d}$ \\
\hline Left & 7 & 20 & 8 & 17.8 & 3 & 5.4 & 10 & 18.9 & 4 & 14.3 & \\
\hline Ambidextrous & 0 & 0 & 0 & 0 & 0 & 0 & 1 & 1.9 & 0 & 0 & \\
\hline
\end{tabular}

Note. Raven's CPM (Raven, 1962) = an estimate of fluid intelligence for which the present study used the following percentile score classification: 1 = percentile $0-25,2=$ percentile $26-50,3=$ percentile $51-75,4=$ percentile 76-100.

${ }^{\mathrm{a}}$ One-way analysis of variance ( $\left.\mathrm{df} 1=4, \mathrm{df} 2=212\right)$.

${ }^{b}$ One-way analysis of variance $(\mathrm{df} 1=4, \mathrm{df} 2=211)$.

'Pearson Chi-square test $(\mathrm{df}=4)$.

${ }^{\mathrm{d}}$ Pearson Chi-square test $(\mathrm{df}=8)$.

$* * \mathrm{p}<.001$. 

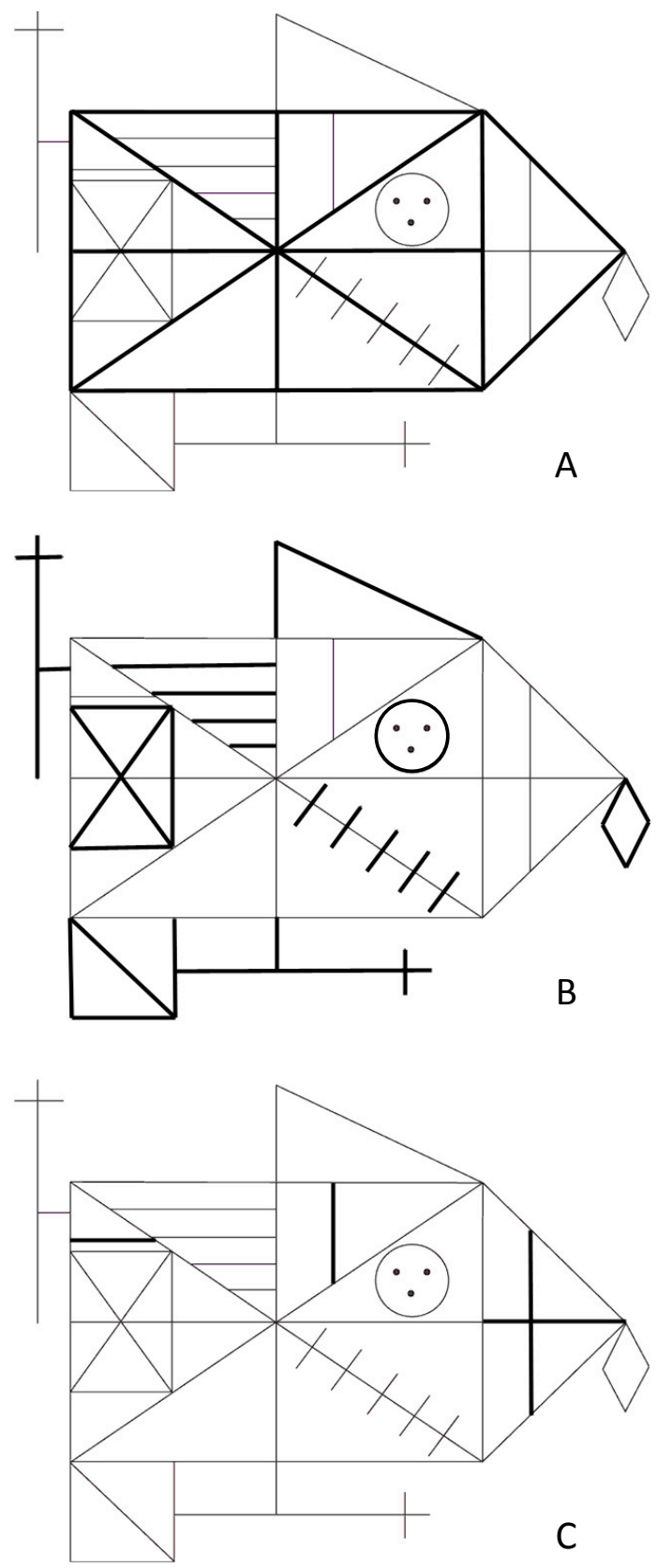

FIGURE 1. Assessment of ROCF accuracy on the basis of three hierarchical levels Note. $\mathrm{A}=$ Global score $\mathrm{B}=$ Elements score, $\mathrm{C}=$ Lines score. 


\section{CHAPTER 5}

\subsection{INSTRUMENTS}

2.2.1 Rey-Osterrieth Complex Figure (ROCF; Rey, 1941; Osterrieth, 1944)

The original ROCF (see Figure 1) requires the child to copy a complex figure (copy condition) and draw it from memory (recall condition) In the present study only the copy condition was administered. The ROCF is presented as a two-dimensional line drawing with a horizontal orientation that points to the right on an A4-size paper. The child is instructed to copy the ROCF as precisely a possible on a similar-sized paper, using a pencil without eraser. There is no time limit. In the present study only the copy condition was administered. Accuracy and organization of drawing were assessed.

Assessment of accuracy. To measure accuracy of copy performance, the present study used the original scoring method that was developed by Osterrieth (1944) and adapted by Taylor (1959). This method discerns 18 elements that are judged on the basis of accuracy and placement. Each element can be awarded 0, 0.5, or 1 point for accuracy and 0 or 1 point for placement. Placement and accuracy are added up to form the total score, with a maximum score of 36 points. In the present study, three subscales were added to assess different aspects of accuracy - in line with Stern et al. (1994). For these subscales, all elements were appointed to one of three hierarchical levels: Global, Elements, and Lines. The Global score is made up of units that are essential to the basic structure of the ROCF. The maximum Global score is 10 . The Elements score represents smaller salient elements that can be awarded a maximum of 18 points. The Lines score is made up of the remaining non-salient elements. Its maximum score is 8 points. Figure 1 depicts the elements that constitute the present study's Global, Elements and Lines scores.

Assessment of organization. Two scoring methods were implemented to assess organization: i.e., (a) the RCF-OSS (Anderson et al., 2001), and (b) the RIDS, a newly developed method that focuses on the initial drawing sequence. The RCF-OSS is a scoring method that rates a child's organizational approach by appointing it to one of seven levels on the basis of scoring criteria. Level 7 represents the highest organizational level (i.e., excellent organization), while level 1 represents a lack of organization (i.e., an unrecognizable or substituted drawing). The intermediate levels are conceptual organization (level 6), part-configural organization (level 5), 
piecemeal/fragmented organization (level 4), random organization (level 3), and poor organization (level 2). For more details see Anderson et al. (2001).

The Rey Initial Drawing Sequence (RIDS) is a scoring method that rates the first eleven steps a child takes in drawing the ROCF. These steps represent the 11 line segments that are needed to draw the global outline of the ROCF (i.e., either the rectangle or the complete outline). Figure 2 depicts these line segments. A child receives 1 point per line segment that is drawn as part of the first eleven steps of the drawing, with a maximum score of 11 . On the basis of these scores, a child's performance is divided into 6 levels (i.e., score 0-1, 2-3, 4-5, 6-7, 8-9, and 10-11). A child is considered to be more detail-oriented if he or she scores lower, while a higher score represents a more global orientation.

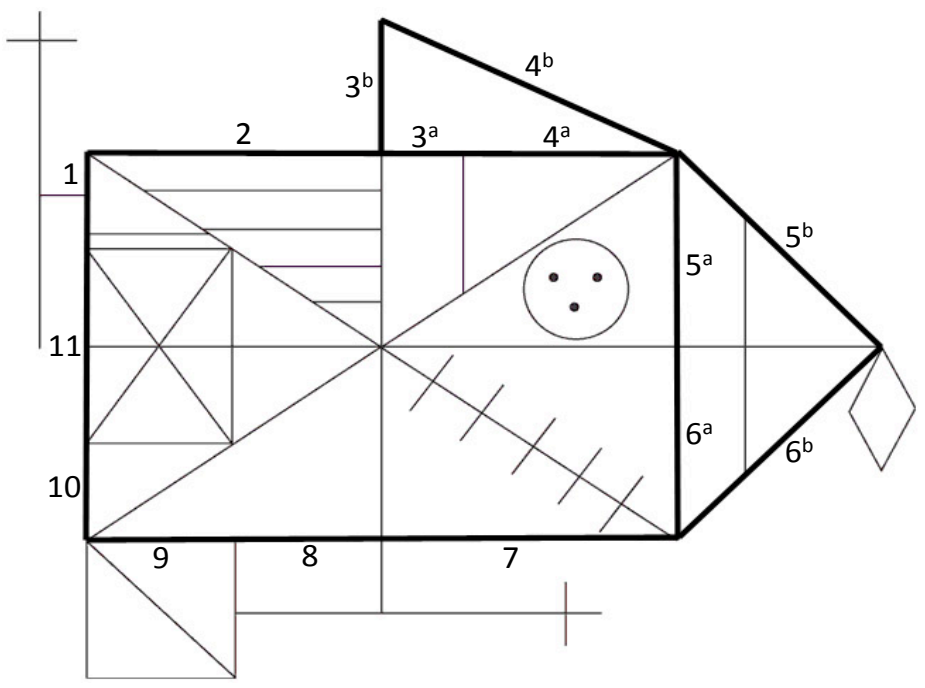

FIGURE 2. RIDS: a measure of initial drawing sequence

Note. The numbers in the figure represent the first eleven drawing steps that make up the maximum score, noted in random order.

\subsubsection{Cognitive measures}

Raven's CPM (Raven, 1958). This measure of fluid intelligence consists of 36 items. The child is shown a pattern with a missing piece and has to select the piece that completes the pattern from six possible options. Items gradually increase in 


\section{CHAPTER 5}

difficulty. One point is awarded per correct answer, with a maximum total raw score of 36. Raw scores were converted into percentile scores, using smoothed norms for the Netherlands (Van Bon, 1986). Since this percentile classification is inexact, we decided to classify the percentile scores as followed: $1=$ percentile $0-25,2=$ percentile $26-50,3$ $=51-75$, and $4=76-100$.

Design Fluency (NEPSY; Korkman et al., 1998). This paper-and-pencil measure of non-verbal fluency consists of two trials in which sheets of paper are presented that depict 70 squares, each containing five dots. These dots are arranged in either (1) a structured array or (2) a random array. The child has to generate as many different designs as possible within 1 minute by connecting two or more dots using straight lines. The total raw score consists of the number of unique, correct drawings summed across the two trials, with a maximum score of 70 .

Visual Attention (NEPSY; Korkman et al., 1998). This measure of focused and divided visual attention consists of two trials in which the child has to search and cross out drawings on a sheet of paper as fast as possible. In the present study only the second, more challenging trial was administered: searching for two specific types of faces amidst distracting faces. If the child is still searching after 180 seconds, administration is cut off. The total raw score consisted of the number of correctly identified items minus the number of incorrect items, with a maximum score of 20.

Digit Span Forward and Backward (Wechsler Intelligence Scales - Fourth Edition [WISC-IV]; Wechsler, 2003). These estimates of working memory require children to repeat a sequence of digits (ranging from 0-9) in the same order as the experimenter (Digit Span Forward) or the reverse order (Digit Span Backward). Both subtests consist of 8 items composed of 2 trials of the same length, starting with 2 digits and increasing to 8 digits (Digit Span Forward) or 9 digits (Digit Span Backward). Item difficulty increases as trial length increases. The child receives 1 point per correct trial with a maximum raw score of 16 points per subtest. Administration is cut off if both trials of the same item are answered incorrectly.

Spatial Memory (Kaufman Assessment Battery for Children [K-ABC]; Kaufman, \& Kaufman, 1983). This measure assesses the child's ability to memorize the locations of pictures that are arranged randomly on a grid and to point to these locations on a similar, blank grid. The test consists of 21 items. Item difficulty increases as the number of pictures on the grid increases. Per correct answer 1 point is awarded, with a 
maximum raw score of 21 points. Administration is cut off when the child answers an indicated number of items incorrectly.

Block Counting (Kaufman Assessment Battery for Children Second Edition [K$A B C$-II]; Kaufman, Lichtenberger, Fletcher-Janzen, \& Kaufman, 2005). This measure provides information on spatial reasoning. It consists of two-dimensional drawings of three-dimensional stacks of blocks. The child must determine the number of blocks in each pile, meanwhile taking into account that some blocks cannot be seen. Items increase in difficulty and the child is awarded 1 or 2 points per item dependent on item difficulty, with a maximum raw score of 44 . Administration is cut of after 4 consecutive incorrect answers.

The Developmental Test of Visual-Motor Integration (VMI; Beery, 1997). This measure of the integration of visual perception and motor coordination requires the child to copy geometrical forms of increasing difficulty. The child is awarded 1 point per correctly copied figure, with a maximum raw score of 24. Administration is cut of after three consecutive incorrectly drawn figures.

Coding (Wechsler Preschool and Primary Scale of Intelligence-III ${ }^{N L}$ [WPPSI$\left.I I I^{N L}\right]$; Hendriksen \& Hurks, 2009). This measure of processing speed requires the child to copy symbols that are paired with five basic geometric shapes. The shapes are presented in a random order on a sheet of paper and the child has to draw the symbols in the corresponding shapes as fast as possible. The child has 2 minutes to complete the test and is awarded a maximum of 59 points for completing all the symbols correctly as well as a time-dependent bonus if all symbols are completed in less than 2 minutes (i.e., extra 1-6 points).

Early Numeracy Test (ENT; Van Luit, Van de Rijt, \& Pennings, 1994). This test consists of 8 sections measuring different aspects of early numeracy. Each section consists of 5 items ( 40 items in total). The child receives 1 point per correct answer, with a maximum raw score of 5 per section and maximum total raw score of 40 . The test has two parallel versions (Form A and B), of which Form B was administered in the present study. For more information about the ENT, see e.g., Aunio, Hautamaki, Heiskari, and Van Luit (2006) and Van de Rijt, Van Luit, and Pennings (1999). 


\section{CHAPTER 5}

\subsection{STATISTICAL ANALYSES}

All analyses were performed using SPSS 16.0 for Macintosh OS X. As a first step, extreme values and missing data were checked for. No extreme values were found i.e., values minimally three times the interquartile distance above the $75^{\text {th }}$ percentile or below the $25^{\text {th }}$ percentile as defined by Huizingh (2002). The missing data were less than $5 \%$ of the total data and were therefore not replaced (Croy \& Novins, 2005).

Firstly, further analyses aimed to establish developmental differences in the distribution of RCF-OSS and RIDS performance by reporting the frequencies of the RCFOSS levels (i.e., 1-7) and scores of the RIDS (i.e., 0-1, 2-3, 4-5, 6-7, 8-9, and 10-11) per age group. Secondly, bivariate correlational analyses were performed between the organizational measures (i.e., RCF-OSS and RIDS) and the accuracy measures (i.e., Global, Elements, Lines, and Total) of the ROCF across our complete sample. In addition, these correlations were studied per age group to assess developmental differences in the connection between the ROCF organizational and accuracy measures. Thirdly, the relationship between ROCF performance and age was studied more in depth by performing a GLM Multivariate analysis with age group as independent variable and the ROCF measures as dependent variables. Finally, ROCF organizational performance was studied in relation to cognitive performance by performing two GLM Multivariate analyses; one analysis with RCF-OSS and the other with RIDS as independent variable. The following cognitive measures were inserted as dependent variables: Raven's CPM, Design Fluency, VMI, Visual Attention, Digit Span Forward and Backward, Spatial Memory, Block Counting, Coding, and ENT. For all measures, except Raven's CPM, raw scores were used, since suitable norms were unavailable in most instances. In these multivariate analyses age was controlled for. For all analyses significance levels were reported and the alpha-value was set at .05.

\section{RESULTS}

\subsection{CORRELATIONS BETWEEN ROCF ORGANIZATIONAL AND ACCURACY MEASURES}

A significant correlation between RCF-OSS and RIDS was found across all age groups ( $r$ $=.37, \mathrm{p}<.001)$. Further, as shown in Table 2, both RCF-OSS and RIDS correlated significantly with all measures of accuracy (i.e., Global, Elements, Lines, Total). Yet, 
there were some differences between these organizational measures in the strength of their correlations with the four accuracy measures. While the RCF-OSS correlated strongly with all accuracy measures ( $r$ varied between .56 - .78), correlations between RIDS and the accuracy measures were less strong and displayed more variability $(r=$ .18 - .40). Nevertheless, the general pattern was similar: both organizational measures correlated more strongly with Global and Total accuracy scores than with scores of Elements and Lines. When studying these correlations per age group we found a fairly similar pattern, as can be observed in Figures 3 and 4. Across all age groups, RCF-OSS and RIDS correlated more strongly with the accuracy scores of Global and Total than with Elements and Lines. In addition, a closer observation of these figures revealed that the correlations between the organizational and accuracy measures were predominantly highest between 5.5 to 6 years of age and declined with age. This effect was particularly noticeable for the RIDS (see Figure 4). In sum, measures of organization - RCF-OSS and RIDS - correlated with all measures of accuracy, particularly with accuracy of Global elements. These correlations were found across all age groups, although most strongly at 5.5 to 6 years of age.

TABLE 2. Correlations between ROCF organizational and accuracy measures

Accuracy measures

\begin{tabular}{lllll}
\hline \hline Organizational measures & Global & Elements & Lines & Total \\
\hline \hline RCF-OSS & $.78^{* *}$ & $.69 * *$ & $.56^{* *}$ & $.76^{* *}$ \\
RIDS & $.40^{* *}$ & $.25^{* *}$ & $.18^{*}$ & $.30^{* *}$ \\
\hline
\end{tabular}

Note. ${ }^{*} \mathrm{p}<.01 .^{* *} \mathrm{p}<.001$

\subsection{DISTRIBUTION OF RCF-OSS AND RIDS LEVELS PER AGE GROUP}

Table 3 displays the distribution of levels of RCF-OSS and RIDS per age group - i.e., represented in percentages. Since none of the children performed at level 6 or 7 of the RCF-OSS, these levels were omitted from Table 3. A closer look at this table revealed an important developmental shift across age groups in terms of the level of organization. This effect was found for both the RCF-OSS and the RIDS. We found that most younger children primarily performed at lower levels of organization (i.e., level 2 of the RCF-OSS and score $0-1$ or 2-3 of the RIDS), while the majority of the older 


\section{CHAPTER 5}

children primarily functioned on more advanced organizational levels (i.e., level 4 of the RCF-OSS and score 4-5 or higher of the RIDS). More specifically, an important shift in organizational performance was observed between the age groups of 5.5-6.0 and 6.0-6.5 years (in particular in the RCF-OSS).

TABLE 3. Changes in organizational strategy use with age

\begin{tabular}{ccccccc}
\hline \hline $\begin{array}{c}\text { Organizational strategy } \\
\text { measure }\end{array}$ & $\begin{array}{c}5.0-5.5 \text { yrs } \\
(n=35)\end{array}$ & $\begin{array}{c}5.5-6.0 \text { yrs } \\
(n=44)\end{array}$ & $\begin{array}{c}6.0-6.5 \text { yrs } \\
(n=56)\end{array}$ & $\begin{array}{c}6.5-7.0 \text { yrs } \\
(n=53)\end{array}$ & $\begin{array}{c}7.0-7.5 \text { yrs } \\
(n=28)\end{array}$ \\
\hline \hline RCF-OSS & Level 1 (\%) & 8.6 & 6.8 & 0.0 & 0.0 & 0.0 \\
& Level 2 (\%) & 62.9 & 59.1 & 25.0 & 18.9 & 10.7 \\
& Level 3 (\%) & 11.4 & 11.4 & 35.7 & 26.4 & 14.3 \\
& Level 4 (\%) & 14.3 & 20.5 & 28.6 & 43.4 & 53.6 \\
& Level 5 (\%) & 2.9 & 2.3 & 10.7 & 11.3 & 21.4 \\
\hline RIDS & Score 0-1 (\%) & 22.9 & 20.5 & 8.9 & 9.4 & 3.6 \\
& Score 2-3 (\%) & 34.3 & 34.1 & 26.8 & 32.1 & 32.1 \\
& Score 4-5 (\%) & 20.0 & 27.3 & 42.9 & 30.2 & 32.1 \\
& Score 6-7 (\%) & 11.4 & 13.6 & 12.5 & 20.8 & 21.4 \\
& Score 8-9 (\%) & 5.7 & 4.5 & 3.6 & 3.8 & 7.1 \\
& Score 10-11 (\%) & 5.7 & 0.0 & 5.4 & 3.8 & 3.6 \\
\hline
\end{tabular}

Note. RCF-OSS levels 6 and 7 were left out, since none of the children performed at these levels.

\subsection{RELATIONSHOP BETWEEN ROCF (ORGANIZATIONAL) PERFORMANCE AND AGE}

For a more detailed study of differences in ROCF (organizational) performance across age groups, a GLM Multivariate analysis was performed. This analysis revealed significant age group differences in RCF-OSS $(F[4,211]=15.79, p<.001, d=.23)$, Global $(F[4,211]=11.50, p<.001, d=.18)$, Elements $(F[4,211]=16.29, p<.001, d=$ $.24)$, Lines $(F[4,211]=11.64, p<.01, d=.18)$, and Total $(F[4,211]=17.40, p<.001, d$ $=.25)$. The age group differences for the RIDS, however, were not significant. When zooming in on RCF-OSS performance, post-hoc Bonferroni analyses revealed that age group differences were primarily explained by a performance shift between the age of 5.5-6.0 and 6.0-6.5 years. For one, while the groups aged 5.0-5.5 and 5.5-6.0 years did not differ significantly from each other, these age groups both differed significantly from the older age groups (i.e., 6.0-6.5, 6.5-7.0, and 7.0-7.5; all p-values <.01). Similarly, these older age groups did not differ significantly from each other. Yet, they all differed significantly from the younger age groups (i.e., 5.0-5.5 and 5.5-6.0 yrs; all pvalues <.01). A similar pattern was found for all accuracy measures. 


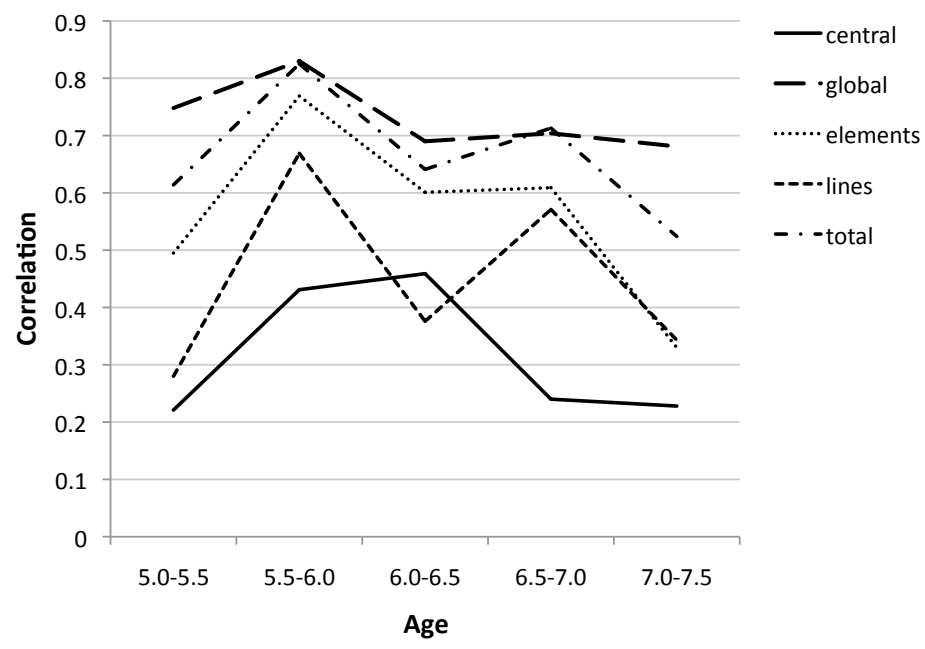

FIGURE 3. Correlations between RCF-OSS scores and other ROCF measures

Note. RIDS = measure of initial drawing sequence. Global = measure of accuracy of global units. Elements = measure of accuracy of elements units. Lines $=$ measure of accuracy of lines units. Total = total accuracy.

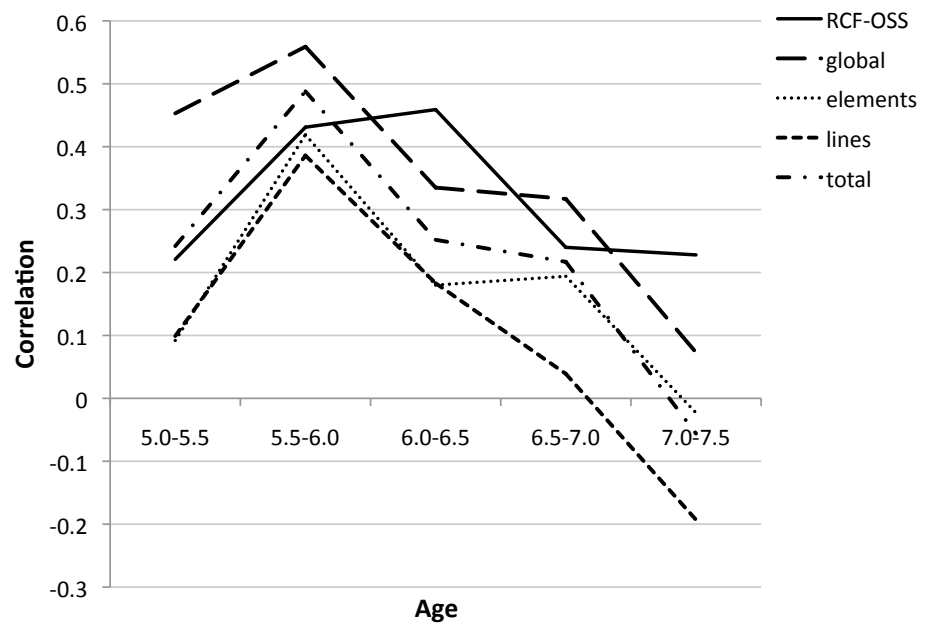

FIGURE 4. Correlations between RIDS scores and other ROCF measures

Note. RCF-OSS= measure of organization. Global = measure of accuracy of global units. Elements = measure of accuracy of elements units. Lines $=$ measure of accuracy of lines units. Total $=$ total accuracy. 


\section{CHAPTER 5}

TABLE 4. Mean test scores per level of the RCF-OSS

\begin{tabular}{llllcccc}
\hline \hline $\begin{array}{l}\text { Levels } \\
\text { of } \\
\text { RCF-OSS }\end{array}$ & $\begin{array}{c}\text { Design } \\
\text { Fluency }\end{array}$ & VMI & ENT & $\begin{array}{c}\text { Visual } \\
\text { Attention }\end{array}$ & $\begin{array}{c}\text { Digit } \\
\text { Span } \\
\text { Backward }\end{array}$ & $\begin{array}{c}\text { Spatial } \\
\text { Memory }\end{array}$ & $\begin{array}{c}\text { Block } \\
\text { Counting }\end{array}$ \\
\hline \hline $\begin{array}{l}\text { Level 1 } \\
(n=6)\end{array}$ & 12.67 & 7.33 & 20.33 & 3.67 & 2.50 & 7.00 & 8.17 \\
\hline $\begin{array}{l}\text { Level 2 } \\
(n=75)\end{array}$ & 13.92 & 10.00 & 25.89 & 8.53 & 4.23 & 9.41 & 8.40 \\
\hline $\begin{array}{l}\text { Level 3 } \\
(n=47)\end{array}$ & 18.24 & 11.72 & 31.24 & 13.26 & 4.72 & 10.50 & 13.80 \\
\hline $\begin{array}{l}\text { Level 4 } \\
(n=68)\end{array}$ & 16.91 & 11.85 & 30.62 & 12.65 & 4.77 & 10.44 & 10.20 \\
\hline $\begin{array}{l}\text { Level 5 } \\
(n=20)\end{array}$ & 18.88 & 12.71 & 34.00 & 13.65 & 5.53 & 11.53 & 39.27 \\
\hline
\end{tabular}

Note. RCF-OSS levels 6 and 7 were left out, since none of the children performed at these levels.

TABLE 5. Mean ENT score per level of the RIDS

\begin{tabular}{lc}
\hline \hline RIDS scores & ENT mean score \\
\hline \hline $\begin{array}{l}\text { Score 0-1 } \\
(n=26)\end{array}$ & 24.21 \\
\hline $\begin{array}{l}\text { Score } 2-3 \\
(n=72)\end{array}$ & 29.90 \\
\hline $\begin{array}{l}\text { Score } 4-5 \\
(n=72)\end{array}$ & 30.82 \\
\hline $\begin{array}{l}\text { Score 6-7 } \\
(n=34)\end{array}$ & 29.12 \\
\hline $\begin{array}{l}\text { Score } 8-9 \\
(n=10)\end{array}$ & 27.50 \\
\hline $\begin{array}{l}\text { Score } 10-11 \\
(n=8)\end{array}$ & 26.75 \\
\hline
\end{tabular}

\subsection{RELATIONSHIP BETWEEN ROCF ORGANIZATIONAL PERFORMANCE AND COGNITIVE} PERFORMANCE

How organizational performance was related to cognitive performance was studied using GLM Multivariate analyses, controlling for age. Significant effects of RCF-OSS levels were found in performance on various cognitive measures: Design Fluency (F [4, $207]=3.11, \mathrm{p}<.05, \mathrm{~d}=.06), \operatorname{VMI}(\mathrm{F}[4,207]=6.19, \mathrm{p}<.001, \mathrm{~d}=.10)$, ENT $(\mathrm{F}[4,207]=$ 7.92, $\mathrm{p}<.001, \mathrm{~d}=.13)$, Visual Attention $(F[4,207]=5.62, \mathrm{p}<.001, d=.10)$, Block Counting $(F[4,207]=3.96, p<.01, d=.07)$, Coding $(F[4,207]=6.36, p<.001, d=.11)$, Spatial Memory $(F[4,207]=5.19, p=.001, d=.09)$, and Digit Span Backward (F [4, 207] $=2.46, p<.05, d=.05)$. Post-hoc Bonferroni analyses revealed that differences in VMI performance between RCF-OSS levels could be explained by differences between children from levels 1 and 2 compared to levels 3, 4 and 5. For one, while level 1 and 2 did not differ significantly from each other, these levels both differed significantly from 
the organizational levels 3,4 , and 5 (respectively: p-values <.01 and p-values <.05). Levels 3, 4 and 5 did not differ significantly from each other. Yet, they all differed significantly from levels 1 (all p-values <.01) and 2 (all p-values <.05). Thus, the mean raw VMI scores were significantly lower for levels 1 and 2 compared to levels 3 to 5 . A similar pattern was found for the ENT and the Visual Attention Test. For the other cognitive measures differences between levels in terms of cognitive performance were also found, although the pattern was less unequivocal. Table 4 illustrates these findings, by showing the mean raw test scores of the cognitive measures per level of RCF-OSS.

The GLM Multivariate analyses with RIDS as independent variable only revealed significant effects of the levels of the RIDS on ENT performance $(F[5,206]=$ $5.26, \mathrm{p}<.001)$. As post-hoc Bonferroni analyses revealed, these differences were caused primarily by significant differences between children scoring level 0-1 compared to level 2-3 $(p=.001)$ and level 4-5 $(p<.001)$. Table 5 illustrates these findings, by showing the mean raw test scores on the ENT per level of the RIDS.

\section{DISCUSSION}

Learning can be facilitated by the ability to organize information in a meaningful manner (e.g., Cornford, 2002; Garner, 2009). Consequently, assessment of children's organizational strategies may provide useful information for the identification of children that are at risk for the development of learning difficulties (Frisk et al., 2005). Although ROCF copying performance can provide important insights into organizational strategies, studies exploring ROCF performance at preschool and early primary school age are scarce, particularly in terms of organizational strategies. Even less is known about the relationship between ROCF performance and cognitive functioning at this age (e.g., Akshoomoff \& Stiles, 1995; Ogino et al., 2009; Waber \& Holmes, 1985; Watanabe et al., 2005). The present study added to the current knowledge of organizational strategy use of preschool-aged children, since it investigated ROCF copying performance (i.e., in terms of accuracy and organization) of children aged 5 to 7 years in relation to a range of cognitive functions. 


\subsection{ACCURACY AND ORGANIZATION OF ROCF PERFORMANCE}

Our findings suggest that the ROCF performance measures of "accuracy" and "organization" are related in children aged 5 to 7 . More specifically, the results revealed significant correlations between measures of organization (i.e., RCF-OSS and RIDS) and all accuracy measures (i.e., Global, Element, Lines, and Total). Correlations between both organizational measures and the accuracy measure Global were strongest (namely, RCF-OSS: $r=.78$ and RIDS: $r=.40$ ). This could be expected, since the ROCF units that constitute the accuracy measure Global play an important role in the classifications of RIDS (i.e., especially the large rectangle and the triangle to the right of the rectangle) and RCF-OSS (i.e., especially the horizontal and vertical centerlines). Our findings of correlations between organizational measures (especially the RCF-OSS) and accuracy measures are somewhat stronger than those reported by Anderson et al. (2001). Yet, they are in line with the significance of the correlations between RCF-OSS and accuracy of ROCF copies, as reported by Anderson et al. (2001) for children aged 7 to 13 . Our findings provide new insights by demonstrating that young children's accuracy scores of more global units of the ROCF are more strongly related to organizational performance (i.e., RCF-OSS and RIDS) than more local units. Hereby our findings demonstrate that even in young children our measures of organization indeed (partly) capture the core features of the ROCF (although in different manners). This implies that the ROCF is a suitable instrument for assessing higher order cognitive functions in preschool aged children.

\subsection{DEVELOPMENT OF ORGANIZATIONAL STRATEGIES BETWEEN 5 AND 7 YEARS}

Our findings indicate that a developmental shift (or growth spurt) in accuracy and organization of copying performance takes place between 5.5 and 6.5 years of age. This is in line with previous studies by e.g., Vinter (1994) and Vinter and Marot (2007) who describe that 6-year-old children are more inclined to adopt a global approach to copying figures - i.e., drawings other than the ROCF - than 5-year-old children, who prefer to construct their drawings on a more local level. The present study adds to these previous findings by taking a closer look at this transitional period through the construction of narrower age groups (per 6 months instead of per 12 months). Thereby we demonstrated that the shift in copying performance seems to occur during an even 
more narrow age interval than previously described - i.e., somewhere between the second half of children's fifth year and the first half of their sixth year. This age period marks children's transition from preschool to primary school, a time that is characterized by an increase in formal instruction at school. In terms of organizational development of 7-year-old children, there are also some differences between the present study and Anderson et al. (2001). In our study the majority of the 7-year-olds already performed at a level of fragmented organization, while in the study by Anderson et al. the majority still performed at a poor organizational level. Whether this is an issue of measurement, sample selection, or cultural differences cannot be determined on the basis of the available information and requires further investigation. Our findings do, however, provide an interesting description of children's transition through organizational levels between the ages of 5 to 7, by showing a clear pattern of organizational development in ROCF copying performance during this period. Lezak et al. (2004) have indicated that the ROCF can only be administered to children from age 6 onward. However, our findings have shown that ROCF administration can already be meaningful at an earlier age, at least in terms of copying performance.

\subsection{ROCF ORGANIZATIONAL PERFORMANCE IN RELATION TO COGNITIVE PERFORMANCE}

To the best of our knowledge, the present study is the first to provide information about the relation between organizational performance (i.e., RCF-OSS and RIDS) and cognitive functioning in a healthy sample of children aged 5 to 7 . Our findings revealed that the ROCF is not exclusively a measure of executive functioning, but is also related to non-executive functioning. More specifically, RCF-OSS scores were linearly related to a range of executive and non-executive cognitive functions - i.e., numeracy, fluency, visual attention, visual-motor integration, spatial memory, working memory, processing speed, and spatial reasoning. This is in line with findings by Anderson et al. (2001). In general, children at lower RCF-OSS levels were characterized by lower cognitive test performance than children at higher RCF-OSS levels. By contrast, the RIDS was only associated with differences in numeracy performance in a non-linear manner. More specifically, children with the most common RIDS scores (i.e., 2-3 and 4- 
5) had the highest numeracy scores. Children with an extremely low or high level of organizational strategy use - as measured with the RIDS - had lower numeracy scores. This seems to suggest that adopting an extremely local or global organizational approach in the initial drawing sequence can have a potentially adverse effect in terms of numeracy development at age 5 to 7 years.

Hereby, our findings suggest that the RIDS can provide complementary information in neuropsychological assessment, given its specific, non-linear relationship with numeracy that differs from the linear relation between RCF-OSS and cognitive functioning. Yet, further research is required to determine the possible value of the RIDS as a measure of organizational abilities. As the findings of the present study seem to indicate, the spread in performance between 5 to 7 years of age is still limited for this measure. We believe that the RIDS may even be more suitable as a measure of organizational abilities to discern differences across a wider age range or in older age groups, since the highest level of organization was only reached by a small percentage of children at 5 to 7 year of age. Further research is required to verify this. Still, the present study's pattern of association was comparable for both measures of organization: children who displayed lower levels of organization also performed at a lower cognitive performance level.

With respect to the relationship between cognitive performance and organization as measured by the RCF-OSS, our findings are in line with Anderson et al. (2001). Although Anderson et al. (2001) only found moderate correlations between RCF-OSS performance and measures of executive functioning and memory (in children aged 7-13 years), the pattern across organizational levels was similar to the pattern reported in the present study. Children who performed on higher organizational levels obtained higher scores on the executive function tasks than children who adopted lower-level strategies. Previous studies that explored similar relationships in schoolaged children and adults with neuropsychological difficulties have reported more varied findings. For instance, Watanabe et al. (2005) and Ogino et al. (2009) found no relationship between organizational performance as measured by the BQSS, and multiple aspects of cognitive functioning in their original sample of 5- to 14-year-old children with neurological problems. In a larger, comparable sample the authors did find a relationship between organizational abilities and planning ability as well as cognitive flexibility. Conversely, Weber et al. (2012) reported correlations between 
ROCF copy performance and tasks measuring general cognitive ability, visual-motor integration, and visual-spatial abilities in a clinically mixed sample of children aged 7 to 16 years. The authors did not find any relationship between ROCF performance and tasks measuring verbal fluency, planning or cognitive flexibility. Comparing the findings of these previous studies and the present study remains difficult, primarily because the samples differ largely in age range and neurological functioning. In addition, different measures were used to quantify cognitive performance (including ROCF measures).

In sum, the present study showed that children aged 5 to 7 years undergo important changes in organization and accuracy of their copying performance as measured on the ROCF. In addition, our study was the first to map the relationship between a range of cognitive functions and organizational strategy use - as measured by RCF -OSS and RIDS - at age 5 to 7 years. Our findings revealed that, even at a young age, ROCF measures of organization are sensitive enough to detect individual differences in children's cognitive abilities and could therefore be of potential use for screening and diagnosis in a clinical environment. 


\section{REFERENCES}

Akshoomoff, N. A., \& Stiles, J. (1995). Developmental trends in visuospatial analysis and planning: I. Copying a complex figure. Neuropsychology, 9(3), 364-377.

Anderson, P., Anderson, V., \& Garth, J. (2001). Assessment and development of organizational ability: The Rey Complex Figure Organizational Strategy Score (RCF-OSS). The Clinical Neuropsychologist, 15(1), 81-94.

Anderson, V., Jacobs, R., \& Anderson, P. J. (2008). Executive functions and the frontal lobes: A lifespan perspective. Philadelphia, PA US: Taylor \& Francis.

Aunio, P., Hautamäki, J., Heiskari, P., \& Van Luit, J. H. (2006). The Early Numeracy Test in Finnish: Children's norms. Scandinavian Journal of Psychology, 47(5), 369-378.

Beery, K. E. (1997). The Beery-Buktenica developmental test of visual-motor integration (4th ed., Revised). Parsippany, NJ: Modern Curriculum Press.

Bernstein, J. H., \& Waber, D. P. (1996). Developmental scoring system for the Rey-Osterrieth Complex Figure: Professional manual. Odessa, FL: Psychological Assessment Resources.

Cornford, I. R. (2002). Learning-to-learn strategies as a basis for effective lifelong learning. International Journal of Lifelong Education, 21(4), 357-368.

Croy, C. D., \& Novins, D. K. (2005). Methods for addressing missing data in psychiatric and developmental research. Journal of the American Academy of Child and Adolescent Psychiatry, 44(12), 12301240.

Davies, S. R., Field, A. J., Andersen, T., \& Pestell, C. (2011). The ecological validity of the Rey-Osterrieth complex figure: Predicting everyday problems in children with neuropsychological disorders. Journal of Clinical and Experimental Neuropsychology, 33(7), 820-831.

Deckersbach, T., Savage, C. R., Henin, A., Mataix-Cols, D., Otto, M. W., Wilhelm, S., et al. (2000). Reliability and validity of a scoring system for measuring organizational approach in the Complex Figure Test. Journal of Clinical and Experimental Neuropsychology, 22(5), 640-648.

Diamond, A., Barnett, W., Thomas, J., \& Munro, S. (2007). Preschool program improves cognitive control. Science, 318(5855), 1387-1388.

Frisk, V., Jakobson, L. S., Knight, R. M., \& Robertson, B. (2005). Copy and recall performance of 6-8-year-old children after standard vs. step-by-step administration of the Rey-Osterrieth Complex Figure. Child Neuropsychology, 11(2), 135-152.

Garner, J. (2009). Conceptualizing the relations between executive functions and self-regulated learning. Journal of Psychology: Interdisciplinary and Applied, 143(4), 405-426. 
Hendriksen, J. G. \& Hurks, P. M. (2009). WPPSI-III-NL Nederlandstalige bewerking: Technische handleiding. [WPPSI-III-NL Dutch adaptation: Technical manual]. Amsterdam: Pearson Assessment and Information BV.

Huizingh, E. (2002). Inleiding SPSS 11 voor Windows [Introduction to SPSS 11 for Windows]. Schoonhoven: Academic Service.

Kaufman, A. S., \& Kaufman, N. L. (1983). Kaufman Assessment Battery for Children. Circle Pines, MN: American Guidance Services.

Kaufman, A. S., Lichtenberger, E. O., Fletcher-Janzen, E., \& Kaufman, N. L. (2005). Essentials of KABC-II assessment. Hoboken, New Jersey: John Wiley \& Sons.

Korkman, M., Kirk, U., \& Kemp, S. (1998). NEPSY: A developmental neuropsychological assessment-manual. San Antonio, Texas: Psychological Corporation.

Lezak, M. D., Howieson, D. B., Loring, D. W., Hannay, H., \& Fischer, J. S. (2004). Neuropsychological assessment (4th ed.). New York, NY US: Oxford University Press.

McConley, R., Martin, R., Palmer, C., Kuzniecky, R., Knowlton, R., \& Faught, E. (2008). Rey Osterrieth complex figure test spatial and figural scoring: Relations to seizure focus and hippocampal pathology in patients with temporal lobe epilepsy. Epilepsy \& Behavior, 13(1), 174-177.

Melhuish, E. C., Phan, M. B., Sylva, K., Sammons, P., Siraj-Blatchford, I., \& Taggart, B. (2008). Effects of the home learning environment and preschool center experience upon literacy and numeracy development in early primary school. Journal of Social Issues, 64(1), 95-114.

Minary, F. \& Vinter, A. (1996). The drawing of complex geometrical figures by children: How graphic strategies may be related to chronological age. In M. L. Simner, C. G. Leedham, A. J. W. Thomassen (Eds.), Handwriting and drawing research: basic and applied issues. Amsterdam: IOS Press.

Mitrushina, M. N., Boone, K., \& D'Elia, L. F. (1999). Handbook of normative data for neuropsychological assessment. New York, NY US: Oxford University Press.

Nakano, K., Ogino, T., Watanabe, K., Hattori, J., Ito, M., Oka, M., et al. (2006). A developmental study of scores of the Boston Qualitative Scoring System. Brain \& Development, 28(10), 641-648.

Ogino, T., Watanabe, K., Nakano, K., Kado, Y., Morooka, T., Takeuchi, A., et al. (2009). Predicting executive function task scores with the Rey-Osterrieth Complex Figure. Brain \& Development, 31(1), 52-57.

Osterrieth, P. A. (1944). Le test de copie d'une figure complexe: Contribution à l'étude de la perception et de la mémoire [Copying a complex figure: Contributions to the study of perception and memory]. Archives de Psychologie, 30, 206-356.

Pintrich, P. R., \& de Groot, E. V. (1990). Motivational and self-regulated learning components of classroom academic performance. Journal of Educational Psychology, 82(1), 33-40.

Raven, J. C. (1958). Guide to using the Coloured Progressive Matrices. Oxford England: H. K. Lewis \& Co. 


\section{CHAPTER 5}

Rey, A. (1941). L'examen psychologique dans les cas d'encéphalopathie traumatique [The psychological examination of cases of traumatic encephalopathy]. Archives De Psychologie, 28, 215-285.

Romine, C. B., \& Reynolds, C. R. (2005). A model of the development of frontal lobe functioning: Findings from a meta-analysis. Applied Neuropsychology, 12(4), 190-201.

Savage, C. R., Baer, L., Keuthen, N. J., Brown, H. D., Rauch, S. L., \& Jenike, M. A. (1999). Organizational strategies mediate nonverbal memory impairment in obsessive-compulsive disorder. Biological Psychiatry, 45(7), 905-916.

Smith, S. R., \& Zahka, N. E. (2006). Relationship between accuracy and organizational approach on the ReyOsterrieth Complex Figure and the Differential Ability Scales: A pilot investigation. Child Neuropsychology, 12(6), 383-390.

Somerville, J., Tremont, G., \& Stern, R. A. (2000). The Boston Qualitative Scoring System as a measure of executive functioning in Rey-Osterrieth Complex Figure performance. Journal of Clinical and Experimental Neuropsychology, 22(5), 613-621.

Stern, R. A., Singer, E. A., Duke, L. M., \& Singer, N. G. (1994). The Boston Qualitative Scoring System for the Rey-Osterrieth Complex Figure: Description and interrater reliability. Clinical Neuropsychologist, 8(3), 309-322.

Taylor, E.M. (1959). Psychological appraisal of children with cerebral defects. Cambridge, MA: Harvard University Press.

Troyer, A. K., \& Wishart, H. A. (1997). A comparison of qualitative scoring systems for the Rey-Osterrieth Complex Figure Test. Clinical Neuropsychologist, 11(4), 381-390.

Van Bon, W. H. J. (1986). Raven's Coloured Progressive Matrices: Nederlandse normen en enige andere uitkomsten van onderzoek (CPM) [Dutch norms and further results from research (CPM)]. Lisse, the Netherlands: Zwets \& Zeitlinger.

Van de Rijt, B. M., Van Luit, J.H., \& Pennings, A. H. (1999). The construction of the Utrecht Early Mathematical Competence Scales. Educational and Psychological Measurement, 59(2), 289-309.

Van Luit, J. H., Van de Rijt, B. M. \& Pennings, A. H. (1994). Utrechtse getalbegrip toets [The Utrecht Numeracy Test]. Doetinchem: Graviant.

Vinter, A. (1994). Hierarchy among graphic production rules: A developmental approach. In C. Faure, P. Keuss, G. Lorette, \& A. Vinter (Eds.), Advances in handwriting and drawing: A multidisciplinary approach (pp. 275-288). Paris: Europia.

Vinter, A., \& Marot, V. (2007). The development of context sensitivity in children's graphic copying strategies. Developmental Psychology, 43(1), 94-110.

Vinter, A., Picard, D., \& Fernandes, V. (2008). Graphic syntax and representational development. In C. LangeKüttner, A. Vintner (Eds.), Drawing and the non-verbal mind: A life-span perspective (pp. 139158). New York, NY US: Cambridge University Press. 
Waber, D. P., \& Holmes, J. M. (1985). Assessing children's copy productions of the Rey-Osterrieth Complex Figure. Journal of Clinical and Experimental Neuropsychology, 7(3), 264-280.

Weber, R. C., Riccio, C. A., Cohen, M. J. (2012). Does Rey Complex Figure copy performance measure executive function in children? Applied Neurpsychology: Child, 1, 1-7.

Watanabe, K., Ogino, T., Nakano, K., Hattori, J., Kado, Y., Sanada, S., \& Ohtsuka, Y. (2005). The Rey-Osterrieth Complex Figure as a measure of executive function in childhood. Brain \& Development, 27(8), 564-569.

Wechsler, D. (2003). WISC-IV: Technical and interpretive manual. San Antonio, TX: The Psychological Corporation.

Weinstein, C. E., \& Mayer, R. E. (1986). The teaching of learning strategies. In M. C. Wittrock (Ed.), Handbook of research on teaching (pp. 315-327). New York: Macmillan. 


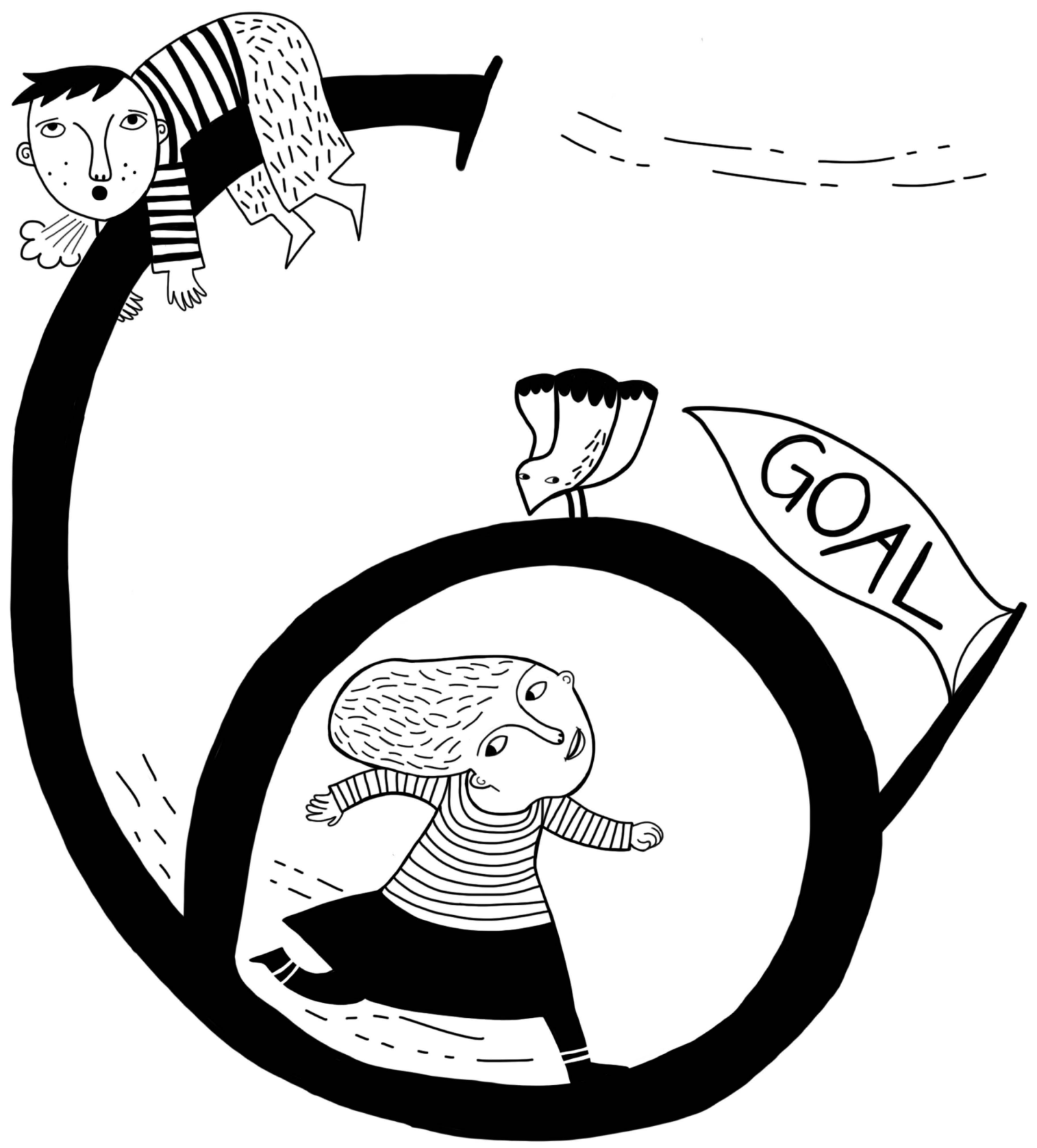



\section{Chapter 6}

\section{Training goal setting in children aged 4-6: Transfer effects through an age by training content interaction}

Martens, R., Hurks, P. M., Schrans, D. \& Jolles, J. (2012). Training goal setting in children aged 4-6: Transfer effects through an age by training content interaction. Submitted. 


\begin{abstract}
The present study examined effectiveness of training strategic organization and conceptual reasoning in healthy children aged 4-6 years. This was based on developmental neuroscience research regarding the role of the fronto-parietal network in the early development of cognitive control. Children ( $n=102)$ were appointed to one of four conditions: conceptual reasoning training, strategic organization training, creative training (active control), or no training (passive control). Each training condition included group meetings (60 $\mathrm{min} / \mathrm{wk}$ ) and paper-and-pencil homework exercises (30-40 $\mathrm{min} / \mathrm{wk}$ ) during a 6-week-period. Pre- and posttests measured a range of EFs, including conceptual reasoning, working memory, fluency and attention. Conclusions were twofold: firstly, conceptual reasoning and strategic organization training resulted in transfer effects to other EFs - verbal fluency and complex working memory. Secondly, improvement depended on an age $x$ training content interaction. Younger preschoolers primarily benefited from conceptual reasoning training, resulting in improved verbal fluency. For older preschoolers strategic organization training led to significant working memory improvement. These findings have potential implications for the development of educational training programs.
\end{abstract}




\section{INTRODUCTION}

Executive functions (EFs) are believed to be critical for the acquisition of mathematical and reading competence at preschool age (e.g., Blair \& Razza, 2007; Cartwright, 2012; Espy, McDiarmid, Cwik, Stalets, Hamby, \& Senn, 2004). The same holds for later scholastic achievement and general success in life (e.g., Bull, Espy, \& Wiebe, 2008; St Clair-Thompson \& Gathercole, 2006). Recent studies have shown that EFs can be trained successfully in both healthy children and children with neurodevelopmental disorders such as ADHD (e.g., Jonkman \& Hurks, 2009; Kerns, Eso, \& Thomson, 1999; Klingberg, 2010; Klingberg, Forssberg, \& Westerberg, 2002). According to Klingberg (2010), these findings are only the beginning of a new research field that explores possibilities to enhance cognitive functions by training, especially in young children. The effectiveness of such training programs has seldom been evaluated for a wider range of EFs at preschool age. If such EFs training programs are implemented successfully at preschool age, they may have a highly significant impact on daily functioning of children with EF problems or deficits, including more generalized consequences for a broad range of cognitive and scholastic domains (Thorell, Lindqvist, Bergman Nutley, Bohlin, \& Klingberg, 2009). In addition, it may lead to long-term benefits in terms of academic success and optimal daily functioning, for reasons mentioned above. Therefore, the central question of the present study was whether (specific) EFs can be trained successfully in children aged 4 to 6 years.

\subsection{THE DEVELOPMENT OF EFS AT PRESCHOOL AGE}

The term EFs refers to a number of functions that are responsible for solving problems in an independent, goal-directed and purposeful manner (e.g., Anderson, 2002; Anderson, Jacobs, \& Anderson, 2008; Lezak, Howieson, \& Loring, 2004). Although many EFs are not fully established until mid-adolescence or early adulthood, research has indicated that the majority of EFs already undergo critical development at preschool and early primary school age (e.g., Anderson, 2002; Cartwright, 2012; Davidson, Amso, Anderson, \& Diamond, 2006). According to Romine and Reynolds (2005), the greatest development of a number of important EFs - i.e., inhibition, verbal fluency, design fluency, and planning - actually takes place between 5 to 8 years of age. This EFs improvement parallels the maturation of areas within the frontal lobe 


\section{CHAPTER 6}

and their connectivity with other brain regions. This is marked by advancing myelination as well as a peak in synapse overproduction at 4 to 5 years of age (Cartwright, 2012; Reynolds \& Horton, 2008).

An important characteristic of EFs development is differentiation. Within a developmental context, Anderson has proposed a model that discerns four interrelated EFs domains that follow different developmental trajectories - i.e., attentional control, information processing, cognitive flexibility, and goal setting (Anderson, 2002; Anderson et al., 2008). EFs in the domains of attentional control (i.e., inhibition) and information processing (i.e., processing speed) are established relatively early in childhood (Davidson et al., 2006). EFs in the domains of cognitive flexibility (i.e., working memory) and goal setting (i.e., planning) show a more protracted development (Anderson, 2002; Anderson et al., 2008). Given these differential developmental trajectories, it may well be that training effectiveness at a certain age differs as a function of the to-be-trained EFs domain. At preschool age, research into training effectiveness across EFs domains is limited. Not many studies have explored training effectiveness at preschool age and those studies that have focused on the preschool period have primarily concentrated on the domains of attentional control (i.e., inhibition) and information processing (i.e., working memory), as will be discussed next.

\subsection{TRAINING EFS AT PRESCHOOL AGE}

Only a limited number of scientific studies have developed EF training programs for preschool children. Diamond, Barnett, Thomas and Munro (2007) designed a training curriculum - the Tools of the Mind program - that was implemented by teachers in regular classrooms during a 1- to 2-year-period. These teachers provided children from low-income families with guidelines to execute and evaluate tasks guided by external aids, thereby promoting EFs skills. The results of this study were promising, indicating that it may be possible to improve diverse EFs (e.g., inhibition) at preschool age. Unfortunately, Diamond et al. did not assess pre-training EFs performance and only included children from low-income families. This limits the generalizability of the results. The authors also did not examine the effects of age - i.e., training effectiveness in early compared to late preschool years. Most importantly, Diamond et al. only 
described EFs improvement in global terms: the training protocol incorporated e.g., inhibition, cognitive flexibility, and memory components. As a consequence, it was impossible to establish which specific EF formed the basis of these highly promising results.

To the best of our knowledge, only five studies have focused on the possibility of stimulating specific EFs domains at preschool and early primary school age (Dowsett \& Livesy, 2000; Röthlisberger, Neuenschwander, Cimeli, Michel, \& Roebers, 2011; Rueda, Rothbart, McCandliss, Saccomanno, \& Posnet, 2005; St Clair-Thompson, Stevens, Hunt, \& Bolder, 2010; Thorell et al., 2009). These researchers have focused predominantly on the EFs domains of attentional control (e.g., inhibition) and cognitive flexibility (e.g., working memory) and far less on the domain of goal setting (Anderson, 2002; Anderson et al., 2008). Thorell et al. (2009), for instance, have studied the possibility of stimulating working memory and inhibition in preschoolers (4-5 yrs) through an intensive computerized training at school (i.e., $15 \mathrm{~min} /$ day for 5 days/week during 5 weeks). They appointed participating children $(n=65)$ to one of four conditions: a working memory training group, an inhibition training group, an active control group or a passive control group. The authors found that working memory training was effective in stimulating working memory skills (both trained and untrained) as well as attention skills. In contrast, the group that received inhibition training only improved on trained inhibition skills, relative to the other groups. The outcome of this study supports the notion that different EFs training programs result in different outcomes. Yet, this study also knows some restrictions. For one, some issues remain unresolved with respect to the ability to achieve transfer to related EFs. Furthermore, Thorell et al. did not analyze age differences within their group of preschoolers. This can be of major importance, given children's rapid neurological and cognitive development during the preschool period (Cartwright, 2012; Reynolds \& Horton, 2008; Romine \& Reynolds, 2005).

Some researchers have indicated that even during the preschool period the age of a child plays an important role both in the level of executive functioning and the ability to consciously assess the approach of a problem or task (e.g., Zelazo \& Frye, 1998), and in the effectiveness of EFs stimulation (i.e., Dowsett \& Livesy, 2000; Röthlisberger et al., 2011; Rueda et al., 2005). Rueda et al. (2005), for instance, found significant age effects while evaluating protocols for training the EFs domain of 


\section{CHAPTER 6}

attentional control. Although 4- and 6-year-olds showed improved attention performance after this type of training, the effect was largest for 4-year-olds. Röthlisberger et al. (2011) reported differences in training effectiveness between 5and 6-year-old children. After receiving a training that focused on attentional control (i.e., inhibition) and cognitive flexibility (including working memory), 5-year-olds showed increased performance on tasks measuring cognitive flexibility and working memory, but not inhibition. A reverse pattern was found for 6-year-olds (i.e., improvement in inhibition only). In line with these findings, Dowsett and Livesy (2000) have reported age-related training effects in inhibitory control for children aged 3 to 5 years. Three-year-olds with inhibitory control problems showed more improvement in inhibition abilities after training compared to 4- and 5-year-olds. Consequently, when studying the effect of training on improvement of EFs, it is important to take the age of the child into account, even when studying a relatively narrow age range. No studies, however, have examined the effect of age on training EFs in the goal setting domain in children between 4 and 6 years of age. In the present study, we focused on this line of research by studying the interaction between age and training effectiveness in aspects of this domain - i.e., strategic organization and conceptual reasoning.

\subsection{THE PRESENT STUDY: TRAINING GOAL SETTING}

Our study is the first to focus on the possibility of successfully training EFs within the goal setting domain in healthy children between 4 and 6 years of age. We focused on children from an average socioeconomic background and differ in that respect from Diamond et al. (2007), who studied children from low-income families. In the present study, two important functions within the goal setting domain were incorporated into two separate EFs training conditions: conceptual reasoning and strategic organization (Anderson, 2002; Anderson et al., 2008). These functions represent, respectively, the preparatory and directive stages of problem solving. Conceptual reasoning encompasses the ability to develop new initiatives and concepts, to understand a situation or problem by identifying patterns or connections, and to address key underlying issues. In the present study, the term conceptual reasoning was used to refer to verbal conceptual reasoning (as opposed to nonverbal conceptual reasoning). Strategic organization includes the capacity to plan actions in advance and approach 
tasks in an efficient and strategic manner. These and other functions in the goal setting domain are highly relevant for daily life. Impairments in this domain will result in poor problem solving abilities, inadequate planning, disorganization, difficulties in developing efficient strategies, and poor conceptual reasoning (Anderson, 2002; Anderson et al., 2008). EFs in the goal setting domain have one of the longest developmental trajectories and fulfill an important role. They are interconnected with and fulfill a coordinating role for other EFs domains. Therefore, it was hypothesized that a large gain in young children's EFs could be realized if their goal setting abilities are successfully stimulated. Consequently, if EFs improvement can be accomplished through our goal-setting-oriented training conditions, it is expected to be more general and to transfer to multiple EF domains. As Klingberg (2010) states, training programs that stimulate higher order functions - i.e., complex working memory - can induce transfer to other related functions through stimulation of a common underlying fronto-parietal network. Therefore, in the present study a broad selection of measures, representing multiple EFs domains, was administered to measure training effects. These measures partly overlap with previous studies, but were seldom studied in terms of transfer effects. It was hypothesized that training strategic organization and conceptual reasoning would lead to improvement in executive functioning and that potential improvements in EFs would differ between these two types of training. Training (verbal) conceptual reasoning skills would primarily lead to improvement in e.g., verbal knowledge, concept formation or conceptual thinking, and verbal reasoning (in line with Lezak, 2004). Conversely, training strategic organization was thought to lead primarily to improvement in e.g., the efficiency of information organization and strategy utilization and the repertoire of strategies that can be accessed. Furthermore, the age of the child was expected to play a role in training effectiveness, in line with previous studies. Younger preschool children were expected to be more receptive to aspects of EFs training than older preschool children.

\section{METHODS}

\subsection{PROCEDURE AND PARTICIPANTS}

In total, 102 healthy children aged 4 to 6 years (i.e., 45 girls; age range $=4.05$ to 6.70 ; mean age $=5.32[S D=0.57])$ participated in the present study. Participants were 


\section{CHAPTER 6}

recruited from six schools in the Netherlands. All parents of children frequenting preschool (first and second year) received an information package distributed via the schools. Parents were asked to give written consent for their child's participation and to fill in a questionnaire that inquired after e.g., the Level of Parental Education (LPE), ranging from (1) primary school to (8) university degree (De Bie, 1987). This system is similar to the International Standard Classification of Education (United Nations Educational Scientific and Cultural Organisation (UNESCO), 1997). In the present study, LPE was defined as the level of education averaged across both parents (see Table 1).

TABLE 1. Characteristics of the participants per condition ( $n=102)$

\begin{tabular}{|c|c|c|c|c|c|c|c|c|c|}
\hline & \multicolumn{2}{|c|}{$\begin{array}{l}\text { Condition A } \\
\qquad(\mathrm{N}=28)\end{array}$} & \multicolumn{2}{|c|}{$\begin{array}{l}\text { Condition B } \\
\qquad(\mathrm{N}=27)\end{array}$} & \multicolumn{2}{|c|}{$\begin{array}{l}\text { Condition C } \\
\quad(N=24)\end{array}$} & \multicolumn{2}{|c|}{$\begin{array}{c}\text { Condition D } \\
(N=23)\end{array}$} & \multirow[t]{2}{*}{$\begin{array}{c}\text { Statistic } \\
F / \chi^{2}\end{array}$} \\
\hline & $\mathrm{N}$ & $\%$ & $\mathrm{~N}$ & $\%$ & $\mathrm{~N}$ & $\%$ & $\mathrm{~N}$ & $\%$ & \\
\hline \multicolumn{10}{|l|}{ Sex } \\
\hline Boys & 14 & 50 & 15 & 56 & 14 & 58 & 14 & 61 & $0.69^{a}$ \\
\hline \multirow[t]{2}{*}{ Girls } & 14 & 50 & 12 & 44 & 10 & 42 & 9 & 39 & \\
\hline & \multicolumn{2}{|c|}{$\mathrm{M}(\mathrm{SD})$} & \multicolumn{2}{|c|}{$\mathrm{M}(\mathrm{SD})$} & \multicolumn{2}{|c|}{$M(S D)$} & \multicolumn{2}{|c|}{$M(S D)$} & \\
\hline Kaufseq & \multicolumn{2}{|c|}{$\begin{array}{l}100.96 \\
(12.47)\end{array}$} & \multicolumn{2}{|c|}{$\begin{array}{l}103.00 \\
(10.43)\end{array}$} & \multicolumn{2}{|c|}{$101.67(9.40)$} & \multicolumn{2}{|c|}{$98.74(9.03)$} & $0.70^{b}$ \\
\hline LPE & \multicolumn{2}{|c|}{$5.84(0.20)$} & \multicolumn{2}{|c|}{$5.74(0.24)$} & \multicolumn{2}{|c|}{$5.98(0.25)$} & \multicolumn{2}{|c|}{$5.14(0.34)$} & $33.55^{c}$ \\
\hline $\begin{array}{l}\text { Age at } \\
\text { measurement }\end{array}$ & \multicolumn{2}{|c|}{$5.28(0.65)$} & \multicolumn{2}{|c|}{$5.22(0.55)$} & \multicolumn{2}{|c|}{$5.33(0.52)$} & \multicolumn{2}{|c|}{$5.49(0.52)$} & $1.00^{b}$ \\
\hline
\end{tabular}

Note. Condition A = conceptual reasoning training; Condition $\mathrm{B}=$ strategic organization training; Condition $\mathrm{C}$ = creative training; Condition $D=$ no training; Kaufseq = estimate of general abilities based on the subtests Word Order and Number Recall of the KABC-II (Kaufman et al., 2005); LPE = mean level of parental education (range: primary school [1] to university degree [8] (De Bie, 1987; Kalff et al., 2001).

${ }^{\mathrm{a}}$ Pearson Chi-square test $(\mathrm{df}=3)$.

${ }^{b}$ One-way analysis of variance (df1=3, df2=98).

${ }^{\mathrm{c}}$ Pearson Chi-square test $(\mathrm{df}=33)$.

After parental consent was obtained, all children were screened for (precursors of) neurodevelopmental disorders (e.g., ADHD and learning disorders), visual and hearing impairments, and the use of medication that might affect cognitive abilities -including EFs performance. None of the children were excluded based on these criteria. Subsequently, each participating child was randomly assigned to one of four conditions: i.e., strategic organization training, conceptual reasoning training, creative training (active control group), or no training (passive control group). An active control group was added to the study, since it minimizes the problem of 
noncompliance and enables researchers to draw unbiased inferences about the effect of EFs training compared to non-EFs training. Moreover, all three training conditions were compared to a group of children that did not receive any form of training (passive control group), which enables researchers to verify that improvement is caused by the training effects and not by general developmental processes.

Since all pre- and posttests and training sessions took place at the schools, children frequenting a particular school always attended a training group with other children from the same school. We endeavored to include a relatively equal number of boys and girls in each condition. The same holds for the distribution of children attending the first and second year of preschool. In Table 1, the descriptive statistics of all children are given per condition. All children completed a neuropsychological test battery twice, during pre- and posttest sessions, that focused on various EFs (see paragraph 'pre- and posttests'). Post-test sessions took place within 2 weeks after the last training session. Well-trained research assistants tested all children. Testing took place in a stimulus-free room at the participating schools and took approximately 45 minutes. All tests were administered in the same order for each child. The Ethics Committee of the Faculty of Psychology of Maastricht University approved the research protocol.

\subsection{TRAINING CONDITIONS}

All children that participated in one of the three training conditions (i.e., strategic organization training, conceptual reasoning training, or creative training) received six weekly training sessions (1 hr each). During each session, a trained psychologist discussed specific topics, following a standardized protocol. Training groups consisted of three to five children (group size was kept equal across training conditions). Group motivation and performance were encouraged through a reward system. As a group, the children could earn stickers if they performed assignments successfully. Between training sessions, the children further practiced the newly acquired and to-be learned skills by completing (paper-and-pencil) homework assignments (30-40 min/week) that corresponded to the themes of the training sessions. For example, as homework for the conceptual reasoning training, children were instructed to find a small and a large object and bring those to the next session. During this session, the concept 'object 
size' and the terms used to describe different sizes, such as larger versus smaller, were illustrated by using these objects. Homework for a strategic organization training session consisted, for instance, of a card with six identical pictures of cats that children had to color to give each cat unique features. During the next session, this card was used to teach the children that paying attention to features of to-be-remembered objects can enhance working memory performance. To ensure that all children did their homework, each assignment was accompanied by a letter informing parents about the content and date of completion of the assignment. To further stimulate children's motivation to complete their homework, all assignments were discussed plenary during the next training session and upon completion the children could earn stickers. When they had earned enough stickers (always after completing the posttest battery), the children received a gift. All children who participated as part of the passive control group also received a gift after completing the posttest battery.

Meichenbaum's 'general self-instructional approach' and Asarnow and Meichenbaum's adapted version of this approach served as a guideline for all conditions' training sessions (Asarnow \& Meichenbaum, 1979; Meichenbaum, 1977). The general idea behind this approach is that children's problem solving abilities and their understanding and use of cognitive strategies (e.g., rehearsal of to-be-learned information) can be enhanced by stimulating children to formulate and answer questions in a stepwise manner (e.g., 'What is my assignment? And what is the best way to deal with this assignment?'). In the present study, the trainer therefore provided all assignments in this stepwise question-and-answer format during each group session. In addition, the materials used during training were primarily paperand-pencil tasks that stimulated children to formulate questions aloud and answer them by giving either a verbal response, e.g., by naming objects that had to be remembered, or a motor response, e.g., by drawing. Assignments that were used in the strategic organization and conceptual reasoning training conditions were derived to a large extent from published educational training programs (in Dutch) for children (e.g., Timmerman \& Van der Schoot, 2001; Timmerman, 2002) and from protocols published in international, peer-reviewed journals (e.g., Bjorklund, Miller, Coyle, \& Slawinski, 1997; St Clair-Thompson et al., 2010). For more details, see Tables 2 and 3. After each assignment, the children - as a group - were stimulated to judge their own work. Subsequently the trainer gave verbal feedback about the formulated questions, 
answers and - in case of the strategic organization training and conceptual reasoning training - the cognitive strategies that were used.

Conceptual reasoning training (condition A). During this training condition, children were given assignments that addressed e.g. the function of naming and communication and concept formation and verbal reasoning (in line with Lezak, 2004). For more information see Table 2. Although each session focused on a different skill, each skill was discussed in relation to the previously learned skills. More concrete, during the first two sessions children were encouraged to reason about the function of naming and communication. During subsequent sessions, children experienced that language can be used to obtain, cluster, arrange, and share information. More concrete, this training included activities such as learning how to ask questions strategically in order to obtain information to solve problems efficiently, to abstract the essence from an overwhelming amount of information, to combine relevant data, and to learn the importance of listening and giving good instructions for correct information transfer.

Strategic organization training (condition B). This training focused on stimulating children's use of cognitive strategies by focusing on skills needed to solve problems in an efficient manner. The training aimed to improve the perception of and attention for relevant information as well as the processing en mental manipulation of information - including visualization and adopting another child's perspective. Further, we intended to expand the available repertoire of memory strategies - i.e., single item repetition, cumulative rehearsal, and meaningful organization (verbalizing and categorizing) - and to improve the efficiency of strategy utilization. See Table 3 for more information.

Creative training (active control condition C). This training focused on stimulating children to be creative. The aim of this condition was to control for the general influence of receiving training, thereby being able to separate the influence of performance being stimulated by working in small groups with a non-EF approach compared to an EF-approach. Each session consisted of assignments that required children to create a specific color by mixing paint and to craft something with that theme color (e.g., creating red paper tulips or an underwater painting). See Table 4 for more information. 
TABLE 2. Overview of the Conceptual Reasoning training

\begin{tabular}{|c|c|c|}
\hline & THEMES & EXAMPLES OF ACTIVITIES \\
\hline $\begin{array}{l}\text { Session } 1 \\
\text { The function of } \\
\text { naming }\end{array}$ & $\begin{array}{l}\text { - Using names for colors } \\
\text { Using names for } \\
\text { animate and inanimate } \\
\text { objects }\end{array}$ & $\begin{array}{l}\text { - What would we look like if there were no colors? } \\
\text { - Why is a dog called a dog? } \\
\text { - Why do we give dogs a name? }\end{array}$ \\
\hline $\begin{array}{l}\text { Session } 2 \\
\text { The function of } \\
\text { communication }\end{array}$ & $\begin{array}{l}\text { - } \text { Making and imitating } \\
\text { sounds } \\
\text { - } \quad \text { Word-analysis } \\
\text { - } \quad \text { Rhyming }\end{array}$ & $\begin{array}{ll}\text { - } & \text { Why are languages important? } \\
\text { - } & \text { Imitating what another child says. } \\
\text { - } & \text { What does a word consist of? } \\
\text { - } & \text { What does rhyming mean? } \\
\text { - } & \text { What rhymes with 'cat'? }\end{array}$ \\
\hline $\begin{array}{l}\text { Session } 3 \\
\text { The function of } \\
\text { comparative } \\
\text { adjectives and } \\
\text { prepositions }\end{array}$ & $\begin{array}{l}\text { - Using 'bigger than' and } \\
\text { 'smaller than' } \\
\text { Using 'in front of', } \\
\text { 'behind', 'next to', } \\
\text { 'underneath', 'above' }\end{array}$ & $\begin{array}{l}\text { - Which shoe is bigger, yours or mine? } \\
\text { - } \quad \text { Can you stand behind the table? } \\
\text { - } \quad \text { Can you sit underneath the table? } \\
\text { 'behind', and 'next to' mean? }\end{array}$ \\
\hline $\begin{array}{l}\text { Session } 4 \\
\text { Concept formation } \\
\text { and verbal reasoning }\end{array}$ & $\begin{array}{l}\text { Object characteristics } \\
\text { and word } \\
\text { categorization } \\
\text { - Verbal reasoning }\end{array}$ & $\begin{array}{l}\text { - Finding out what object another child has is } \\
\text { mind. What are good questions to ask and what } \\
\text { not? } \\
\text { Answering questions, such as 'Linda is older than } \\
\text { Anna, and Anna is older than Kim. Who is the } \\
\text { eldest?' }\end{array}$ \\
\hline $\begin{array}{l}\text { Session } 5 \\
\text { Story telling and } \\
\text { reasoning about } \\
\text { emotions }\end{array}$ & $\begin{array}{l}\text { - } \quad \text { Creating a story on the } \\
\text { basis of pictures } \\
\text { - } \quad \text { Story completion } \\
\text { The recognition and } \\
\text { function of emotions }\end{array}$ & $\begin{array}{l}\text { - Can you place these pictures in the right order to } \\
\text { create a story? } \\
\text { - I'm going to tell a story and when I stop, you } \\
\text { have to finish it. } \\
\text { - Can you make up a story with this picture? } \\
\text { What is the animal in the picture feeling? How } \\
\text { can you tell? Why is it important that someone } \\
\text { knows how you feel? }\end{array}$ \\
\hline $\begin{array}{l}\text { Session } 6 \\
\text { Information transfer }\end{array}$ & $\begin{array}{ll}\text { - } & \text { Giving instructions } \\
\text { - } & \text { Verbal navigation } \\
& \text { Transferring } \\
\text { instructions }\end{array}$ & $\begin{array}{l}\text { - Can you describe the drawing you made, so that } \\
\text { the other children know what you have drawn? } \\
\text { I'm going to tell you how to draw a figure. Did } \\
\text { everybody draw the same figure? What went } \\
\text { wrong? Why did it go wrong? } \\
\text { I'm going to whisper a sentence in the ear of the } \\
\text { child next to me, who will whisper it in the ear of } \\
\text { the child next to him/her, etc. What is the correct } \\
\text { sentence according to the last child? What went } \\
\text { wrong en why? }\end{array}$ \\
\hline
\end{tabular}


TABLE 3. Overview of the Strategic Organization training

\begin{tabular}{|c|c|c|}
\hline & THEMES & EXAMPLES OF ACTIVITIES \\
\hline $\begin{array}{l}\text { Session } 1 \\
\text { Perception }\end{array}$ & $\begin{array}{ll}\text { - } & \text { Observing } \\
\text { - } & \text { Listening } \\
\text { - } & \text { Feeling } \\
\text { - } & \text { Tasting }\end{array}$ & $\begin{array}{l}\text { - Two children in the group will switch places. Can } \\
\text { you tell which children? } \\
\text { - What can you hear when you are really quiet? } \\
\text { - Can you guess which child is standing in front of } \\
\text { you if you are blindfolded? } \\
\text { Can you guess what you are eating if you are } \\
\text { blindfolded? How did you do that? }\end{array}$ \\
\hline $\begin{array}{l}\text { Session } 2 \\
\text { Attention }\end{array}$ & $\begin{array}{l}\text { - The function of } \\
\text { attention } \\
\text { - } \quad \text { Paying attention }\end{array}$ & $\begin{array}{l}\text { What do you do when you concentrate? Why is it } \\
\text { important? } \\
\text { Follow my instructions: 'Split this square up into } \\
\text { four equal parts and give each part a different } \\
\text { color'. } \\
\text { - Playing animal-bingo. }\end{array}$ \\
\hline $\begin{array}{l}\text { Session } 3 \\
\text { Information } \\
\text { processing }\end{array}$ & $\begin{array}{l}\text { - Organizing and } \\
\text { categorizing } \\
\text { Estimating time, speed, } \\
\text { quantity and weight }\end{array}$ & $\begin{array}{l}\text { - Sorting geometrical figures of different sizes and } \\
\text { colors. Why do these figures belong together? } \\
\text { Can you sort them in another way? } \\
\text { Can you finish this necklace by placing the beads } \\
\text { in the same order? } \\
\text { What fruit has the most pips? Can you make a } \\
\text { drawing of the inside of an apple, a mango and a } \\
\text { watermelon? } \\
\text { What lakes longer, } 10 \text { seconds or } 1 \text { minute? }\end{array}$ \\
\hline $\begin{array}{l}\text { Session } 4 \\
\text { Mental manipulation }\end{array}$ & $\begin{array}{ll}\text { - } & \text { Perspective taking } \\
\text { - } & \text { Visualizing }\end{array}$ & $\begin{array}{l}\text { - Can you copy this drawing of a house from where } \\
\text { you are sitting? Now switch drawings with the } \\
\text { other children. Can you guess who's drawing you } \\
\text { got? } \\
\text { Can you copy this drawing of a triangle from the } \\
\text { perspective of the child sitting opposite of you? } \\
\text { Can you draw something on the basis of my } \\
\text { clues? It's usually round and hangs on the wall. It } \\
\text { has numbers on it and two hands. What is it? }\end{array}$ \\
\hline $\begin{array}{l}\text { Session } 5 \\
\text { Memory strategies I }\end{array}$ & $\begin{array}{ll}\text { - } & \text { Single item repetition } \\
\text { - } & \text { Meaningful organization } \\
\text { through verbalization }\end{array}$ & $\begin{array}{l}\text { - Let's draw a picture from this stack. Look at it } \\
\text { and put it back. Can you point to the picture you } \\
\text { saw on this card? Now let's try it with } 2 \text { or } 3 \\
\text { pictures at the same time. } \\
\text { Can you memorize all the cats on this card? How } \\
\text { could we make it easier to memorize them? Let's } \\
\text { give them names. Now draw a picture from this } \\
\text { stack. Look at it and put it back. Can you point to } \\
\text { the cat that you saw on this card? }\end{array}$ \\
\hline $\begin{array}{l}\text { Session } 6 \\
\text { Memory strategies II }\end{array}$ & $\begin{array}{ll}\text { - } & \text { Cumulative rehearsal } \\
\text { - } & \text { Meaningful organization } \\
\text { through categorization }\end{array}$ & $\begin{array}{l}\text { - How can you memorize } 4 \text { or } 5 \text { pictures? By } \\
\text { repeating them in your mind. Shall we try? } \\
\text { I'm going to show you } 4 \text { pictures. Can you tell me } \\
\text { what pictures you saw? } \\
\text { This time you have to remember all the pictures. } \\
\text { How can we do that? By grouping them. Let's try } \\
\text { it. }\end{array}$ \\
\hline
\end{tabular}


TABLE 4. Overview of the Creative training

\begin{tabular}{|c|c|c|}
\hline & THEMES & EXAMPLES \\
\hline Session 1 & $\begin{array}{l}\text { Creating and using colors: } \\
\text { Orange and brown }\end{array}$ & $\begin{array}{l}\text { - } \quad \text { Create orange and brown by mixing paint. } \\
\text { - } \quad \text { Make a bal from papier-mâché. }\end{array}$ \\
\hline Session 2 & $\begin{array}{l}\text { Creating and using colors: } \\
\text { Grey }\end{array}$ & $\begin{array}{l}\text { - } \quad \text { Create grey by mixing paint. } \\
\text { - } \quad \text { Make a winter landscape with sugar and paint. }\end{array}$ \\
\hline Session 3 & $\begin{array}{l}\text { Creating and using colors: } \\
\text { Red and green }\end{array}$ & $\begin{array}{l}\text { - } \quad \text { Create green by mixing paint. } \\
\text { - } \quad \text { Making red paper tulips }\end{array}$ \\
\hline Session 4 & $\begin{array}{l}\text { Creating and using colors: } \\
\text { Pink and purple }\end{array}$ & $\begin{array}{l}\text { - } \quad \text { Create pink and purple by mixing paint. } \\
\text { - } \quad \text { Making a house out of candy. }\end{array}$ \\
\hline Session 5 & $\begin{array}{l}\text { Creating and using colors: } \\
\text { Light blue }\end{array}$ & $\begin{array}{l}\text { - } \quad \text { Create light blue by mixing paint. } \\
\text { Make an underwater painting with the use of potato } \\
\text { stamps and paint. }\end{array}$ \\
\hline Session 6 & $\begin{array}{l}\text { Using colors: } \\
\text { All colors }\end{array}$ & $\begin{array}{l}\text { - Create masks with the use of magazine cuttings and } \\
\text { color pencils. }\end{array}$ \\
\hline
\end{tabular}

No training (passive control condition D). Children in this condition did not receive any form of training. Pre- and post-tests were administered over the same 6-week-interval as the other three conditions to control for performance improvement without having received any form of explicit (i.e., metacognitive) training.

\subsection{PRE- AND POSTTESTS}

The neuropsychological test battery, that administered one week before and after training, contained seven tests that concentrated on multiple EFs domains. These were selected from the Kaufman Assessment Battery for Children Second Edition (KABC-II; Kaufman, Lichtenberger, Fletcher-Janzen, \& Kaufman, 2005) and the NEPSY battery (Korkman et al., 1998). All tests produced scaled scores ranging between 1 and 19 ( $M=$ $10, S D=3$ ). For children aged 3 to 6 , the test-retest reliability for the KABC-II subtests ranges from .50 to .81 (Kaufman et al., 2005). The corrected test-retest coefficients of the NEPSY subtests vary between .59 and .73 (Korkman et al., 1998).

Number Recall (KABC-II) is a measure of sequential information processing and short-term memory in the auditory modality (Kaufman et al., 2005). The child is asked to repeat a sequence of digits (ranging from 0-10) in the same order as the experimenter. Item difficulty increases as sequence length increases. The child 
receives 1 point per correct sequence with a maximum raw score of 22 points. After 3 consecutive incorrect answers administration is cut off.

Word Order (KABC-II) is a cross-modal measure of working memory and shortterm memory (Kaufman et al., 2005). A series of pictures is placed in front of the child. The experimenter reads series of words that correspond to these pictures aloud in a set order. The child has to point to the corresponding pictures in the same order as the series read by the experimenter. Item difficulty increases as the length of the sequence increases. Per item 1 or 2 points can be obtained, depending on the item, with a maximum raw score of 31 . Administration is cut off after 3 consecutive incorrect answers.

Hand Movements (KABC-II) is a visual-kinesthetic measure of working memory that requires the child to repeat series of hand movements that are demonstrated by the experimenter in the same order (Kaufman et al., 2005). Item difficulty increases during test administration. Per item 1 point is given up to a maximum raw score of 23 . After 3 consecutive incorrect answers administration is cut off.

Conceptual Thinking (KABC-II) is a measure of the ability to think and classify in terms of concepts (Kaufman et al., 2005). The child has to point to the picture that stands out from a series of four or five pictures and receives 1 point per correct sequence. The maximum raw score is 28 points. Item difficulty increases during test administration. Administration is cut off after 4 incorrect answers out of 5 consecutive items.

Verbal Fluency (NEPSY) is a measure of retrieval from semantic memory (Korkman et al., 1998). In the present study only the semantic category fluency part was administered, which consists of two trials: the child has to generate as many different (1) animal names and (2) things you can eat or drink as possible in 60 seconds. Total raw score consists of the sum of the number of correct responses of the two trials.

Verbal Knowledge (KABC-II) is a measure of linguistic and general knowledge (Kaufman et al., 2005). The child is given sheets with six pictures each and has to point to the picture that corresponds best to a word or question provided by the experimenter. Per correct answer the child receives 1 point. The maximum raw score is 90. Administration is cut off after 5 incorrect answers out of 6 consecutive items. 
Visual Attention (NEPSY) is a measure of focused and divided visual attention (Korkman et al., 1998). It consists of two trials in which the child has to search and cross out drawings on a sheet of paper as fast as possible: (1) cats amidst distracting objects, or (2) two specific types of faces amidst distracting faces. During each trial, administration is cut off if the child is still searching after 180 seconds. The total raw score is the ratio between the number of correct items minus the number of incorrect items and the number of seconds summed across both trials.

Kaufman Sequence. In line with KABC-II instructions, an estimate of general abilities - more specifically sequential processing - was calculated on the basis of Number Recall and Word Order standard scores $(M=100, S D=15$; Kaufman et al., 2005).

\subsection{STATISTICAL ANALYSES}

All analyses were performed using SPSS 16.0 for Macintosh OS X. Firstly, no extreme values were found for the pre- and posttest measures - i.e., values minimally three times the interquartile distance above the $75^{\text {th }}$ percentile or below the $25^{\text {th }}$ percentile as defined by Huizingh (2002). Incomplete datasets were available for four children: for three children scores of only one pretest were missing and for one child the complete posttest was missing due to absence. Missing data were less than $5 \%$ of the total data, therefore these were not replaced (in line with Croy \& Novins, 2005). Univariate analyses of variance (ANOVA) revealed no significant differences between the four conditions with respect to the intelligence estimate (Kaufman sequence), LPE or ratio boys:girls (see Table 1 ).

Secondly, cross-sectional comparisons were conducted to compare differences between pre- and posttest performance across all four conditions, using GLM Repeated Measures analyses. All children who were absent during more than one training session were excluded (i.e., two children in condition $B$ and three children in condition C). Training effects were tested in two steps. First, all conditions were inserted separately, i.e., Comparison 1 - A vs. B vs. C vs. D. These analyses will be referred to as the primary analyses. Second, additional analyses were executed in order to gather the most complete overview of possible training effects, by using three types of comparisons: Comparison $2-A+B$ vs. C vs. D (i.e., EFs training [independent 
of content] vs. placebo training vs. no training), Comparison $3-A+B+C$ vs. $D$ (i.e., group meetings vs. no meetings), and Comparison $4-A+B$ vs. C + D (i.e., EFs training [independent of content] vs. control conditions).

In all analyses, standard scores of pre- and posttest measures were inserted as dependent variables and type of condition as independent variable. To assess differences in training effects due to the age of the participants (i.e., a condition $x$ age interaction), additional GLM Repeated Measures analyses were conducted separately for both younger and older preschool children. This division was made somewhat arbitrary on the basis of the mean age of the participants $(M=5.32)$, separating the younger preschoolers (age $<5.32$ years) from the older preschoolers (age $\geq 5.32$ years) within our sample. We opted for a division based on age instead of grade (i.e., first vs. second year of preschool), since children in the Netherlands are predominantly placed in mixed groups that consist of children frequenting the first and second year of preschool. In all analyses, Kaufman $A B C$ - sequential processing scores were included as a covariate. Since similar results were found when analyses were repeated without a covariate, only the initial analyses (with Kaufman sequence as covariate) are described in the Results-section.

Significance levels were reported and the alpha-value was set at .05. In accordance with Thorell et al. (2009), trends were defined as .05 $<p<.10$ and only reported if they were observed in at least two of the four comparisons. In addition, effect sizes (i.e., partial $\eta^{2}$ ) were calculated. In line with Cohen (1969) and Richardson (2011), effect size values between .01 and .06 were considered small, values in the range of .06 to .14 were considered medium, and values larger than 0.14 were considered large. In case of significant overall group differences - in terms of p-values or effect size values - post-hoc comparisons using a Bonferroni correction were conducted. However, the use of a Bonferroni correction in post-hoc tests increases the risk of a Type II error (Field, 2005). As a result existing group differences may be overlooked. Therefore, we decided to include descriptions of observed group differences in mean scores as depicted in Figures 1 to 5. 


\section{RESULTS}

\subsection{EFFECTS OF STRATEGIC ORGANIZATION AND CONCEPTUAL REASONING ACROSS}

\section{ALL AGES}

Significant overall differences between Conditions A, B, C and D in pretest-posttest improvement were only found in terms of Verbal Fluency performance. For all other tests no significant differences were found between the four conditions in performance improvement between pre- and posttest. More specifically, differences between the four conditions in Verbal Fluency performance improvement were found in all comparisons (Pillai's Trace for Comparison 1: $F(3,91)=3.26, p<.05$, partial $\eta^{2}=$ .10 , Comparison 2: $F(2,92)=2.56, p=.083$, partial $\eta^{2}=.05$, Comparison 3: $F(1,93)=$ 3.81, $p=.054$, partial $\eta^{2}=.04$ and Comparison 4: $F(1,93)=4.38, p<.05$, partial $\eta^{2}=$ .05). Observations of mean difference scores (i.e., posttest-pretest), as represented in Figure 1, suggest that these findings may be attributed to a large performance improvement for children in the conceptual reasoning training (condition A) and to a lesser extent for those in the strategic organization training (condition $B$ ) compared to control conditions $C$ and $D$. These observations are in general supported by separate post-hoc analyses of group differences (i.e., Condition A vs. B: $F(1,49)=3.59, p=.064$, partial $\eta^{2}=.07$, Condition A vs. C: $F(1,45)=4.21, p<.05$, partial $\eta^{2}=.09$, Condition $A$ vs. $D: F(1,47)=7.42, p<.01$, partial $\eta^{2}=.14$, Condition $B$ vs. $C: F(1,43)=0.00, p=$ .985 , partial $\eta^{2}=.00$, Condition B vs. D: $F(1,45)=1.17, p=.286$, partial $\left.\eta^{2}=.03\right)$.

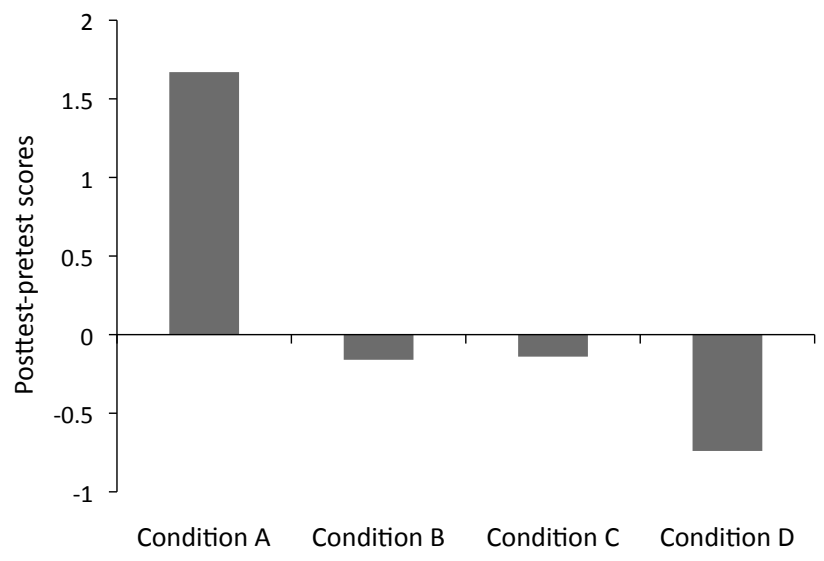

FIGURE 1. Verbal Fluency: mean posttest-pretest difference per condition for all preschool children 


\subsection{INTERACTIONS BETWEEN TRAINING EFFECTIVENESS AND AGE}

Children < 5.32 years. For children younger than 5.32 years significant differences between the four conditions were found, while comparing pre- and posttest performance. The four groups differed in terms of improvement in Verbal Fluency and Verbal Knowledge performance. For all other tests no significant differences were found between the four conditions in this age group.

For Verbal Fluency performance improvement, significant differences were found in all comparisons (Pillai's Trace for Comparison 1: $F(3,42)=5.98, p<.01$, partial $\eta^{2}=.30$, Comparison 2: $F(2,43)=8.32, p<.01$, partial $\eta^{2}=.28$, Comparison 3: $F$ $(1,44)=7.34, p<.05$, partial $\eta^{2}=.14$, and Comparison $4: F(1,45)=1.56 E 1, p<.001$, partial $\eta^{2}=.26$ ). As can be observed in Figure 2, these significant group differences may be attributed to a large performance improvement for children in condition $A$ and to a lesser extent for those in condition B compared to control conditions C and D. In general these observations are supported by separate post-hoc analyses of group differences, revealing both small and large effect sizes (i.e., Condition A vs. B: $F(1,24)$ $=0.86, p=.36$, partial $\eta^{2}=.04$, Condition A vs. $C: F(1,23)=10.21, p<.01$, partial $\eta^{2}=$ .30 , Condition A vs. D: $F(1,19)=11.77, p<.01$, partial $\left.\eta^{2}=.38\right)$.

For Verbal Knowledge performance improvement, GLM Repeated Measures analyses revealed differences between the conditions for Comparisons 2, 3 and 4 (Pillai's Trace: respectively $F(2,43)=2.57, p=.088$ partial $\eta^{2}=.11, F(1,44)=4.04, p=$ .05 , partial $\eta^{2}=.08$, and $F(1,44)=3.70, p=.061$, partial $\left.\eta^{2}=.08\right)$. As can be observed in Figure 3, these differences may be attributed primarily to a larger gain in mean performance between pre- and posttest for children in Condition A compared to the other three conditions. This observation is generally supported by separate post-hoc analyses of group differences, revealing small to large effect sizes (i.e., Condition A vs. B: $F(1,24)=0.85, p=.365$, partial $\eta^{2}=.03$, Condition A vs. C: $F(1,23)=1.93, p=.179$, partial $\eta^{2}=.08$, Condition A vs. $D: F(1,19)=4.14, p=.056$, partial $\left.\eta^{2}=.18\right)$.

Children $\geq 5.32$ years. Differences between children aged 5.32 years and older in the four conditions were found for Hand Movements performance improvement (post-test versus pre-test) in all comparisons (Pillai's Trace: respectively Comparison 1: $F(3,43)=2.52, p=.070$, partial $\eta^{2}=.15$, Comparison $2: F(2,44)=2.78, p=.073$, partial $\eta^{2}=.11$, Comparison 3: $F(1,45)=5.29, p<.05$, partial $\eta^{2}=.11$, and 


\section{CHAPTER 6}

Comparison 4: $F(1,45)=4.23, p<.05$, partial $\left.\eta^{2}=.09\right)$. Differences were also found for Word Order performance improvement in Comparison 1 (Pillai's Trace: $F(3,44)=$ $3.29, p<.05$, partial $\eta^{2}=.18$ ). As the observed mean difference scores in Figures 4 and 5 illustrate, significant differences between conditions in both Hand Movements and Word Order performance may be explained by a consistent progress between pre- and posttest for children in Condition B compared to no or less progress for children in the other three conditions. In general these observations are supported by separate posthoc analyses of group differences. For Hand Movements performance, post-hoc analyses revealed medium to large effect sizes (i.e., Condition $B$ vs. A: $F(1,22)=1.93$, $p=.179$, partial $\eta^{2}=.08$, Condition B vs. C: $F(1,17)=3.69, p=.072$, partial $\eta^{2}=.18$, Condition B vs. D: $F(1,24)=7.89, p=.01$, partial $\left.\eta^{2}=.25\right)$. For Word Order performance, the post-hoc analyses revealed medium to large effect sizes (i.e., Condition B vs. A: $F(1,22)=7.19, p<.05$, partial $\eta^{2}=.25$, Condition B vs. C: $F(1,18)=$ 3.05, $p=.098$, partial $\eta^{2}=.15$, Condition B vs. $D: F(1,24)=2.58, p=.121$, partial $\eta^{2}=$ .10). For the other tests (i.e., Conceptual Thinking, Verbal Fluency, Verbal Knowledge, Number Recall, and Visual Attention) no significant overall differences were found between the four conditions in pre- and posttest performance improvement.

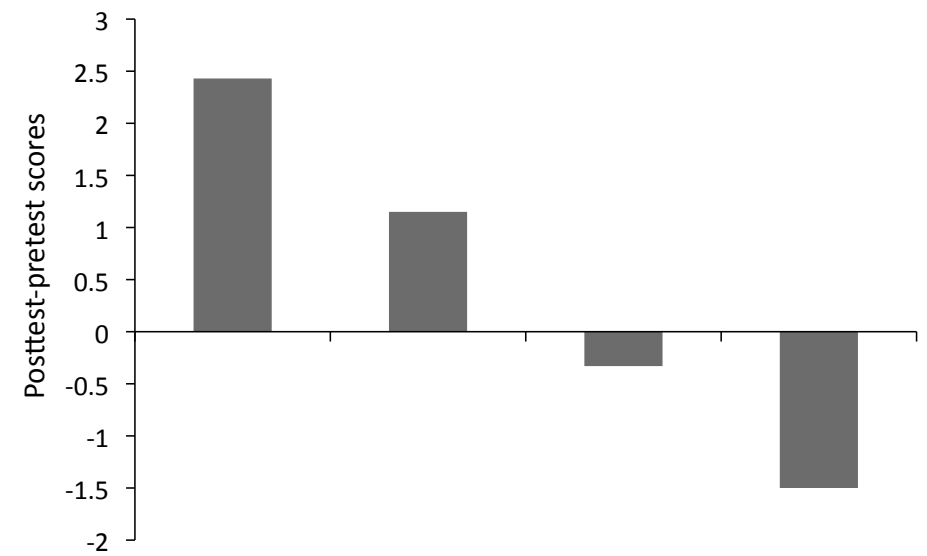

Condition A Condition B Condition C Condition D

FIGURE 2. Verbal Fluency: mean posttest-pretest difference per condition for children $<5.32$ years 


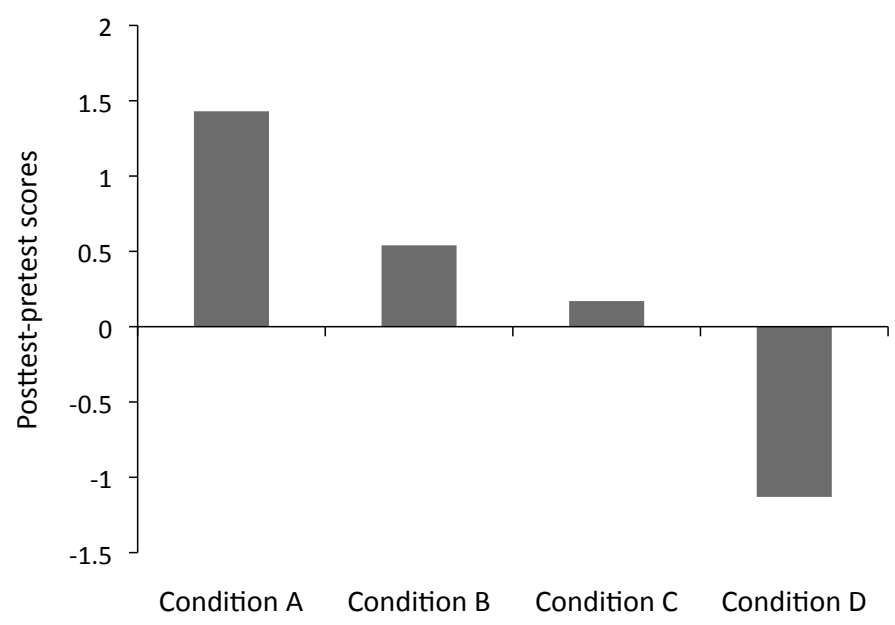

FIGURE 3. Verbal Knowledge: mean posttest-pretest difference per condition for children $<5.32$ years

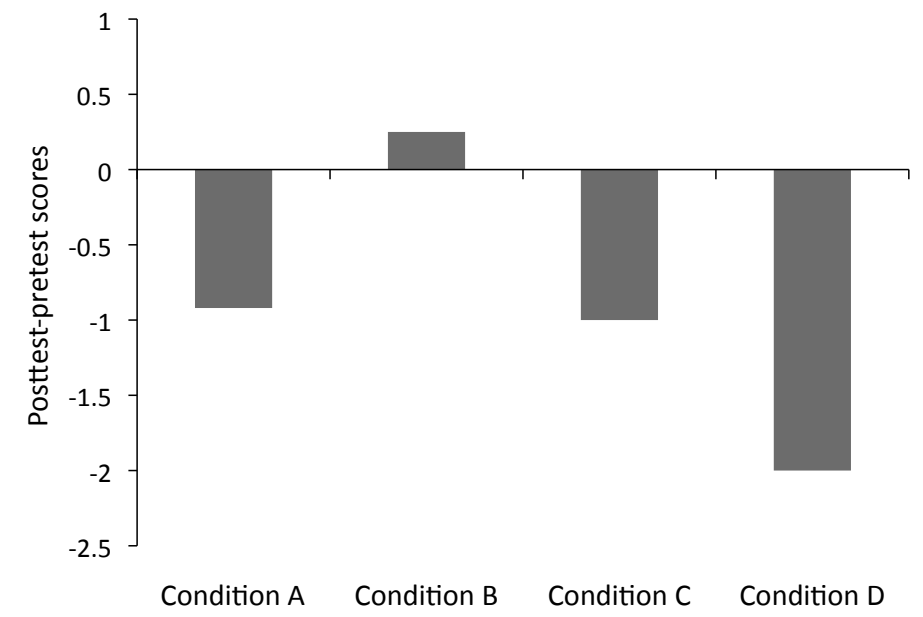

FIGURE 4. Hand movements: mean posttest-pretest difference per condition for children $\geq 5.32$ years 


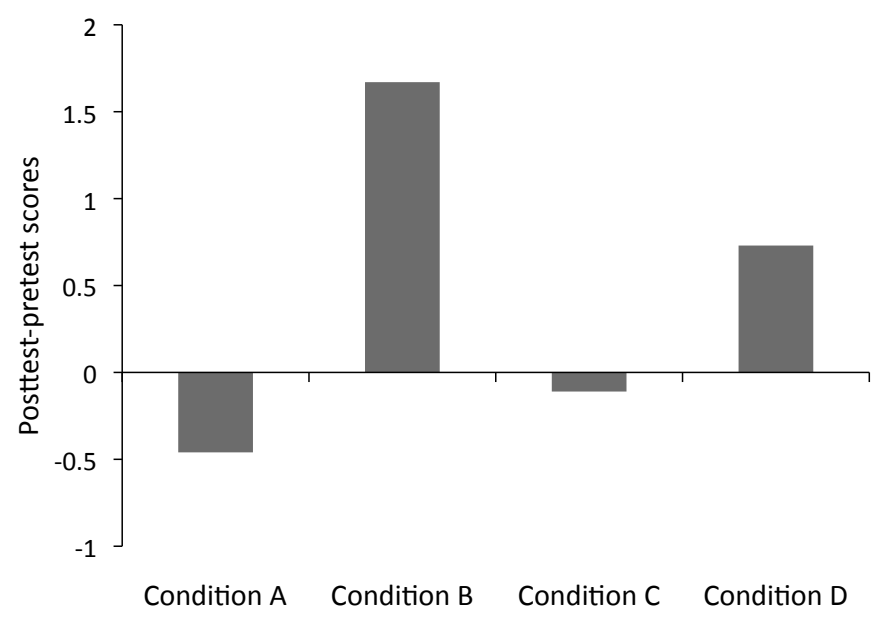

FIGURE 5. Word order: mean posttest-pretest difference per condition for children $\geq 5.32$ years

\section{DISCUSSION}

4.1 TRAINING STRATEGIC ORGANIZATION AND CONCEPTUAL REASONING: TRANSFER EFFECTS

The present study was the first to focus on training EFs in the goal setting domain, more specifically strategic organization and conceptual reasoning, in healthy children aged 4 to 6 years. Our study showed that training strategic organization and conceptual reasoning in preschool children can lead to EFs improvement. More specifically, transfer effects were described on tests measuring two specific EFs domains - i.e., complex working memory (domain of cognitive flexibility) and verbal fluency (domain of information processing). Contrary to our hypotheses, no training effects were found on a test claiming to measure goal setting abilities (i.e., Conceptual Thinking; Kaufman et al., 2005). In the present study this domain was represented by one test, measuring conceptual thinking as an aspect of conceptual reasoning. Yet, Anderson (2002)'s original definition of the goal setting domain was broader - also including e.g., planning abilities. Thus, it cannot be ruled out that our study's training protocols could potentially have an impact on other EFs in the goal setting domain. Further research should establish whether our training program can induce both transfer effects in other EFs domains and direct improvement of EFs in the goal setting 
domain. In sum, our study provides new insights regarding training potential for EFs in the goal setting domain. Hereby it complements the limited number of presently available studies that have described effects of training EFs in the domains of attentional control and cognitive flexibility at preschool age (Diamond et al., 2007; Dowsett \& Livesy, 2000; Röthlisberger et al., 2011; Rueda et al., 2005; St ClairThompson et al., 2010; Thorell et al., 2009).

\subsection{TRAINING EFFECTIVENESS: AN INTERACTION BETWEEN AGE AND TRAINING CONTENT}

An important finding of the present study was that training effectiveness depended on an interaction between the content of the training (i.e., strategic organization vs. conceptual reasoning) and the child's age. As the reported effect sizes seem to suggest, merely describing an overall training effect may disguise stronger effects in subgroups -i.e., findings of small to medium effect sizes for overall training effects in comparison with medium to large effect sizes in separate analyses of younger and older preschoolers. Primarily younger preschoolers (i.e., younger than 5.32 years) showed improvement in EFs that depended on verbal abilities (i.e., verbal fluency and verbal knowledge) after conceptual reasoning training, and to a lesser extent strategic organization training. Such specific stimulation of EFs dependent verbal skills through conceptual reasoning training may in part be explained by stimulation of children's knowledge on logical relationships and categorizing during training. According to Luria (as described by Lezak et al. [2004]), thinking about logical relationships - e.g., connections between objects and features of objects - can help the process of categorizing objects (i.e., concept formation). In turn, successful categorization can support EFs performance that is related to verbal skills, such as verbal fluency, by facilitating retrieval of information from memory through the ability to search different (sub)categories. For instance, in the present study verbal fluency performance required the retrieval of animals from memory, which in theory may have been aided by children's ability to tap into and switch between subcategories of animals (e.g., farm animals or zoo animals), as was described by e.g., Crowe and Prescott (2003). Our findings indicate that only younger preschool children benefit from stimulation through cognitive reasoning training, at least when measures of 


\section{CHAPTER 6}

verbal abilities (i.e., verbal fluency and verbal knowledge) are studied. The present study also revealed a reverse effect in favor of older preschool children (i.e., 5.32 years and older). Performance of these children only seemed to improve significantly after a training of EFs that require strategic organization (in particular more complex, crossmodal working memory). No meaningful effects were found for the conceptual reasoning training in this age group.

With regards to the found age effects, one comment should be made: we do not want to imply that 5.32 years is a strict cut-off point. Rather, based on our findings we hypothesize that in preschoolers the effects of conceptual reasoning training gradually decreases with age, while the effects of strategic organization training gradually increases with age. The procedure that was applied in the present study was merely an exploratory method to show that age plays an important role in training outcome. If in fact age-related differences in training effectiveness exist, an important question remains what could cause discrepancies in training effectiveness between younger and older preschoolers.

\subsection{AGE-RELATED TRAINING EFFECTS: PARALLELS BETWEEN THE PRESENT STUDY AND PAST RESEARCH}

A few studies have reported on age differences in training effectiveness. Dowsett and Livesy (2000) and Rueda et al. (2005) have described similar age-related training effects in favor of young children - i.e., 3 and 4 years of age respectively - for inhibition and attention. Röthlisberger et al. (2011) have also reported training effects in terms of inhibition improvement, although in favor of 6-year-olds compared to 5year-olds. For the same training program, the authors described effects favoring 5year-old children in terms of flexibility and working memory improvement. In their review article, Bjorklund et al. (1997) have described age effects on memory performance improvement in favor of older children after strategy training. Yet, this review only described findings for older children in primary and secondary school (age range: 6-18 yrs). Together these past studies seem to suggest that the age of a child influences training effectiveness, although the findings have been somewhat varied in terms of training content, the EFs that were stimulated and the age at which training was most effective. Therefore, at this point, we can only hypothesize about the origin 
of interactions between age and training content as described in the present study. An explanation for age differences in the effect of conceptual reasoning training on verbal fluency performance may lie in the strong development of verbal fluency abilities between 5 and 8 years of age (Romine \& Reynolds, 2005). A peak in the development of verbal fluency at this age could potentially make stimulation of verbal fluency abilities ineffective for older preschoolers. In line with this, Garon, Bryson and Smith (2008) have shown that, although fundamental forms of the core EFs (e.g., attention control) already emerge during the early stages of the preschool period, major changes in EFs occur during the latter half of the preschool period.

For the strategic organization training, observed age differences may in part be explained by one of two principles described by Bjorklund et al. (1997). Firstly, younger preschoolers may not have mastered the strategies that were practiced during the training to the same extent as older preschoolers (i.e., a mediation deficiency). Secondly, if younger preschoolers did learn the strategies, they may have been less able to use these strategies to improve their memory performance than older preschoolers (i.e., a utilization deficiency). A more general explanation for the present study's findings may be found in the different developmental trajectories of EFs: basic EFs develop earlier than more complex EFs. This is also reflected in brain development trajectories as reported in multiple imaging studies; brain regions and networks related to more basis functions mature earlier than regions and networks involved in more complex functioning such as strategic organization (e.g., Casey, Tottenham, Liston, \& Durston, 2005; Gogtay et al., 2004). Consequently, the present study's findings of age-related training effects may reflect differences in the age at which preschoolers are most receptive to stimulation of specific EFs.

With respect to strategic organization, previous studies by Kendler, Kendler, and Carrick (1966) and Jones, Ridgway and Bremner (1983) have also described performance improvement after strategy training in 5- and 6-year olds. Kendler et al. (1966) have claimed that the extent to which children profit from training of specific strategies depends on the child's initial use of strategies, which is an age-related function. The authors showed that performance of preschool children (i.e., 5-6 years) can be improved directly, merely by using a single type of inferential problem solving task that stimulates the use of support strategies. Yet, in third grade (i.e., 8-9 years) performance remained equal if the trained strategy matched strategies that were 


\section{CHAPTER 6}

already implemented by a child or even hindered performance if the newly learned strategy conflicted with the child's own preferred strategy. Jones et al. (1983) also found an effect of age on optimal training effectiveness: at 5 and 9 years of age children's recall performance improved after feedback on strategy use, while 11-yearsold children already evaluated their own performance internally and therefore did not profit from external feedback anymore.

The few, currently available studies (e.g., Baker-Ward, Ornstein, \& Holden, 1984; Bjorklund \& Harnishfeger, 1987) in this field differ from the present study in that (a) previous studies have included only a one-session memory training protocol, (b) did not include 4-year-old children, and (c) only studied direct effects, leaving out the possibility of transfer. However, such underlying mechanisms may - at least in part provide an explanation for our findings. Specific training programs may be most effective at certain ages. More specifically, the present study's findings may be an indication of the necessity of having a strong base of verbal abilities and basic EFs (e.g., attention, simple memory skills), before children can be trained to improve their complex EFs (e.g., planning and strategic organization). Further research is necessary to fully unravel the mechanisms that underlie the suggested age differences in training efficacy.

\subsection{CONCLUSIONS AND FUTURE DIRECTIONS}

To conclude, the fin dings of the present study suggest that conceptual reasoning and strategic organisation training can be implemented at preschool age, thereby potentially leading to transfer effects on EFs in other domains (i.e., complex working memory and verbal fluency). Further, our findings seem to indicate that even in a narrow age range, such as the preschool years, the effect of training on specific EFs can be age-related. While younger preschoolers' improvement was found primarily in EFs that depend on verbal abilities (i.e., verbal fluency and verbal knowledge), older preschoolers' improvement was found in EFs that require strategic organization (i.e., complex working memory). Hereby our findings seem to indicate that training can only stimulate the development of specific EFs when it builds upon a child's existing EFs, which is supported by findings of Hurks (2012). The present study's findings thereby provide an exciting starting point for further research with the aim of optimizing EFs 
training for preschoolers. Our study has revealed that designing training programs for preschoolers is by no means easy. Researchers should be aware that, even during the short age period of 4 to 6 years, training effectiveness may potentially be influenced by a complex interaction between age, training content and the EFs in which improvement is measured. Given the sample size of the present study, we recommend additional research, in particular with regard to the found age effects. Further research steps also need to be taken to establish during which age periods and under which conditions (e.g., the optimal duration and spacing of training) specific EFs are most sensitive to particular EF training approaches and how transfer effects can best be realized. Future research additions may include a closer monitoring of the completion of homework assignments (e.g., by asking parents to provide information about the time that a child spent on these assignments), studying the influence of other interindividual differences (e.g., sex differences) and implementing our EFs training program in the classroom by using teachers as trainers (in line with e.g., Diamond et al., 2007) to test long term training effects for specific EFs and to provide a basis for broader training implementation. Although much additional research is required, our training program may be implemented in the future in special education or clinical settings to test its effectiveness for children with specific weaknesses in learning, cognitive performance and executive functioning. 


\section{REFERENCES}

Anderson, P. (2002). Assessment and development of executive function (EF) during childhood. Child Neuropsychology, 8(2), 71-82.

Anderson, V., Jacobs, R., \& Anderson, P. J. (2008). Executive functions and the frontal lobes: A lifespan perspective. Philadelphia, PA US: Taylor \& Francis.

Asarnow, J. R., \& Meichenbaum, D. (1979). Verbal rehearsal and serial recall: The mediational training of kindergarten children. Child Development, 50(4), 1173-1177.

Baker-Ward, L., Ornstein, P., \& Holden, D. J. (1984). The expression of memorization in early childhood. Journal of Experimental Child Psychology, 37(3), 555-575.

Bjorklund, D. F., \& Harnishfeger, K. K. (1987). Developmental differences in the mental effort requirements for the use of an organizational strategy in free recall. Journal of Experimental Child Psychology, 44, 109-125.

Bjorklund, D. F., Miller, P. H., Coyle, T. R., \& Slawinski, J. L. (1997). Instructing children to use memory strategies: Evidence of utilization deficiencies in memory training studies. Developmental Review, 17, 411-441.

Blair, C., \& Razza, R. P. (2007). Relating effortful control, executive function, and false belief understanding to emerging math and literacy ability in kindergarten. Child Development, 78(2), 647-663.

Bull, R., Espy, K. A., \& Wiebe, S. A. (2008). Short-term memory, working memory, and executive functioning in preschoolers: Longitudinal predictors of mathematical achievement at age 7 years. Developmental Neuropsychology, 33(3), 205-228.

Cartwright, K. B. (2012). Insights from cognitive neuroscience: The importance of executive function for early reading development and education. Early Education And Development, 23(1), 24-36.

Casey, B. J., Tottenham, N., Liston, C., \& Durston, S. (2005). Imaging the developing brain: what have we learned about cognitive development? Trends in Cognitive Sciences, 9(3), 104-110.

Cohen, J. (1969). Statistical power analysis for the behavioural sciences. New York: Academic Press.

Croy, C. D., \& Novins, D. K. (2005). Methods for addressing missing data in psychiatric and developmental research. Journal of the American Academy of Child and Adolescent Psychiatry, 44(12), 12301240.

Crowe, S. J., \& Prescott, T. J. (2003). Continuity and change in the development of category structure: Insights from the semantic fluency task. International Journal Of Behavioral Development, 27(5), 467-479.

Davidson, M.C., Amso, D., Anderson, L. C., \& Diamond, A. (2006). Development of cognitive control and executive functions from 4 to 13 years: evidence from manipulations of memory, inhibition and task switching. Neuropsychologia, 44(11), 2037-2078. 
De Bie, S. E. (1987). Standaardvragen 1987: Voorstellen voor uniformering van vraagstellingen naar de achtergrondkenmerken en interviews [Standard questions 1987: Proposal for the uniformization of questions regarding background variables and interviews] ( $2^{\text {nd }}$ ed.). Leiden, The Netherlands: Leiden University Press.

Diamond, A., Barnett, W. S., Thomas, J., \& Munro, S. (2007). Preschool program improves cognitive control. Science, 318(5855), 1387-1388.

Dowsett, S. M., \& Livesey, D. J. (2000). The development of inhibitory control in preschool children: effects of "executive skills" training. Developmental Psychobiology, 36(2), 161-174.

Espy, K. A., McDiarmid, M. M., Cwik, M. F., Stalets, M. M., Hamby, A., \& Senn, T. E. (2004). The contribution of executive functions to emergent mathematic skills in preschool children. Developmental Neuropsychology, 26(1), 465-486.

Field, A. (2005). Discovering statistics using SPSS (and sex, drugs and rock ' $n$ ' roll) ( $2^{\text {nd }}$ ed.). London: Sage.

Garon, N., Bryson, S. E., \& Smith, I. M. (2008). Executive function in preschoolers: a review using an integrative framework. Psychological Bulletin, 134(1), 31-60.

Gogtay, N., Giedd, J. N., Lusk, L., Hayashi, K. M., Greenstein, D., Vaituzis, A. C., et al. (2004). Dynamic mapping of human cortical development during childhood through early adulthood. Proceedings of the National Academy of the Sciences, 101(21), 8174-8179.

Huizingh, E. (2002). Inleiding SPSS 11 voor Windows [Introduction to SPSS 11 for Windows]. Schoonhoven: Academic Service.

Hurks, P. P. (2012). Does instruction in semantic clustering and switching enhance verbal fluency in children? The Clinical Neuropsychologist, 26(6), 1019-1037.

Jones, H., Ridgway, J., \& Bremner, J. G. (1983). The effect of encouraging self evaluation on children's ability to transfer the use of a mnemonic strategy. Human Learning, 2, 327-338.

Jonkman, L. M., \& Hurks, P. P. (2009). Memory strategy training improves recollection and associated left parietal ERP activity in children with ADHD. Paper presented at the European Society for Child and Adolescent Psychiatry.

Kaufman, A. S., Lichtenberger, E. O., Fletcher-Janzen, E., \& Kaufman, N. L. (2005). Essentials of KABC-II assessment. Hoboken, New Jersey: John Wiley \& Sons.

Kendler, T. S., Kendler, H. H., \& Carrick, M. A. (1966). Verbal labels and inferential problem solution of children. Child Development, 37(4), 749-763.

Kerns, K. A., Eso, K., \& Thomson, J. (1999). Investigation of a direct intervention for improving attention in young children with ADHD. Development Neuropsychology, 16(2), 273-295.

Klingberg, T. (2010). Training and plasticity of working memory. Trends in Cognitive Sciences, 14(7), 317-324.

Klingberg, T., Forssberg, H., \& Westerberg, H. (2002). Training of working memory in children with ADHD. Journal of Clinical and Experimental Neuropsychology, 24(6), 781-791. 


\section{CHAPTER 6}

Korkman, M., Kirk, U., \& Kemp, S. (1998). NEPSY: A developmental neuropsychological assessment-manual. San Antonio, Texas: Psychological Corporation.

Lezak, M. D., Howieson, D. B., \& Loring, D. W. (2004). Neuropsychological assessment (4th ed.). New York: Oxford University Press.

Meichenbaum, D. (1977). Cognitive-behavior modification: An integrative approach. New York: Plenum Press.

Reynolds, C. R., \& Horton, A. R. (2008). Assessing executive functions: A life-span perspective. Psychology In The Schools, 45(9), 875-892.

Richardson, J. T. E. (2011). Eta squared and partial eta squared as measures of effect size in educational research. Educational Research Review, 6, 135-147.

Romine, C. B., \& Reynolds, C. R. (2005). A model of the development of frontal lobe functioning: Findings from a meta-analysis. Applied Neuropsychology, 12(4), 190-201.

Röthlisberger, M., Neuenschwander, R., Cimeli, P., Michel, E., \& Roebers, C. M. (2011). Improving executive functions in 5- and 6-year-olds: Evaluation of a small group intervention in prekindergarten and kindergarten children. Infant and Child Development, 21(4), 411-429.

Rueda, M. R., Rothbart, M. K., McCandliss, B. D., Saccomanno, L., \& Posner, M. I. (2005). Training, maturation, and genetic influences on the development of executive attention. Proceedings of the National Academy of the Sciences, 102(41), 14931-14936.

St Clair-Thompson, H. L., \& Gathercole, S. E. (2006). Executive functions and achievements in school: Shifting, updating, inhibition, and working memory. Quarterly Journal of Experimental Psychology, 59(4), 745-759.

St Clair-Thompson, H. L., Stevens, R., Hunt, A., \& Bolder, E. (2010). Improving children's working memory and classroom performance. Educational Psychology, 30(2), 203-219.

Thorell, L. B., Lindqvist, S., Bergman Nutley, S., Bohlin, G., \& Klingberg, T. (2009). Training and transfer effects of executive functions in preschool children. Developmental Science, 12(1), 106-113.

Timmerman, K. (2002). Kinderen met aandachts- en werkhoudingsproblemen [Children with attention and working memory problems] (2nd ed.). Leuven/Voorburg: Acco.

Timmerman, K., \& Van der Schoot, D. (2001). Kinderen met geheugen- en inprentingsproblemen [Children with memory and imprint problems]. Leuven/Leusden: Acco.

United Nations Educational, Scientific and Cultural Organization (UNESCO). (1997). International Standard Classification of Education (ISCED). Paris: UNESCO.

Zelazo, P. D., \& Frye, D. (1998). Cognitive complexity and control: II. The development of executive function in childhood. Current Directions in Psychological Science, 2(4), 121-126. 


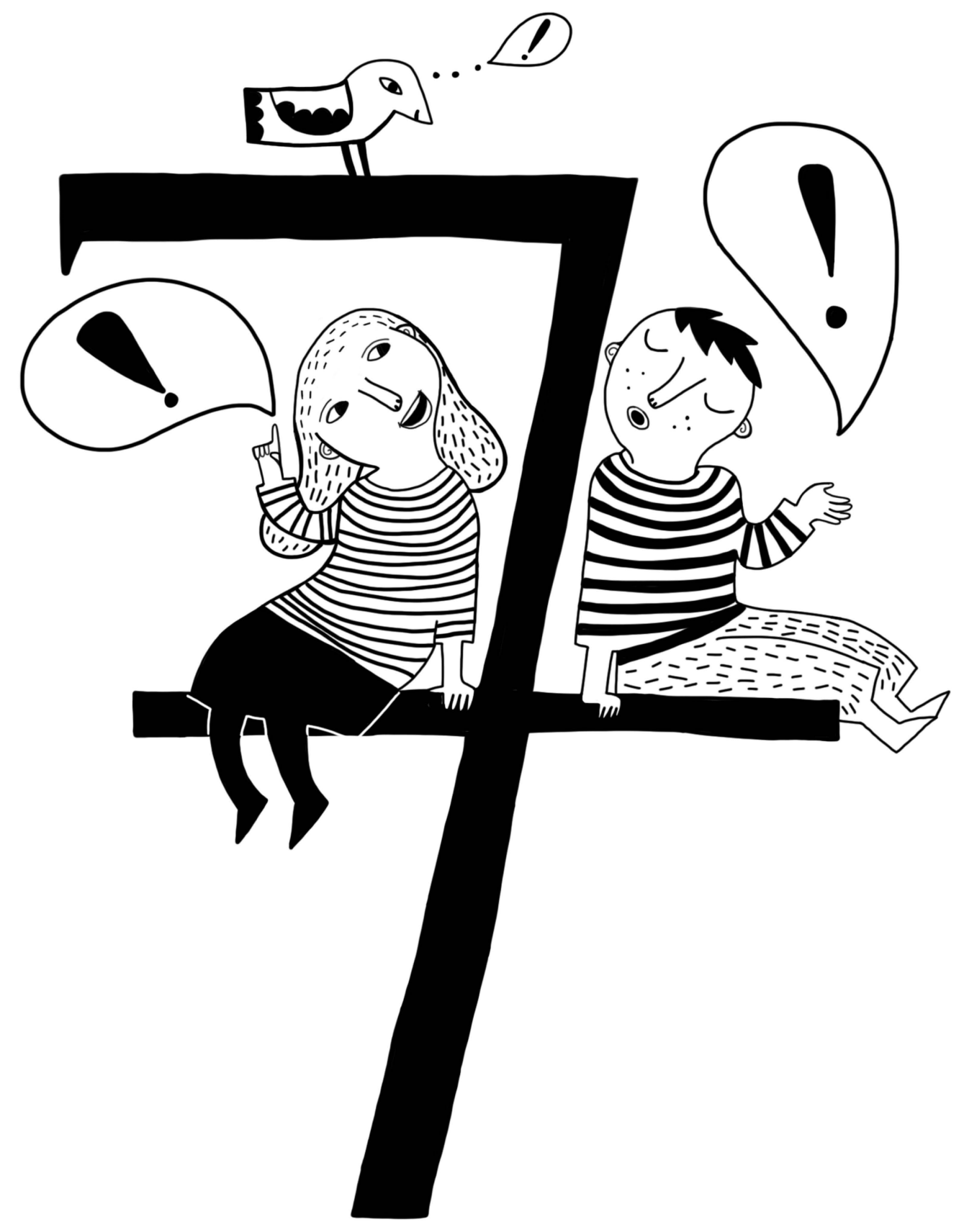





\section{Chapter 7}

Concluding remarks 


\section{THE CONTEXT OF THIS THESIS}

The realization of this thesis lies in national and international initiatives that aim to further knowledge about learning processes. In the past decade, researchers, experts in the field of education and policy makers have become increasingly interested in the potential cross-pollination between cognitive science, neuroscience, educational science and educational practice. In 2002 and 2007, the Centre for Educational Research and Innovation (CERI) of the OECD published two reports that state the importance of multidisciplinary research for the realization of a new learning science that advances knowledge about learning processes. These initiatives have been followed in the Netherlands, with the publication of two reports about brain, learning and education by Jolles et al. $(2005,2006)$.

According to the $\operatorname{OECD}(2002,2007)$ and Jolles et al. $(2005,2006)$, new insights into learning processes can be realized through an exchange of knowledge between different fields of research. Although the fields of cognitive science, neuroscience, educational science and educational practice are characterized by diversity, increasing dialogue and collaboration between these fields is considered desirable. For one, research in the field of neuroscience and neuropsychology has provided insights into learning processes that are potentially interesting for future applications in educational practice (e.g., knowledge about sensitive periods in brain development can be used to match instruction to appropriate sensitive periods, thereby facilitating learning processes). However, more evidence-based research is needed in an attempt to unite e.g., neuropsychological and educational research fields and generate insights that can be implemented in educational practice. As the OECD $(2002,2007)$ and Jolles et al. $(2005,2006)$ have indicated, attention should be given to the central role of higher-order cognitive functions - i.e., executive functions - in learning. In addition, inter-individual differences in cognitive functioning, their characteristics, and origin were also considered as an important focus of research. Further, the importance of mapping changes in adaptability and learning potential in relation to age were underlined.

In line with recommendations made by the $\operatorname{OECD}(2002,2007)$ and Jolles et al. (2005), this thesis aspired to combine research in the fields of neuropsychology and education. Mathematical development was studied in light of a developmental 
neuropsychology perspective. This fairly unique approach incorporated biological (age, sex), psychological (cognitive functions, initiative-taking), and environmental (home learning environment) factors to increase our understanding of inter-individual differences in (early) mathematical development. Thus far, inter-individual differences in mathematical development and their origin have received limited attention. Most studies have focused on a restricted number of topics in relation to mathematical development: cognitive functions, sex differences, mathematical difficulties, or the role of motivation. This thesis, however, wanted to reach new insights into mathematical development, by studying interactions between factors and by giving attention to factors that have been studied very limitedly at preschool and early primary school age. For one, this includes interactions between the home learning environment and a child's own initiative in learning or the development of strategic organization.

Past research has indicated that child- and environment-related factors play a role in the origin of inter-individual differences (e.g., OECD, 2007). For example, the child's sex, his or her initiative-taking in learning, and the home learning environment have been described as potential sources of differences in mathematical achievement. In addition, many studies have attributed differences in mathematical achievement to underlying higher-order cognitive abilities - also referred to as 'executive functions' (EFs), in particular working memory capacity (Raghubar, Barnes \& Hecht, 2010). As research findings in neuropsychology and in neuroscience have shown, these higherorder cognitive abilities are characterized by protracted development trajectories that continue into adolescence and (early) adulthood (Anderson et al., 2008; Romine \& Reynolds, 2005). Consequently, higher-order cognitive abilities are trainable over a prolonged period of time. This makes them interesting candidates for interventions aimed at improving cognitive functioning and potentially also scholastic success.

The studies described in the preceding chapters of this thesis have contributed to scientific knowledge about the role of child- and environment-related factors in mathematical development in various manners. In Chapter 1, the general outline of the thesis was given. Chapter 2 focused on sex differences in mathematical abilities in primary and secondary school. In Chapters 3 and 4, factors contributing to inter-individual differences in mathematical development at preschool and early primary school age were studied (i.e., home learning environment, child's own 


\section{CHAPTER 7}

initiative in learning, cognitive abilities). Chapter 5 explored aspects of complex higherorder cognitive functioning of young children by focussing on strategic organization development between 5 to 7 years of age. According to DiPerna et al. (2007), selfregulated learning at preschool age - e.g., goal-directed behavior and organization has been suggested to influence mathematical development in primary school. It would therefore be an interesting point of departure for the identification of children at risk for developing mathematical difficulties and for the design of early interventions. Chapter 6 focused on the effectiveness of strategic organization and conceptual reasoning interventions at preschool age. In the present chapter, the most important findings are discussed in light of the objectives of this thesis (as described in Chapter 1). In addition, practical implications of these findings will be discussed as well as suggestions for future research.

\section{THE YOUNG CHILD AS A FOCUS OF RESEARCH}

Past research has described the predictive power of preschool children's mathematical abilities for later mathematical development in primary and secondary school. In addition, past research has reported great stability of individual differences in these abilities (Duncan et al., 2007; Siegler \& Ramani, 2009). Researchers have even described that these early mathematical abilities are predictive of an individual's academic opportunities, competitive position in the job market, and daily functioning (e.g., problem solving, managing finances, and planning activities; Rivera-Batiz, 1992; Statistics Canada and Organization for Economic Cooperation and Development [OECD], 2005). These findings form a central motivation for the pursuit of optimal mathematical development for all children from an early age onward, especially since many children do not reach their full potential in school (National Research Council, 2009; Onderwijsraad, 2011). Important advances can be made through the improvement of mathematics education programs during the preschool period, thereby providing children with a foundation that is critical for scholastic success (National Research Council, 2009).

Mathematics education should fit the individual mathematical development and educational needs of each child (National Mathematics Advisory Panel, 2008; National Research Council, 2009; Van Groenestijn et al., 2011). An important condition 
for realizing optimal mathematics education for all children from an early age onward includes increasing knowledge about the predictors of inter-individual differences in mathematical development. Studying the influence of child- and environment-related factors at preschool and early primary school age can potentially contribute important insights. Yet, attention for many aspects of this research topic has been very limited. For one, as the National Research Council (2009) has described, past research has often focused on reading development. Only a few studies have explored the influence of the home learning environment on mathematical development, particularly in relation to the child's own initiative. This is surprising, since the National Research Council (2009) has described the importance of the home learning environment in shaping early mathematics learning.

The National Research Council (2009) has further indicated that learning mathematics is facilitated by the skills that children develop to regulate their own learning, which includes the development of higher-order cognitive functions. Surprisingly, detailed studies of the relationship between these functions and preschool mathematical development and the training potential of these functions at preschool age have also received limited attention in past research. As findings described in Chapter 4 have indicated, the level of higher-order cognitive functioning i.e., in terms of working memory, short-term memory, visual-spatial reasoning and design fluency -at preschool age can dissociate between children who are mathematically gifted and children who experience mathematical difficulties. In Chapters 5 and 6 attention was given to two more complex higher-order functions i.e., strategic organization and conceptual reasoning. As the findings presented in Chapter 5 have indicated, even 5-year-olds already possess rudimentary strategic organization abilities and their abilities improve rapidly between 5 and 7 years of age. Moreover, the study described in Chapter 6 has indicated that strategic organization and conceptual reasoning can be trained as early as preschool age. These findings underline the great importance and potential of studying precursors of cognitive and academic development at a young age, to increase knowledge about the origin of inter-individual differences as well as their implications for interventions. In the next paragraphs, our findings regarding the importance of child- and environment-related factors for mathematical development at preschool and early primary school age will be discussed in more detail. 


\section{THE IMPORTANCE OF CHILD- AND ENVIRONMENT-RELATED}

\section{FACTORS}

As mentioned before, higher-order cognitive functions play a central role in mathematical development (Bull \& Scerif, 2001; Espy et al., 2004). For one, working memory has been described in past research as an important influence on mathematical abilities in preschool and primary school (e.g., Bull et al., 2008; Kroesbergen et al., 2009). In line with these findings, Chapter 4 reported that children's level of cognitive functioning at preschool age - in terms of performance on working memory, short-term memory, visual spatial reasoning, and design fluency tasks - corresponds to their level of mathematical performance at preschool and early primary school age. In our study, children with mathematical difficulties showed the weakest performance, while mathematically gifted children showed superior performance. These findings underline, that preschool cognitive characteristics can potentially be used for early signaling of risk as well as protective factors for mathematical development. There is, however, no one-to-one correspondence between cognitive and mathematical development. Other child- and environmentrelated factors also influence the development trajectories of children's mathematical abilities (and underlying cognitive abilities). For one, sex differences have been suggested to play a role, given reported differences between males and females in brain development, cognitive test performance, and academic achievement profiles (Halpern et al., 2007). The study discussed in Chapter 2 has indicated that sex differences exist in computational fluency (i.e., addition and subtraction). In addition, our findings suggested that these differences only emerged during the last year of primary school and the first years of secondary school and were found primarily among children with the highest levels of arithmetical achievement.

There are other factors that have been suggested to impact on mathematical development from an early age onward, including the home learning environment (HLE) and the child's own initiative (CI) in learning (Blevins-Knabe \& Musun-Miller, 1996). As the findings of Chapter 3 have indicated, HLE and $\mathrm{Cl}$ both have a separate and a shared influence on children's numerical abilities. More specifically, our findings suggested that number and letter activities initiated by a parent, reading books on initiative of parent or child, looking in books by the child, and watching educational 
television were significantly related to numerical abilities of 5- to -7-year-olds. However, their influence was moderated by children's cognitive abilities (i.e., fluid intelligence, working memory, and phonological processing), their age (i.e., preschool or first grade), and the numerical abilities that were studied. Together the findings described in Chapters 2, 3 and 4 indicate that a different outlook on previous findings and on developmental processes can be achieved by studying mathematical abilities in the context of interactions between factors. This includes both interactions between child-related factors and interactions with environment-related factors. Increasing knowledge about the influence of specific factors and interactions among factors on mathematical development (and underlying cognitive abilities) may provide potential leads for improving the effectiveness of interventions.

\section{THE POTENTIAL OF EARLY COGNITIVE INTERVENTIONS}

The findings presented in Chapter 4 provide a starting point for early interventions for children who struggle with mathematics. In Chapter 4 we examined differences in preschool cognitive functioning between children with varied levels of mathematical abilities. We hypothesized that specific cognitive characteristics would discern children with mathematical difficulties and giftedness from typically achieving children. This is based on previous findings that indicated similar differences in early primary school, primarily in working memory performance (e.g., Passolunghi \& Cornoldi, 2008; Swanson et al., 2008). As the results of Chapter 4 indicated, specific cognitive abilities measured at preschool age may provide a profile that corresponds to the level of mathematical development between preschool and primary school. Children who experienced mathematical difficulties between 4 and 8 years of age showed the lowest performance at preschool age on working memory, short-term memory, visual-spatial reasoning and design fluency tests. Conversely, mathematically gifted children showed the highest performance.

Chapter 4 provides leads for early interventions, by e.g., showing that cognitive characteristics can discern children with mathematical difficulties from children with typical achievement and mathematical giftedness. Preschool interventions may focus on this underlying cognitive risk profile instead of the mathematical difficulties itself. Some past interventions have focus directly on training 
children's mathematical abilities (e.g., Aunio et al., 2005; Starkey et al., 2004). However, if interventions can target underlying cognitive weaknesses, they can tackle more general risk factors for learning difficulties (e.g., working memory deficiencies) instead of focusing on specific mathematical abilities. Previous studies have indicated that higher-order cognitive functions, in particular working memory, can be trained in children at preschool age (Diamond \& Lee, 2011; Thorell et al., 2009). Past research has also shown that preschool interventions, that effectively stimulate working memory performance, can indirectly also lead to improvement in mental arithmetic performance (St Clair-Thompson, Stevens, Hunt \& Bolder, 2010).

Based on our findings and past research it can be hypothesized that training cognitive abilities at preschool age may provide an interesting and effective approach for counteracting early cognitive weaknesses of children at risk for developing learning difficulties. Indirectly, this may also alter their early mathematical development, thereby preventing the development of persistent mathematical difficulties. Although interesting, past interventions have focused primarily on frequently described cognitive predictors of mathematical development (e.g., working memory, inhibition; Bull et al., 2008; Geary, 2011; Swanson \& Kim, 2007; Passolunghi et al., 2007). The findings discussed in Chapter 4 are also an example of this line of research. Yet, the future of (early) interventions in this respect may lie in another area of cognitive functioning: complex higher-order cognitive functions (e.g., strategic organization, conceptual reasoning, planning). These functions have been associated with goaldirected, self-regulated learning, which is suggested to influence mathematical development (DiPerna et al., 2007). Impairments in these complex functions are associated with e.g., disorganization, difficulties in developing efficient strategies and reliance on previously learned strategies (Anderson et al., 2008). Given that important changes in complex higher-order order functioning already take place between preschool and early primary school - as Chapter 5 has illustrated, strategic organization increases between 5 to 7 years of age - stimulation of self-regulated learning processes may potentially even be realized from an early age onward through interventions that focus on these complex higher-order functions.

The findings discussed in Chapter 6 suggest that early interventions can stimulate more complex higher-order cognitive functions that are involved in selfregulated learning at preschool age (e.g., strategic organization). The study described 
in Chapter 6 focused on two short interventions, designed to stimulate two aspects of complex higher-order cognitive functioning at preschool age: strategic organization and conceptual reasoning. We found training effectiveness for both interventions through transfer to verbal fluency and working memory performance respectively. Thereby, our study's findings seem to indicate that complex higher-order cognitive functioning training can already be implemented at preschool age. Important to note is that training effectiveness was found to be age dependent. Younger preschoolers responded best to conceptual reasoning training, while older preschoolers showed improvement primarily after strategic organization training.

Findings regarding age-related effects of our strategic organization training are in line with Chapter 5, where an important development in strategic organization was described between 5.5 and 6.5 years of age. Together our findings suggest that interventions aimed at training complex higher-order cognitive functioning can already be implemented at preschool age, but that age can be an important factor in determining training effectiveness. Such early interventions provide interesting possibilities for children at risk for executive functioning difficulties (e.g., ADHD), by stimulating complex higher-order cognitive functions when they are still at an early stage in their prolonged development. Yet, the effectiveness of such interventions remains to be investigated further, for instance by implementing them over a longer period of time and making them applicable in an educational setting (in line with Diamond et al., 2007 and Diamond \& Lee, 2011). In addition, it would be interesting to implement such interventions for older primary school children, particularly in terms of strategic organization. Furthermore, implementation of such interventions may also be feasible for gifted underachievers. This group of gifted children is characterized by scholastic performance does not correspond to their cognitive capacities (Reis \& McCoach, 2000). Underachievement of gifted children can be explained in part by difficulties in goal-directed behavior and self-regulated learning, which involve strategic functioning (Muir-Broaddus, 1995; Reis \& McCoach, 2000). Interventions aimed at stimulating strategic organization of gifted underachievers may therefore be an interesting theme for future research. 


\section{PRACTICAL IMPLICATIONS AND FUTURE DIRECTIONS}

The studies that are described in this thesis have several potential implications for educational practice as well as future studies into mathematical (and cognitive) development. In the previous paragraphs, some suggestions for future directions have already been given, e.g., in terms of differentiation in educational practice, the importance of cognitive abilities for mathematical development, and the potential of early cognitive interventions. As the studies discussed in these concluding remarks have indicated, greater awareness is needed of the potential relevance of research that focuses on inter-individual differences in (preschool) mathematical development. These insights can in turn be of value for the prevention and intervention of mathematical difficulties as well as the realization of optimal schooling opportunities for all children. Past research has already described the potential benefits of early prevention and intervention for reading disorders (e.g., Duff \& Clarke, 2011).

This thesis has underlined the importance of increasing awareness that research results are influenced by the design of a study; the inclusion or exclusion of factors or interactions between factors can change the outcome of studies. For instance, as was indicated in Chapter 2, findings of sex differences can be influenced by the age or achievement level of the participants. Age-related differences have also been found in Chapters 3, 4, and 6. Although these findings only provide a few examples, they illustrate the need for cautious interpretation of scientific findings (e.g., of sex differences). In many instances, research can shed new light on past findings by including additional child- or environment-related factors or taking interactions between factors into account. In addition, our findings have indicated that further research is needed to explore the effectiveness of interventions aimed at stimulating complex higher-order cognitive functions at preschool age. Such explorations could include long-term effectiveness and educational implementation. Further, these interventions may be converted to training programs for older children and children at risk for developing learning problems (e.g., gifted children, children with ADHD, or with mathematical difficulties).

In terms of practical implications, the issues brought that were forward in this thesis provide points of interest for educational practice. These issues are in line with current educational spearheads of international advisory panels (e.g., National 
Mathematics Advisory Panel, 2008; National Research Council, 2009) as well as the Dutch Ministry of Education, Culture and Science: (1) tailor-made education for all children ('passend onderwijs'), with particular attention for children with special educational needs, and (2) stimulating paths towards excellence. In terms of tailormade education, the studies discussed in this thesis have underlined the importance of awareness of the potential influence of a child's home learning environment, own initiative in learning, cognitive abilities, age, and sex on (early) mathematical development. These child- and environment-related factors are an important source of inter-individual differences and should therefore be considered as possible indicators of protective and risk factors in the development of mathematical abilities. Thereby, this thesis provides important insights into the contribution of various child- and environment-related factors, particularly at preschool age. Hereby, our findings suggest that tailor-made education can already be a point of attention in preschool.

Future research is, however, necessary to explore age-related fluctuations in the relative contribution of these factors as well as interactions between these factors. In terms of excellence, two important issues are distinguishing children with extraordinary cognitive abilities and contributing to the optimal development of these abilities. In general, excellence is established through achievement in formal schooling. However, as the findings described in this thesis have suggested, the potential for excellence is already present before formal schooling. More attention should be given to early recognition of extraordinary abilities. In addition to being recognized, excellence should also be supported by interventions that anticipate potential treats to optimal development (e.g., strategic organization training for gifted children to prevent difficulties in self-regulated learning).

\section{CONCLUSIONS}

Based on the results of the studies described in this thesis, we conclude that this thesis has contributed to our awareness of the importance of furthering knowledge about the origin of inter-individual differences in mathematical development. Although the contribution of child- and environment-related factors to mathematical development has proven to be a complex puzzle, important insights can be achieved by studying parts of this puzzle. As this thesis has shown, in preschool and early primary school 


\section{CHAPTER 7}

various child- and environment-related factors already have an important influence on inter-individual differences in mathematical development (and underlying cognitive abilities). Hereby this thesis stresses the need for attention for these factors not only in teaching formal mathematics, but also before the start of formal schooling. Thereby this thesis underlines the international plea for more educational differentiation as well as early interventions. 


\section{REFERENCES}

Anderson, V., Jacobs, R., \& Anderson, P. J. (2008). Executive functions and the frontal lobes: A lifespan perspective. Philadelphia, PA US: Taylor \& Francis.

Aunio, P., Hautamäki, J., \& Van Luit, J. H. (2005). Mathematical thinking intervention programmes for preschool children with normal and low number sense. European Journal of Special Needs Education, 20(2), 131-146.

Blevins-Knabe, B., \& Musun-Miller, L. (1996). Number use at home by children and their parents and its relationship to early mathematical performance. Early Development \& Parenting, 5(1), 35-45.

Bull, R., Espy, K., \& Wiebe, S. A. (2008). Short-term memory, working memory, and executive functioning in preschoolers: Longitudinal predictors of mathematical achievement at age 7 years. Developmental Neuropsychology, 33(3), 205-228.

Bull, R., \& Scerif, G. (2001). Executive functioning as a predictor of children's mathematics ability: Inhibition, switching, and working memory. Developmental Neuropsychology, 19(3), 273-293.

Diamond, A., Barnett, W. S., Thomas, J., \& Munro, S. (2007). Preschool program improves cognitive control. Science, 318(5855), 1387-1388.

Diamond, A., \& Lee, K. (2011). Interventions shown to aid executive function development in children 4 to 12 years old. Science, 333(6045), 959-964.

DiPerna, J., Lei, P., \& Reid, E. E. (2007). Kindergarten predictors of mathematical growth in the primary grades: An investigation using the Early Childhood Longitudinal Study--Kindergarten cohort. Journal of Educational Psychology, 99(2), 369-379.

Duff, F. J., \& Clarke, P. J. (2011). Practitioner review: Reading disorders: What are the effective interventions and how should they be implemented and evaluated?. Journal Of Child Psychology And Psychiatry, 52(1), 3-12.

Duncan, G. J., Dowsett, C. J., Claessens, A., Magnuson, K., Huston, A. C., Klebanov, P., et al. (2007). School readiness and later achievement. Developmental Psychology, 43(6), 1428-1446.

Espy, K., McDiarmid, M. M., Cwik, M. F., Stalets, M., Hamby, A., \& Senn, T. E. (2004). The Contribution of Executive Functions to Emergent Mathematic Skills in Preschool Children. Developmental Neuropsychology, 26(1), 465-486.

Geary, D. C. (2011). Cognitive predictors of achievement growth in mathematics: A 5-year longitudinal study. Developmental Psychology, 47(6), 1539-1552.

Halpern, D. F., Benbow, C. P., Geary, D. C., Gur, R. C., Hyde, J. S., \& Gernsbacher, M. A. (2007). The science of sex differences in science and mathematics. Psychological Science in the Public Interest, 8(1), 151. 


\section{CHAPTER 7}

Jolles, J. (2011). Ellis en het verbreinen: Over hersenen, gedrag \& educatie [Ellis and the brainification: About brain, behavior \& education]. Amsterdam - Maastricht: Neuropsych Publishers.

Jolles, J., De Groot, R., Van Benthem, J., Dekkers, H., De Glopper, C., Uijlings, H., et al. (2005). Leer het brein kennen [Learning to know the brain]. The Hague: the Netherlands Organization for Scientific Research (NWO).

Jolles, J., De Groot, R., Van Benthem, J., Dekkers, H., De Glopper, C., Uijlings, H., et al. (2006). Brain lessons: A contribution to the international debate on Brain, Learning \& Education. Maastricht: Neuropsych Publishers.

Kroesbergen, E. H., Van Luit, J. H., Van Lieshout, E. M., Van Loosbroek, E. E., \& Van de Rijt, B. M. (2009). Individual differences in early numeracy: The role of executive functions and subitizing. Journal of Psychoeducational Assessment, 27(3), 226-236.

Muir-Broaddus, J. E. (1995). Gifted underachievers: Insights from the characteristics of strategic functioning associated with giftedness and achievement. Learning And Individual Differences, 7(3), 189-206.

National Mathematics Advisory Panel (2008). Foundations for Success: The Final Report of the National Mathematics Advisory Panel. Washington, DC: U.S. Department of Education.

National Research Council (2009). Mathematics learning in early childhood: Paths towards excellence and equity. Committee on Early Childhood Mathematics, Christopher T. Cross, Taniesha A. Woods, and Heidi Schweingruber, Editors. Center for Education, Division of Behavioral and Social Sciences and Education. Washington, DC: The National Academies Press.

OECD (2002). Understanding the brain: Towards a new learning science. Paris: OECD Publishing.

OECD (2007). Understanding the Brain: The birth of a learning science. Paris: OECD Publishing.

Onderwijsraad (2011). Een stevige basis voor iedere leerling [A solid basis for every student]. Den Haag: Onderwijsraad.

Passolunghi, M., \& Cornoldi, C. (2008). Working memory failures in children with arithmetical difficulties. Child Neuropsychology, 14(5), 387-400.

Passolunghi, M., Vercelloni, B., \& Schadee, H. (2007). The precursors of mathematics learning: Working memory, phonological ability and numerical competence. Cognitive Development, 22(2), 165-184.

Raghubar, K. P., Barnes, M. A., \& Hecht, S. A. (2010). Working memory and mathematics: A review of developmental, individual difference, and cognitive approaches. Learning and Individual Differences, 20(2), 110-122.

Reis, S. M., \& McCoach, D. (2000). The underachievement of gifted students: What do we know and where do we go?. Gifted Child Quarterly, 44(3), 152-170.

Rivera-Batiz, F. L. (1992). Quantitative literacy and the likelihood of employment among young adults in the United States. The Journal of Human Resources, 27(2), 313-328.

Romine, C. B., \& Reynolds, C. R. (2005). A model of the development of frontal lobe functioning: Findings from a meta-analysis. Applied Neuropsychology, 12(4), 190-201. 
Siegler, R. S., \& Ramani, G. B. (2009). Playing linear number board games-but not circular ones-improves low-income preschoolers' numerical understanding. Journal Of Educational Psychology, 101(3), 545-560.

St Clair-Thompson, H. L., Stevens, R., Hunt, A., \& Bolder, E. (2010). Improving children's working memory and classroom performance. Educational Psychology, 30(2), 203-219.

Starkey, P., Klein, A., \& Wakeley, A. (2004). Enhancing young children's mathematical knowledge through a pre-kindergarten mathematics intervention. Early Childhood Research Quarterly, 19(1), 99-120.

Statistics Canada and Organization for Economic Cooperation and Development. (2005). Learning a living: First results of the adult literacy and life skills survey. Ottawa and Paris: Author.

Swanson, H., Jerman, O., \& Zheng, X. (2008). Growth in working memory and mathematical problem solving in children at risk and not at risk for serious math difficulties. Journal of Educational Psychology, 100(2), 343-379.

Swanson, L., \& Kim, K. (2007). Working memory, short-term memory, and naming speed as predictors of children's mathematical performance. Intelligence, 35(2), 151-168.

Thorell, L. B., Lindqvist, S., Bergman Nutley, S., Bohlin, G., \& Klingberg, T. (2009). Training and transfer effects of executive functions in preschool children. Developmental Science, 12(1), 106-113.

Van Groenestijn, (2011). Op weg naar gecijferdheid [The road to numeracy]. Utrecht: Hogeschool Utrecht. 



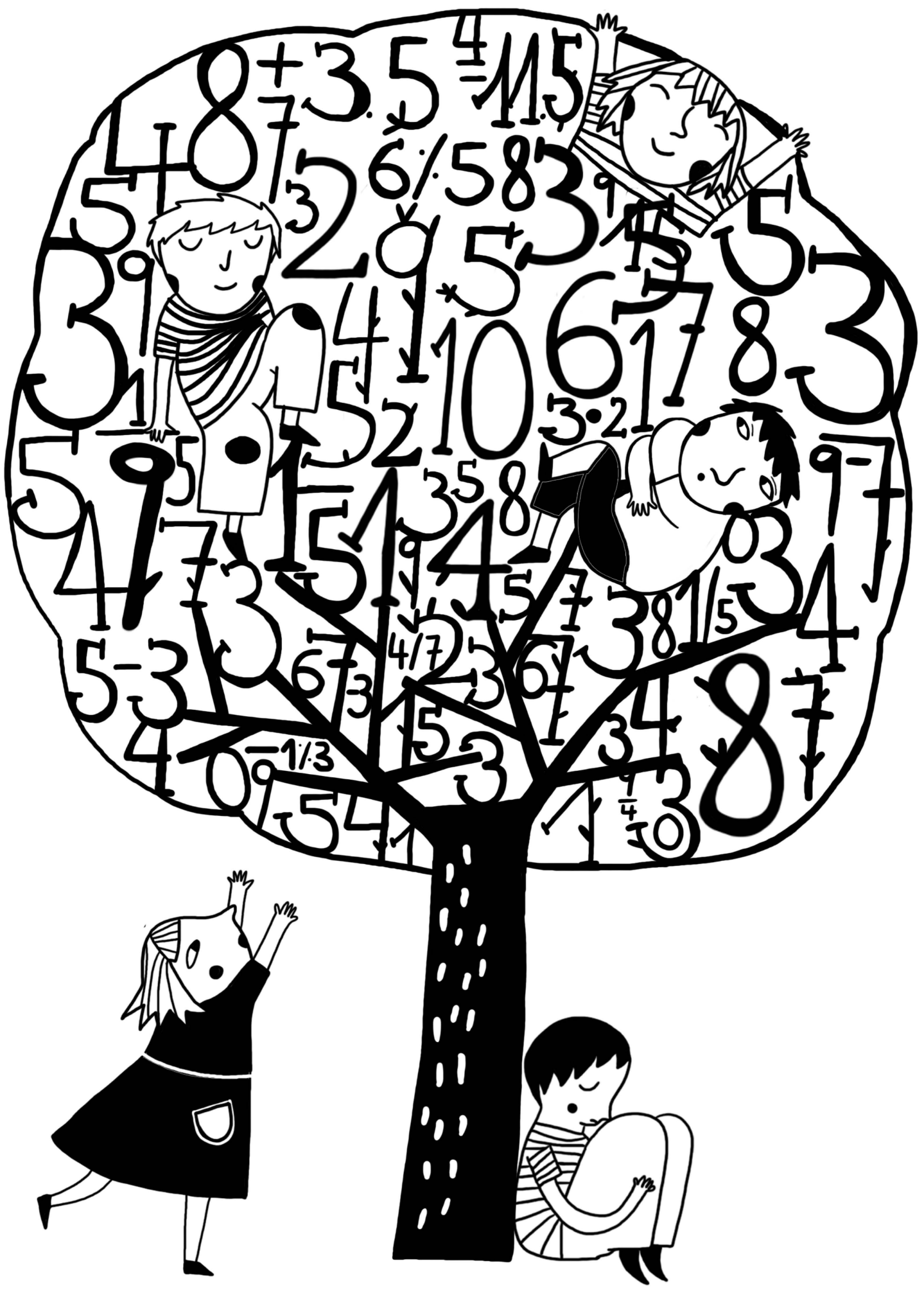





\section{Summary}

Although the preschool period has been described as an important time in the development of mathematical abilities, much less is known about inter-individual differences in mathematical abilities at this early age. Reports and protocols published by organizations in the Netherlands as well as international organizations, such as the OECD, have underlined the importance of awareness of the role that inter-individual differences play in mathematical development. According to these reports, mathematics education has to be tailor-made to fit the mathematical development and educational needs of the individual child (e.g., National Research Council, 2009). As an important first step in the organization of tailor-made mathematics education, the child- and environment-related factors that underlie inter-individual differences in mathematical development have to be mapped (Jolles et al., 2005, 2006; OECD, 2007). Since past research has shown that early mathematical abilities have a life-long impact, optimizing mathematical development as early as possible is vital.

Thus far, limited research has focused on (a) early predictors of mathematical development, and (b) the effect of early interventions on cognitive and academic functioning. This thesis aimed to contribute insights into these points of interest. For one, the majority of the studies presented in this thesis (i.e., Chapters 3, 4, and 5) focused on topics related to the first point of interest: mapping the relationship between mathematical development and various child- and environment-related factors at preschool and early primary school age. Special attention was given to the influence of children's cognitive abilities, since past research has shown that these abilities (e.g., working memory) are predictive of mathematical development (Bull et al., 2008; Swanson \& Kim, 2007; Passolunghi et al., 2007). More specifically, we were interested in the interaction between cognitive abilities and other factors, e.g., children's sex and own interest in learning, and the home learning environment provided by parents.

This thesis contributes to existing literature on these factors, by studying their influence at a younger age than previous research has explored, and by exploring the combined influence of factors (e.g., the interaction between sex, age and 
mathematical achievement level). Secondly, as mentioned above in relation to the second point of interest, this thesis dedicated a chapter (i.e., Chapter 6) to exploring the effectiveness of preschool interventions that aimed to stimulate strategic organization and conceptual reasoning. Since these higher-order cognitive functions have been associated with goal-directed learning, knowledge about the development of these functions provides an interesting basis for the design of early educational interventions.

An overview of the chapters in this thesis is given here:

Chapter 1 . This chapter discussed the rationale and relevance of the research topics in more detail and provided an outline of the thesis.

Chapter 2. The research described in this chapter focused on sex differences in arithmetical abilities between the ages of 6 to 15 years. Past research has focused predominantly on sex differences in arithmetical performance in terms of central tendency (Halpern et al., 2007; Strand, Deary, \& Smith, 2006). Homogeneity of variance among sexes was implicitly assumed, even though support for the validity of this assumption was scarce. The large-scale cross-sectional study discussed in this chapter explored sex differences in arithmetical performance in terms of central tendency as well as variability. In total, 390 healthy children aged 6 to 15 (193 boys) performed a time-restricted arithmetic test (i.e., addition, subtraction, multiplication and division). Central tendency analyses revealed a significant male advantage in arithmetical performance, predominantly in addition and subtraction, from grade 6 onward. Variability analyses showed that these findings could be attributed to sex differences among average and high achievers in grades 6 to 9, although the largest differences were found between high-achieving boys and girls. No significant sex differences were found between low achievers. Together these findings showed that sex differences in arithmetical performance exist, but depend on the studied arithmetical operation, age group and achievement level. Hereby this study indicated the need for a broader perspective on sex differences, thereby offering new directions for future research.

Chapter 3. In past research, early numerical abilities have been strongly associated with subsequent academic success (e.g., Duncan et al., 2007). Thus far, limited attention has been given to child- and environment-related factors that affect 
the development of numerical abilities positively or negatively, particularly in comparison to literacy research (e.g., Anders et al., 2012). In Chapter 3, the specific influence of both the home learning environment (HLE) and child-related factors (i.e., cognitive abilities and own initiative in learning [CI]) on early numeracy were explored in a sample of 211 children aged 5 to 7 . Of the six HLE and $\mathrm{Cl}$ factors that were studied, the following four were related to early numerical abilities (uniquely or combined): the number and letter activities that parents initiated, books reading activities on initiative of parent or child, whether the child enjoys looking in books, and whether the child watches educational television. The influence of these factors was moderated by children's cognitive abilities and age as well as the specific numerical ability under study. Together these findings provide new insights into the interactive effects of HLE and child-related factors on numerical development.

Chapter 4. The study described in this chapter explored mathematical and cognitive characteristics of mathematical difficulties and mathematical giftedness of 162 children aged 4 to 8 years. Data was collected when children were enrolled in the first or second year of preschool (i.e., 4-6 yrs) and two years later, when they were in grade 1 or 2 (i.e., 6-8 yrs). In terms of stability of mathematical performance, five groups were discerned: children with persistent mathematical difficulties (MD-p), transient mathematical difficulties (MD-t), typical achievement (TA), transient mathematical giftedness (MG-t) and persistent mathematical giftedness (MG-p). Next, differences between these groups were assessed across a broad range of cognitive abilities, measured at preschool age. Thereby, we aimed to discern early cognitive characteristics that underlie inter-individual differences in level and stability of mathematical performance. This study was the first to evaluate how preschool cognitive abilities relate to differences in mathematical abilities between children with MD, TA, and MG. We focused on two types of mathematical abilities: computational fluency (i.e., lower order) and mathematical problem solving (i.e., higher order). The findings of our study were twofold. Firstly, the majority of children showed variable mathematical performance between preschool and primary school. For one, of the children with MD in preschool (i.e., performance $\leq 25$ th percentile), only 43 to $53 \%$ was classified as MD-p (i.e., these percentages reflect computational fluency and mathematical problem solving respectively). Secondly, preschool working memory, short-term memory, visual-spatial reasoning and design fluency performance were 
found to parallel mathematical performance. Children with MD predominantly had the lowest mean scores, while children with MG often had the highest mean scores. These findings have potential implications for educational practice, in terms of differentiation in teaching activities as well as early prevention and intervention of learning difficulties.

Chapter 5. The ability to organize information in a meaningful manner facilitates learning and is an important determinant of academic performance (e.g., Cornford, 2002; Garner, 2009). Consequently, assessment of organizational strategies may be useful for the identification of children with or at risk for learning difficulties. A well-known test that enables the assessment of organizational strategies is the ReyOsterrieth Complex Figure (ROCF; Rey, 1941). This established diagnostic and research instrument measures e.g., an individual's ability to plan, initiate, and complete a task, to use strategies, and organize complex visual information. Surprisingly, its potential value for the assessment of young children's organizational strategy use has received limited attention. The study described in Chapter 5 investigated the developmental trajectories of children's organizational approach to copying the ROCF in a crosssectional sample of healthy 5 - to 7-year-old children $(n=217)$. Organizational strategy use was assessed using two measures: the RCF-OSS (Anderson et al., 2001) and the Rey Initial Drawing Sequence (RIDS), a new measure that assessed the initial order of drawing. We explored the relationship between these two measures and a broad range of cognitive functions. Our findings indicated that children's organizational strategy use undergoes significant developmental changes during the age of 5 to 7 years, with significant maturation occurring between 5.5 to 6.5 years of age. In addition, we found that organizational strategy use, as measured by RCF-OSS, was significantly related to various aspects of cognitive functioning at this age (i.e., numeracy, fluency, visual attention, visual-motor integration, spatial memory, working memory, processing speed, and spatial reasoning). Conversely, the RIDS was only related to numeracy. Thus, these measures seem to reflect different aspects of organizational strategy use and can therefore be used as complementary measures. Together our findings showed that both RCF-OSS and RIDS can provide interesting information on the development of organizational strategy use between preschool and early primary school. To the best of our knowledge our study is one of the first to shed light on the important changes that take place in children's strategic organization 
between 5 to 7 years of age, thereby providing an interesting starting point for future research and potential clinical use.

Chapter 6. The effectiveness of executive functions training for preschool children has been described by previous studies, predominantly focusing on working memory training (e.g., Diamond et al., 2007; Thorell et al., 2009). Whether more complex executive functions can be trained explicitly (using a metacognitive approach) remains to be investigated. The study described in Chapter 6 examined the effectiveness of training strategic organization and conceptual reasoning in a sample of healthy children aged 4 to 6 years $(n=102)$. Children were appointed randomly to one of four conditions: conceptual reasoning training, strategic organization training, creative training (active control), or no training (passive control; only pre- and posttesting). For each training condition, overall training time included group meetings (60 $\mathrm{min} / \mathrm{wk}$ ) and paper-and-pencil homework exercises (30-40 min/wk) for 6 weeks. Preand posttest measurements consisted of a range of tests, including conceptual reasoning, working memory, fluency and attention. The findings of our study showed that conceptual reasoning and strategic organization training led to transfer effects through induced improvement in respectively verbal fluency and working memory performance. However, improvement depended on an interaction between age and training content. Younger preschoolers primarily benefited from conceptual reasoning training, leading to improvement in verbal fluency. In contrast, older preschoolers only benefited from strategic organization training, leading to improvement in working memory. These findings have implications for the development of preschool training programs for regular and special education as well as clinical settings.

Chapter 7. In this final chapter the findings of Chapters 2 to 6 were discussed in light of the aims of the thesis. We explored the influence of a broad range of childand environment-related factors on mathematical development at a younger age than past research has explored. Our findings have shown that studying the effects of childand environment-related factors at preschool and early primary school age provides new insights into mathematical development as well as the development of underlying cognitive abilities. At this early age mathematical development is already related to children's own initiative in learning, the home learning environment, and children's cognitive abilities (as well as interactions between these factors). In addition, our findings have shown that effects on mathematical development are not limited to 
individual factors; the outcome of a study can also be influenced by interactions between child- or environment-related factors (e.g., interactions between sex, age and mathematical achievement level - see Chapter 2). Further, this thesis has shown that preschool children are already capable of higher-order cognitive functioning (i.e., strategic organization) and has underlined possibilities for stimulating this functioning (i.e., strategic organization and conceptual reasoning) through early interventions. Together the findings discussed in this thesis underline the added value of a developmental neuropsychology perspective on learning processes; i.e., an approach that incorporates biological (age, sex), psychological (cognitive functions, initiativetaking), and environmental (home learning environment) factors to increase our understanding of inter-individual differences in (early) mathematical development. By underlining the importance of the early effects of child- and environment-related factors on inter-individual differences in mathematical development, our findings support international pleas for educational differentiation. In addition, our findings have potential implications for educational practice and provide starting points for early prevention and intervention aimed at realizing optimal individual development. 


\section{REFERENCES}

Anders, Y., Rossbach, H., Weinert, S., Ebert, S., Kuger, S., Lehrl, S., \& von Maurice, J. (2012). Home and preschool learning environments and their relations to the development of early numeracy skills. Early Childhood Research Quarterly, 27(2), 231-244.

Anderson, P., Anderson, V., \& Garth, J. (2001). Assessment and development of organizational ability: The Rey Complex Figure Organizational Strategy Score (RCF-OSS). The Clinical Neuropsychologist, 15(1), 81-94.

Bull, R., Espy, K., \& Wiebe, S. A. (2008). Short-term memory, working memory, and executive functioning in preschoolers: Longitudinal predictors of mathematical achievement at age 7 years. Developmental Neuropsychology, 33(3), 205-228.

Cornford, I. R. (2002). Learning-to-learn strategies as a basis for effective lifelong learning. International Journal of Lifelong Education, 21(4), 357-368.

Diamond, A., Barnett, W. S., Thomas, J., \& Munro, S. (2007). Preschool program improves cognitive control. Science, 318(5855), 1387-1388.

Duncan, G. J., Dowsett, C. J., Claessens, A., Magnuson, K., Huston, A. C., Klebanov, P., et al. (2007). School readiness and later achievement. Developmental Psychology, 43(6), 1428-1446.

Garner, J. (2009). Conceptualizing the relations between executive functions and self-regulated learning. Journal of Psychology: Interdisciplinary and Applied, 143(4), 405-426.

Halpern, D. F., Benbow, C. P., Geary, D. C., Gur, R. C., Hyde, J. S., \& Gernsbacher, M. A. (2007). The science of sex differences in science and mathematics. Psychological Science in the Public Interest, 8(1), 151.

Jolles, J., De Groot, R., Van Benthem, J., Dekkers, H., De Glopper, C., Uijlings, H., et al. (2005). Leer het brein kennen [Learning to know the brain]. The Hague: the Netherlands Organization for Scientific Research (NWO).

Jolles, J., De Groot, R., Van Benthem, J., Dekkers, H., De Glopper, C., Uijlings, H., et al. (2006). Brain lessons: A contribution to the international debate on Brain, Learning \& Education. Maastricht: Neuropsych Publishers.

National Research Council (2009). Mathematics learning in early childhood: Paths towards excellence and equity. Committee on Early Childhood Mathematics, Christopher T. Cross, Taniesha A. Woods, and Heidi Schweingruber, Editors. Center for Education, Division of Behavioral and Social Sciences and Education. Washington, DC: The National Academies Press.

OECD (2007). Understanding the Brain: The Birth of a Learning Science. Paris: OECD Publishing.

Passolunghi, M., Vercelloni, B., \& Schadee, H. (2007). The precursors of mathematics learning: Working memory, phonological ability and numerical competence. Cognitive Development, 22(2), 165-184. 


\section{SUMMARY}

Rey, A. (1941). L'examen psychologique dans les cas d'encéphalopathie traumatique [The psychological examination of cases of traumatic encephalopathy]. Archives De Psychologie, 28, 215-285.

Strand, S., Deary, I. J., Smith, P. (2006). Sex differences in cognitive abilities test scores: A UK national picture. British Journal of Educational Psychology, 76(3), 463-480.

Swanson, L., \& Kim, K. (2007). Working memory, short-term memory, and naming speed as predictors of children's mathematical performance. Intelligence, 35(2), 151-168.

Thorell, L. B., Lindqvist, S., Bergman Nutley, S., Bohlin, G., \& Klingberg, T. (2009). Training and transfer effects of executive functions in preschool children. Developmental Science, 12(1), 106-113. 


\section{Samenvatting}

Hoewel de kleuterschooltijd wordt beschreven als een belangrijke periode in de ontwikkeling van rekenvaardigheden, is er relatief weinig bekend over interindividuele verschillen in rekenvaardigheden op deze jonge leeftijd in relatie tot onderliggende vaardigheden, zoals getalbegrip en cognitieve vaardigheden. Rapporten en protocollen gepubliceerd door Nederlandse organisaties, zoals NWO (Nederlandse Organisatie voor Wetenschappelijk Onderzoek), en internationale organisaties, zoals de OECD (Organization for Economic Cooperation and Development) en het daarbij aangesloten CERI (Centre for Educational Research and Investigation), onderschrijven de visie dat inter-individuele verschillen een significante rol spelen in de ontwikkeling van rekenvaardigheden. Volgens deze rapporten is het belangrijk dat rekenonderwijs al vanaf jonge leeftijd aansluit bij (de ontwikkeling van) individuele vaardigheden evenals de onderwijsbehoeften van elk kind (e.g., National Research Council, 2009). Een eerste belangrijke stap in het organiseren van passend rekenonderwijs op basisscholen is daarom het in kaart brengen van kind- en omgevingsgebonden factoren die ten grondslag liggen aan inter-individuele verschillen in de ontwikkeling van rekenvaardigheden (Jolles et al., 2005, 2006; OECD, 2007). Aangezien eerder onderzoek heeft aangetoond dat vroege rekenvaardigheden een levenslange invloed hebben, is het essentieel dat de ontwikkeling van rekenvaardigheden zo vroeg mogelijk wordt gestimuleerd en dat de voorwaarden voor deze ontwikkeling worden geoptimaliseerd.

Tot op heden heeft onderzoek zich slechts in beperkte mate gericht op (a) vroege voorspellers van de ontwikkeling van rekenvaardigheden en (b) het effect van vroege interventies op cognitief en academisch functioneren. Dit proefschrift beoogde nieuwe inzichten bij te dragen aan deze aandachtspunten. Zo richtte de meerderheid van de studies die beschreven worden in dit proefschrift (i.e., Hoofdstukken 3, 4 en 5) zich op het eerste aandachtspunt: het in kaart brengen van de relatie tussen de ontwikkeling van rekenvaardigheden en diverse kind- en omgevingsgebonden factoren 
tijdens de kleuter- en vroege basisschoolperiode. Aangezien eerder onderzoek heeft aangetoond dat cognitieve vaardigheden, zoals het werkgeheugen, voorspellend zijn voor de ontwikkeling van rekenvaardigheden, werd speciale aandacht besteed aan de invloed van deze kindgebonden vaardigheden (Bull et al., 2008; Swanson \& Kim, 2007; Passolunghi et al., 2007). In het bijzonder waren we geïnteresseerd in de interactie tussen cognitieve vaardigheden en andere kindgebonden factoren, zoals de sekse van het kind en diens eigen initiatief tot leren, en factoren zoals de leeromgeving die ouders thuis bieden.

Het doel van dit proefschrift was allereerst het leveren van een bijdrage aan de bestaande literatuur over inter-individuele verschillen in rekenvaardigheden. Dit doel werd nagestreefd door de invloed van kind- en omgevingsgebonden factoren te bestuderen op een jongere leeftijd dan eerder onderzoek heeft gedaan en door de gecombineerde invloed van diverse factoren te onderzoeken. Een voorbeeld hiervan is de interactie tussen sekse, leeftijd en het niveau van rekenvaardigheid. Ten tweede is in dit proefschrift een hoofdstuk gewijd aan de effectiviteit van interventies op kleuterleeftijd, in lijn met het tweede aandachtspunt dat hierboven vermeld werd. Deze interventies waren gericht op het stimuleren van strategische organisatie en conceptueel redeneren (i.e., Hoofdstuk 6). Aangezien deze hogere orde cognitieve functies geassocieerd worden met doelgericht leren, kan kennis over de ontwikkeling van deze functies een waardevol uitgangspunt vormen voor de ontwikkeling van vroege onderwijsinterventies.

Een overzicht van de hoofdstukken in dit proefschrift volgt hieronder:

Hoofdstuk 1. In dit hoofdstuk wordt het doel van het proefschrift in een maatschappelijke en wetenschappelijke context geplaatst. Deze algemene introductie geeft achtergrondinformatie bij de onderzoeksonderwerpen evenals een overzicht van de inhoud van het proefschrift.

Hoofdstuk 2. Het onderzoek dat wordt beschreven in dit hoofdstuk richtte zich op sekseverschillen in rekenvaardigheden bij kinderen van 6 tot 15 jaar. Eerder onderzoek naar sekseverschillen heeft zich overwegend gericht op groepsgemiddelden ten aanzien van rekenvaardigheden. Homogeniteit van variantie tussen de seksen werd hierbij impliciet verondersteld, hoewel steun voor de validiteit van deze aanname schaars was. Het grootschalig, cross-sectioneel onderzoek dat wordt 188 
besproken in dit hoofdstuk verkende zowel algemene trends als variabiliteit van sekseverschillen in rekenvaardigheden. In totaal werd bij 390 gezonde kinderen van 6 tot 15 jaar (193 jongens) de Tempo Test Rekenen (De Vos, 1992) afgenomen. Dit is een tijdgebonden test die de vaardigheden optellen, aftrekken, vermenigvuldigen en delen meet. Analyses met groepsgemiddelden lieten een significant voordeel voor jongens zien in rekenprestaties. Dit gold met name voor optellen en aftrekken en pas vanaf groep 8. Uit variabiliteitsanalyses bleek echter dat deze bevindingen vooral verklaard konden worden door verschillen tussen jongens en meisjes die op een gemiddeld of hoog niveau presteerden - in het bijzonder in groep 8 en klas 1, 2, en 3 . De grootste verschillen werden gevonden tussen jongens en meisjes die op een hoog niveau presteerden. Tussen jongens en meisjes die op een laag niveau presteerden werden geen significante verschillen gevonden. Samen tonen deze bevindingen aan dat sekseverschillen in rekenvaardigheden bestaan. Echter, ze zijn afhankelijk van de rekenkundige vaardigheden, de leeftijdsgroep en het prestatieniveau dat bestudeerd wordt. Hiermee laat deze studie zien dat het belangrijk is om sekseverschillen vanuit een breder perspectief te benaderen. Dit biedt nieuwe aanknopingspunten voor toekomstig onderzoek.

Hoofdstuk 3. In eerder onderzoek zijn vroege rekenvaardigheden sterk geassocieerd met daaropvolgend academisch succes. Tot nu toe is echter weinig aandacht uitgegaan naar kind- en omgevingsgebonden factoren die van invloed zijn op de ontwikkeling van rekenvaardigheden. Dit geldt met name in vergelijking met onderzoek naar leesvaardigheden. In Hoofdstuk 3 wordt de specifieke invloed van de leeromgeving die ouders thuis creëren (Home Learning Environment [HLE]) en kindgebonden factoren, zoals cognitieve vaardigheden en het eigen initiatief tot leren (Child's Initiative [CI]) op getalbegrip verkend in een steekproef van 211 kinderen van 5 tot 7 jaar oud. Van de zes onderzochte HLE en $\mathrm{Cl}$ factoren waren er vier (uniek of gezamenlijk) gerelateerd aan vroege rekenvaardigheden. Het betrof cijfer- en letteractiviteiten die door ouders aangeboden worden, het lezen van boeken op initiatief van ouder of kind, het plezier waarmee een kind in boeken kijkt, en het kijken naar educatieve televisie door het kind. Het effect van deze factoren werd beïnvloed door de cognitieve vaardigheden en leeftijd van het kind, evenals de specifieke rekenvaardigheid die bestudeerd werd. Samen bieden deze bevindingen nieuwe 
inzichten in het effect van interacties tussen HLE and kindgebonden factoren op de ontwikkeling van (vroege) rekenvaardigheden.

Hoofdstuk 4. De experimentele studie die beschreven wordt in dit hoofdstuk verkende de rekenkundige en cognitieve kenmerken van rekenproblemen (mathematical difficulties [MD]) en rekenbegaafdheid (mathematical giftedness [MG]) van 162 kinderen van 4 tot 8 jaar. Alle gegevens werden verzameld op het moment dat kinderen in groep 1 of 2 zaten (i.e., 4-6 jaar) en twee jaar later, toen ze in groep 3 en 4 zaten (i.e., 6-8 jaar). Met betrekking tot de stabiliteit van rekenprestaties konden vijf groepen onderscheiden worden: kinderen met persistente rekenproblemen (MD-p), kinderen met voorbijgaande ('transient') rekenproblemen (MD-t), gemiddeld presterende kinderen (Typically Achieving [TA]), kinderen met voorbijgaande rekenbegaafdheid (MG-t), en kinderen met persistente rekenbegaafdheid (MG-p). Vervolgens werden verschillen tussen deze vijf groepen onderzocht in een groot aantal cognitieve vaardigheden, gemeten op kleuterleeftijd. Hiermee beoogden we specifieke cognitieve kenmerken te onderscheiden die ten grondslag liggen aan inter-individuele verschillen in het niveau en de stabiliteit van rekenprestaties. Onze studie was de eerste die de relatie tussen cognitieve vaardigheden op kleuterleeftijd en verschillen in rekenvaardigheden tussen kinderen met MD, TA en MG bestudeerde. We richtten ons op twee typen rekenvaardigheden, namelijk eenvoudige rekenkundige bewerkingen (i.e., vaardigheid van lagere orde) en probleemoplossend rekenen (i.e., vaardigheid van hogere orde). De bevindingen van de studie waren tweeledig. Allereerst bleek dat, van de kinderen met MD op kleuterleeftijd (i.e., rekenprestaties $\leq 25^{\mathrm{e}}$ percentiel), slechts 43 tot $53 \%$ persistente rekenproblemen ontwikkelde. Deze percentages geven respectievelijk problemen in eenvoudige rekenkundige bewerkingen en probleemoplossend rekenen weer. Ten tweede bleek dat prestaties op het gebied van het werkgeheugen, het kortetermijngeheugen, het visueel-ruimtelijk redeneren en de non-verbale vloeiendheid overeenkwamen met het niveau van de rekenprestaties. Kinderen met MD hadden overwegend de laagste gemiddelde scores, terwijl kinderen met MG doorgaans de hoogste gemiddelde scores behaalden. Deze bevindingen hebben mogelijke implicaties voor de onderwijspraktijk. In het bijzonder zouden onze bevindingen kunnen leiden tot een nadere differentiatie van lesactiviteiten en een verbetering van vroege preventie en interventie bij leerproblemen. 
Hoofdstuk 5. Het meten van organisatiestrategieën kan een goede manier zijn om kinderen te identificeren die leerproblemen ervaren of het risico lopen om deze te ontwikkelen. Een bekende test die beoordeling van organisatiestrategieën mogelijk maakt is de 'Rey-Osterrieth Complex Figure' (ROCF; Rey, 1941). Deze test meet het vermogen om een taak te plannen, te initiëren en te voltooien, om strategieën te gebruiken en om complexe visuele informatie te organiseren. Het is verrassend dat de potentiële waarde van deze test voor het meten van de organisatiestrategieën van jonge kinderen relatief weinig aandacht heeft gekregen. De studie die wordt beschreven in dit hoofdstuk onderzocht de ontwikkelings-trajecten van de organisatorische aanpak van kinderen bij het kopiëren van de ROCF in een crosssectionele steekproef van gezonde 5 - tot 7-jarige kinderen $(n=217)$. Organisatorisch strategiegebruik werd beoordeeld aan de hand van twee maten: de RCF-OSS (Anderson et al., 2001) en de RIDS (Rey Initial Drawing Sequence), een nieuwe maat die de initiële volgorde van tekenen beoordeelt. We verkenden de relatie tussen deze twee maten en een breed scala aan cognitieve functies. Onze bevindingen lieten zien dat organisatorisch strategiegebruik een significante ontwikkeling doormaakt tussen de leeftijd van 5 tot 7 jaar. In het bijzonder vond significante rijping plaats tussen de leeftijd van 5,5 tot 6,5 jaar. Aanvullend vonden we dat organisatorisch strategiegebruik, zoals gemeten door de RCF-OSS, significant gerelateerd was aan verschillende aspecten van cognitief functioneren op deze leeftijd. Het ging daarbij om getalbegrip, vloeiendheid, visuele aandacht, visueel-motorische integratie, ruimtelijk geheugen, werkgeheugen, verwerkingssnelheid en ruimtelijk redeneren. Daarentegen was de RIDS alleen gerelateerd aan getalbegrip. Hiermee lijken deze beide maten verschillende aspecten van organisatorisch strategiegebruik te meten en kunnen daarom mogelijk als complementaire maten gebruikt worden. Samengenomen laten deze resultaten zien dat zowel de RCF-OSS als de RIDS interessante informatie kunnen opleveren over de ontwikkeling van organisatorisch strategiegebruik tussen de kleutertijd en de vroege basisschoolperiode. Hiermee is onze studie één van de eerste die een licht werpt op belangrijke veranderingen die plaatsvinden tussen 5 en 7 jaar in het gebruik van organisatiestrategieën.

Hoofdstuk 6. De effectiviteit van het trainen van de executieve functies van kleuters is door diverse studies beschreven, die zich overwegend richtten op werkgeheugentraining. Of meer complexe executieve functies expliciet getraind 
kunnen worden, door middel van een metacognitieve aanpak, moet nog onderzocht worden. De studie die beschreven wordt in Hoofdstuk 6 onderzocht de effectiviteit van het trainen van strategische organisatie en conceptueel redeneren in een steekproef van gezonde 4- tot 6-jarige kinderen $(n=102)$. De kinderen werden willekeurig toegewezen aan één van vier condities: een conceptueel redeneren training, een strategische organisatie training, een creatieve training (actieve controle), of geen training (passieve controle, alleen voor- en nameting). Elke trainingsconditie bestond uit groepsbijeenkomsten (60 min. per week) en huiswerkoefeningen op papier (30-40 min. per week) die gedurende zes weken werden aangeboden. Voor- en nametingen bestonden uit tests die conceptueel redeneren, werkgeheugen, vloeiendheid, en aandacht meten. De bevindingen van de studie lieten zien dat de conceptueel redeneren en strategische organisatie trainingen leidden tot transfer effecten via respectievelijk verbeteringen in verbale vloeiendheid en werkgeheugenprestaties. Echter, deze verbeteringen waren afhankelijk van interacties tussen de leeftijd van het kind en de inhoud van de training. Jongere kleuters profiteerden overwegend van de conceptueel redeneren training, wat leidde tot verbetering in verbale vloeiendheid. Daarentegen profiteerden oudere kleuters alleen van de strategische organisatietraining, die leidde tot verbetering van de werkgeheugenprestaties.

Hoofdstuk 7. Dit laatste hoofdstuk bespreekt de bevindingen van Hoofdstukken 2 tot en met 6 in het licht van de doelen van dit proefschrift. We verkenden de invloed van een breed scala aan kind- en omgevingsgebonden factoren op de ontwikkeling van rekenvaardigheden op een jongere leeftijd dan eerder onderzoek heeft gedaan. Onze bevindingen hebben laten zien dat het bestuderen van de effecten van kind- en omgevingsgebonden factoren op kleuterschool- en vroege basisschoolleeftijd nieuwe inzichten kan bieden in de ontwikkeling van rekenvaardigheden en onderliggende cognitieve vaardigheden. Op jonge leeftijd is de ontwikkeling van rekenvaardigheden al gerelateerd aan het eigen initiatief tot leren van het kind, de leeromgeving die ouders thuis bieden en de cognitieve vaardigheden van het kind (evenals interacties tussen deze factoren). Eveneens hebben onze bevindingen laten zien dat de effecten op de ontwikkeling van rekenvaardigheden niet beperkt blijven tot individuele factoren. De uitkomst van een studie kan beïnvloed worden door interacties tussen kind- en omgevingsgebonden factoren, zoals de interactie tussen sekse, leeftijd en prestatieniveau (zie Hoofdstuk 2). Verder laat dit 192 
proefschrift zien dat kleuters al in staat zijn tot hogere orde cognitief functioneren, zoals strategische organisatie. Het proefschrift ondersteunt eveneens de stelling dat het mogelijk is om deze functies, in het bijzonder strategische organisatie en conceptueel redeneren, te stimuleren door vroege interventies. Samen onderschrijven de bevindingen die in dit proefschrift besproken worden de toegevoegde waarde van een ontwikkelingsneuropsychologisch perspectief op leerprocessen. Centraal staat een aanpak die biologische, psychologische en omgevingsfactoren samenbrengt om ons begrip van inter-individuele verschillen in de (vroege) ontwikkeling van rekenvaardigheden te vergroten. Het gaat hierbij om factoren zoals de leeftijd, sekse, cognitieve functies en initiatiefname van het kind en de leeromgeving die ouders thuis bieden. Door het belang te onderschrijven van de vroege effecten die kind- en omgevingsgebonden hebben op inter-individuele verschillen in de ontwikkeling van rekenvaardigheden, ondersteunen onze bevindingen (inter)nationale pleidooien voor differentiatie in het onderwijs. Daarnaast hebben onze bevindingen mogelijke implicaties voor de onderwijspraktijk en bieden ze uitgangspunten voor vroege preventie en interventie. Een belangrijk doel in deze is het realiseren van optimale individuele ontwikkeling. 


\section{REFERENCES}

Anderson, P., Anderson, V., \& Garth, J. (2001). Assessment and development of organizational ability: The Rey Complex Figure Organizational Strategy Score (RCF-OSS). The Clinical Neuropsychologist, 15(1), 81-94.

Bull, R., Espy, K., \& Wiebe, S. A. (2008). Short-term memory, working memory, and executive functioning in preschoolers: Longitudinal predictors of mathematical achievement at age 7 years. Developmental Neuropsychology, 33(3), 205-228.

De Vos, T. (1992). Tempo Test Rekenen [Arithmetic Tempo Test]. Lisse: Swets \& Zeitlinger.

Jolles, J., De Groot, R., Van Benthem, J., Dekkers, H., De Glopper, C., Uijlings, H., et al. (2005). Leer het brein kennen [Learning to know the brain]. The Hague: the Netherlands Organization for Scientific Research (NWO).

Jolles, J., De Groot, R., Van Benthem, J., Dekkers, H., De Glopper, C., Uijlings, H., et al. (2006). Brain lessons: A contribution to the international debate on Brain, Learning \& Education. Maastricht: Neuropsych Publishers.

OECD (2007). Understanding the Brain: The Birth of a Learning Science. Paris: OECD Publishing.

National Research Council (2009). Mathematics learning in early childhood: Paths towards excellence and equity. Committee on Early Childhood Mathematics, Christopher T. Cross, Taniesha A. Woods, and Heidi Schweingruber, Editors. Center for Education, Division of Behavioral and Social Sciences and Education. Washington, DC: The National Academies Press.

Passolunghi, M., Vercelloni, B., \& Schadee, H. (2007). The precursors of mathematics learning: Working memory, phonological ability and numerical competence. Cognitive Development, 22(2), 165-184.

Rey, A. (1941). L'examen psychologique dans les cas d'encéphalopathie traumatique [The psychological examination of cases of traumatic encephalopathy]. Archives De Psychologie, 28, 215-285.

Swanson, L., \& Kim, K. (2007). Working memory, short-term memory, and naming speed as predictors of children's mathematical performance. Intelligence, 35(2), 151-168. 


\section{Curriculum Vitae}

Rosa Martens werd op 25 september 1983 geboren te Nijmegen. In 2001 behaalde ze haar VWO diploma aan het Udens College, waarna zij in hetzelfde jaar begon aan haar studie Psychologie aan de Universiteit Maastricht. Ze koos voor de afstudeerrichting Biologische Psychologie (specialisatie Ontwikkelingspsychologie). In 2006 studeerde zij af, na het voltooien van een wetenschappelijke stage binnen het IMAGE project aan de Radboud Universiteit en een klinische stage bij Karakter Universitair Centrum te Nijmegen. Vervolgens ging zij terug naar Maastricht, alwaar ze als onderzoeksmedewerker betrokken was bij twee onderzoeksprojecten van het Departement Medische, Klinische en Experimentele Psychologie van de Universiteit Maastricht. Deze projecten richtten zich op het bestuderen van de effectiviteit van angstpreventie bij basisschoolkinderen en cognitieve gedragstherapie voor angststoornissen bij kinderen met en zonder een autisme spectrum stoornis. In september 2007 startte zij met haar promotieonderzoek naar de ontwikkeling van reken- en cognitieve vaardigheden van (jonge) kinderen. Het resulterende onderzoek wordt beschreven in dit proefschrift. Momenteel is Rosa als postdoc-onderzoeker verbonden aan de afdeling Neuropsychologie en Psychofarmacologie van de Universiteit Maastricht. 



\section{Publications}

Martens, R., Hurks, P. M., Meijs, C., Wassenberg, R., \& Jolles, J. (2011). Sex differences in arithmetical performance scores: Central tendency and variability. Learning And Individual Differences, 21(5), 549-554.

Martens, R., Hurks, P. M., \& Jolles, J. (2012). Rey-Osterrieth Complex Figure performance in children aged 5-7: Development of organizational strategies and its relation to cognitive functioning. Submitted.

Martens, R., Hurks, P. M., Schrans, D. \& Jolles, J. (2012). Training goal setting in children aged 4-6: Transfer effects through an age by training content interaction. Submitted.

Martens, R., Hurks, P. M., \& Jolles, J. (2012). Impact of home learning environment, child's own initiative, and cognition on young children's numeracy. In preparation.

Martens, R., Hurks, P. M., Keulers, E. H. \& Jolles, J. (2012). Early cognitive characteristics of children aged 4-8 with persistent mathematical difficulties versus giftedness: A longitudinal study. In preparation.

\section{OTHER PUBLICATIONS}

Martens, R., Hurks, P. M., \& Jolles, J. (2010). Kijken naar verschillen. TalentenKracht Magazine, 87-88.

Hurks, P. M., \& Martens, R. (2009). Talenten bij jonge kinderen. Vamos, 2, 3-4.

Hurks, P. M., Schrans, D., Martens, R., Meijs, C., \& Jolles, J. (2010). Stimulering van talenten bij jonge kinderen. TalentenKracht Magazine, 48-52. 



\section{Dankwoord}

Mijn dankwoord hoort natuurlijk te beginnen met degenen zonder wie dit proefschrift niet geschreven had kunnen worden. Onderzoek begint immers bij de dataverzameling. Graag wil ik daarom alle ouders en kinderen bedanken die aan onze studies hebben meegewerkt! Ook zonder de medewerking van vele Limburgse basisscholen was ons onderzoek nooit mogelijk geweest. Bedankt!

Ik had al die onderzoeksdata nooit alleen kunnen verzamelen. Mijn dank is groot voor de enthousiaste inzet van alle assistenten en stagiaires die door heel Zuid-Limburg hebben gereisd voor onze studies: Stefan, Mariza, Doortje, Tanja, Nadine, Linda, Desiree, Stefanie, Dennis, Mia, Judith, Anouk, en Pleun. In het bijzonder wil ik mijn onderzoeksassistenten Kim en Ellen bedanken, zonder wiens enthousiasme en inzet de VORCK-studie nooit zo goed zou zijn verlopen. Allemaal ontzettend bedankt voor jullie bijdrage! Debby, het is misschien gek om iemand te bedanken die je niet kent, maar zonder jou was er geen interventiestudie geweest. Als mijn voorganger heb je veel werk verricht waarop ik verder heb kunnen bouwen. Bedankt daarvoor.

Petra, zonder jou was ik nooit aan dit promotietraject begonnen en had ik het waarschijnlijk ook niet afgemaakt. Bedankt voor je tomeloze energie en het vertrouwen dat je me hebt gegeven. Bedankt dat je altijd beschikbaar was wanneer ik je nodig had. Jij geloofde in mijn kwaliteiten als onderzoeker en jouw enthousiasme was aanstekelijk. Ik ben trots op alles wat we bereikt hebben in de afgelopen jaren en hoop dat we onze samenwerking nog lang kunnen voortzetten. PS hopelijk heb je ditmaal geen genante e-mails bewaard om voor te lezen op 'de grote dag'.... 


\section{DANKWOORD}

Jelle, als geen ander kun jij onderzoek begrijpelijk en aantrekkelijk maken voor een breder publiek. Bedankt dat je me hebt geleerd hoe je uit de wolligheid van de wetenschap helderheid kunt destilleren. Bedankt ook voor de uitzonderlijke kans die je me hebt gegeven door me aan te nemen als promovendus. Je hebt me alle vrijheid gegeven die ik nodig had om prachtig onderzoek te verrichten en om de artikelen te schrijven die ik wilde.

Uiteraard is een dankwoord niet compleet zonder alle collega's en oud-collega's te bedanken met wie ik in de loop der jaren heb samengewerkt aan de Universiteit Maastricht binnen Psychiatrie \& Neuropsychologie en Neuropsychologie \& Psychofarmacologie en aan de Vrije Universiteit binnen het Centrum Brein en Leren. Ik durf geen namen te noemen uit vrees dat ik er toch een paar ga vergeten. Bedankt dus allemaal voor jullie belangstelling, het meedenken, de lunches, wandelingen, dagjes uit en alle andere momenten van afleiding!

Esther, een persoonlijk bedankje voor jou mag niet ontbreken in dit dankwoord. Dankzij jou hebben we de dataverzameling van onze VORCK-studie kunnen voortzetten. Bedankt voor je interesse, je hulp en het meedenken. Ik ben blij dat we de kans krijgen om samen aan nieuwe projecten te werken!

In het bijzonder wil ik ook Nico, Elian en Astrid bedanken voor hun hulp. Nico, zonder jou was de verwerking van alle onderzoeksdata een grote uitdaging geworden. Dank dat je altijd beschikbaar was voor hulp en het beantwoorden van mijn vragen. Astrid, jouw inzet was een waardevolle aanvulling voor de VORCK-studie. Elian, dank voor alle hulp die je me hebt geboden in de afgelopen jaren. Fijn dat ik altijd bij je terecht kon met mijn vragen en verzoeken!

Celeste en Annemarie, het lijkt alweer een eeuwigheid geleden dat jullie mijn eerste kamergenootjes waren en inmiddels is er ontzettend veel veranderd in al onze levens. Het blijft leuk om te horen hoe het met jullie gaat! Celeste, jij hebt me echt op weg geholpen die eerste tijd als promovendus en nog steeds profiteer ik van jouw tips van toen. Annemarie, we kennen elkaar inmiddels alweer een hele tijd. Leuk dat we nu ongeveer tegelijkertijd klaar zijn! 
Dear Alexandros, thanks for being my roommate these last few years. Thanks also for sharing your taste in movies and music and your love of good food. Thanks for providing the necessary distractions when I was fed up with writing and for making me laugh. You are a great roommate! PS I hope that I will be invited to the opening of your exhibition if you ever decide to become a famous 'brain'- artist... ;-)

Lieve Ellen, mijn derde paranimf, wat had ik graag gewild dat jij me bij had kunnen staan tijdens mijn promotie. Helaas heb ik de kans niet gekregen om je te bedanken en om je te vertellen wat een fantastische kamergenoot je was in de drie jaar dat we een kamer hebben gedeeld. Mijn dankwoord zou niet compleet zijn zonder jou. Dank voor je bezorgdheid en attentheid op de momenten dat ik het nodig had. Bedankt voor alle liters thee, je belangstellende vragen, steun, hulp, en afleiding. Jouw belangstelling, relativeringsvermogen en scherpe gevoel voor humor maakten mijn werkdagen zoveel leuker. Ik ben blij en dankbaar dat ik je heb leren kennen.

Lieve WIAN-vriendinnetjes, wat hebben we veel meegemaakt in 11 jaar tijd! Rosa, Mieke, Deliane, Sandra, Fleur, Lia en Michelle, wat ben ik blij dat ik jullie heb leren kennen. Zonder jullie was mijn tijd in Maastricht zoveel minder leuk geweest. Bedankt dat jullie er altijd voor me zijn op de leuke en de moeilijke momenten. Mede dankzij jullie ben ik niet vergeten dat een baan maar een baan is en dat er belangrijkere dingen zijn in het leven. Ik ben zo ontzettend benieuwd wat dat leven ons nog allemaal zal brengen. Op naar het volgende decennium van vriendschap en op naar het bejaardentehuis! ;-)

Lieve Rosa en Deliane, wat fijn dat jullie me als paranimfen op de grote dag bij willen staan! Gedeelde smart is halve smart toch? Bedankt dat jullie er altijd waren voor het aanhoren van mijn momenten van frustratie of om mij uit mijn motivatiedip te halen. Af en toe had ik het even nodig om te horen dat promoveren iets heel bijzonders is. Bedankt ook voor alle leuke momenten: voor de vele lunches, sportsessies, etentjes en niet te vergeten Falstaff-avonden! 
Lieve opa, ook al noemde je me af en toe lachend 'vreemdeling', altijd wilde je weten hoe het met mij en mijn 'studie' ging. Wat had je graag bij mijn promotie willen zijn, maar helaas heb je dit moment niet meer mee kunnen maken. Bedanken kan ik je gelukkig nog wel. Dank voor je trots, je belangstelling en je bezorgdheid. Dank voor je vele verhalen met een knipoog en een lach.

Lieve oma, wat had jij dit moment ongelooflijk graag mee willen maken. En, al kan je dit niet meer lezen, ontbreken mag je absoluut niet in mijn dankwoord. Dank voor je belangstelling en steun, zelfs al begreep je mijn wereld in het verre Maastricht niet altijd en maakte jij je af en toe zorgen. Dank voor je onvoorwaardelijke liefde en trots. Dank dat ik jouw Roosje mocht zijn.

Lieve papa en mama, dank voor jullie onvoorwaardelijke vertrouwen en steun in mijn momenten van zekerheid en in mijn momenten van twijfel. Voor het gevoel dat jullie altijd achter me zouden staan en trots op me zouden zijn, welke beslissingen ik ook zou nemen in mijn leven. Dank voor de ruimte en de mogelijkheden die jullie me hebben geboden om de vrouw te worden die ik ben. Dank ook voor de veilige en liefdevolle basis. Door jullie steun en liefde heb ik vol vertrouwen mijn vleugels uit durven slaan.

Lieve Laurenz, gek eigenlijk dat een leven zonder jou deze afgelopen jaren zo ondenkbaar is geworden. Nooit had ik kunnen denken dat liefde zo moeiteloos en zonder twijfel kan zijn. Dank voor je rust, je geduld, je relativeringsvermogen en je strenge aansporingen hier en daar. Dank dat je me zo goed begrijpt en weet wat ik nodig heb. Inmiddels hebben we al meerdere avonturen in binnen- en buitenland beleefd en overleefd. Hopelijk gaan er in de toekomst nog vele volgen en hou jij me daarbij rustig en met beide benen op de grond. Met jou kan ik de wereld aan! 